\title{
GENDER EQUITY IN STEM IN HIGHER EDUCATION
}

INTERNATIONAL PERSPECTIVES ON POLICY, INSTITUTIONAL CULTURE, AND INDIVIDUAL CHOICE

\section{Edited by}

Hyun Kyoung Ro, Frank Fernandez and Elizabeth J. Ramon

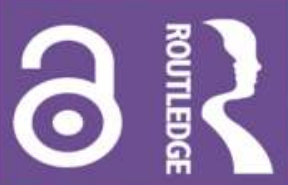


"Gender, STEM, and education are mainstays of global economic and development agendas, but finally Ro, Fernandez, and Ramon have created a broadly representative collection of empirical and conceptual work that addresses issues of access at the institutional level alongside accounts of the experiences and choices that individual women make as part of their everyday experiences and inequities as they participate in STEM education and eventually in their professional lives as well. This volume bridges the macro-to-micro gap better than any I've seen on this topic."

- Alexander W. Wiseman, Professor of Educational Psychology \& Leadership, Texas Tech University, USA

"The editors and contributors of this penetrating volume fill a hole in the comparative higher education literature. Readers will appreciate the attention to the worldwide pipeline, to intersectionality, and to policy approaches that may effect greater gender equity in STEM at a global level."

- David M. Post, Professor of Education at Pennsylvania State University and Past-President of Comparative and International Education Society, USA

"A talented group of emerging scholars have spearheaded a timely contribution to STEM higher education on six continents. It will, undoubtedly, make significant contributions to factors affecting linkages among gender and university enrollments and degree completions. This anthology impressively discusses topics - culture, demographics, geography, and statistics - as variables, contributing to enhanced comprehension of STEM and its impact on higher education among different types of university structures."

- Beverly Lindsay, Co-Director and Principal Investigator, Division of Social Sciences, University of California, USA

"Gender Equity in STEM provides a balance and much needed examination of gender and STEM at the global level, and, across ten countries. The balance of statistical analyses of patterns over time, and deeper qualitative examinations of specific dynamics offers readers a nuanced understanding of gender and STEM beyond assumptions about lack of preparation for girls, gender stereotyping, and chilly climates within STEM fields. It is an important book for moving our thinking beyond equality toward understanding and action for equity. The collection of case studies, both quantitative and qualitative, contextualize how gender in STEM fields plays out and what inhibits or enables equitable practices and outcomes."

- Karen Monkman, Professor Emerita of Education Policy, DePaul University, USA 
"Science is the hope of the world yet most of the world is excluded from it. Gender is a barrier everywhere and more so for those emerging women scientists that must contend with English as a second language, patchy infrastructure and opportunities and the brutal embedded heritage of racism that permeates many post-colonial settings. In this important and timely volume Hyun Kyoung Ro, Frank Fernandez and Elizabeth Ramon help us to respect what has been achieved and also remind us how far there is to go."

- Simon Marginson, Professor of Higher Education, University of Oxford, UK, and Foint Editor in Chief of Higher Education 


\section{Gender Equity in STEM in Higher Education}

This timely volume brings together a range of international scholars to analyse cultural, political, and individual factors which contribute to the continued global issue of female underrepresentation in STEM study and careers.

Offering a comparative approach to examining gender equity in STEM fields across countries including the UK, Germany, the United States, Hong Kong, Taiwan, South Africa, and China, the volume provides a thematic breakdown of institutional trends and national policies that have successfully improved gender equity in STEM at institutions of higher education. Offering case studies that demonstrate how policies interact with changing social and cultural norms, and impact women's choices and experiences in relation to the uptake and continuation of STEM study at the undergraduate level, the volume highlights new directions for research and policy to promote gender equity in STEM at school, university, and career levels.

Contributing to the United Nations' (UN) 2030 Agenda for Sustainable Development, this text will benefit researchers, academics, and educators with an interest in science education, higher education, and gender equity in STEM fields. The text will also support further discussion and reflection around multicultural education, educational policy and politics, and the sociology of education more broadly.

Hyun Kyoung Ro is Associate Professor of Counseling and Higher Education at the University of North Texas, USA.

Frank Fernandez is Assistant Professor of Higher Education at the University of Florida, USA.

Elizabeth J. Ramon is a PhD student in Counseling and Higher Education at the University of North Texas, USA. 


\section{Routledge Research in STEM Education}

The Routledge Research in STEM Education series is home to cutting-edge, upperlevel scholarly studies and edited collections covering STEM Education.

Considering science, technology, engineering, and mathematics, texts address a broad range of topics including pedagogy, curriculum, policy, teacher education, and the promotion of diversity within STEM programmes.

Titles offer dynamic interventions into established subjects and innovative studies on emerging topics.

\section{An Asset-Based Approach to Advancing Latina Students in STEM Increasing Resilience, Participation, and Success Edited by Elsa M. Gonzalez, Frank Fernandez, and Miranda Wilson}

\section{Teacher Education to Enhance Diversity in STEM}

Applying a Critical Postmodern Science Pedagogy

A. Anthony Ash II, Greg A. Wiggan, and Marcia F. Watson-Vandiver

\section{Teaching Early Algebra through Example-Based Problem Solving} Insights from Chinese and U.S. Elementary Classrooms Meixia Ding

\section{Gender Equity in STEM in Higher Education}

International Perspectives on Policy, Institutional Culture, and Individual Choice

Edited by Hyun Kyoung Ro, Frank Fernandez, and Elizabeth 7. Ramon

Mathematics Education for Sustainable Economic Growth and Job Greation

Edited by David Burghes and Fodie Hunter

For more information about this series, please visit: www.routledge.com/ Routledge-Research-in-STEM-Education/book-series/RRSTEM 


\section{Gender Equity in STEM in Higher Education \\ International Perspectives on Policy, Institutional Culture, and Individual \\ Choice}

\section{Edited by}

Hyun Kyoung Ro, Frank Fernandez, and Elizabeth J. Ramon 
First published 2022

by Routledge

605 Third Avenue, New York, NY 10158

and by Routledge

2 Park Square, Milton Park, Abingdon, Oxon OX14 4RN

Routledge is an imprint of the Taylor E Francis Group, an informa business

(C) 2022 selection and editorial matter, Hyun Kyoung Ro, Frank Fernandez, and Elizabeth J. Ramon; individual chapters, the contributors

The right of Hyun Kyoung Ro, Frank Fernandez, and Elizabeth J. Ramon to be identified as the authors of the editorial material, and of the authors for their individual chapters, has been asserted in accordance with sections 77 and 78 of the Copyright, Designs and Patents Act 1988.

The Open Access version of this book, available at www.taylorfrancis.com, has been made available under a Creative Commons Attribution-Non Commercial-No Derivatives 4.0 license.

Trademark notice: Product or corporate names may be trademarks or registered trademarks, and are used only for identification and explanation without intent to infringe.

Library of Congress Cataloging-in-Publication Data

A catalog record for this title has been requested

ISBN: 978-0-367-51293-4 (hbk)

ISBN: 978-1-032-04803-1 (pbk)

ISBN: 978-1-003-05321-7 (ebk)

DOI: $10.4324 / 9781003053217$

Typeset in Baskerville

by Taylor \& Francis Books 
For Jiyoon and Joonhee for whom I hope to fight for gender equity through education wherever they decide to live.

\section{Hyun Kyoung Ro}

For Autumn and Reagan who have shown me how resilient children can be and how well they can learn when they are safe, healthy, and unconditionally loved.

Frank Fernandez

For Rebecca whose many inventions and experiments have shown me that girls are natural scientists.

Elizabeth J. Ramon 
$\Longrightarrow$ Taylor \& Francis Taylor \& Francis Group http://taylorandfrancis.com 


\section{Contents}

List of Illustrations $\quad$ xi

List of Contributors xiii

Foreword $\quad \mathrm{xx}$

Acknowledgements xxiv

1 Introduction: Gender Equity in STEM in Higher Education:

International Perspectives on Policy, Institutional Culture, and Individual Choice

HYUN KYOUNG RO, ELIZABETH J. RAMON AND FRANK FERNANDEZ

\section{PART 1}

Demographic Trends and National Initiatives

2 A Cross-National Analysis of Women Graduates with Tertiary Degrees in Science, Technology, Engineering, and Math, 1998-2018: Commonalties and Variations

SEUNGAH S. LEE, CHRISTINE MIN WOTIPKA AND FRANCISCO O. RAMIREZ

3 The Rise of Women in STEM Higher Education in China:

Achievements and Challenges

LIU LINGYU, SHEN WENQIN AND LI CHAO

4 The Higher Education Trajectories of Taiwanese Women in STEM: A Longitudinal Analysis

YUAN CHIH FU, AMELIO SALVADOR QUETZAL AND YUEHLUEN HU

5 STEM Bachelor's Degree Attainment among Women of Color in the United States: Using Geographic Analysis for Gender and Racial Equity Research 
6 A Comprehensive Approach to Addressing Gender Equity in STEM Subjects at Four-Year Universities in England HYUN KYOUNG RO, FRANK FERNANDEZ AND BENJAMIN ALCOTT

\section{PART 2}

Women's Ghoice and University Contexts

7 Women in STEM in Chilean Higher Education: Social

Movements and Institutional Transformations

JEONGEUN KIM AND SERGIO CELIS

8 Examining Gender (In)Equality in German Engineering:

Considering the Importance of Interest, Perceptions, and Choice JENNIFER DUSDAL AND FRANK FERNANDEZ

9 Gender Equity in STEM Higher Education in Kazakhstan ANNA COHENMILLER, ARAY SANIYAZOVA, ANARA SANDYGULOVA AND ZHANNA IZEKENOVA

10 Black African Women in Engineering Higher Education in South Africa: Contending with History, Race, and Gender YEUKAI ANGELA MLAMBO

11 Approaches for Attracting, Retaining, and Progressing Women in Australian Undergraduate Engineering: Curricular Innovation Focused on Humanitarian and Human-Centered Design Concepts ANDREA M. GONCHER AND SHARA CAMERON

12 Aspiring and Becoming STEM Teachers in Hong Kong: A Gender Perspective HEI-HANG HAYES TANG, DEREK WAI SUN CHUN, IRIS CHI YAN LEUNG AND THOMAS SIU HO YAU

13 Conclusion: Unique but Transferable Approaches for Pursuing Gender Equity in STEM in Higher Education across the World HYUN KYOUNG RO, ELIZABETH J. RAMON AND FRANK FERNANDEZ 


\section{Illustrations}

\section{Figures}

2.1 Women's share of STEM graduates across countries by level of economic development, as classified by the World Bank (2019)

3.1 Number of students (in 10,000; Histogram) and the proportion of women students (line chart) in ordinary institutions of higher learning in China from 1949 to 2004

3.2 Number and proportion of female graduate students in China from 1997 to 2018

$4.1 \mathrm{~A}-\mathrm{D}$. The share of male and female graduates by educational track, 1979-2017

4.2 The impact of education expansion on occupational choice, 1979-2017

6.1 Percentages of men and women by STEM and non-STEM enrollment in the United Kingdom and EU

7.1 First-year Enrollment: Women in STEM vs non-STEM

8.1 Percentages of secondary school leavers who considered studying engineering at a university or university of applied sciences

9.1 Percentage of women in BS and BEng degrees across six programs of SEDS for 2015-2020

9.2 Percentage of women in MS degrees across six programs of SEDS for 2015-2020

\section{Tables}

2.1 The Complete List of Countries in the Sample, by Income Level

3.1 Ratio of Women Students in Different Departments of Harbin Institute of Technology in 1998

3.2 Development of Self-Evaluation Ability of Science and Engineering Graduates by Gender at Peking University in 2018 (N=774)

4.1 The Participation Rate of 25-35-year-olds in STEM Professions 
5.1 STEM Bachelor's Degree Recipients and Population by Gender, Race, and Geographic Region

5.2 STEM Bachelor's Degree Attainment and Geography of Opportunities

6.1 Women's Odds of Studying STEM or Attending Russell Group Universities: Data from Longitudinal Study of Young People in England (LSYPE)

7.1 Percentage of Women by Major, First-year Students: All Universities

8.1 Reasons High School Leavers Decided Not to Start an Engineering Degree

11.1 Engineering Community Engagement Evaluation Matrix

12.1 Research Respondents Information

12.2 Summary of Conversion Factors From Capabilities into Functionings among Women STEM Pre-service Teachers in Hong Kong 


\section{Contributors}

Benjamin Alcott is a Lecturer at the Institute of Education, University College London, United Kingdom. His work primarily uses economic principles and methods to examine the equity effects of education policies. Benjamin received his $\mathrm{PhD}$ in higher education policy from the University of Michigan.

Shara Gameron is a civil engineering graduate and has spent 16 years living and working in Central West NSW, Australia as a water engineer. For the past 5 years she has taught project-based learning subjects at Charles Sturt University and leads their woman in engineering program. Her role as Engineer in Residence allows her to continue her professional work as a consulting engineer, which informs her teaching practice from current industry practice.

Sergio Celis is an Assistant Professor in the School of Engineering and Sciences at Universidad de Chile, Chile. He conducts research on higher education, with a focus on organizational change, faculty work, and teaching and learning in STEM fields. His primary research interest is in how multiple forces, internal and external to the institution, influence what colleges and universities do. He serves as vice president of the Chilean Society for Engineering Education (Sociedad Chilena de Educación en Ingeniería [SOCHEDI]). Sergio received his professional degree in industrial engineering at Universidad de Chile and his $\mathrm{PhD}$ in higher education at the University of Michigan.

Li Chao is a doctoral student of the Graduate School of Education, Peking University, China, majoring in higher education. Her research focuses on the gender experiences of female $\mathrm{PhD}$ students in STEM subjects. She received her bachelor's degree in Foreign Languages and Global History from Yuanpei College, Peking University.

Derek Wai Sun Ghun is a senior research assistant at The Education University of Hong Kong, China. His research interests include global career guidance development, career and life planning education and vocational education development and education policy studies in Hong Kong. 
Currently, he is exploring his research focus on ongoing development of vocationalization of English, STEM aspirations of post-secondary students, and STEM learning from different perspectives in Hong Kong.

Anna CohenMiller is qualitative methodologist who focuses on equity and inclusion in higher education in Kazakhstan and internationally. She specializes in arts-based research, innovative pedagogy, and gender. Currently, Dr. CohenMiller is an Assistant Professor in the Graduate School of Education, Nazarbayev University, Kazakhstan, Co-Founding Director of The Consortium of Gender Scholars (Kazakhstan), Editorin-Chief of Dialogue: The Interdisciplinary Journal of Popular Culture and Pedagogy, and Founder of The Motherscholar Project. Select current work includes a forthcoming qualitative textbook Questions in Qualitative Research in Multicultural Contexts, Routledge), a photovoice study of motherscholars during the COVID-19 pandemic, a study examining the use of innovative technology for educational equity, an examination of gender in schooling in Kazakhstan, and a comparative international study (UK, Kazakhstan, Nigeria, Morocco, India) funded by the British Academy addressing the co-construction of gender equitable futures in higher education.

Jennifer Dusdal is a Postdoctoral Research Scientist in the Institute of Education \& Society at the University of Luxembourg, Luxembourg. She is also Postdoctoral Research Fellow at the Leibniz Center for Science and Society (LCSS), Leibniz University of Hannover, Germany. Her research expertise lies at the intersection of higher education research, sociology of science, and bibliometrics. Her specific topics of interest include higher education systems, institutions and organizations, international research collaborations, social network analysis, political reform and societal change processes, higher education governance and evaluation as well as science capacity-building and production.

Frank Fernandez is Assistant Professor of Higher Education at the University of Florida, United States. He studies educational policy and equity issues. He is co-editor of An Asset-Based Approach to Advancing Latina Students in STEM: Increasing Resilience, Participation, and Success (Routledge, 2021).

Yuan Ghih Fu is an Assistant Professor of the Graduate Institute of Technological and Vocational Education at National Taipei University of Technology (Taipei Tech). He received his $\mathrm{PhD}$ degree in Higher Education from the Pennsylvania State University (2017). Before making his transition to academia, He worked in Taiwan's Ministry of Education as a policymaker in higher education, dedicating his professional work to the construction of national data infrastructure and its application in higher education governance. His research focuses on the impact of educational policy on individual, higher education institutions and society. His area of expertise is policy evaluation and quantitative research. His papers have been published in leading international journals (e.g., Studies in Higher Education, Higher Education Policy, 
and Minerva) and presented in international conferences (e.g., AEFP, ASHE, CIES, and AERA). He also serves as reviewer for several leading international journals.

Andrea M. Goncher is an Instructional Assistant Professor in Engineering Education at the University of Florida, United States. She earned her PhD in Engineering Education and focuses on teaching and learning projects in human-centered design and humanitarian engineering. Her research interests include text analytics, international higher education, and engineering design education. She has served as an academic fellow with EWB Australia and is a chartered engineer with Engineers Australia.

Yuehluen Hu is a Professor of the Department of Education at National Cheng-Chi University. She received her $\mathrm{PhD}$ degree in Educational Psychology from Indiana University. Her research focuses on educational psychometrics, educational assessment, and psychology of personality. Her papers have been published in leading international journals (e.g., International Fournal of Research Studies in Education and International Journal of Research Studies in Psychology) and presented in international conferences (e.g., AERA). She also serves as a reviewer for several leading international journals.

Zhanna Izekenova is a $\mathrm{PhD}$ student in the Graduate School of Education and Research Assistant as part of the Executive and Organizing Committee for The Consortium of Gender Scholars at Nazarbayev University, Kazakhstan. Her research interests include, but are not limited to, the following areas: mothers in academia, gender, school leadership, equity, and shadow education.

Jeongeun Kim is an Assistant Professor of Higher and Postsecondary Education at Mary Lou Fulton Teachers College and faculty affiliate at the Center for Organizational Research and Design at Arizona State University, United States. Dr. Kim's research focuses on how academic programs use their autonomy to organize admission policies, financial aid, tuition and fees, as well as strategies for revenue generation and resource allocation to remain competitive. Her research adopts STEM fields in order to explain how those prestige-seeking behaviors would impact stakeholders, including the students and faculty at those universities. In particular, her research examines how different institutional and departmental contexts affect STEM students' postgraduate outcomes.

Seungah S. Lee is a PhD candidate at Stanford University in the United States studying International Comparative Education and Organizational Studies. She is broadly interested in how nation-states, especially Arab Gulf states, negotiate changing demands of a globalized world and adapt global models around youth development, education, entrepreneurship, and innovation to their respective local contexts as part of the national and human development agenda. Her dissertation research focuses on how 


\section{xvi List of Contributors}

Arab Gulf states foster a culture and environment for entrepreneurship and innovation among young people through various government, quasi-governmental, and education institutions. Prior to her doctoral studies, she worked in the Middle East designing teacher leadership programs, leading program evaluation efforts, and building monitoring and evaluation systems.

Iris Chi Yan Leung obtained her Bachelor of Arts (Major in Geography), Postgraduate Certificate in Education (Geography), Master of Philosophy and Doctor of Philosophy from The University of Hong Kong, China. She has engaged in various research projects on teacher professional development, school-university partnership, mentoring, and teaching and learning. She also has experience in curriculum development of the Personal and Social Humanities Education in secondary education in Hong Kong. Her research interests include teacher development, teacher education, curriculum studies, Liberal Studies education and STEM education. Iris is currently an Assistant Project Manager at the Department of Science and Environmental Studies, The Education University of Hong Kong, helping with school-based support of STEM education to primary and secondary schools.

Liu Lingyu is a $\mathrm{PhD}$ student of the Graduate School of Education, Peking University, China, majoring in higher education. Her research focuses on non-market effects of higher education and graduate education.

Yi Meng is a doctoral candidate of the Higher Education Program in the Department of Education Policy Studies at the Pennsylvania State University in the United States. She is fascinated by how higher education affects social dynamics and individuals' life experiences. Her work revolves around education policies, education access and equity, STEM education, program evaluation and assessment, and student development. She is currently working as a graduate data analyst in the Student Affairs Assessment and Research Office at the Pennsylvania State University. Some of her representative publications are "Does schooling foster environmental values and action? A cross-national study of priorities and behaviors," "The Impact of No-loan Policies on Student Economic Diversity at Public Colleges and Universities," and "Reconciling Multiple Identities: Experiences of International Undergraduate Students in the United States."

Yeukai Angela Mlambo is the Director of Mastercard Foundation Digital Initiatives at EdPlus at ASU as well as an Assistant Research Professor in the Mary Lou Fulton Teachers College at Arizona State University, United States. Her research centers on addressing higher education leadership representation through broadening access, inclusion and equity for underrepresented groups in higher education. In particular her work focuses on issues related to the recruitment, retention, persistence and trajectories of underrepresented populations in STEM fields. More broadly her interests include higher education institutions and faculty development in sub-Saharan 
Africa and the developing world, women in higher education leadership, international student experiences and the role of higher education partnerships in institutional development. Her work relies on critical frameworks which center the experiences of marginalized groups, attend to history when interrogating phenomena, and advocate for social change. Yeukai holds a $\mathrm{PhD}$ in Higher, Adult and Lifelong Education from Michigan State University.

Amelio Salvador Quetzal is a doctoral candidate at the College of Education, National Chung Cheng University in Chiayi, Taiwan. He holds an M.Ed. in Leadership and Management where he focused most of his research on curriculum leadership and design. Currently, he is working on a study of internationalization policy and practice in Taiwan's higher education. Most of his current research focuses on higher education policy, internationalization, and international students some of which have been published in book chapters and SSCI journals.

Francisco O. Ramirez is Professor of Education and (by courtesy) Sociology at Stanford University, United States. His work has contributed to the development of the world society perspective in the social sciences and in international comparative education. His current research interests focus on the worldwide rationalization of university structures and processes, on the institutionalization of human rights and human rights education, and on terms of inclusion issues as regards gender and education. Recent publications may be found in Comparative Education Review, Social Forces, and Sociology of Education. Ramirez is also the co-editor of Universities as Agencies: Reputation and Professionalization (2019). He has been a fellow at the Center for the Advanced Studies of the Behavioral Sciences (2006-07) and the Swedish Collegium for Advanced Studies (2017).

Elizabeth J. Ramon is a PhD candidate in Counseling and Higher Education at the University of North Texas, United States. Her research interests include women in STEM, access and mobility, community college leadership, and globalization in higher education. She is currently working as a graduate research assistant in the Higher Education Program Office on issues surrounding gender and racial equity in STEM.

Hyun Kyoung Ro is Associate Professor of Counseling and Higher Education at the University of North Texas, United States. She studies gender and racial equity in STEM Education and Workforce in the USA. She has been the leading author on articles that were published in higher education and engineering education journals, such as The Review of Higher Education, Research in Higher Education, Educational Policy, Journal of Engineering Education, and Journal of Women and Minorities in Science and Engineering. She is co-editor of Voices from the Margins: Creating Inclusive Assessment for Marginalized Students in Higher Education (Jossey-Bass). 
Anara Sandygulova is an Assistant Professor in the Department of Robotics and Mechatronics at the School of Engineering and Digital Sciences, Nazarbayev University, Kazakhstan. Dr. Sandygulova received her PhD from the School of Computer Science at University College Dublin. Her research interests include human-robot interaction, social robotics, and artificial intelligence.

Aray Saniyazova is a postdoctoral scholar at the Laboratory for Student Experience Studies, Center of Sociology of Higher Education, Institute of Education, the National Research University Higher School of Economics, Moscow, Russia. She is involved in the international project Student Experience in the Research University located at the Center for Studies in Higher Education (CSHE) at the University of California Berkeley (UCB), USA. She holds a master's degree in Higher Education Administration from Vanderbilt University (2011), and a PhD in Education from Nazarbayev University (NU) (2017). Her research interests center on the topics of gender in higher education, doctoral education, and student experience in university including transition from high school to university; student academic and social integration; student well-being and campus climate; student retention and persistence; gendered issues of student experience.

Hei-hang Hayes Tang is an Assistant Professor in the Department of Education Policy and Leadership, and Programme Leader of MA in Leading Innovative Learning Organizations (LILO) at The Education University of Hong Kong, China. He currently serves as Associate Editor of the Fournal of Comparative and International Higher Education and Humanities and Social Sciences Communications, and Editorial Board Member of Chinese Education E Society. As a sociologist, Dr. Tang is interested in the fields of higher education, education policy, academic profession, and youth studies. His research focuses on the sociological role of higher education in entrepreneurial society and global city. He is committed to creating new knowledge in application for better education governance and policy innovation in East Asia.

Shen Wenqin is Associate Professor of Higher Education at Peking University, China. He mainly studies the higher education system from the perspectives of history and science studies (sociology of science, philosophy of science, etc.). He has authored and co-authored publications focused on transnational history of the idea and practice of liberal education (China, UK and US), international academic mobility (especially the mobility of doctoral students and postdocs), and doctoral career trajectories.

Christine Min Wotipka is Associate Professor (Teaching) of Education and (by courtesy) Sociology and Director of the Master's Program in International Comparative Education and International Education Policy Analysis at the Stanford Graduate School of Education, United States. From 2012 to 2016, she served as Director of the Program in Feminist, Gender, and Sexuality Studies at Stanford University. Dr. Wotipka's research centers 
around two main themes examined from cross-national and longitudinal approaches. The first relates to leadership in higher education with a focus on gender, race and ethnicity, and sexuality. The second theme, that of citizenship and education, explores how social science curricula, namely school textbooks, have shifted focus away from the development of national identities to ones that emphasize global citizenship. Her articles have appeared in Social Forces, Sociology of Education, Gender E Society, American fournal of Education, Comparative Education Review, International Journal of Comparative Sociology, and Fournal of LGBT Youth.

Thomas Siu Ho Yau is a postgraduate student at the Department of English, the Chinese University of Hong Kong, China. His main research interests are in psycholinguistics, second language acquisition, and cognitive linguistics. He has also pursued research on language and society, language policy, curriculum and education policy, vocational education in Hong Kong, technology enhanced learning, and learning analytics.

Qiong Zhu is a postdoctoral research associate in the Education Policy Innovation Collaborative at Michigan State University, United States. Dr. Zhu earned her PhD from the Pennsylvania State University in Higher Education. Her research interests include economics of education, education policy in both K-12 and higher education, and the regional impacts of educational institutions. Her research examined the effect of double majors on post-baccalaureate outcomes, the impact of loan-reduction programs on student economic diversity, and the economic impact of international students on local housing prices and employment opportunities. Her research has been published in Education Finance and Policy, Educational Researcher, and Research in Higher Education. Dr. Zhu also holds a bachelor's degree in Economics and a master's degree in Economics of Education from Peking University, China. 


\section{Foreword}

When I heard that this book was being put together, I was thrilled because I have spent my career - though research, policy, leadership, and service-examining the topic of women in STEM. While my own career has mostly centered on systemic issues of policy and institutional culture and issues of individual choice specific to women pursing STEM education in the United States, the authors of this collection demonstrate how women in countries around the globe are grappling with these macro and micro issues in their specific contexts.

STEM and STEM education are both historical and political, and the book's focus on how policies and practices in different countries influence women's participation in STEM makes the historical and political contexts of STEM and STEM education clear. And, because even within one country "women" are such a diverse group, we know that one-size-fits-all policies and practices will not suffice. They must be equally diverse. If we deny this fact, we risk oversimplifying the problem. I appreciate the way the editors' vision of presenting unique and potentially transferrable successes for women in STEM challenge us to reflect on how practices and policies could be adapted in new ways while drawing parallels across contexts.

I am a qualitative researcher, so the transferability of the work in this book resonates with me. We qualitative researchers aim to tell a story whose truths will be recognizable and applicable in other contexts. Allow me to illustrate the transferability that excites me about this edited collection with two stories from my own research, those of Chavone and Maria.

Both Chavone and Maria were women of color in the United States, pursuing engineering degrees, and while they experienced specific events in their STEM education, their experiences are not unique. As the authors of the following chapters illustrate with research from around the world, women everywhere face inequitable policies that preclude them from accessing STEM education and they possess individual motivations and make personal choices for pursuing STEM education and careers. Chavone's story illustrates how systemic barriers and policies addressed in Part I of the book contribute to inequity (Martin \& Garza, 2020). Maria's story is an example of individuallevel choices and experiences - specifically her motivation for pursuing STEM - that are addressed in Part II (Trenor et al., 2008). 
Chavone is an African American woman who grew up in Kansas City, Missouri, a city with an egregious history of resistance to the Supreme Court's 1954 Brown vs. Board of Education ruling to desegregate schools in the southern United States. More than 30 years after the ruling, district courts determined that de facto segregation still existed and ordered the creation of highly funded magnet schools to entice White students to enroll in certain schools possessing nearly all-Black student populations. The school district implemented a "Black quota system" which limited the percentage of Black students to a maximum of $60 \%$ of the student population for each magnet school. Chavone discovered this policy when she was denied admission to the only college preparatory high school in Kansas City. Instead, she was assigned to a magnet school with a "Classical Greek" curriculum that focused on athletics, even though she did not play a sport. Despite a $\$ 33 \mathrm{M}$ price tag for the new school building that included an Olympic-sized pool with an underwater viewing room, the school was not equipped with counselors to guide students with college aspirations like Chavone. This lack of guidance impacted Chavone in many ways. For example, when Chavone took a school-administered aptitude test that, based on her skills, revealed "engineer" and "scientist" were top-recommended career choices, no one at the school was positioned to dispel her misconception that being an engineer involved working on a train, let alone guide her next steps. Despite her high mathematics and science grades, she did not pursue STEM. Later in life, and as a mother of two, Chavone finally enrolled in an engineering program. She explained:

I saw a movie ... which was a defining moment for me in my pathway to being in an engineering program ... [and] everything came together for me. There I was, 10 or more years after the results to my college aptitude test and I'd finally found out what an engineer was-and it had nothing to do with trains. But, in that moment, I decided I was going to go back to school- I was going to be an engineer!

For Maria, earning a degree in engineering was her ticket to a better life that was more financially stable than what her parents achieved. Her mother had been born in Mexico and possessed a third-grade education; her father had died when she was a baby. While her mother had successfully learned English, her job in the hospitality industry was not what Maria wanted for her mother. She wanted her mother to have an easier job, perhaps in an office. Or better yet, Maria wanted her mother to be able to retire after working so hard to raise Maria on her own. Maria enrolled in an undergraduate engineering program and worked full-time to pay for her own education and living expenses. Her motivation for pursuing an engineering degree was to have stable employment that would provide a good income to support her mother. Maria's greatest dream was to buy her mother a house. She and her mother had lived in a rented house for more than 20 years, explaining: 
We've been living in a house that's not even our own. I mean, like, it took us 12 years to put a nail in one of the walls because the day we move out, we don't want them to tell us something... We painted the walls, put in new carpet, redid the bathroom and at the end none of that's ours. We're going to move out one day and what do we have to show for it? And so that's my thing. I need to have that financial stability where I can get the house for my mom. At least something I can say, "This is yours... You want to put a nail in the wall, put a nail in the wall!"

Women in STEM - and especially women of color in the United States - are underrepresented. To succeed in STEM, and first in STEM education, women face a myriad of enormous hurdles. While Chavone's story illustrates how systemic inequities, reckless policies, and unscrupulous budgeting can impact one student, Maria's story is one that vividly illustrates individual motivation and persistence in pursuing STEM, and intersects with systemic inequities.

I have often been asked to provide a "silver bullet" answer to the issue of women's underrepresentation in STEM in various roles throughout my career. As the national president of Women in Engineering ProActive Network (WEPAN), an organization whose mission is to advance cultures of inclusion and diversity in engineering higher education and workplaces, I was frequently invited into national conversations about women in STEM at entities such as the National Academy of Engineering, the National Science Foundation (NSF), and even the White House Office of Science and Technology Policy. My stint as a rotator program director at NSF further led me to have a birds-eye national view of STEM education in the United States and the ways we might broaden participation. As the current editor-in-chief of the Journal of Women and Minorities in Science and Engineering, I read and review research from many countries that is doing the hard work of making sense of the promise and limitations of policy, culture, and individual choice in the quest for equity for women in STEM.

If I am honest, I must admit that I feel more and more frustrated that people keep asking for the all-encompassing, silver bullet solution to women's underrepresentation in STEM. I am frustrated because people tend to ask for easy fixes to long-standing, complex problems only when the populations in question are marginalized. Easy fixes to women's global underrepresentation in STEM and STEM education do not exist.

I am excited about the work in Gender equity in STEM in higher education: International perspectives on policy, institutional culture, and individual choice because the volume acknowledges that addressing women's underrepresentation in STEM requires us to look both at systemic issues that perpetuate inequity and how we support the individuals who are currently marginalized by the system as we work to change the culture. I am confident that you will be as excited as I am when you see the transferability of this work to your own. 
Julie P. Martin, Associate Professor, The Ohio State University

\section{References}

Martin, J. P., \& Garza, C. (2020). Centering the marginalized student's voice through autoethnography: Implications for engineering education research. Studies in Engineering Education, 1(1).

Trenor, J. M., Yu, S. L., Waight, C. L., Zerda, K. S., \& Sha, T. L. (2008). The relations of ethnicity to female engineering students' educational experiences and college and career plans in an ethnically diverse learning environment. Fournal of Engineering Education, 97(4), 449-465. 


\section{Acknowledgements}

In the early period of collaboration with our chapter authors from nine different countries, the coronavirus pandemic attacked our health and lives. Just like any other educators in the world, we needed to prepare and teach online classes for our students, help our kids at home with their online schooling, take care of elderly family members, and stay home to avoid crowds. While we were adjusting to the new normal, we continued our work on this volume with our chapter authors who encountered very similar challenges in different time zones. We want to begin our book by acknowledging how much we appreciate and respect the contributors' dedication to the volume.

The edited volume would not be possible without the support, guidance, and thoughtful advice of our editorial team at Routledge: Ellie Wright and AnnaMary Goodall. Frank and Hyun Kyoung presented at the 2019 Comparative and International Education Society conference in San Francisco. While we presented our study on gender disparities in STEM education in England, we also attended several sessions where scholars and practitioners expressed their concerns about gender equity across the world. When Ellie emailed us to ask about our interest in publishing our work with Routledge, we knew that we would like to compile a book to address how undergraduate education has improved gender equity in STEM via international and comparative perspectives. Through several Zoom calls and multiple email communications, Ellie has been so supportive and helpful in every stage of our publication process. We especially appreciate that Ellie nominated and supported our volume to be selected for Open Access funding as part of the Knowledge Unlatched funding program. Ellie guided us through all the logistical matters so we could keep our focus on the content of the volume.

Hyun Kyoung would like to thank Lisa Lattuca, Pat Terenzini, and David Post for encouraging her to study equity issues in STEM higher education and comparative education. Frank thanks Dave Baker and Justin JW Powell for encouraging his interest in writing about international higher education. Elizabeth would like to thank V. Barbara Bush and Alma Martinez-Egger for their support and guidance during her higher education journey.

Finally, we want to thank the following individuals: Brittany House Conrad who helped us develop a proposal at the early stage of this project. 
Additionally, David Knight, Jeongeun Kim, and Jisun Jung recommended potential chapter authors for this volume. We also want to thank the anonymous reviewers who offered thoughtful insights on our proposal to Routledge and Julie Martin who provided a thoughtful foreword for the volume. We thank Alex Wiseman, David Post, Beverly Lindsay, Karen Monkman, and Simon Marginson for their kind words endorsing the project. All of our contributors made this a strong volume that we hope will help scholars and practitioners improve gender equity in STEM higher education across the world. 
$\Longrightarrow$ Taylor \& Francis Taylor \& Francis Group http://taylorandfrancis.com 


\title{
1 Introduction
}

\section{Gender Equity in STEM in Higher Education: International Perspectives on Policy, Institutional Culture, and Individual Choice}

\author{
Hyun Kyoung Ro, Elizabeth F. Ramon and \\ Frank Fernandez
}

Even before the global pandemic of 2020, people across the world faced unexpected challenges and hardships, often surrounding issues of climate change, poverty, and human rights. Carbon emissions that fuel climate change reached new heights in 2019 and, while decreasing during the pandemic-induced slowdown, are expected to return to high levels worldwide (Lindsay, 2020). Poverty projections indicate the COVID-19 economic crisis will more severely affect countries that are already struggling with high poverty rates and numbers of poor (The World Bank, 2020). Estimates show that COVID19 could force over 70 million people into extreme poverty, with close to half of them found in South Asia and more than a third in Sub-Saharan Africa (The World Bank, 2020). More social movements and activism for human rights have been observed in the world. In the United States, for example, the Black Lives Matter movement has expanded and grown, and students and faculty have protested together against police brutality, White supremacy, and the endless injustices faced by the Black community (Flowers, 2020).

Everything that happened before and during (potentially after) the COVID-19 pandemic has called us to reflect upon what these events mean to women, and particularly women in science, technology, engineering, and mathematics (STEM) education and the STEM workforce across the world. Even before the pandemic, women faculty who had children were more likely to serve as primary caregivers at home than their men partners (Bianchi et al., 2012). Thus, it is not surprising that COVID-19 has diminished research productivity among STEM women faculty and researchers who have young children (Krukowski et al., 2020). A recent study also shows that women faculty in more advanced stages of their careers submitted proportionally fewer manuscripts than men colleagues during the COVID-19 lockdown periods (Squazzoni et al., 2020). Women college students, particularly ethnic minority and low-socioeconomic (SES) women, have faced similar obstacles since they were obliged to stay home and shelter in place (Morabito, 2020). Because of gendered norms, women may have more expectations to help with household labor or care for younger siblings (Sy \& Romero, 2008), while at the same time suffering a lack

DOI: $10.4324 / 9781003053217-5$ 
of resources and access to technology and learning. We do not attempt to argue who has been the most victimized by the pandemic, because we all have suffered to a certain degree. Rather, we recapitulate the relevance of this book during the period of COVID-19 and the time it takes to recover from its impact. We therefore shape the Introduction and Conclusion of this book to be more reflective of the COVID-19 era.

\section{Our Motivation and Volume Title}

When we proposed this book to Routledge in early 2020 (not anticipating a pandemic), we were motivated to contribute to international efforts to improve gender equity in STEM by emphasizing the role of STEM undergraduate education. This volume is timely and internationally relevant based on the United Nations' (UN) 2030 Agenda for Sustainable Development (n.d.). Building on the success of the Millennium Development Goals, the UN's fourth Sustainable Development Goal (Quality Education) sets targets to "ensure equal access for all women" and to "eliminate gender disparities in education." Additionally, the fifth Sustainable Development Goal (Gender Equality) is to "achieve gender equality and empower all women and girls." Similarly, Organization for Economic Co-operation and Development (OECD) countries have implemented initiatives to increase interest in science and engineering among youth (OECD, 2018). The report, OECD Science, Technology, and Innovation Outlook 2018, devotes a chapter to gender inequalities in STEM from primary education to careers (Chapter 7). The report confirms that gender disparities in STEM persist even though most OECD countries have implemented a variety of policies to address them. We seek to inform scholarship and practice through the next decade as international organizations and national governments make and document their progress toward achieving Sustainable Development Goals related to gender equity in STEM by highlighting the contribution of STEM undergraduate education for women.

This book, Gender Equity in STEM in Higher Education: International Perspectives on Policy, Institutional Culture, and Individual Choice, is the result of international and collaborative efforts to shed light on national-, institutional-, and individual-level efforts to recruit and retain more women through STEM undergraduate education. A discussion of each title word follows, in order to share what motived us to initiate this volume.

Why Equity? We choose the term gender "equity," rather than "equality." Over the past four decades, policy analysts, policy makers, government officials, scholars, and educators have used equity and equality interchangeably (Espinoza, 2007). However, some scholars claim these two concepts have important distinctions in terms of goals and purposes (see Espinoza, 2007). We stand for pursuing gender equity in STEM as defined by Samoff when he describes "equity" in relation to schooling. Samoff (1996, as cited in Espinoza, 2007) explains: "Achieving equality requires insuring that children [students] are not excluded or discouraged from the tracks that lead to better jobs 
because they are girls" (p. 346). Conversely, "Equity, however, has to do with fairness and justice" (Samoff, 1996, as cited in Espinoza, 2007, p. 346). Samoff argues that equality is necessary, but not sufficient, for pursuing equity.

And there is the problem ... [Indeed] where there has been a history of discrimination, justice may require providing special encouragement and support for those who were disadvantaged in the past ... To achieve equity - justice - may require structured inequalities, at least temporarily. Achieving equal access, itself a very difficult challenge, is a first step toward achieving equity. (Samoff, 1996, as cited in Espinoza, 2007)

We seek to approach ways to change structured inequalities against women in STEM, which requires an understanding of the history and context of each country and its school systems. Our chapter authors aim to offer not only individual- and classroom-level insights but also system- and structure-level implications for promoting gender equity in undergraduate education and ultimately throughout STEM education and the STEM workforce. Although the title uses the term equity, our chapter authors use both equity and equality when explaining the context of their countries' national policies and institutional practices.

Why International Perspectives? Gender inequity in STEM higher education is not only a national issue; it is a global phenomenon (Ramirez \& Wotipka, 2001). A series of reports have shown that women remain significantly underrepresented in certain areas of STEM disciplines, such as such as engineering, computer science, physics, and mathematics or statistics, even though the proportion of women in higher education has increased across the world (OECD, 2018). Despite national-level initiatives and investment, gender inequity in STEM disciplines has persisted in most countries. The goal of this volume is not to present which country has better (or worse) initiatives to improve gender equity. Rather, we asked chapter authors to demonstrate the different historical, societal, and cultural aspects of those endeavors to better understand national policies and institutional practices to increase the number of women in STEM higher education. Recognizing the national context is necessary for policy makers and scholars to learn about unique, but potentially transferable, policies and practices for supporting gender equity. In other words, we hope readers will consider whether successful policies and practices in one country may work in other contexts.

Why Policy? For decades policy makers and scholars have offered numerous interventions to broaden women's participation in STEM fields throughout primary, secondary, or tertiary education - and ultimately in the workforce. Yet most countries still face concerns about gender in STEM fields. National governments in many post-industrial countries have issued policy reports and implemented educational initiatives policies due to concerns about the lack of parity in STEM and its effects on economic development (Wotipka \& Ramirez, 2003). While these efforts to improve STEM education and national 


\section{Hyun Kyoung Ro et al.}

development would not be achieved without securing more future women scientists and engineers, scholars have claimed that gender equity should be an equally important mission in and of itself (Barton, 2003; Baillie \& Pawley, 2012). This book shows, for each country case, how national policies are shaped and implemented to achieve these two missions.

Why Institutional Culture? We need a culture in science that encourages women to not just choose to enroll in STEM, but that also supports them to persist to graduation and to apply their expertise in the workforce. One of the key reasons that women do not persist in STEM is the combined effects of a "chilly," "weedout," and "masculine" culture of STEM, which favors men from middle- or upper-income backgrounds. STEM pathway or pipeline studies have shown that culturally responsive curricula and pedagogies, same-gender faculty mentoring, inclusive interactions with peers, and networks and women role models through professional associations are crucial factors to promote retention of women in STEM fields (e.g., Gonsalves, 2011; Gonzalez et al., 2021). We seek to broadly capture how efforts for STEM gender equity among faculty, administrators, leaders from professional associations, and STEM industries can influence and improve the culture of institutions and STEM disciplines.

Why Individual Choice? We asked our chapter authors to provide an account of the experiences and choices that individual women make as part of their everyday challenges and opportunities as they participate in STEM higher education. Rather than reiterating that there are few women in STEM, some chapters reveal successful stories of women students who choose and stay in STEM disciplines. Chapter authors also address how individual women students' psychological (e.g., aspiration, motivation, or interests) and family- and school-level factors affect their choice of STEM subjects or majors in higher education. Furthermore, our authors supply empirical evidence of how women students beat the low odds of completing STEM four-year degrees through the telling of their experiences inside and outside classrooms on campus.

\section{Organization of the Volume and Overview of Chapters}

In this volume, we seek to bridge the macro (international/comparative studies)-to-micro (student-focused research) gap to better understand and approach women undergraduates who study STEM in higher education. We divide the book into two parts. Part I of the volume begins with a chapter that provides an international overview of access and success for women in STEM undergraduate programs, which is followed by four country case studies (China, Taiwan, the United States, and England). The chapters in Section One address demographic trends and national policies that affect gender equity in STEM at four-year higher education institutions (for example, educational expansion, national examinations and stratified admissions systems, and government funding initiatives). The chapters in Part II of this volume examine six other countries (Chile, Germany, Kazakhstan, South Africa, Australia, and Hong Kong) and focus on individual-level women's 
choices and experiences within certain university contexts (e.g., sub-STEM disciplines, curricular and co-curricular programs, and faculty roles). Although we divided the two sections by empirical foci, both sections address nationallevel policies, broader socio-historical contexts, and access and success among women undergraduates in STEM. Each chapter offers the context of the country, attempts to highlight unique but potentially transferable policies, institutional culture and practices, empirical evidence including quantitative and qualitative data, and implications for increasing gender equity in STEM at the individual, institutional, and national levels. In the conclusion chapter, we offer suggestions for policymakers and STEM educators who wish to learn from successes in other countries. We also discuss how STEM programs in higher education are situated within a context of changing economic, political, and social norms and suggest directions for innovative research and policy for gender equity in STEM fields in the 21st century.

In Chapter 2, "A Cross-National Analysis of Women Graduates with Tertiary Degrees in Science, Technology, Engineering, and Math, 1998-2018: Commonalities and Variations," Lee et al. conduct a cross-national analysis of 143 countries and territories to examine women's global participation in STEM. The chapter focuses on women's share of STEM graduates to explore trends and compare women's enrollment in STEM to men's enrollment in STEM and to higher education in general. Lee et al. begin the policy discussion by indicating institutional- and government-level practices that can be adopted to increase women STEM graduates. The authors conclude by highlighting the need to increase women's participation in the STEM labor market for increases in women's participation in STEM higher education to have effects on economic development.

Chapter 3, "The Rise of Women in STEM Higher Education in China: Achievements and Challenges," furthers the discussion of policy by providing an account of how China's government-level policies promoting gender equality in education in general, and STEM in particular, have increased women's participation levels. Policies for compulsory education and enrollment quotas are discussed in the context of women students' learning experiences and labor market outcomes. Similar to Chapter 2, Lingyu et al. note that women college graduates remain at a disadvantage in the labor market relative to men.

Chapter 4, "The Higher Education Trajectories of Taiwanese Women in STEM: A Longitudinal Analysis," focuses on the expansion of higher education in Taiwan as it relates to the improved participation of women in STEM tertiary education and in the STEM labor market. Despite expanded opportunities, Fu et al. find evidence that women in Taiwan are still likely to self-select out of STEM during upper secondary and tertiary education and that expansion itself is insufficient to achieve equity. The authors acknowledge that policy is only one of many available tools and suggest it may be important to consider individual-level reasons women students may have for self-selecting out of STEM, even though policy initiatives have successfully addressed certain "leaky pipeline" issues. 
In Chapter 5, "STEM Bachelor's Degree Attainment among Women of Color in the United States: Using Geographic Analysis for Gender and Racial Equity Research," Ro et al. delve into the ways the number of women of color residents who obtain STEM bachelor's degrees varies by access to local higher education opportunities. The authors also incorporate a discussion of additional challenges women of color face that exacerbate the structural barrier of geographic disparity in educational opportunities. Strategies to combat these challenges and facilitate the success of women of color range from institutional level practices to national level policies.

In Chapter 6, "A Comprehensive Approach to Addressing Gender Equity in STEM Subjects at Four-Year Universities in England," Ro et al. study gender disparity in undergraduate STEM enrollment in England, including enrollment at prestigious Russell Group universities. The authors locate this discussion within the context of the expansion of higher education in England and a consideration of differing social classes and academic backgrounds of women students who pursue STEM subjects in higher education. The authors claim that more research should examine how the relationship between STEM subject choice and the selectivity of institution admission varies by gender.

Chapter 7, "Women in STEM in Chilean Higher Education: Social Movements and Institutional Transformations," begins our conversation about individual-level factors and women's choices and experiences in STEM. Kim and Celis provide an account of social and intellectual movements in Chile that improved policies and participation in higher education for women, such as increased representation in faculty and leadership positions and an increase in STEM majors. The authors address how women have experienced discrimination and stereotyping in Chilean society and remain underrepresented in STEM by analyzing historical enrollment data. The authors posit that recognizing and replicating how women are recruited and retained in STEM majors will further improve women's STEM representation, especially those policies that have worked so well in Chile.

In Chapter 8, "Examining Gender (In-)Equality in German Engineering: Considering the Importance of Interest, Perception, and Choice," Dusdal and Fernandez focus on the persistence of gender inequality in undergraduate engineering education in Germany by analyzing individual factors that contribute to women's tendency to consider but then opt out of engineering. Similar to Chapter 7, the authors provide strategies to facilitate success and increase participation such as policy initiatives to recruit and retain women students to STEM and to support parents and teachers for early intervention.

In Chapter 9, "Gender Equity in STEM in Higher Education: Kazakhstan," CohenMiller et al. describe three challenges to gender-based equity in STEM in a post-Soviet context and offer multiple policy suggestions for improvement. The authors highlight ways that legal and political reforms have benefited women but have not changed cultural norms and expectations for women that influence their opportunities and their decision-making in STEM education and employment. CohenMiller et al. examine the pipeline in Kazakhstan, which 
shows "leaks" in recruitment and promotion in academia and employment for STEM students, graduates, and faculty.

In Chapter 10, "Black African Women in Engineering Higher Education in South Africa: Contending with History, Race and Gender," Mlambo describes women's higher education in South Africa, with a focus on Black women engineers, and underscores how they are discouraged from pursuing engineering degrees and academic careers. Black women in South Africa "experience higher education as racialized and gendered" and interact with institutions and a higher education system that is mostly White. The author offers numerous suggestions for making higher education and engineering both more welcoming for Black women and for dismantling the culture of whiteness within South African higher education.

In Chapter 11, "Approaches for Attracting, Retaining, and Progressing Women in Australian Undergraduate Engineering: Curricular Innovation Focused on Humanitarian and Human Centered Design Concepts," Goncher and Cameron illustrate how collaboration between stakeholders, such as academia, government, and industry, and across programs aids in the recruitment and retention of women students and faculty in engineering. Utilizing Australia as an example, the authors advocate for a cohesive message to promote gender diversity in STEM and higher education.

In Chapter 12, "Aspiring and Becoming STEM Teachers in Hong Kong: A Gender Perspective," Tang et al. focus on the importance of teacher education for inspiring pre-service STEM teachers. Their chapter offers insights about the critical role pre-service STEM teachers have in the classroom to provide professional training, avoid gender stereotyping against students, and act as role models for a more gender equitable future in STEM. The authors used educational ethnography methods to interview pre-service women teachers majoring in STEM-related programs at the largest teacher training university in Hong Kong. They recommend policy changes for deconstructing gender stereotyping and diminishing gender disparities to achieve justice in STEM teacher education.

\section{For Our Readers}

Gender Equity in STEM in Higher Education: International Perspectives on Policy, Institutional Culture, and Individual Choice takes an international and comparative approach to examining gender equity in STEM fields at the undergraduate-university level. The two sections of the volume allow us to organize chapters based on two themes: those that primarily focus on national policy initiatives and those that primarily focus on women's agency and choice. This volume brings together experts from around the world to identify unique but potentially transferrable implications for increasing gender equity - that is, to not only describe the successes of a single country but to consider whether policies and practices to support gender equity in STEM may work in other contexts. 
We want to circle back to where we started in this chapter: by calling for readers to consider gender equity in the wake of the COVID-19 pandemic. The pandemic offered a compelling narrative about the importance of women and internationalization in STEM, specifically, in vaccinology (Bora, 2020; Wadman, 2020). Dr. Nita Patel was born in India and has led an all-women team of scientists at Novavax Lab in the United States, which has been at the forefront of developing a COVID-19 vaccine. One member of Patel's team, Dr. Sonia Maciejewski, previously made productive and valuable contributions to vaccine development to address the international threat caused by the Zika virus (Maciejewski et al., 2020).

The story of women scientists developing vaccines to address a global pandemic was inspiring during the difficult period we spent compiling this volume (particularly because all of us have daughters). During and after the COVID-19 pandemic, we believe that women like those who work on vaccines will continue to support future women scientists and engineers. Women have been underrepresented in STEM in the past, and we worry that the pandemic's social and economic impact is disproportionately affecting women and could disrupt progress toward gender equity in STEM. We hope this volume will offer implications not only for individual-level efforts but also institutionaland national-level commitments to improve gender equity in STEM through undergraduate education.

\section{References}

Baillie, C., \& Pawley, A. (Eds.). (2012). Engineering and social justice: In the university and beyond. Purdue University Press.

Barton, A. C. (2003). Teaching science for social justice. Teachers College Press.

Bianchi, S. M., Sayer, L. C., Milkie, M. A., \& Robinson, J. P. (2012). Housework: Who did, does or will do it, and how much does it matter? Social Forces, 9(1), 55-63.

Bilimoria, D., \& Lord, L. (Eds.). (2014). Women in STEM careers: International perspectives on increasing workforce participation, advancement, and leadership. Edward Elgar Publishing.

Bora, S. (2020, January 5). Meet Nita Patel, an American-Indian scientist who is breaking ground in vaccinology. Shethepeople. https://www.shethepeople.tv/shetec $\mathrm{h} /$ american-indian-scientist-nita-patel-covid-vaccine/

Espinoza, O. (2007). Solving the equity - equality conceptual dilemma: A new model for analysis of the educational process. Educational Research, 49(4), 343-363

Flowers, J. C. (2020, June 6). The coming campus protests: College leaders will be judged by their actions - not their words. The Chronicle of Higher Education. https:// www.chronicle.com/article/the-coming-campus-protests

Freeman, B., Marginson, S., \& Tytler, R. (Eds.). (2014). The age of STEM: Educational policy and practice across the world in science, technology, engineering and mathematics. Routledge.

Gonsalves, A. J. (2011). Gender and doctoral physics education: Are we asking the right questions? In L. McAlpine \& C. Amundsen (Eds.), Doctoral education: Researchbased strategies for doctoral students, supervisors and administrators (pp. 117-132). Springer.

Gonzalez, E. M., Fernandez, F., \& Wilson, M. (Eds.). (2021). An asset-based approach to advancing Latina students in STEM: Increasing resilience, participation, and success. Routledge.

Kodate, N., \& Kodate, K. (2015). Fapanese women in science and engineering: History and policy change. Routledge. 
Kruger, M., \& Nel, H. (2019). The development of women and young professionals in STEM careers: Tips and tricks. CRC Press.

Krukowski, R. A., Jagsi, R., \& Cardel, M. I. (2020). Academic productivity differences by gender and child age in science, technology, engineering, mathematics, and medicine faculty during the COVID-19 pandemic. Fournal of Women's Health. Advance online publication. https://doi.org/10.1089/jwh.2020.8710

Lindsay, J. M. (2020, December 17). Ten most significant world events in 2020. Council on Foreign Relations. https://www.cfr.org/blog/ten-most-significant-world-events-2020

Maciejewski, S., Ruckwardt, T.J., Morabito, K. M., Foreman, B. M., Burgomaster, K. E., Gordon, D. N., Pelc, R. S., DeMaso, C. R., Sung-Youl, K., Fisher, B. E., Yang, E. S., Nair, D., Foulds, K. E., Todd, J. P., Kong, W-P., Roy, V., Aleshnick, M., Speer, S. D., Bourne, N ...Pierson, T. C. (2020). Distinct neutralizing antibody correlates of protection among related Zika virus vaccines identify a role for antibody quality. Science Translational Medicine, 12(547). https://doi.org/10.1126/scitranslmed.aaw9066

Morabito, A. (2020, November 13). The crossroads of COVID: Class, race and gender. Inside Higher Ed. https://www.insidehighered.com/advice/2020/11/13/col leges-should-especially-support-low-income-women-color-during-pandemic-opinion

OECD. (2018). OECD science, technology, and industry outlook. OECD Publishing. https:// read.oecd-ilibrary.org/science-and-technology/oecd-science-technology-and-innova tion-outlook-2018_sti_in_outlook-2018-en\#page 1

Pearson Jr, W., Frehill, L. M., \& McNeely, C. L. (Eds.). (2015). Advancing women in science: An international perspective. Springer.

Ramirez, F. O., \& Wotipka, C. M. (2001). Slowly but surely? The global expansion of women's participation in science and engineering fields of study, 1972-92. Sociology of Education, 74(3), 231-251.

Samoff, J. (1996). Which priorities and strategies for education? International Fournal of Educational Development, 16(3), 249-271.

Squazzoni, F., Bravo, G., Grimaldo, F., Garcia-Costa, D., Farjam, M., \& Mehmani, B. (2020). No tickets for women in the COVID-19 race? A study on manuscript submissions and reviews in 2347 Elsevier journals during the pandemic. SSRN Electronic Fournal. doi:doi:10.2139/ssrn.3712813

Sy, S. R., \& Romero, J. (2008). Family responsibilities among Latina college students from immigrant families. Fournal of Hispanic Higher Education, 7(3), 212-227.

The World Bank. (2020, June 8). Projected poverty impacts of COVID-19 (coronavirus). https://www.worldbank.org/en/topic/poverty/brief/projected-povertyimpacts-of-COVID-19

UNESCO Institute for Statistics. (2011). International standard classification of education: ISCED 2011. http://uis.unesco.org/sites/default/files/documents/international-sta ndard-classification-of-education-isced-2011-en.pdf

United Nations. (n.d.). Sustainable development goals. https://sustainabledevelopment. un.org/?menu $=1300$

Wadman, M. (2020). 'Nothing is impossible,' says lab ace Nita Patel. Science, 370(6517), 652. https://doi/org/10.1126/science.370.6571.652

Wotipka, C. M., \& Ramirez, F. O. (2003). Women in science: For development, for human rights, for themselves. In G. S. Drori, J. W. Meyer, F. O. Ramirez, \& E. Schofer (Eds.), Science in the modern world polity: Institutionalization and globalization (pp. 174-195). Stanford University Press. 
$\Longrightarrow$ Taylor \& Francis Taylor \& Francis Group http://taylorandfrancis.com 


\section{Part 1}

\section{Demographic Trends and National Initiatives}


$\Longrightarrow$ Taylor \& Francis Taylor \& Francis Group http://taylorandfrancis.com 


\title{
2 A Gross-National Analysis of Women Graduates with Tertiary Degrees in Science, Technology, Engineering, and Math, 1998-2018
}

\section{Commonalties and Variations}

\author{
Seungah S. Lee, Christine Min Wotipka and \\ Francisco O. Ramirez
}

Much of the growing comparative scholarship on women and higher education focuses on women and the fields of science, technology, engineering, and math (STEM). This literature has mostly addressed issues of access and examined patterns of women's enrollments in STEM relative to those of men (Charles, 2011). What has motivated this literature is the sense that there are higher monetary payoffs for women who enter these fields than non-STEM fields, as well as higher entry barriers. This motivation is grounded in a women's rights perspective. The literature is further motivated by the belief that national economic development is fostered by innovations triggered by STEM. This motivation is rooted in a human capital perspective. From both perspectives, more women in STEM is a desideratum, benefiting women and their societies.

In what follows, we briefly review the literature and studies that address women in STEM. However, our paper focuses on graduation numbers, not merely enrollment patterns, as both perspectives ultimately are concerned with outcomes better captured via data on graduation patterns. The women's rights perspective has generated the "chilly climate" idea that can be more rigorously examined through an inspection of graduation patterns. The human capital perspective with its emphasis on expanding human resources is also better assessed with data on outcomes. Both perspectives are evident in many policy reports that highlight the importance of having more women in STEM. The European Technology Assessment Network (2000), for example, champions women in STEM, emphasizing women both as rights bearers and as contributors to human capital. Our chapter explores cross-national trends in STEM degree graduates at the tertiary level ${ }^{1}$ from 1998 to 2018 for 143 countries.

The first part of this chapter examines women in STEM cross-national studies. These studies reveal both some common change patterns as well as variations. Next, we reflect on the STEM for national economic development literature. Lastly, we provide evidence on interrelated but different questions: 


\section{Seungah S. Lee et al.}

(a) What percentage of women graduates obtained STEM degrees, and how does this compare to men graduates with STEM degrees? (b) What percentage of STEM graduates are women relative to men?

We have learned from prior studies that there are gender gaps, with men continuing to dominate in STEM fields, which is an international trend (Charles \& Bradley, 2009). The issue though is whether these gaps persist over time, globally, and across levels of economic development. Or, alternatively, have there been changes, and have these changes been in the direction of greater gender equality? Earlier modernization-inspired studies implied that changes would be more evident in more developed countries (Boserup, 1981). However, recent research suggests otherwise (Charles \& Bradley, 2009). We directly address this question by comparing changes in countries that vary with respect to their level of development.

\section{Women and STEM}

Throughout the 20th century, women's social movements have pressed to change the status of women, from mainly wives and mothers to citizens and persons (Berkovitch, 1999). These social movements led to the global acquisition of the franchise (Ramirez, et al., 1997) and to other legal and social changes in the direction of greater equality in some societal domains (Dorius \& Firebaugh, 2010). In the realm of higher education, the impact of women's movements was neither anticipated nor well understood. As higher education greatly expanded in the post-World War II era (Schofer \& Meyer, 2005), women's share of higher education increased. Between 1970 and 2010, this increase was evident across all the regions of the world, with women's share at $50 \%$ or more in every region except Sub-Sahara Africa. In the latter, however, women's share tripled, from a little over $10 \%$ in 1970 to over $30 \%$ by 2010 (Ramirez \& Kwak, 2015). The worldwide expansion of higher education is in good part driven by the growing presence of women therein (Bradley \& Ramirez, 1996).

However, some scholars were quick to correctly point out that much of this increase likely took place in fields like the humanities, social sciences, and education, and not in STEM (Bradley, 2000; Kelly, 1989). Expanded participation by women in higher education may be less consequential for women if they entered fields of study that do not yield the higher occupational and income payoffs associated with STEM. Furthermore, from a national policy perspective increasingly focused on STEM as a crucial launching pad for economic development, expanded participation by women outside STEM also could be less significant.

These reservations led some researchers to directly examine women's share of STEM in higher education. Several findings emerge from these studies: first, as expected, women's share of STEM enrollments was lower between 1972 and 1992 in Ramirez and Wotipka's study (2001) and between 1970 and 2010 in Ramirez and Kwak's study (2015). STEM has been and continues to be more inhabited by men. 
A second finding, however, was not expected: women's share of STEM increased over time. Perhaps even more surprising, is that the increase is found in every region of the world (Ramirez \& Kwak, 2015). In the 1970s, women's share was between 10 and $20 \%$, but by 2010 the share was between 30 and $40 \%$. The trend, albeit slowly, is moving in the direction of greater gender equality. This trend may reflect earlier developments in lower levels of schooling. Over time, girls' scores in math and science international tests have improved, narrowing the gender achievement gap in these domains (Baker \& Jones, 1993; Wiseman, 2008). Furthermore, math educators have increasingly advocated for reforms in math pedagogy and curricula with the goal of undercutting the gender gap (Boaler, 1997). The gender gap may be declining, but it is garnering more global attention than in earlier eras.

Bear in mind that these comparative studies examined enrollments. In some systems of higher education (for example, the United States), students can readily change majors, thereby shifting from STEM to other disciplines. This chapter focuses on graduation patterns for all tertiary levels precisely because it is a more rigorous measure of the degree to which STEM has opened or failed to open to women. That is, one can imagine increased enrollments due to greater demand and less barriers to entry, but nevertheless more obstacles to degree completion that result in graduation rates patterns that differ from enrollment patterns. Women have shown to be particularly vulnerable to the "chilly climate" in STEM that leads to a "leaky pipeline" (Blickenstaff, 2005). In fact, studies have found that women are more likely to leave the STEM pipeline at various milestones for reasons such as lower mathematical confidence (Ellis, et al., 2016), lack of women role models (Shapiro \& Sax, 2011), perception of major, and negative feedback in the form of relatively low grades (Kugler, et al., 2017).

Before we examine change in STEM graduation patterns, we also review the literature on STEM for national economic development. First, we examine the global, regional, and national policy discourse emphasizing the centrality of science, technology, and engineering in the pursuit of national economic development. Next, we review studies that seek to empirically ascertain the relationship between STEM and national economic development. In both instances, we consider references to the role of women in this development endeavor. Lastly, we raise and seek to answer our main research question: Given so much interest in STEM, what does the STEM share of higher education degree holders look like?

\section{STEM for National Economic Development}

The United Nation's (UN) Sustainable Development Goals adopted in 2015 focus on three dimensions of development - economic, social, and environmental. Key to each aspect is the role played by the STEM fields as well as by women. As affirmation of the combined importance of STEM and women, the UN declared February 11 of each year the International Day of Women 
and Girls in Science. In doing so, the UN recognized that the underrepresentation of women in STEM was not only a matter of women's economic and social rights but also needed to be rectified for the good of countries and the global community (Wotipka \& Ramirez, 2003).

This global push for STEM resonates with many regions and countries, as manifested in their calls for greater investments in STEM. For example, the European Union's Horizon 2020, the largest research and innovation program of its kind, aims to drive economic growth and create jobs. Science education, especially for girls, is regarded as key to these efforts. Similarly, the African Union's Agenda 2063 sees science, technology, and innovation as critical to its inclusive growth and sustainable development (African Union, 2020). In East Asia, although students perform very well on the OECD's Program for International Student Assessment (PISA), including science and mathematical knowledge in real-world contexts and creativity, efforts are underway to utilize more student-centered learning approaches, which may help attract more girls and women to STEM fields in a region where their representation is lacking (Huyer, 2015). Arab States' Strategy for Science, Technology and Innovation calls for science education and universities and research and development to be expanded (Zou'bi, et al., 2015). We also find country level initiatives that display a positive reception to the global science for development agenda and women in science as a feature of this agenda.

This global push has been propped up by the growth of international testing regimes with math and science achievement garnering the most attention in policy circles and in the mass media. In the US, the publication of $A$ Nation at Risk (NCEE, 1983) boldly claimed that the lower standing of American students in the Second International Mathematics Study (SIMS) foreshadowed the decline of the country on the world stage. Earlier concerns in the Cold War era were more attuned to geopolitical and military competition, but the Nation at Risk fear was mostly framed in economic terms with Japan (and later the so-called Asian Tigers as the rising competitors). The same fear underlies Rising above the Gathering Storm (Committee on Prospering in the Global Economy of the 21st Century, 2007) with this report specifically focused on STEM in higher education. Not surprisingly, this report also points to the need for more women in STEM. Appraising the report, Vest (2010) stresses the need to train more STEM teachers, support more science and engineering research, train more higher education STEM students, and provide more incentives for innovations to avoid a "category 5" storm.

Underlying these global, regional, and national policy prescriptions is the belief in a direct relationship between STEM education and national economic development. This has led to a greater focus on science and math achievement, including efforts to improve countries' standings on international tests (Ritz \& Fan, 2015). The evidence on whether higher international test scores is associated with economic development is mixed. Hanushek and Kimko (2000) find a positive association while other researchers conclude that the association is mostly an "Asian Tigers" effect (Ramirez, et al., 2006). A review of empirical 
research on the link between science education and economic development finds that the evidence is inconclusive (Drori, 2000). However, there is evidence of a positive association between the level of tertiary science and engineering enrollments and economic development. Other indictors of national scientific activity (for example, numbers of publications or citations) fail to positively influence economic development (Ramirez \& Lee, 1995; Schofer, et al., 2000).

So, what impact, if any, do global, regional, and national STEM for development pressures have on the growth of STEM? Focusing on enrollments, Wotipka and Ramirez (2003) find that while STEM enrollments grow in absolute terms, relative to the rest of higher education, one does not see growth over time. A similar finding is reported in Ramirez and Kwak (2015). What this means is that the global expansion of higher education is not driven by STEM. Other sectors of higher education grow more extensively than STEM does. Of course, we are here dealing with a global average, and there is variation across regions and countries. As we report later in our findings, the Middle East and North Africa region, for example, shows small growth in STEM enrollments between 1998 and 2018. Likewise, sub-Saharan Africa shows minimal growth in STEM graduates between 1998 and 2018. But we see declines in other regions of the world such as Asia, Latin America, North America, and Western Europe. In fact, the overall STEM share of higher education graduates decreased from $33.47 \%$ in 1998 to $22.56 \% 20$ years later in 2018 .

Despite increased efforts to bring more students into STEM fields of study, we do not observe a spike in the STEM share of higher educational enrollments or graduates. One could argue that where there was less push for STEM, one might actually find sharp declines. In fact, only in Eastern Europe does one detect a sharp decline in STEM enrollments between 1970 and 2010 (Ramirez \& Kwak, 2015). With regards to STEM graduates, we detect a sharp decline in Latin America and the Caribbean between 1998 and 2018.

This overview of the literature and arguments leads us to the questions central to our study: (a) What percentage of women graduates obtained STEM degrees, and how does this compare to men graduates with STEM degrees? (b) What percentage of STEM graduates are women relative to men?

\section{Data and Methods}

The data on tertiary graduates by sex, field of study, and country were gathered from the online database of the UNESCO Institute for Statistics. UNESCO uses the International Classification of Education (ISCED) system to categorize higher education institutions by levels and students by field of study, thus categorizing STEM versus non-STEM fields. Three levels of higher education, i.e., higher technical/vocational, undergraduate, and postgraduate, are all included in our analyses as per ISCED's definition of tertiary education (UNESCO, 2012). Additional country level indicators (e.g., level of economic development) were collected from the World Bank (2019). 
The sample includes 143 countries, including territories, throughout the world from 1998 to 2018. UNESCO collects higher education graduation data from national governments around the world on a yearly basis, but not all governments have participated in data collection every year. Countries in the sample vary by level of economic development across different regions. For a complete list of countries included in the sample, see Table 2.1.

\section{Findings}

To answer our first question, we look at the percentage of higher education graduates who obtained STEM degrees. We do so for both women and men. If the acquisition of a STEM degree was unrelated to gender, the percentage for women would be similar to that for men. Quite the contrary - the global average percentage of higher education graduates with STEM degrees is much higher for men throughout this period. In 1998, the percentage for men was 46.98 while it was $21.98 \%$ for women. Twenty years later, the percentage for men had declined to 31.84 and the percentage for women also declined to $13.07 \%$. These common decline patterns add up to and account for why the overall STEM share of higher education graduates has decreased from $34.88 \%$ to $22.44 \%$ in 2018 .

The global pattern of more men than women graduates with STEM degrees is not due to some outlier regions or set of countries. There are regional variations across patterns for both genders, but we find that more men graduate with STEM degrees than women in all regions between 1998 and 2018. As regards the percentage of men graduates with STEM degrees, we find less regional variation in 2018 than in 1998. In 1998, the highest percentage for men was in Latin America at $69.29 \%$, and the lowest was in sub-Saharan Africa at $14.42 \%$. By 2018, however, the percentage of men graduating with STEM degrees across regions converge at around $32 \%$, with the percentages for Latin America and sub-Saharan Africa being 36.49 and 23.01, respectively. With regard to percentage of women graduates with STEM degrees, we also find more regional variation in 1998 than in 2018. The highest percentage of women graduates in STEM fields throughout was found in the Middle East and North Africa, at 21.12 in 1998 and 20.71 in 2018. Sub-Saharan Africa has the lowest percentage of women graduates with STEM degrees throughout, at 9.49 in 1998 and 7.97 in 2018. This suggests that although the rate at which the percentage of STEM graduates is decreasing is higher for men than that for women between 1998 and 2018, higher proportions of men are graduating with STEM degrees than women in all world regions.

To answer our second question, we examine women's share of STEM degree holders, i.e., of STEM graduates, what percentage are women? The global and regional trends in studies that examine women's share in STEM are in the direction of increased women's share of STEM enrollments, from about 10 to $20 \%$ in 1970 to about 30 to $40 \%$ in 2010 (Ramirez \& Kwak, 2015).

What do we find when we shift from enrollments to graduation patterns and extend the trend to 2018? Our main finding is that women's share of STEM degree holders has undergone a modest increase, from 32.5\% in 1998 
Table 2.1 The Complete List of Countries in the Sample, by Income Level

\begin{tabular}{|c|c|c|c|}
\hline High Income & $\begin{array}{l}\text { Upper-Middle } \\
\text { Income }\end{array}$ & $\begin{array}{l}\text { Lower Middle } \\
\text { Income }\end{array}$ & Low Income \\
\hline Andorra & $\begin{array}{l}\text { Antigua and } \\
\text { Barbuda }\end{array}$ & Albania & Angola \\
\hline Aruba & Argentina & Algeria & Armenia \\
\hline Australia & Bahrain & Belarus & Azerbaijan \\
\hline Austria & Barbados & Belize & Bangladesh \\
\hline Belgium & Brazil & Botswana & Benin \\
\hline Bermuda & Chile & Bulgaria & Bosnia and Herzegovina \\
\hline Brunei & Croatia & Cabo Verde & Burkina Faso \\
\hline Canada & Czechia & Colombia & Burundi \\
\hline Cayman Islands & Hungary & Costa Rica & Cambodia \\
\hline Cyprus & Malaysia & Cuba & Cameroon \\
\hline Denmark & Malta & Ecuador & Chad \\
\hline Finland & Mauritius & Egypt & Comoros \\
\hline France & Mexico & El Salvador & Congo \\
\hline Germany & Oman & Estonia & Dem. Rep. of the Congo \\
\hline Greece & Poland & Eswatini & Eritrea \\
\hline Hong Kong & Puerto Rico & Georgia & Ethiopia \\
\hline Iceland & Saudi Arabia & Grenada & Gambia \\
\hline Ireland & Seychelles & Guatemala & Ghana \\
\hline Israel & Slovakia & Indonesia & Guyana \\
\hline Italy & Slovenia & Iran & Honduras \\
\hline Liechtenstein & South Africa & Iraq & India \\
\hline Luxembourg & Uruguay & Jordan & Kenya \\
\hline Macao & & Kazakhstan & Kyrgyzstan \\
\hline Netherlands & & Latvia & Laos \\
\hline New Zealand & & Lebanon & Lesotho \\
\hline Norway & & Lithuania & Madagascar \\
\hline Portugal & & Maldives & Mauritania \\
\hline Qatar & & Morocco & Mongolia \\
\hline Singapore & & Namibia & Mozambique \\
\hline South Korea & & North Korea & Myanmar \\
\hline Spain & & North Macedonia & Niger \\
\hline Sweden & & Palestine & Pakistan \\
\hline Switzerland & & Panama & Rwanda \\
\hline UAE & & Peru & Sri Lanka \\
\hline UK & & Philippines & Sudan \\
\hline \multirow[t]{2}{*}{ USA } & & Romania & Uganda \\
\hline & & Samoa & Vietnam \\
\hline
\end{tabular}


Table 2.1 (Cont.)

\begin{tabular}{|c|c|c|c|}
\hline High Income & $\begin{array}{l}\text { Upper-Middle } \\
\text { Income }\end{array}$ & $\begin{array}{l}\text { Lower Middle } \\
\text { Income }\end{array}$ & Low Income \\
\hline & & Syria & Zimbabwe \\
\hline & & Thailand & \\
\hline & & Tunisia & \\
\hline & & Turkey & \\
\hline & & Ukraine & \\
\hline & & Uzbekistan & \\
\hline & & Venezuela & \\
\hline
\end{tabular}

to $35.2 \%$ in 2018 . Here, too, we see less variation between regions over time. By 2018 , virtually every region is at about $30 \%$ or above but only one is over $40 \%$. Women's share in the Middle East and North Africa is highest at about $45 \%$, and it is lowest in sub-Saharan Africa at just under 30\%. Despite being often seen as the center of scholarship critiquing the lack of women's access to STEM as well as the attention to remedy their lower representation, women's share for North America and Western Europe barely changes over this period, and at slightly over $30 \%$ is comparable to sub-Saharan Africa.

To further probe variation, we examine women's share of STEM graduates across countries by level of economic development, as classified by the World Bank (2019), based on income groups (see Figure 2.1). We do so for each time

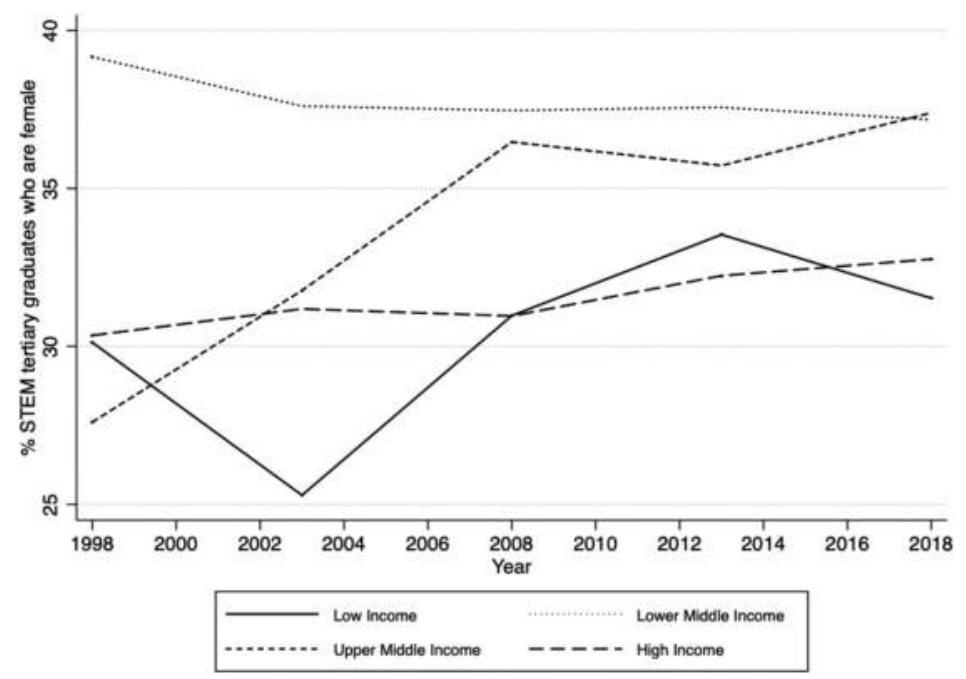

Figure 2.1 Women's share of STEM graduates across countries by level of economic development, as classified by the World Bank (2019). 
point from 1998 to 2018. Since country income levels change over time, we base our analysis on the classification of countries in 1998 across these four categories: high income, upper-middle income, lower-middle income, and low income. We again find less variation in 2018 than in 1998, reflecting increases in three of these economic categories and a modest decline in the upper middle-income group that in 1998 was ahead. By 2018, women's share of STEM graduates is over $35 \%$ in both the upper-income and middle-income groups and below $35 \%$ in both the low- and high-income groups of countries. There appears to be no modernization advantage for women in the top income countries. This finding is consistent with the lack of advantage for the North America and Western Europe region where many of the top income countries find themselves.

To summarize, our exploratory study shows that when one compares higher education graduates with STEM degrees, one finds that men are more likely than women to be STEM graduates. This finding is stable across regions and between 1998 and 2018. However, when the focus is on women's share of STEM graduates, we find a modest increase over time. This increase is not driven by the more developed or more Westernized countries. These developments in women in STEM are taking place in a global context in which feminist scholars and national policy analysts often emphasize the importance of having more women in STEM to meet women's needs and interests but also to foster national economic growth. The global education context, however, is one in which STEM enrollments and graduations are not increasing relative to overall growth in higher education.

In what follows, we seek to make sense of these findings and sketch future lines of inquiry to further our understanding of women graduates and STEM.

\section{Discussion}

At first glance, the answers to our two different but interrelated questions may seem paradoxical. Men graduates are more likely to obtain a degree in STEM, yet women graduate's share of STEM has increased, albeit modestly. This is not as odd as it may seem. The key to understanding these different trends is the realization that the decrease in men graduates with a STEM degree was sharper than that of women graduates. In relative terms, both men and women are opting to graduate with non-STEM degrees. Between 1998 and 2018, this choice pattern is more pronounced for men. The increase in women's share of STEM degrees logically follows. Growth in women's share of STEM degrees is not mainly a function of increased interest and demand for STEM degrees on the part of women. Rather, only relative to men do we see a small increase in women's share of STEM degrees. The absence of an overall surge of interest in STEM degrees in comparison to non-STEM degrees is intriguing. Is this because STEM degrees are harder to obtain? Or, is this due to students making choices not strongly driven by considerations of occupational and earnings payoffs? Frank and Gabler (2006) find that the 
higher education fields of study that grow the most across the world are within the social sciences. Other studies indicate that students, both boys and girls, express less favorable attitudes toward math in the most affluent countries (Charles et al., 2014).

But even more intriguing is why the lack of a surge is more pronounced for men. STEM fields have often been discussed as culturally defined domains for men. That is why these fields are seen as harder to crack for women. STEM as a male-dominated field may be especially the case not only in Western contexts, but also in highly individualist cultures where selection of a field of study is left up to individual tastes, the latter often shaped by sex stereotyping of subject matter. This is the core argument advanced by Charles and Bradley (2009) in making sense of why women veer away from STEM more so in countries with a stronger individualist culture. Charles and Bradley (2009) call the process by which women opt out of STEM as "indulging our gendered selves" (p. 924). Perhaps the globalization of an individualist culture and "changing cultural characteristics" (Aycan \& Fikret-Pasa, 2003, p. 129) result in both men and women self-indulging and making choices more contingent on immediate tastes than on subject matter competence. Perhaps in some societies, it is the study of the humanities, e.g., religion, philosophy, and literature, that is regarded as more appropriate for men while seemingly more mundane subjects like the basic and applied natural sciences are more open to women. The association between STEM and male appropriateness may vary across regions, and that may account for why the Middle East and North Africa region (traditional in some respects) may nevertheless be more open to women in STEM.

In less individualist cultures, selection of a field of study may be more guided by ideas about subject specific competence, perhaps shaped by counseling and/or tracking systems. Offsetting this argument is that some of the less individualist cultures are also characterized by traditional gender role structures that would block women from entry into STEM but also benefit from having younger systems of higher education (and STEM therein) that came about at a time when women had greater rights. Evidence is growing that women fare better in STEM in less economically developed countries as well as in less developed parts of countries (Perez-Felkner et al., 2020). Images of who constitute scientists and engineers are evolving to include women in growing economies (Gupta, 2012 for India and Mellström, 2009 for Malaysia). Yet, labor market segregation remains (Gupta, 2015). Entry into STEM in higher education is easier than entering and remaining in occupations related to STEM (Chow \& Charles, 2019; Jacobs, 1996).

\section{Areas for Future Research and Conclusions}

Our findings show that the story of women in STEM is more nuanced than commonly imagined. Although women are underrepresented in STEM fields globally, women's share of STEM graduates has increased over time, especially in growing economies. In some parts of the world such as the Middle East and North Africa, findings suggest that there actually may be a reverse gender gap 
in higher education although this does not necessarily translate into labor market outcomes. Moreover, it appears that there has not been an upsurge in STEM graduates for both men and women, suggesting that there may be a need to promote STEM pathways to all genders given the importance of STEM fields to fulfill the needs of the future workforce.

Early policy interventions to boost confidence and interest in students and exposing students to real-life experiences and applications in STEM fields, as well as role models in and outside the classroom, can help attract more young people to STEM fields. What is perhaps more important - and a greater policy concern - than increasing the number of women pursuing STEM in higher education, however, is translating higher education outcomes to labor market outcomes. Nonetheless, the reasons why fewer women, especially those in higher income countries, are in STEM fields need to be explored and explained further.

We conclude by recommending several future research directions. First, to get a better longer-term picture, graduation data from earlier eras would be useful. We see from our study that there was more change in the direction of gender equality between 1998 and 2008 than in the last ten years. Was there even greater positive change earlier? Should we think of the last ten years as a temporary stall, or can one imagine another spike in the future? And if so, what societal and global conditions would facilitate further increases?

Second, the "E" in STEM is a domain often more difficult to enter for women. Kwak and Ramirez (2019) find that globally women are less likely to be in engineering fields of study than in the natural sciences. Is this also the case when we examine degree holders rather than enrollments? If engineering is more of a chilly climate for women with regard to enrollments, one would expect a "Siberian impact" with regard to graduations in engineering.

Third, ideas about pipelines often start with access to math and science instruction at lower levels and academic achievements therein (Wiseman, 2008). Exposed to less challenging courses in STEM at the pre-collegiate level often taught in ways that are assessed as male biased (Boaler, 1997), women enter higher education less well prepared and less inclined to major in STEM fields. One could further argue that there may be a gap between enrollment and graduation rates. More directly studying cross-national variation in the gap will shed light on whether some higher education systems are more open with respect to entry but nevertheless obstruct degree completion.

Fourth, higher education students do not merely face curriculum. They also face professors. Cross-national research on women in tenured faculty positions shows fewer tenured women in the natural sciences and engineering (Nakagawa, Wotipka, \& Buckner, 2020). Tracing the relationship between women in positions of authority in STEM (professors, deans, presidents) and women STEM degree holders is a much-needed endeavor.

Lastly, we need more cross-national, qualitative case studies to better understand what likely facilitates and hinders entry into and completion of STEM degrees. These studies should compare women and men over extended periods of time, ideally from secondary schools to higher education and beyond. 


\section{Note}

1 Our data come from the UNESCO Institute for Statistics, which uses the International Classification of Education (ISCED) system to categorize higher education institutions by levels. ISCED levels $5-8$ are included under UNESCO's tertiary education category, which includes short-cycle tertiary education, bachelor's, master's, and doctoral degrees (UNESCO, 2012).

\section{References}

African Union. (2020). Goals \& priority areas of Agenda 2063. https://au.int/agenda 2063/goals

Aycan, Z., \& Fikret-Pasa, S. (2003). Career choices, job selection criteria, and leadership preferences in a transitional nation: The case of Turkey. Fournal of Career Development, 30(2), 129-144.

Baker, D. P., \& Jones, D. P. (1993). Creating gender equality: Cross-national gender stratification and mathematical performance. Sociology of Education, 66(2), 91-103.

Berkovitch, N. (1999). From motherhood to citizenship: Women's rights and international organizations. Johns Hopkins University Press.

Blickenstaff, J. C. (2005). Women and science careers: Leaky pipeline or gender filter? Gender and education, 17(4), 369-386.

Boaler, J. (1997). Reclaiming school mathematics: The girls fight back. Gender and Education, 9(3), 285-305.

Boserup, E. (1981). Population and technological change: A study of long-term trends. Chicago University Press.

Bradley, K. (2000). The incorporation of women into higher education: Paradoxical outcomes. Sociology of Education, 73(1), 1-18.

Bradley, K., \& Ramirez, F. O. (1996). World polity and gender parity: Women's share of higher education, 1965-1985. Research in Sociology of Education and Socialization, 11(1), 63-91.

Charles, M. (2011). What gender is science? Contexts, 10(2), 22-28.

Charles, M., \& Bradley, K. (2009). Indulging our gendered selves? Sex segregation by field of study in 44 countries. American Fournal of Sociology, 114(4), 924-976.

Charles, M., Harr, B., Gech, E., \& Hendley, A. (2014). Who likes math where? Gender differences in eighth-graders' attitudes around the world. International Studies in Sociology of Education, 24(1), 85-112.

Chow, T., \& Charles, M. (2019). An inegalitarian paradox: On the uneven gendering of computing work around the world. In C. Frieze \& J. L. Quesenberry (Eds.), Cracking the digital ceiling: Women in computing around the world (pp. 25-45). Cambridge University Press.

Committee on Prospering in the Global Economy of the 21st Century. (2007). Rising above the gathering storm: Energizing and employing America for a brighter economic future. National Academies Press.

Dorius, S. F., \& Firebaugh, G. (2010). Trends in global gender inequality. Social Forces, 88(5), 1941-1968.

Drori, G. S. (2000). Science education and economic development: Trends, relationships, and research agenda. Studies in Science Education, 35(1), 27-57.

Ellis, J., Fosdick, B. K., \& Rasmusen, C. (2016). Women 1.5 times more likely to leave STEM pipeline after calculus compared to men: Lack of mathematical confidence a potential culprit. PLOS ONE, 11(7), 1-14. 
European Technology Assessment Network. (2000). Science Policies in the European Union: Promoting excellence through mainstreaming gender equality. European Union Publications Office.

Frank, D. J., \& Gabler, J. (2006). Reconstructing the university: Worldwide shifts in academia in the 20th century. Stanford University Press.

Gupta, N. (2012). Women undergraduates in engineering education in India: A study of growing participation. Gender, Technology and Development, 16(2), 153-176.

Gupta, N. (2015). Rethinking the relationship between gender and technology: A study of the Indian example. Work, Employment and Society, 29(4), 661-672.

Hanushek, E. A., \& Kimko, D. D. (2000). Schooling, labor-force quality, and the growth of nations. American Economic Review, 90(5), 1184-1208.

Huyer, S. (2015). Is the gender gap narrowing in science and engineering? (UNESCO Science Report Series 6, Chapter 3). UNESCO. https://en.unesco.org/sites/default/files/ usr15_is_the_gender_gap_narrowing_in_science_and_engineering.pdf

Jacobs, J. A. (1996). Gender inequality and higher education. Annual Review of Sociology, 22, 153-185.

Kelly, G. P. (1989). Achieving equality in education-prospects and realities. In G. P. Kelly (Ed.), International handbook of women's education (pp. 547-569). Greenwood Press.

Kugler, A. D., Tinsley, C. H., \& Ukhaneva, O. (2017). Choice of majors: Are women really different from men? NBER Working Paper No. 23735. National Bureau of Economic Research. https://econpapers.repec.org/paper/nbrnberwo/23735.htm

Kwak, N., \& Ramirez, F. O. (2019). Is engineering harder to crack than science? A cross-national Analysis of women's participation in male-dominated fields of study in higher education. In A. W. Wiseman (Ed.), Annual review of comparative and international education 2018 (pp. 159-183). Emerald Publishing.

Mellström, U. (2009). The intersection of gender, race and cultural boundaries, or why is computer science in Malaysia dominated by women?. Social Studies of Science, 39(6), 885-907.

Nakagawa, M., Wotipka, C. M., \& Buckner, E. (2020). Faculty in globally-ranked universities in comparative perspective: Differences by gender, fields, and tenure status. [Unpublished manuscript]. Stanford University.

National Commission on Excellence in Education. (1983). A nation at risk: The imperative for educational reform. The Elementary School fournal, 84(2), 113-130.

Perez-Felkner, L., Felkner, J. S., Nix, S., \& Magalhães, M. (2020). The puzzling relationship between international development and gender equity: The case of STEM postsecondary education in Cambodia. International Fournal of Educational Development, 72, pp. 1-11.

Ramirez, F. O., \& Kwak, N. (2015). Women's enrollments in STEM in higher education: Cross-national trends, 1970-2010. In W. Pearson, L. Frehill, \& C. McNeely (Eds.), Advancing women in science (pp. 9-49). Springer.

Ramirez, F. O., \& Lee, M. (1995). Education, science, and economic development. In G. A. Postiliogne \& W. O. Lee (Eds.), Social change and educational development in Mainland China, Taiwan, and Hong Kong (pp. 15-39). University of Hong Kong, Center for Asian Studies.

Ramirez, F. O., \& Wotipka, C. M. (2001). Slowly but surely? The global expansion of women's participation in science and engineering fields of study, 1972-92. Sociology of Education, 74(3), 231-251.

Ramirez, F. O., Luo, X., Schofer, E., \& Meyer, J. W. (2006). Student achievement and national economic growth. American Fournal of Education, 113(1), 1-29.

Ramirez, F. O., Soysal, Y., \& Shanahan, S. (1997). The changing logic of political citizenship: Cross-national acquisition of women's suffrage rights, 1890 to 1990. American Sociological Review, 62(5), 735-745. 


\section{Seungah S. Lee et al.}

Ritz, J. M., \& Fan, S. (2015). STEM and technology education: International state-ofthe-art. International Fournal of Technology and Design Education, 25(4), 429-451.

Schofer, E., \& Meyer, J. W. (2005). The worldwide expansion of higher education in the twentieth century. American Sociological Review, 70(6), 898-920.

Schofer, E., Ramirez, F. O., \& Meyer, J. W. (2000). The effects of science on national economic development, 1970 to 1990. American Sociological Review, 65(6), 866-887.

Shapiro, C. A., \& Sax, L. J. (2011). Major selection and persistence for women in STEM. New Directions for Institutional Research, 2011(152), 5-18.

UNESCO. (2012). International standard classification of education ISCED 2011. United Nations International Family of Economic and Social Classifications, UNESCO Institute for Statistics.

Vest, G. M. (2010). Rising above the gathering storm revisited: Rapidly approaching category 5. National Academy of Sciences.

Wiseman, A. W. (2008). A culture of (in)equality?: A cross-national study of gender parity and gender segregation in national school systems. Research in Comparative and International Education, 3, 179-201.

World Bank. (2019). Historic classification by income [Data file]. https://datahelpdesk. worldbank.org/knowledgebase/articles/906519-world-bank-country-and-lending-groups

Wotipka, C. M., \& Ramirez, F. O. (2003). Women in science: For development, for human rights, for themselves. In G. S. Drori, J. W. Meyer, F. O. Ramirez, \& E. Schofer (Eds.), Science in the modern world polity: Institutionalization and globalization (pp. 174-195). Stanford University Press.

Zou'bi, M. R., Mohamed-Nour, S., El-Kharraz, J., \& Hassan, N. (2015). The Arab States. (UNESCO Science Report Series 6, Chapter 17). UNESCO. https://en. unesco.org/sites/default/files/usr15_the_arab_states.pdf 


\title{
3 The Rise of Women in STEM Higher Education in Ghina

\author{
Achievements and Challenges
}

\author{
Liu Lingyu, Shen Wenqin and Li Chao
}

The rise of women in the higher education system is a worldwide achievement. In the United States, women's college completion rates are already higher than men's (Buchmann \& DiPrete, 2006). Some comparative studies have also shown that women's rate of return to higher education is higher than that of men (Dougherty, 2005; Montenegro \& Patrinos, 2014). These facts all point to the rise of women in the higher education system. By contrast, research has pointed out that this rise is mainly in non-science, technology, engineering, and mathematics (STEM) fields, and progress in STEM fields remains limited. The proportion of women in STEM fields, especially in computer and engineering, remains low (Sax et al., 2017; Shi, 2018). The degree of gender imbalance varies substantially within scientific fields; in medicine and biology, the gender distribution is relatively balanced, whereas in the fields of computer and engineering, men dominate (Varma, 2010; Sax et al., 2016; Sax et al., 2017). This finding shows that the gender issue in STEM fields needs in-depth and detailed analysis.

China has developed into the world's largest higher education system, and the number of bachelor's and doctoral degrees awarded by China in science and engineering has surpassed that of the United States. Correspondingly, China's publication in STEM has also rapidly progressed, and China is now the world's second-largest producer of STEM publications (Zhong et al., 2019). However, owing to the traditional concept of gendered division of labor and gender-based socialization, Chinese women's participation in STEM education has considerable room for growth. Women scientists in China are underrepresented, and the number of high-level experts and scholars in the female scientific and technological group is relatively small. Science and technology, as the frontier of China's development strategy, play an important role in economic production and social development, and in the long run, women's participation in STEM education affects the development of women in the scientific community.

The full development of women in the scientific community not only promotes the development of national production but also contributes to the improvement of women's social status and gender segregation in the social division of labor. To solve this problem, we must reform the training system of scientists. At the same time, women's participation in STEM education is a

DOI: $10.4324 / 9781003053217-8$ 
challenge to the traditional power structure where men control core resources; women also need to continuously deepen their participation and development in the public sphere and strive for their own power. Thus, what role do women play in China's emergence as a global leader in STEM? What are their representativeness, learning experience, and labor market results in this system? What type of policy and institutional background has promoted the development of Chinese women in STEM higher education? These questions motivate this chapter.

The chapter is structured as follows. First, we discuss a brief historical review of the development of Chinese women's higher education. Then, we review China's policy efforts to promote gender equality in education and their effects since national reform and opening up has occurred. After that, we focus on the performance of women students in STEM fields at the undergraduate level in terms of enrollment, learning experiences, and labor market outcomes. Finally, we offer discussion and concluding comments.

\section{Historical Context}

China's first public school for girls was established in 1898. Co-education at the primary school level was approved in 1912 after the founding of the Republic of China. Before 1919, several higher education institutions were open to women that were run by Western missionaries. These institutions included Yanjing Women's University in Beijing (1908), Huanan Women's University in Fuzhou (1914), and Jinling Women's University in Nanjing (1915). In 1919, Beijing Higher Women's Normal School was established as the first official higher education institution for Chinese women (Bailey, 2007:108).

In 1919, the Ministry of Education of the Provisional Government of the Republic of China promulgated the "Regulations for Women's Higher Normal Education," which established a system for women to receive higher education. In the spring of 1920, Peking University began to enroll women students, prompting other universities to follow suit. In 1947, the number of college students in China was 155,036, of which 27,604 were women, accounting for $17.8 \%$ (Education Yearbook Compilation Committee of the Ministry of Education, 1948). Owing to the lack of economic resources to develop STEM, the disciplinary structure of higher education during the Republic of China was dominated by humanities and social sciences. In 1947-1948, the total proportion of Chinese college students in engineering, science, agriculture, forestry, and medicine was 38.46\% (Ministry of Higher Education, PRC, 1956, p. 7).

Since the founding of the People's Republic of China (PRC), major changes have taken place in the circumstances of women receiving higher education degrees in STEM. On the one hand, the Constitution of the Central Government in 1954 clearly stipulated equal right of men and women to receive education, laying a legal foundation for the rapid development of women's participation in higher education. At the same time, the central government 
adjusted the existing institutions of higher learning, incorporating women's colleges into ordinary institutions of higher learning and implementing the universal coeducational class system. The implementation of the national college entrance examination system and the people's financial aid system has removed institutional and economic barriers for women to participate in higher education. Women can enter universities through objectified examinations, avoiding sexism in interviews. For women with poor economic conditions, the people's financial aid also effectively ensures that they will not drop out of school for financial reasons. In addition, in terms of ideology, the government has vigorously promoted women's liberation slogans such as "men and women in revolution side by side" and "women hold half of the sky," contributing to the consciousness of equality between men and women as the mainstream cultural thought of the new society. In a good social environment, women's higher education has developed rapidly in terms of quantity and proportion. Affected by national policies at the time, the number of women students in higher education system reached a peak in 1954 and 1974 (Figure 3.1). In 1954, the proportion of women students among college students increased to $26.27 \%$ (Ministry of Higher Education, 1956, p. 19). Owing to this special political and historical background, the development of women's higher education in this stage is circuitous but generally shows an upward trend.

Different from the period of the Republic of China, the PRC was eager to promote industrial modernization, so it attached great importance to STEM. The proportion of college students in science, engineering, agriculture, and medicine increased rapidly to $58.46 \%$ in $1951-1952$, among which engineering received special attention, and its proportion reached $38.1 \%$ in 1955

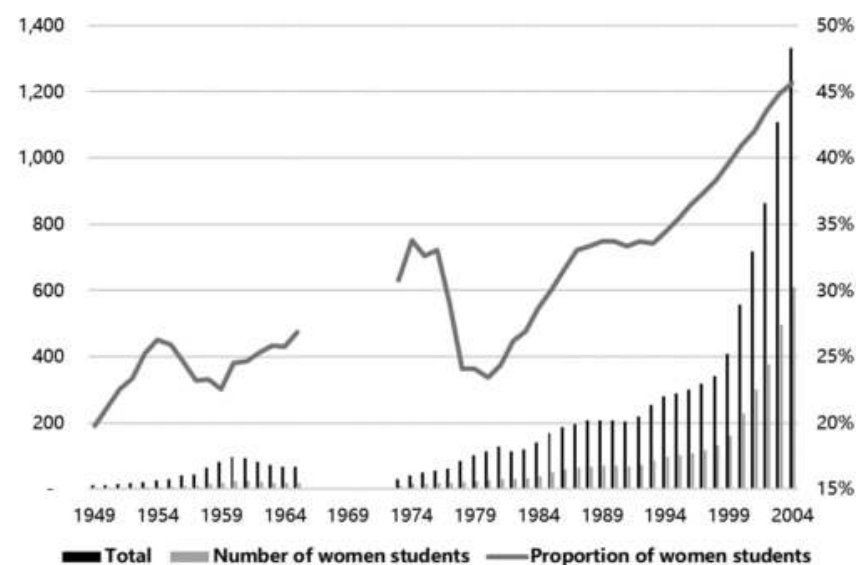

Figure 3.1 Number of students (in 10,000; Histogram) and the proportion of women students (line chart) in ordinary institutions of higher learning in China from 1949 to 2004.

Notes: Data sources: China Education Achievement (statistics), Chinese Educational Affairs Book (higher education volume), China Education Yearbook (1949-1981), Chinese Gender Statistics (1990-1995), and yearly China Education Statistics Yearbook or Education Statistics Yearbook. 
(Ministry of Higher Education, PRC, 1956, p. 7). These "red engineers" later became an important source of Chinese political elites (Andreas, 2009). The idea of prioritizing the development of STEM to serve the national strategy laid the foundation during this period that continues to the present. Priority in STEM remains a tenet of China's higher education policy.

Since the reform and opening up, the focus of China's national work has shifted from class struggle to economic construction. In 1985, the central government promulgated the "Decision on Reforming the Education System," initiating an all-around reform of China's higher education. The realization of four modernizations was the preeminent goal of China at that time, and the prioritization of science and engineering became the policy means to achieve this goal. A popular saying at the time was "learn mathematics, physics and chemistry well, and you can go all over the world," which reflected the preferences of parents and students. After the expansion of college enrollment in 1999, the scale of higher education grew rapidly. By 2003, the gross enrollment rate of higher education had reached $17 \%$, entering the stage of massification of higher education. As a result, women had more access to higher education. By 2004, the proportion of female students among undergraduate and junior college students in China had reached 45\% (see Figure 3.1). At this stage, the level of Chinese women's participation in higher education has also been continuously improved, and the distribution of majors has become increasingly extensive. An increasing number of women are entering traditionally "male-dominated fields" such as politics, science and engineering, agriculture and forestry, but the pattern of traditionally "female-dominated fields" such as language, medical care, and humanities remains unchanged.

The development of higher education from elitism to massification is an important reason for the continuous increase in the number and proportion of Chinese women receiving higher education since the reform and opening up. In addition, after the reform and opening up, the number of institutions of higher learning in China has increased rapidly, and the scope of education has extended from ordinary higher education to adult higher education and vocational and technical higher education. At the same time, private colleges and universities have emerged, as have those funded by overseas institutions or individuals. This type of higher education requires a short time and low cost to develop, and with wide distribution and diversified forms, most people can go to school immediately. The cost of admission is reduced, especially for women. The diversified development of the higher education system has greatly increased the participation of women in higher education.

\section{Policy Considerations}

Since the reform and opening up, the Chinese government has made consistent effort in relevant policies and organizations to improve women's access to education, and various national mechanisms to guarantee women's right to education have been constantly improved. At the institutional level, China has 
gradually established such national institutions as the Working Committee on Women and Children under the State Council and the All-China Women's Federation to improve the status of women and promote gender equality. Furthermore, Chinese governments at all levels hold regular meetings on women and children to establish and improve gender equality assessment mechanisms for laws and policies. In addition, state funds and resources for women's education have been increasing, and therefore so have the statistics and monitoring assessments of women's education.

Universal gender equality in compulsory education has been promoted to the upper level of the education system step by step. The one-child policy introduced at the end of the 20th century also indirectly promoted women's participation in higher education. Since the 1980s, China has resumed setting up separate women's colleges and universities, which has become an important way for women to achieve higher education.

\section{Relevant Laws and Regulations}

Education legislation such as the 1986 "Compulsory Education Law" and the 1995 "Education Law" stipulates that men and women have equal rights to education. In 1992, the state enacted and implemented the Law on the Protection of The Rights and Interests of Women, establishing a special chapter to clarify women's rights to culture and education. In 1995, the United Nations Fourth World Conference on Women was held in Beijing. The Chinese government has clearly stated that gender equality is a basic national policy of China and education is one of the important breakthrough areas in promoting women's development. Since 1995, the three issues of the "Program for the Development of Chinese Women" promulgated and implemented by the State Council have all put education as one of the priority areas for advancing gender equality. Specific goals, strategies, and measures on how to thoroughly implement the basic national policy of gender equality in the education field were put forward. The "Thirteenth Five-Year Plan" for the Development of National Education, promulgated in 2017, proposes to further protect the equal rights of women and children to education. Since the 1980s, in response to the fact that the proportion of girls who are out of school in primary and secondary schools is high, the China Children and Teenagers' Fund, under the guidance of the All-China Women's Federation, has sponsored millions of poor rural girls to return to school through the "Spring Bud Program." Many funded girls have access to higher education (Ma, 2019).

\section{One-Child Policy}

In the early 1970s, China began to control its excessively rapid population growth by gradually implementing a family planning policy. China's family planning policy is not a single one-child policy. Since 1984, policies have included at least one child (the one-child policy); one and a half children (if 
the first child is a boy, childbirth stopped; if the first child is a daughter, the second child is allowed at intervals); the two-child policy; and unrestricted childbearing. The one-child policy is only implemented in urban areas and a few rural areas. Only rural areas in six provinces and cities, including Beijing, Tianjin, Shanghai, Chongqing, Jiangsu, and Sichuan, implement the onechild policy. The implementation of this policy has lasted for more than 30 years, leading to the continuous expansion of the size of China's only children and the continuous growth of the proportion of the population of the same age. At the turn of the century, this proportion has exceeded $50 \%$, marking the advent of the only child era. The educational process of the only child in China is deeply influenced by national policy and overlaps with the reform and massification of higher education, playing an important role in promoting the improvement of gender equality in higher education.

Owing to differences in family economic conditions and cultural concepts, the gap in opportunities for women from different social backgrounds to participate in higher education has widened. In general, girls in families with abundant cultural capital and better financial conditions have significantly higher chances of enrollment than do girls in families from poorer conditions. As universities shift from free admission to charging tuition, this difference has gradually expanded. The one-child policy has made urban women beneficiaries and has improved gender equality in higher education to a considerable extent. On the one hand, the one-child policy has reduced the number of children born to the family, even if the family's economic conditions remain unchanged, thus the child's educational resources increases. On the other hand, the reduction of the number of children changes the focus of the parent-child relationship, strengthens the family centrality of children, raises parents' expectations of children, and increases the possibility of strengthening the educational investment. The "Research on Chinese Women's Higher Education Facing the 21 st Century" conducted a questionnaire survey of universities in Beijing, Shanghai, Shandong, Heilongjiang, Guangdong, and Gansu and five women's universities. The results showed that the proportion of only children in the sample was $34.3 \%$. Among them, girls accounted for $71 \%$. The prevalence of only children in the sample was significantly correlated with the regional characteristics of urban and rural areas (An, 2002).

\section{Universal Nine-Year Compulsory Education}

Higher education is based on compulsory education in China. The enrollment rate of girls in K-12 has a direct effect on the proportion of women who receive higher education. After the reform and opening up, universal primary education was put on the national agenda. In 1986, the state promulgated the "Law of the People's Republic of China on Compulsory Education," which explicitly required the implementation of nine-year compulsory education and provided legal protection for girls to receive compulsory education. At the same time, the state has continued to increase its investment in compulsory education in rural 
areas. Through the establishment of bursaries for primary and secondary schools and special support policies for girls such as the "Spring Bud Program" and "Project Hope," the educational opportunities of rural girls have been greatly increased. In the 21 st century, with the advancement of the integrated development of urban and rural compulsory education and the complementation of the shortcomings of rural compulsory education, rural girls have more opportunities to receive education and the gender gap in the primary education stage has been eliminated. In 2017, the retention rate of China's nine-year compulsory education reached $93.8 \%$, and the net enrollment rate of girls in primary schools reached $99.9 \%$, the same as that of boys.

\section{Supporting Women's Colleges}

Since the 1980s, under the influence of the Western feminist movement, the women's movement in China has been on the rise. Due to the effect of the market economy, the voice of "women returning home" appeared in society, directly conflicting with the principles of gender equality and rights protection, triggering the awareness of gender issues in the whole of society. During this period, many female activists, scholars, and officials conducted considerable research, discussion, and formation of various parties, creating an atmosphere that values women's issues in society. The formulation and implementation of women-related policies were thus included as independent issues on the government's agenda.

In this context, starting in 1984, China resumed setting up separate women's colleges and universities, and quickly established or restored more than ten women's colleges. Most of them are for practical and applied higher vocational and technical education. Women's colleges have also played an important role in narrowing the urban-rural gap in access opportunities. According to the survey of women's colleges and universities conducted by the group of "Research on Chinese Women's Higher Education Facing the 21st Century" of China Women's University, $46.7 \%$ of the students in the sample of women's universities come from rural areas, while $22.1 \%$ of the students in other universities come from rural areas (An, 2002). The proportion of rural students in women's colleges is higher than that of ordinary colleges and universities, indicating that women's colleges and universities play an important role in providing opportunities for women to achieve higher education.

\section{Rise of Women Students in STEM Fields}

After the restoration of the college entrance examination system in 1978, China's higher education system made considerable progress. In 2009, for the first time, the number of women students in higher education institutions exceeded that of men. The advantage of women in higher education is not only reflected in the distribution of educational opportunities but also in their academic performance. However, from the perspective of educational outcomes, women continue to face many challenges in the labor market and in graduate education. 


\section{Gender Differences in Higher Education Enrollment}

From 2002 to 2019, the gross enrollment rate of China's higher education has increased from $15 \%$ to $51.6 \%$, realizing a huge structural change from massification to universalization of higher education. During this period, not only the scale of higher education but also the distribution of educational opportunities for different genders became more equal.

Overall, women's enrollment in higher education gradually exceeded that of men. In 1980, Ghina had 268,000 women students and 876,000 men students participating in higher education. In 2009, China had 10.82 million women students and 10.62 million men students (the number of women students in higher education institutions exceeded that of men for the first time). In 2019, the number of women enrolled in colleges and universities was 14.87 million, and the number of men was only 13.43 million (Ministry of Education, PRC, 1980, 2010, 2019). The proportion of women students in higher education has steadily increased. Especially after the expansion of higher education enrollment in 1999, the proportion of women students in college has increased rapidly and exceeded $50 \%$ in 2009. The gap in higher education entrance opportunities between different genders has been narrowed or is even disappearing.

From the perspective of the vertical level of higher education enrollment opportunities, national survey data from 2011 to 2012 found that the difference in entrance opportunities between men and women in key universities (referring to universities funded by the government's Project 211), ${ }^{1}$ non-key universities, and junior colleges is shrinking. The increase in women enrollment opportunities in top universities is mainly due to the substantial increase of women students from urban China, whereas women college students in non-key universities are mainly from rural areas. Urban women are the main beneficiaries of high-quality higher education resources (Wang \& Li, 2015).

This trend of gender equality in the distribution of higher education opportunities has been proven to be related to the expansion of higher education in China. An analysis based on the 2008 National Comprehensive Social Survey data shows that the expansion of higher education enrollment has reduced the gender gap of higher education opportunities in poor families and well-off families. After the expansion of higher education, the disadvantaged position of rural women has been significantly improved, and the opportunity gap with men has been narrowed (Zhang \& Chen, 2013).

\section{Gender Differences in Academic Majors}

Similar to the current situation in Western countries, China's higher education remains highly gender-segregated by disciplines. China's official statistics do not include the gender distribution of undergraduate students by different disciplines at the national level. Therefore, this chapter can only speculate based on the nationwide data of master's degrees and the data of undergraduates of some universities across disciplines. 
According to statistics from the Ministry of Education of China, as of 2017, the proportion of women with master's degrees in STEM fields in China has reached $54.2 \%$, surpassing that of men. In 2017, the proportion of women postgraduates in mathematics reached $64.8 \%$, and that in physics reached $43.4 \%$. Presumably, at the undergraduate level, the proportion of women students in mathematics has exceeded the proportion of men students. The ratio of men to women in physics is also balanced. However, in the computer field, only $33.5 \%$ of women obtained master's degrees, and only $24.4 \%$ of women received master's degrees in civil engineering (Yang \& Shen, 2020).

In the distribution of majors at the B.A. level in Harbin Institute of Technology in 1998 (Table 3.1), the percentage of women students majoring in foreign languages reached $66 \%$, and the percentage of women students in the Department of Social Sciences was $48.3 \%$, but the percentage of women students in the Department of Computer and Information Engineering was only $22.8 \%$. The proportion of women students was $11.4 \%$ in the Department of Dynamic Engineering and $8.1 \%$ in the Department of Mathematical Mechanics (Ma, 2002).

Among the first-year students enrolled at Peking University in 2000, the proportion of women students in language and literature, history, law, foreign languages, and economics was much higher than that of men students (the percentages of female students were $72 \%, 61 \%, 61 \%, 60 \%, 60 \%$, and $57 \%$ ). In physics, mechanics and engineering, mathematics, computer technology, chemistry, and chemical molecular engineering, the proportion of men is much higher than that of women $(85.6 \%, 85.5 \%, 78.3 \%, 73.1 \%, 65.4 \%$, and $65.3 \%$, respectively) (Ma, 2005). According to the "Report on Growth of Chinese

Table 3.1 Ratio of Women Students in Different Departments of Harbin Institute of Technology in 1998

\begin{tabular}{|c|c|c|c|}
\hline Majors & $\begin{array}{l}\text { Proportion of } \\
\text { Women }\end{array}$ & Majors & $\begin{array}{l}\text { Proportion } \\
\text { of Women }\end{array}$ \\
\hline $\begin{array}{l}\text { Department of Foreign } \\
\text { Languages }\end{array}$ & $66.0 \%$ & Physics Department & $17.4 \%$ \\
\hline $\begin{array}{l}\text { School of Economics and } \\
\text { Management }\end{array}$ & $51.5 \%$ & $\begin{array}{l}\text { Department of Ship and } \\
\text { Ocean Engineering }\end{array}$ & $16.9 \%$ \\
\hline Department of Sociology & $48.3 \%$ & $\begin{array}{l}\text { School of Mechanical and } \\
\text { Electrical Engineering }\end{array}$ & $16.6 \%$ \\
\hline $\begin{array}{l}\text { Department of Chemical } \\
\text { Engineering }\end{array}$ & $30.7 \%$ & $\begin{array}{l}\text { Department of Power } \\
\text { Engineering }\end{array}$ & $11.4 \%$ \\
\hline $\begin{array}{l}\text { Department of Computer } \\
\text { and Information } \\
\text { Engineering }\end{array}$ & $22.8 \%$ & $\begin{array}{l}\text { Department of Mathema- } \\
\text { tical Mechanics }\end{array}$ & $8.1 \%$ \\
\hline $\begin{array}{l}\text { Department of Architecture } \\
\text { and Civil Engineering }\end{array}$ & $17.6 \%$ & & \\
\hline
\end{tabular}

Source: An (2000). 
Universities 2015," among the college students in Beijing, the proportion of women students majoring in humanities, history, and art is more than $65 \%$, whereas the percentages of majors in engineering and science are only $37.2 \%$ and 28.8\%. Among China's top elite universities (Peking University, Tsinghua University, and Beijing Normal University), gender segregation in academic fields is serious (Li, 2015).

\section{Gender Differences in Academic Performance}

Women's increasing opportunities to enter the higher education system in China are largely due to their academic achievements in primary and secondary schools and their outstanding performance in college entrance examinations. As early as the 1980s, women's performance in elementary school had surpassed that of men. In the 1990s, women's performance advantage has been maintained at the junior high school stage. Entering the 21st century, women's college entrance examination scores also surpassed that of men. A survey of rural primary school students in the three provinces of Guizhou, Shaanxi, and Jiangxi showed that girls' reading performance was better than that of boys (Gao et al., 2019). The 1999-2008 national college entrance examination champions (those whose college entrance examination score ranked first in the province) data also indirectly reflects the fact that boys lag behind girls in academic studies. The proportion of men among the college entrance examination champions dropped from $66.59 \%$ in 1999 to $38.93 \%$, and the percentage of females rose from $33.42 \%$ to $61.07 \%$ (Sun et al., 2010).

In the university stage, the gender gap in academic performance continues, and women's academic performance remains better than that of men. Wen (2005) analyzed data from the national graduate survey in 1998 and 2003 and pointed out that women are better than men in academic performance and scholarships. Yue (2010) used the 2009 national graduate survey data to come to a similar conclusion. Women score significantly better than men in indicators such as "top 25\% GPA" and "passing CET-4 (6)". ${ }^{2}$ Superior GPA scores often mean women receive more awards and honors. A survey covering 18 universities in China, including Wuhan University and China University of Science and Technology, showed that boys are significantly behind girls in the proportion of scholarships received (Li \& Sun, 2012).

An analysis of the data from a sample survey of whole undergraduates at Peking University in 2018 found that GPAs of women were significantly higher than that of men. Even in the most elite Chinese universities, women students of science and engineering are not at a disadvantage compared with men in academic performance, and they also have advantages in certain disciplines. No significant difference in academic achievement was observed between men and women in traditional science and engineering fields, such as physics, technology, mathematics, chemistry and molecular engineering, information science and technology, and environmental science. In the College of Life Sciences, the GPAs of women students were significantly higher than that of men students (Xie, 2019). 


\section{Gender Differences in Learning Experiences}

According to a survey of Peking University graduates in 2018, women have significantly higher GPAs than do men, and more women students choose double degrees or minors in other courses and earn the opportunity to study abroad. Women pay more attention to extracurricular practice and community activities than do men. Women with more than 10 hours of extracurricular practice activities per week account for $31 \%$ of all women. However, men are more involved in extracurricular scientific research activities $(40 \%$ of men spend more than 10 hours a week engaged in extracurricular scientific research activities).

Owing to the differences in learning experiences between men and women, gains and ability development in the process of education have also shown differentiation. According to the self-report of Peking University graduates, women's social communication ability has significantly improved compared to men; this result may be related to women's large participation in extracurricular practical community activities and studying abroad (Table 3.2).

\section{Labor Market Outcome}

At present, a large number of studies on gender inequality in higher education in China mostly focus on the inequality of college entrance opportunities, especially the changes in gender enrollment opportunities under the expansion of university enrollment (Zhang \& Chen, 2013). Then, after undergraduate education, from the perspective of education results, what changes will occur for women students?

For the vast majority of college graduates, directly entering the labor market has become the first choice. With the adjustment of China's economic structure and the expansion of the scale of education, the employment situation for graduates has become increasingly severe in recent years, and the employment pressure on women graduates, in particular, has been increasing. Although women are similar to or even ahead of men in education and academic performance, gender inequality in the labor market remains. According to a survey conducted by the Chinese Academy of Social Sciences in 2013, the difficulty of women college students finding employment is mainly reflected in the quality of employment, not the employment rate. The employment rate of women graduates is only slightly lower than that of men, but women graduates' average monthly salary for the first job is much lower than that of men. The probability of women entering state-owned enterprises and government agencies is significantly lower than that of men. This finding shows that the "female advantage" is only reflected in the college entrance examination scores and academic performance during undergraduate studies, but no "female advantage" exists in employment (Cai, 2016).

Scholars believe that the reason for this phenomenon is not only the external environmental effect of the industry employment system but also that men 


\section{Liu Lingyu, Shen Wenqin, and Li Chao}

Table 3.2 Development of Self-Evaluation Ability of Science and Engineering Graduates by Gender at Peking University in 2018 (N=774)

\begin{tabular}{|c|c|c|c|c|c|c|}
\hline Ability & Gender & Mean & $S D$ & Min & Max & $T$-test \\
\hline \multirow[t]{2}{*}{ Professional knowledge and skills } & women & 3.47 & 0.61 & 1 & 4 & \multirow[t]{2}{*}{0.380} \\
\hline & men & 3.49 & 0.64 & 1 & 4 & \\
\hline \multirow{2}{*}{$\begin{array}{l}\text { Computer and information } \\
\text { literacy }\end{array}$} & women & 3.27 & 0.63 & 1 & 4 & \multirow[t]{2}{*}{1.783} \\
\hline & men & 3.37 & 0.67 & 1 & 4 & \\
\hline \multirow{2}{*}{$\begin{array}{l}\text { International vision and sense of } \\
\text { globalization }\end{array}$} & women & 3.25 & 0.68 & 1 & 4 & \multirow[t]{2}{*}{-0.306} \\
\hline & men & 3.23 & 0.69 & 1 & 4 & \\
\hline \multirow[t]{2}{*}{ Critical thinking } & women & 3.35 & 0.59 & 1 & 4 & \multirow[t]{2}{*}{-0.353} \\
\hline & men & 3.33 & 0.66 & 1 & 4 & \\
\hline \multirow{2}{*}{$\begin{array}{l}\text { Ability to identify, analyze, and } \\
\text { solve problems }\end{array}$} & women & 3.43 & 0.58 & 2 & 4 & \multirow[t]{2}{*}{-1.483} \\
\hline & men & 3.36 & 0.65 & 1 & 4 & \\
\hline \multirow[t]{2}{*}{ Verbal and writing skills } & women & 3.16 & 0.78 & 1 & 4 & \multirow[t]{2}{*}{-1.625} \\
\hline & men & 3.05 & 0.74 & 1 & 4 & \\
\hline \multirow[t]{2}{*}{ Autonomous learning ability } & women & 3.23 & 0.75 & 1 & 4 & \multirow[t]{2}{*}{-0.349} \\
\hline & men & 3.21 & 0.77 & 1 & 4 & \\
\hline \multirow[t]{2}{*}{ Innovation ability } & women & 2.99 & 0.70 & 1 & 4 & \multirow[t]{2}{*}{-1.092} \\
\hline & men & 2.93 & 0.68 & 1 & 4 & \\
\hline \multirow[t]{2}{*}{ Social skills } & women & 3.09 & 0.77 & 1 & 4 & \multirow[t]{2}{*}{$-2.381^{* *}$} \\
\hline & men & 2.92 & 0.82 & 1 & 4 & \\
\hline \multirow[t]{2}{*}{ Organizational leadership } & women & 2.91 & 0.75 & 1 & 4 & \multirow[t]{2}{*}{-1.461} \\
\hline & men & 2.82 & 0.74 & 1 & 4 & \\
\hline \multirow[t]{2}{*}{ Self-cognition ability } & women & 3.29 & 0.67 & 1 & 4 & \multirow[t]{2}{*}{-1.449} \\
\hline & men & 3.21 & 0.69 & 1 & 4 & \\
\hline
\end{tabular}

$* * * p<0.001 * * p<0.01 * p<0.05$.

and women are concentrated in different occupations or industries. This obvious isolation will lead to the wage gap between different genders after graduation. Women students' occupation choice and attainment are directly related to their academic fields. In other words, part of the income gap between men and women in the employment stage is directly derived from the gender difference in university majors (He, 2018).

The traditional concept of the gender division of labor and the different socialization of men and women have affected the professional structure of women's participation in higher education, and formed a path from major choice to employment, possibly leading to the difference in social status between men and women. Studies have confirmed that in China, the average income of graduates who graduated from majors such as literature, history, law, and economics 
with a large number of women is usually lower than that of graduates majoring in science and engineering (Wen, 2005). In some jobs with good social reputations and high incomes, the competitiveness of women college students is far lower than that of men students $(\mathrm{Li}, 2016)$. At the same time, most of the income gap between men and women graduates cannot be explained after stripping off the influence of occupational isolation, personal employability, internship experience, promotion, and fertility, providing strong evidence for gender discrimination in the labor market (Qing \& Zheng, 2013).

In addition to entering the labor market, studying for a postgraduate degree at home and abroad after graduation has become an important choice for college students. The number of postgraduate candidates in China has increased from 1.406 million in 2010 to 3.41 million in 2020, and graduate education has increasingly become an important factor affecting social status attainment. From the perspective of historical development, women's access to university education has been significantly improved, but in the process of receiving higher-level graduate education, women continue to face greater challenges (Berggren, 2006).

In 1997, women accounted for $33.82 \%$ of master's degree students in China, whereas women accounted for only $18.3 \%$ of doctoral students. In 2010, for the first time, Chinese women surpassed men in their master's degree programs. In 2018, the number of women with master's degrees exceeded 1.19 million, accounting for $51.18 \%$ of the total number. By contrast, $40.36 \%$ of women were studying for a doctoral degree in 2018, which is 75,100 fewer than the number of men. The relatively smaller portion of women's doctoral students compared with master's students is also one of the reasons for gender inequality in academic fields (Figure 3.2). Some studies have shown that whether women choose to pursue a doctoral degree is affected by age. The probability of women under 30 years old studying for a doctoral degree is 1.88 times higher than that of women over 30 years old (Shen \& Liu, 2018). Compared with men, the older women are the more likely they are to be disadvantaged in marriage and labor markets. At the same time, women also face greater pressure to start a family, causing their resistance to pursuing doctoral education after a certain age (Shen \& Liu, 2018).

\section{Discussion and Conclusion}

Since the 1970s, the number of women students in higher education has increased twice as fast as that of men. According to data from the UNESCO Institute for Statistics, from 1970 to 2018, the proportion of women in higher education globally increased from $41 \%$ to $51 \%$. Specifically, in the 1980 s, the number of women receiving higher education in North America, and Central, Eastern, and Western Europe has surpassed that of men. Then, in the 1990s, the proportion of women college students in Latin America and the Caribbean and Central Asia also exceeded 50\%. In the 21st century, women in East Asia and the Pacific and Arab states have gained advantages in the allocation of higher education opportunities. At present, the proportion of women in higher 

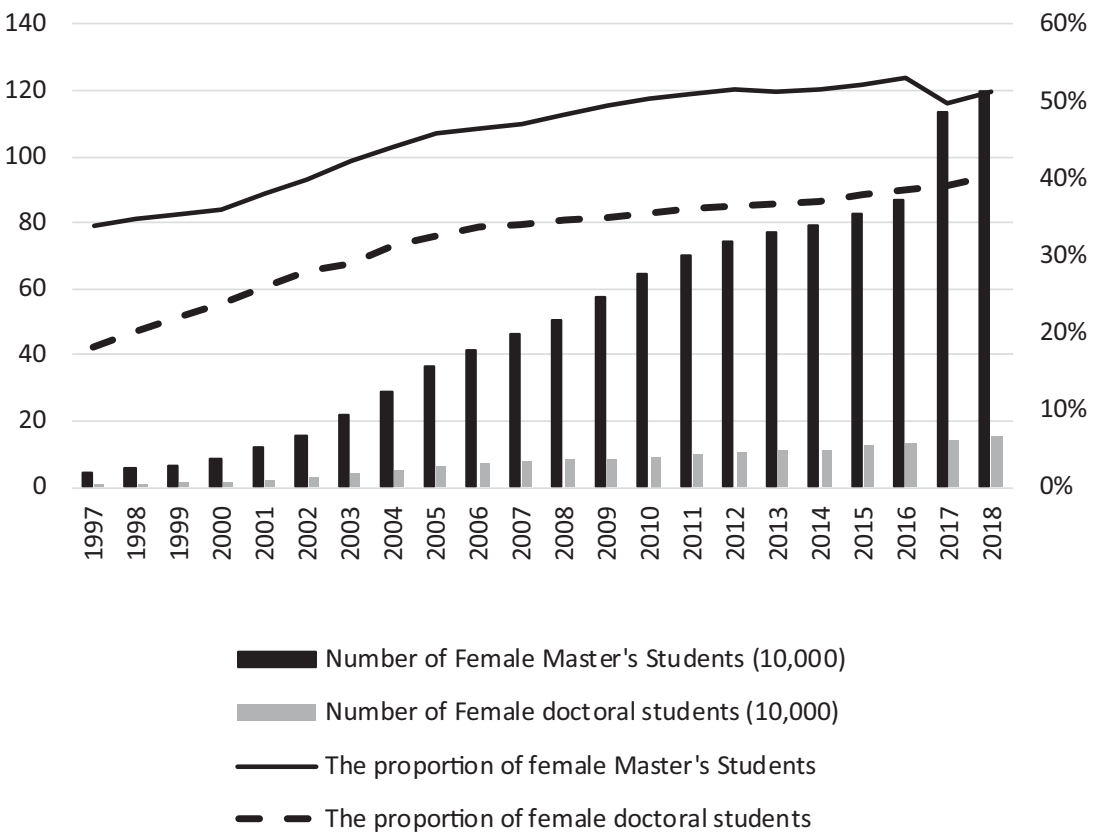

Figure 3.2 Number and proportion of female graduate students in China from 1997 to 2018. Note: The $\mathrm{X}$-axis is the year; The right $\mathrm{Y}$-axis is the proportion of female master's students; The left Y-axis is the number of female students.

Data Source: Yearly China Education Statistics Yearbook or Education Statistics Yearbook.

education in South and West Asia and sub-Saharan Africa remains lower than $50 \%(47 \%$ and $42 \%)$.

In the past decade, the rise of women's participation in education was one of the most important manifestations of gender equality in China. From 1980 to 2018, the proportion of women in higher education increased from $23 \%$ to $52 \%$. A gender reversal has occurred. And, while gender isolation remains, women are not at a disadvantage in all STEM fields. In mathematics, the proportion of women college students has exceeded that of men students, and the proportion of women students in physics is close to half. Women's advantages are not only reflected in access to higher education opportunities but also in aspects such as academic performance, participation in practical activities, and honor acquisition in the process of education. In the survey and analysis of the graduates of Peking University in 2017, the academic performance of women is significantly higher than that of men, and they are also significantly more likely than men to study abroad, obtain a double degree or a minor, and participate in community activities.

Under the leadership of the Chinese government, economic development, the adjustment of the population structure, and the promulgation of policies and laws to protect women's rights and interests have provided support and help in the development of women's education. For example, the one-child 
policy has led to continuous changes in fertility rates and the population structure and has greatly affected gender differences in family educational investment (Tsui \& Rich, 2002). At the same time, the discipline structure of China's higher education system is not entirely the result of market competition. A quota system exists for enrollment in different disciplines, and the number of students in different academic fields is completely determined by the central government and universities, reflecting the characteristics of a planned economy (Shen \& Ma, 2018). Since the 1950s, the Chinese government has been implementing the development strategy of prioritizing science and technology, putting most of the enrollment quota into science and technology, meaning that many women students who have access to higher education can only choose to study STEM fields. This, to a certain extent, explains why the proportion of Chinese women in STEM fields is higher than that of Western countries such as the United States and Britain.

\section{Limitations and Future Challenges}

The rise of women in higher education also faces many challenges. Although the proportion of women students in biology, physics, and mathematics in China is significantly higher than that of Western countries, gender segregation among different majors remains significant. Most women study humanities and social sciences but less frequently study engineering and science. The occupational segregation caused by disciplinary segregation has affected the quantity and quality of women's employment in terms of income and other social welfare.

Our data analysis of a top university in China shows no significant difference in academic performance between women and men undergraduate students in STEM fields, and women students' academic performance is even better than men students in life science. However, in terms of participation in undergraduate scientific research activities, women students seem to receive fewer opportunities than do men students.

As in Western countries, compared with men college graduates, Chinese women college graduates remain at a disadvantage in employment. Through the analysis of the college entrance examination scores, academic achievements, and employment of 6,782 undergraduate students enrolled in 2010 (from enrollment to graduation) in four years, the research found that women's college entrance examination scores are better than men's, and women's scores in a foreign language, physical education, public compulsory courses, public elective courses, and GPA are significantly higher than men's. However, when they are employed, the employment of men is significantly better than that of the women, and the probability of women entering state-owned enterprises and institutions is significantly lower than that of men. This finding shows that "female advantage" is only reflected in college entrance examinations and academic performance during the undergraduate period, while no "female advantage" exists in the labor market (Cai, 2016). Furthermore, some studies have found that gender discrimination is the reason for women's disadvantage in the labor market (Qing \& 
Zheng, 2013). Considering that many women need to take care of their families and children, it could be that employers restrict the recruitment of women. Women's promotion to leadership positions is also a barrier due to "the glass ceiling effect" in China (Wang \& Yu, 2013).

Many postgraduates may not choose to pursue further studies due to various factors such as economic pressure, family obligations, time pressure, personal ability, or career trajectory. Less than $20 \%$ of postgraduates continued to pursue doctoral degrees after graduation (Liu et al., 2019). Chinese women seem to choose master's degrees but not doctoral degrees for their advanced education. In 2018 , the number of women studying for a master's degree accounted for $51.18 \%$ of the total number of master's degree students, while the proportion of doctoral students in the same year was only $40.36 \%$. From master's education to doctoral education, the number of women students has been inverted. Women may face more pressure than men in the process of choosing to continue their studies because of age, family obligation, or pressure for marriage.

In the mid-1990s, women comprised 35\% of China's science and technology workers (excluding the health care industry), and $5.7 \%$ of them were national-level women experts. The proportion of women academicians in the academy of Sciences and the Academy of Engineering was 5.3\% and 6.2\% (An, 2002). In STEM, the proportion of women faculty members in universities remains very low, making it harder for female students to find role models in STEM. Previous studies have shown that the academic output and satisfaction of female science and engineering students supervised by female faculty members are significantly higher (Yang \& Shen, 2020), indicating the importance of women role models. Therefore, to further improve the performance of women students in STEM, additional attention should be paid to gender equality in the recruitment and promotion of university teachers.

\section{Notes}

1 "Project 211" is an important measure taken by the Chinese government in 1995 to promote the development of higher education by building 100 universities and a number of key disciplines in the 21 st century.

2 CET (College English TEST) is a national test of English proficiency of college students, divided into two levels: level 4 and level 6 .

\section{References}

An, S. F. (2002). 中国女性高等教育研究 [Research on women's higher education in China]. Higher Education Press.

Andreas, J. (2009). Rise of the red engineers: The Cultural Revolution and the origins of China's new class. Stanford University Press.

Bailey, P. J. (2007). Gender and education in China: Gender discourses and women's schooling in the early twentieth century. Routledge.

Berggren, C. (2006). Labour market influence on recruitment to higher educationgender and class perspectives. Higher Education, 52(1), 121-148. 
Buchmann, C., \& DiPrete, T. A. (2006). The growing female advantage in college completion: The role of family background and academic achievement. American Sociological Review, 71(4), 515-541.

Cai, W. P. (2016). 女性教育优势能否延续到劳动力市场一基于高考成绩、本科 学业表现和就业情况的分析 [Can the advantages of female education continue to the labor market? _ Analysis based on the college entrance examination scores, undergraduate academic performance and employment situation]. Contemporary Youth Research, 6, 52-58.

Dougherty, C. (2005). Why are the returns to schooling higher for women than for men? Fournal of Human Resources, 40(4), 969-988.

Education Yearbook Compilation Committee of the Ministry of Education. (1948). The second China education yearbook. The Commercial Press.

Gao, Q., Wang, H., Chang, F., Yi, H., \& Shi, Y. (2019). Reading achievement in China's rural primary schools: A study of three provinces. Educational Studies, 1-25.

He，G. Y. (2018). 专业选择与初职获得的性别差异:基于“首都大学生成长追踪调 查”的发现 [The gender difference between major selection and initial job acquisition: Based on the findings of the "Capital University Growth Tracking Survey]. Society, 38(2), 213-240.

Li, C. L. (2016). “男孩危机” “剩女现象”与“女大学生就业难”一教育领域性别比 例逆转带来的社会性挑战 [“Boys crisis", “leftover women” and "Difficult employment of female college students" - Social challenges brought by the reversal of the gender ratio in education]. Women's Studies, 2, 33-39.

Li, L. L. (2015). 中国大学生成长报告 [Report on the growth of Chinese college students]. Renmin University of China Press.

Li, W. D., \& Sun, Y. X. (2012). The status quo, causes and reflections of boys' "academic backwardness" in China. Educational Research, 9, 38-43.

Liu, L. Y., Shen, W. Q., \& Jiang, K. (2019). 谁接受了博士教育:家庭背景对博士教育 机会获得的影响 [Who received doctoral education: The influence of family background on the acquisition of doctoral education opportunities]. University Education Science, 6, 51-60+121.

Ma, W. H. (2005). 中国女性高等教育发展的历史、现状与问题 [The history, current situation and problems of Chinese women's higher education development]. Educational Development Research, 3, 1-5.

Ma, Y. H. (2019). 大众化再考察 高等教育女性化的起点与内在逻辑 [Re-examination of massif cation: The starting point and inner logic of feminization of higher education]. Journal of Nanjing Normal University, 6, 49-59.

Ma, X. L. (2002). 黑龙江省地域性研究报告 [A regional research report of Heilongjiang Province]. In A. Shufeng (Ed.), Chinese women's higher education research. Higher Education Press.

Ministry of Higher Education of the People's Republic of China. (1956). Compilation of national higher education statistics in 1955. Beijing, Internal material.

Ministry of Higher Education of the People's Republic of China. (1980). Compilation of national education statistics in 1980. Beijing: People's Education Press.

Ministry of Education of the People's Republic of China. (2010). China Education Statistics Yearbook 2009. People's Education Press.

Ministry of Education of the People's Republic of China. (2019). China Education Statistics 2019. http://www.moe.gov.cn/s78/A03/moe_560/jytjsj_2019/

Montenegro, C. E., \& Patrinos, H. A. (2014). Comparable estimates of returns to schooling around the world. The World Bank. 
Qing, S. S., \& Zheng, J. M. (2013). 专业选择还是性别歧视? 男女大学生起薪差 距成因解析 [Professional choice or gender discrimination? - An analysis of the causes of the starting salary gap between male and female college students]. Economics Quarterly, 3, 255-274.

Sax, L. J., Kanny, M. A., Jacobs, J. A., Whang, H., Weintraub, D. S., \& Hroch, A. (2016). Understanding the changing dynamics of the gender gap in undergraduate engineering majors: 1971-2011. Research in Higher Education, 57(5), 570-600.

Sax, L. J., Lehman, K. J., Jacobs, J. A., Kanny, M. A., Lim, G., Monje-Paulson, L., \& Zimmerman, H. B. (2017). Anatomy of an enduring gender gap: The evolution of women's participation in computer science. Fournal of Higher Education, 88(2), 258-293. https://doi.org/10.1080/00221546.2016.1257306

Shen, W., \& Ma, W. (2018). The neoliberalism reform under the legacy of planned economy: The Peking University Case. In J. S. Shin (Ed.), Higher education governance in East Asia: Transformations under neoliberalism (pp. 143-159). Springer.

Shen, W .Q., \& Liu, L. Y. (2018). 性别、院校类型与读博结果一基于2016年全国 硕士毕业生调查的分析 [Gender, type of institution and access to doctoral education: An analysis based on the 2016 National Survey of Master Graduates]. China Higher Education Research, 12, 65-72.

Shi, Y. (2018). The puzzle of missing female engineers: Academic preparation, ability beliefs, and preferences. Economics of Education Review, 64, 129-143. https://doi.org/ 10.1016/j.econedurev.2018.04.005

Sun, Y. X., Li, W. D., \& Zhao, X. (2010). 拯救男孩 [Save the Boys]. Writers Publishing House.

Tsui, M., \& Rich, L. (2002). The only child and educational opportunity for girls in urban China. Gender \& Society, 16(1), 74-92.

Varma, R. (2010). Why so few women enroll in computing? Gender and ethnic differences in students' perception. Computer Science Education, 20(4), 301-316.

Wang, G. T., \& Yu, J. (2013). “玻璃天花板”效应:职业晋升中的性别差异 [The "Glass Ceiling" Effect: An Empirical Analysis of Gender Differences in Career Advancement among Chinese Women]. Fournal of Chinese Women's Studies, 6, 21-27.

Wang, W. Y., \& Li, J. (2015). 高等教育入学机会性别差异的多维分析 [Multidimensional analysis of gender differences in higher education opportunities]. Educational Research, 8, 54-60.

Wen, D. M. (2005). 我国高等教育机会、学业及就业的性别比较 [A comparative study on the gender disparity in higher education opportunity, school work achievement and graduate employment in China]. Tsinghua Fournal of Education, 5, 16-21.

Xie, X. Y. (2019, December 1). Women's academic performance in elite universities [PowerPoint slides].

Yang, J., \& Shen, W. (2020). Master's Education in STEM Fields in China: Does Gender Matter? Higher Education Policy, 1-22.

Yue, C. J. (2010). 高等教育与就业的性别比较 [Gender comparison of higher education and employment]. Educational Research of Tsinghua University, 6, 74-81.

Zhang, Z. X., \& Chen, Q. (2013). 高校扩招与高等教育机会的性别平等化一基于 中国综合社会调查(CGSS2008)数据的实证分析 [College expansion and gender equalization in higher education: An empirical study based on 2008 Chinese general social survey]. Sociological Research, 2, 173-196.

Zhong, Z., Liu, L., Coates, H., \& Kuh, G. (2019). What the US (and rest of the world) should know about higher education in China. Change: The Magazine of Higher Learning, 51(3), 8-20. 


\title{
4 The Higher Education Trajectories of Taiwanese Women in STEM
}

\author{
A Longitudinal Analysis
}

\author{
Yuan Chih Fu, Amelio Salvador Quetzal and \\ Tuehluen $\mathrm{Hu}$
}

The participation and status of women, compared with men, in science, technology, engineering and mathematics (STEM) has been of utmost global concern (van Staden et al. 2019; Penner, 2015). This concern is derived from two sets of issues that countries deal with: the provision of human resources for the STEM workforce and social equity in access to and rewards for professional participation in these fields (Fox, 2010). Although women now surpass men in college participation (DiPrete \& Buchmann, 2013), there are still concerns about an undersupply of STEM graduates and a shortfall of women in the pursuit of STEM majors and careers (U.S. Department of Commerce and National Economic Council, 2012). Though the numbers may have improved over the decades, it might still be a long way to go before women are on a par with men in STEM fields (Blickenstaff, 2005).

The expansion of tertiary education has become a global norm of modernization over the past decades, particularly because there has been an increasing demand for it (Marginson, 2016). At the policy level, expanding tertiary education might translate into creating increased accessibility for all, especially for women. Notwithstanding that, it remains unclear whether creating access through expansion really translates into a more equal world (Marginson, 2016; Baker, 2011). While there are many facets to explore within the issue of expansion and accessibility of tertiary education, this study focuses on women in STEM and how they have been impacted by the expansion of tertiary education in Taiwan.

The capacity of Taiwan's tertiary education system has expanded rapidly since the 1990s. The number of four-year universities increased from 50 in 1992 to 140 in 2018. Similarly, the number of students attending universities increased from 0.27 million to 0.93 million (Ministry of Education, 2019a). At this stage, Taiwan now has what Trow (1973) calls a universal education system given that its gross enrollment ratio (GER) in Higher Education Institutions (HEIs) has exceeded 50\% of the tertiary education schooling age cohort. Taiwan has also grown as an important producer of STEM research in the region (Fu, 2017). However, what remains to be understood is whether

DOI: $10.4324 / 9781003053217-9$ 
the expansion of Taiwan's tertiary education provided more access and opportunities for women in STEM. Along those lines, further statistics show that the GER of the relevant age group was $14.50 \%$ among women in 1981, which increased to $89.53 \%$ in 2018 , much higher than the GER (80.24\%) among men in the same year (Ministry of Education, 2019b).

Despite the existence of several studies which have analyzed the importance of tertiary education expansion across countries (Breen, 2010; Shavit, et al., 2007; Hannum \& Buchmann, 2005), some key questions are still unclear in the case of Taiwan. First, has the expansion of Taiwan's tertiary education system provided more access and opportunities for women in STEM? If it has, how did it happen? Second, does the growth of women's participation in the STEM educational pipeline influence their participation in the labor market? Do they experience discrimination which prevents them from pursuing STEM professions? With 38 years of data in education and the labor market, this study investigates how the expansion of the tertiary education system reshaped the educational opportunity of women in STEM and subsequently the structure in the labor market of STEM professionals in Taiwan.

\section{Historical Overview of Educational Reform in Taiwan}

Since the 1990s, the Taiwanese government initiated a series of educational reforms mainly designed to facilitate educational equality. The policy, driven by this purpose of educational equality, directly impacted upper secondary and tertiary schools. Before the policy action, at the upper secondary level, vocational-oriented senior high schools were seen as secondary to the academic-oriented senior high schools. Moreover, the academic-oriented programs offered in the senior high schools would lead students to university enrollment, whereas the vocational-oriented programs would only lead them to enroll in junior college. The intensive pressure derived from striving to gain admission into senior high schools was often mentioned as the reason for lower secondary high schools focusing solely on preparing their students for admission exams.

Thus, the first policy action was educational reform at the upper secondary school. Taiwan follows the dual-track system which was set up during the Japanese colonial period. Junior high school graduates may choose between an academic-oriented senior high school or a vocational-oriented one. Since 1992, the Ministry of Education (hereafter, MOE) began to increase the number of upper secondary schools from 177 to 513 . With this policy change, some vocational-oriented senior high schools began to replace their vocational-oriented programs with academic-oriented ones.

The second policy action was the transformation of junior colleges into universities. The expansion of tertiary education in Taiwan was mainly driven by increasing the number of four-year technological universities by upgrading two-year junior colleges. From 1996 to 2007, among 70 two-year junior colleges, 53 were upgraded to four-year technological universities or institutes of 
technology. The impact of such expansion was dramatic in two ways. First, the extension of an additional two years transformed vocational education into professional education, offering an opportunity for students to compete for professional positions in the labor market. Second, the increasing capacity of tertiary education accommodated more school-age youth and offered them more opportunities to explore their career options. ${ }^{1}$

\section{Human Capital Theory and Educational and Occupational Choices}

Despite the existence of a copious amount of studies and decades of statistics which underscore the underrepresentation of women in STEM fields, particularly in the United States (Bentley \& Adamson, 2003), little is known about the opportunities provided to and occupational choices of women in STEM after the expansion of Taiwan's education system. To better understand such phenomenon, this study is guided partly by the principles of the human capital theory (HCT) and self-selection as observed from literature mostly derived from the United States.

Under the lens of HCT, individuals make educational and occupational decisions based upon a calculation of associated costs and benefits (Xu, 2015), which can potentially increase their human capital and affect their participation in the labor market. Within this context, women tend to perceive STEM careers as being thing-oriented (compared to personal contact-oriented), resulting in less time for oneself, and being antithetical to communal goals (Kang et al. 2018). Women continuously demonstrate less interest in STEM occupations (Ceci \& Williams, 2010; Diekman et al., 2010) because they prefer more family-friendly, personal contact-oriented occupations than men (Konrad et al. 2000). Put differently, HCT attributes the underrepresentation of women in STEM partly to differences in gender role socialization and the selectivity bias derived from self-selection (Fox, 2010). Such preconditions on STEM fields can in turn determine women's choice of occupation and employment $(\mathrm{Xu}, 2015)$.

Thus, from the HCT perspective, the underrepresentation of women is a result of women choosing not to pursue STEM careers. Despite the notion that tertiary education expansion is expected to raise the human capital of women entering STEM fields, it appears that they perceive entering into such grounds as less beneficial to them. In fact, due to gender-related career expectations and the traditional division of household labor, women have different preferences than men in choosing college majors and subsequent occupational paths (Frome et al. 2006). Women's low participation in STEM, therefore, becomes a social problem as women tend to choose female-dominated occupations which have lower income levels and less advancement opportunities than traditionally male-dominated occupations (Okamoto \& England, 1999).

In addition to the self-selection driven by social expectation along gender lines, the education system itself plays a crucial role in worsening such 
segregation. For example, in the classroom, teachers tend to underestimate the academic ability of women in STEM, thereby giving women students less attention and encouragement (Riegle-Crumb et al., 2011). This barrier creates the notion that STEM programs are male-dominated (Lee, 2008), which is exacerbated by the stereotyping beliefs of teachers, parents, and peers (Saucerman \& Vasquez, 2014). The effect of gender stereotyping is that women get the idea they need to avoid studying in an environment where they are "not treated equally or fairly," a concept that Seaton $(2011$, p. 6) described as a "chilly climate." This may eventually lead to a pattern of women opting out of pursuing STEM which is driven by the education system itself.

Lastly, it has been documented that having women as role models increases young women's attitudes and self-concepts on mathematics and science subjects, thereby expanding their ability to consider STEM fields as major and career options (Corbett \& Hill, 2015; Cheryan et al., 2011). However, in school and society, girls lack role models such as successful women STEM professionals (Lee et al. 2015). Such a situation further exacerbates the idea of a chilly climate that women students face in the STEM fields. Additionally, studies have documented that parents influence their daughters' tertiary educational decisions to choose non-STEM fields (Astin \& Sax, 1996; Shapiro \& Sax, 2011). In sum, women may choose to study in the non-STEM fields because the rewards are different between genders (Mann \& DiPrete, 2013).

\section{Schools and The Leaky Pipeline}

Although there is abundant knowledge about how women are discriminated against within the "STEM pathway" (Wang \& Degol, 2013, p. 305), we know very little about how the structure of the schooling system could worsen or improve such gender inequality. Probably one of the most cited metaphors that describes how schools affect or impact the participation of women in STEM is the "leaky pipeline."

According to the leaky pipeline metaphor, as students move through the STEM pathway, a leaky pipeline leads to decreased representation of women in STEM resulting from a steady attrition of women in the education system and the professional hierarchy (Blickenstaff, 2005). This steady attrition of women might be attributed to system related factors. For instance, preparation in science and mathematics during the middle and high school years is often cited as an important influence on women's decisions to enter or exit STEM majors in college (Seymour \& Hewitt, 1997). Similarly, studies have shown that the disadvantages women face could potentially appear much earlier than expected and exacerbate attrition as they move through the STEM pathway. By studying Germany's population, Kinzie (2007) found that women's pathways into or out of STEM fields are already formed in eighth grade. At this age, it appears that feelings of belonging and integration appear to be essential to be able to fit in and persist in STEM disciplines. 
Furthermore, women's differential STEM course-taking and preparation in their pre-college years appear to be influenced by different factors, which can limit their access to STEM careers later on. Women who do not take the math and science courses needed to access a STEM career are often unable to stay in the science and mathematics pipeline (Huang \& Brainard, 2001) and are eventually "leaked out." Empirical evidence also exists for the assumption that STEM courses are primarily "masculine" and are consequently less appealing to female students (Wang \& Degol, 2013; Blickenstaff, 2005), thereby making them persist less than men within the STEM pathway. Some studies also show that the instructional techniques adopted by STEM teachers favor men over women because they use fewer cooperative approaches, which are more appealing to women (Kelly, 2016; Wang \& Degol, 2013). The longstanding gender stereotype inherent in the STEM field might also influence teachers and advisors towards a biased assumption that women do not belong in the STEM field (van den Hurk et al., 2019). Such prejudiced notions might create a negative social atmosphere for girls pursuing STEM programs, thereby adversely influencing their sense of belonging and competence (Eddy \& Brownell, 2016; Kelly, 2016; Wang \& Degol, 2013). Thus, although STEM disciplines are ostensibly gender-blind, structural barriers appear to have emerged which allow women to be "leaked out" because they are treated as "strangers" in STEM fields (Sonnert et al., 2007; Smith, 2011).

Aside from looking at women's differential STEM course-taking patterns in their pre-college years, early streamlining in a schooling system might exacerbate such segregation (Jacobs, 1989) to a point of no return. In Taiwan, for instance, where the schooling system adopts early streamlining, students make their first educational decision by the ninth grade. At the upper secondary level, students are placed in the academic-oriented or vocational-oriented tracks. Unique to Taiwan, students in the vocational-oriented tracks can go into STEM or nonSTEM programs. The vocational non-STEM program is particularly designed for those students who commit to non-STEM careers. True to its mission, the course structure in the vocational non-STEM program leaves almost no space for STEM courses, which means that students' exploration of STEM courses would be halted by the ninth grade; these students are subsequently excluded from the STEM pathway. The junior college, which only offers two-year associate degree programs, cannot fully prepare students for STEM professions within that time. Thus, under such circumstances, and given the preconditions previously discussed, women are most likely vulnerable in the "leaky pipeline," thereby further widening the gap between men and women within STEM fields.

\section{The Effects of Tertiary Education Expansion on Women in STEM}

It appears that expanded higher education systems have afforded more opportunities for higher education participation across the globe. A result of such expansion is a significant impact on patterns of gender parity and the 
participation of men and women in selected fields (Chang \& ChangTzeng, 2018). For instance, by studying three distinct cohorts representing the high school graduating classes of 1972, 1982, and 1992 in the United States, Flashman (2013) indicates that the expansion of higher education, particularly from two-year to four-year colleges, increased opportunities for enrollment, and women disproportionately took advantages of these opportunities. Regarding the participation of women in STEM fields, Xie and Shauman (2003), who followed a life course perspective (from middle school through career years) and used rigorous multivariate methods on data from 17 large national datasets in the United States, found that gender differentiation has declined little compared to decades ago in a less expanded education system. More recently, Severiens and ten Dam's (2012) study, which used Dutch census data on higher education from 1995 to 2006, indicated that women, on average, outnumber men and are more successful in the bachelor years of higher education.

Thus, it remains obvious that an expanded education system provides differential opportunities for participation. In Taiwan, in particular, the number of students participating in higher education has increased substantially since its expansion in the early 1980s. According to the '2015 Education Statistical Indicators,' the tertiary education GER reached $83.88 \%$ in 2013, higher than their counterparts in most Asian countries (Chang, 2018). Furthermore, as it relates to women's participation in higher education, there are more women students than men students who enrolled in higher education institutions since 1995 (Ministry of Education, 2019b). This trend shows that in Taiwan the expansion of higher education has favored women students more than men. However, what is not clear is whether it transformed the traditional gender stereotype inherent in STEM educational fields and occupational choice.

\section{Methodology}

\section{Data Description}

We use 38 years (1979 through 2017) of national survey data, including the 'manpower utilization quasi-longitudinal data' managed by Academic Sinica (2018), a leading national research institute in Taiwan. We calculate the participation rate in STEM professions and the educational matching rate of men and women at the ages of 25-35. Using administrative records managed by the MOE, we also calculate the share of graduates by gender and educational track over the past 30 years at the upper secondary and tertiary educational levels. The compiled longitudinal data reflects the changing structure in the labor market fueled by the expansion of higher education. The compiled data contains three dimensions. The first one is the share of graduates at the upper secondary level from 1992 to 2017 by three different tracks: academic, vocational education in STEM, and non-STEM. The second one is the share of graduates at the tertiary education level from 1992 to 2017 by four different 
tracks: associate degree in STEM, associate degree in non-STEM, bachelor's degree in STEM, and bachelor's degree in non-STEM. The last one is occupational participation from 1979 to 2017 by gender and professional type.

\section{Analytic Strategy}

To ensure consistency in definition, this study differentiates the STEM and non-STEM disciplines and professional occupations by referring to Beede et al. (2011)'s classification. In order to measure the historical change, we use the percentage share of men and women in the STEM educational track (i.e., upper secondary and tertiary educational levels) and professional occupations accounting for their own gender population. This approach can obviate the confusion inherent in using total amount or percentage changes, particularly in historical investigations (Geiger \& Feller, 1995). Additionally, since the 'manpower utilization quasi-longitudinal data' follow the survey design, data were weighted. We then use frequency weights to estimate the descriptive statistics (Academia Sinica, 2018). Since the interest of this study is to capture the historical trend of women's participation rate in STEM, it uses the median spline method to smoothen the line connecting each annual value point.

\section{Findings}

\section{Shifting Composition of Educational Pipeline}

Figure 4.1 indicates the shifting composition of the educational pipeline of the two gender groups at the upper secondary and tertiary educational levels. Figure 4.1A and 4.1B indicate the changing composition of men and women upper secondary school graduates among three different tracks. The solid line indicates the share of graduates in the academic track, the dashed line indicates the share of graduates in the vocational STEM track, and the dotted line indicates the share of graduates in the vocational non-STEM track. Figure 4.1C and 4.1D indicate the changing composition of male and female postsecondary graduates. The solid line indicates the share of graduates in STEM at bachelor degree level and the dashed line indicates the share of graduates in STEM at associate degree level.

The educational reform during the late 1990s brought direct but heterogeneous impacts on the two gender groups in terms of accessibility in STEM. First, the educational reform at the upper secondary level was to downsize the scale of vocational track programs and to expand the scale of the academic track. Since 1990s, the ratio of total graduates between academic and vocational tracks changed from 2.5:7.5 to 4.8:5.1. About $22.5 \%$ of youth who used to be placed in the vocational track program changed to academic programs at the upper secondary high school level.

Such change also reshaped the educational opportunity of the two gender groups. In 1992, the men in the academic track accounted for $29.3 \%$ of the 

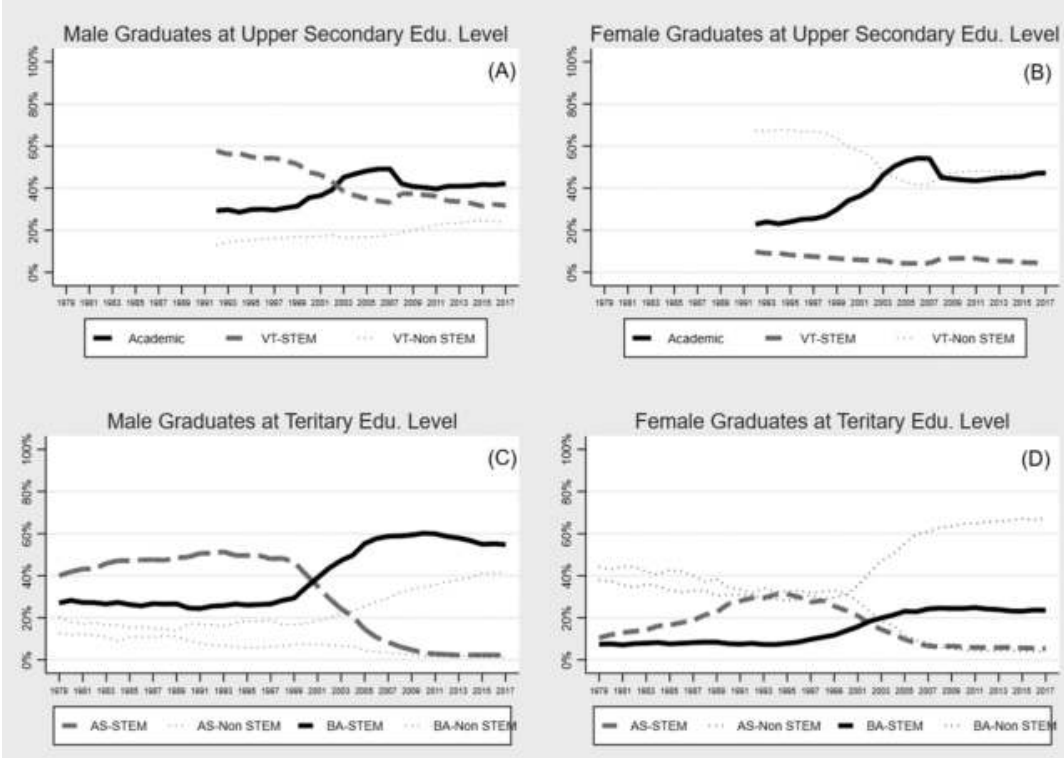

Figure 4.1 A-D. The share of male and female graduates by educational track, 19792017.

total enrolled men students, while women students in the academic track accounted for $22.9 \%$ of all women. By 2017 , the percentage in the men group increased to $42.2 \%$ while the women group increased to $47.2 \%$. The additional growth in the academic track on the two gender groups came from different resources. As for the men group, during the same period, the vocational track STEM programs decreased from $57.7 \%$ to $31.8 \%$, yielding $25.9 \%$ to the rest of the tracks. The share of men students in the academic track program increased by $12.9 \%$. Simultaneously, the vocational track nonSTEM program increased by $10.8 \%$, from $13.1 \%$ in 1992 to $23.9 \%$ in 2017 . Overall, more men students delayed their tracking decision. However, among those early-decided men students, the portion of men students choosing not to go on the STEM track increased as well.

Different from the decrease of the men students in the vocational track STEM programs, the significant decline among women appears in the vocational track non-STEM programs. In 1992, 67.4\% of women students were in vocational track non-STEM programs. By 2017, only $46.6 \%$ of women students were left. The vocational track STEM programs also experienced a modest decline, decreasing from $9.7 \%$ to $4.3 \%$ during the same period. The vocational track lost women students to the academic track programs, which experienced $24.3 \%$ growth. Compared to the older generation, the younger women generation had more opportunity to explore their interest in STEM fields via the academic track. On the other hand, there were still $46.6 \%$ of 
women students who chose a non-STEM track through the vocational track; but only $23.9 \%$ of men students made the same choice.

We then focus our investigation on the impact of tertiary education expansion on the two gender groups. Due to the notion that tertiary education expansion is mainly driven by the transformation of junior colleges, the direct impact based on this change is the extended length of education and the type of degree awarded. Particularly for those students who used to finish their studies at junior college, four-year tertiary education meant the transformation of vocational education into professional education. This change offered them better opportunities to obtain a STEM professional position.

As observed at the upper secondary school level, tertiary education expansion brought heterogeneous effects to the two gender groups. Referring to men, in 1979, $40.0 \%$ of men who enrolled in tertiary education had an associate degree in STEM fields. In the same year, only $27.1 \%$ of the men completed four-year tertiary education and graduated with a bachelor's degree in STEM fields. Since 2000, affected by the increasing capacity at universities, the percentage of men students studying in STEM fields started growing. Within ten years, by 2010, the percentage of fouryear STEM degrees reached a peak of $60.2 \%$. At the same time, only $3.3 \%$ of men students graduated with an associate degree in STEM fields.

Soon after the peak in 2010, the percentage of men students choosing STEM fields at the university level started to decline. By 2017, the number decreased to $54.8 \%$. The percentage of men students choosing non-STEM programs at universities increased from $34.6 \%$ in 2010 to $41.7 \%$ in 2017 . The reduction of men students in STEM fields implies that men students no longer enrolled overwhelmingly in STEM fields. To a certain degree, young men were less constrained by the gender stereotype in choosing their major fields.

Tertiary education expansion also changed the landscape of educational choice for women students. In 1979, only 7.5\% of women who enrolled at tertiary education earned bachelor's degrees in STEM fields. Even for associate's degrees, only $10.5 \%$ of women students graduated in STEM fields. The percentage of women students graduating with an associate degree in STEM increased to $31.3 \%$ in 1995 . At that time, only $7.9 \%$ of women students at universities were studying in STEM programs.

Soon after 1995, when the majority of the junior colleges started to transform into universities, women who would have graduated with an associate's degree in STEM fields now graduated with a bachelor's degree. From 1995 to 2007, the percentage of women who graduated with a bachelor's degree gradually increased and reached a saturation point $(24.2 \%)$ in 2007 followed by a ten-year flat curve until 2017. On the other hand, from 1995 to 2007, the percentage of women who graduated with associate's degrees in STEM continually declined. By 2017, only $5.4 \%$ of women students were left in two-year STEM programs. As observed among men, the growth of women in STEM bachelor programs came from the loss in associate degree programs. However, compared to 2005, by 2017 there were $10.2 \%$ less women students enrolled in STEM programs either at a junior college or a university. 


\section{Yuan Chih Fu et al.}

From the upper secondary to tertiary level, there are different degrees on the leaky pipeline among the two gender groups. Upon their graduation from upper secondary school, by 2017 , there were $42.2 \%$ and $31.8 \%$ of men students in the academic and vocational track STEM programs, respectively. By 2017, 54.8\% of men students earned bachelor degrees in STEM fields. Although there were $47.2 \%$ and $4.3 \%$ of women students in the academic and vocational track STEM program, respectively, only $23.6 \%$ of them earned bachelor degrees in STEM fields. Although our statistics cannot show their preferences for academic tracks at the upper secondary level, this suggests that among 100 men and women senior high school graduates who chose academic tracks in STEM programs, 74 men and 45 women students would eventually choose STEM fields and graduate.

Based on the historical overview, two important findings appear. First, the expansion of tertiary education did enhance women's opportunities to complete four-year tertiary education for STEM professions. However, during the period of expansion, the percentage of men and women in STEM decreased at both the junior college and university levels. Second, although the reform at the upper secondary level postponed women's educational choice and provided them more opportunities to explore STEM courses, women students still appeared to face severe problems within the leaky pipeline between the upper secondary and tertiary levels.

\section{Convergence of Participation in STEM Professional Positions}

The increasing number of women with professional education in STEM fields changed the structure of human resources in the labor market. Table 4.1 reveals the participation rate of the population at ages 25-35 in STEM professions by gender while Figure 4.2 visualizes the historical trend.

Table 4.1 The Participation Rate of 25-35-year-olds in STEM Professions

\begin{tabular}{lrrrrrrrrr}
\hline & Weighted sampling size & & \multicolumn{3}{c}{ STEM professionals (\%) } & \multicolumn{4}{c}{$\begin{array}{l}\text { STEM education and occupa- } \\
\text { tion match }(\%)\end{array}$} \\
\hline Year & Men & Women & Total & Men & Women & total & Men & Women & Total \\
\hline 1979 & 487,124 & 458,485 & 945,609 & 1.98 & 0.12 & 1.08 & 46.42 & 25.18 & 44.82 \\
1981 & 671,656 & 637,759 & $1,309,415$ & 1.92 & 0.30 & 1.13 & 35.65 & 50.26 & 36.78 \\
1986 & 847,265 & 752,384 & $1,599,649$ & 1.76 & 0.47 & 1.16 & 31.65 & 53.58 & 34.00 \\
1991 & 893,062 & 825,421 & $1,718,483$ & 2.43 & 0.95 & 1.72 & 40.36 & 60.05 & 43.81 \\
1996 & 909,554 & 838,710 & $1,748,264$ & 3.50 & 1.09 & 2.35 & 43.77 & 57.12 & 46.24 \\
2001 & 918,671 & 855,287 & $1,773,958$ & 6.11 & 1.77 & 4.01 & 52.94 & 52.09 & 52.78 \\
2006 & 968,146 & 918,688 & $1,886,834$ & 11.43 & 4.58 & 8.09 & 56.11 & 60.63 & 57.19 \\
2011 & $1,007,265$ & 959,640 & $1,966,905$ & 14.71 & 6.42 & 10.66 & 49.22 & 56.47 & 51.08 \\
2016 & 932,326 & 894,055 & $1,826,381$ & 14.73 & 10.40 & 12.61 & 44.94 & 57.90 & 48.77 \\
2017 & 834,190 & 838,348 & $1,672,538$ & 15.74 & 10.01 & 12.87 & 41.74 & 53.34 & 45.14 \\
\hline
\end{tabular}


Shown in Figure 4.2A, over the past 38 years, both gender groups experienced three different stages. In the first stage, from 1979 to 1990, the share of STEM professional occupations by gender basically reflects the gender composition within tertiary education. During this period, men dominated STEM professional occupations as they dominated STEM programs in universities. On average, the ratio between the two gender groups was 5:1. Inequality in the education pipeline followed by inequality in the labor market is very apparent.

Entering the second stage, from 1991 to 2001, Taiwan's economy gradually shifted towards high-tech industries. The growth of high-tech industries offered more professional positions. The percentage of 25-35-year-olds who had STEM professional occupations increased from $1.72 \%$ to $4.01 \%$, almost 2.5 times. During this period, men took the lion's share of this growth. In 1991, only $2.43 \%$ of men took a STEM professional position in the labor market. By 2001, this number increased to $6.11 \%$, almost 2.5 times more. In contrast, the growth of women was under the national average. In 1991, $0.95 \%$ of women took STEM professional positions. By 2001, this number increased about 1.8 times to $1.77 \%$. The participation rate of women in STEM professions increased as a reflection of the increasing share of women graduates with bachelor's degrees in STEM since 1995. As seen in Figure $4.1 \mathrm{D}$, the trend took off soon after 1995. By 2001, about $17 \%$ of women had

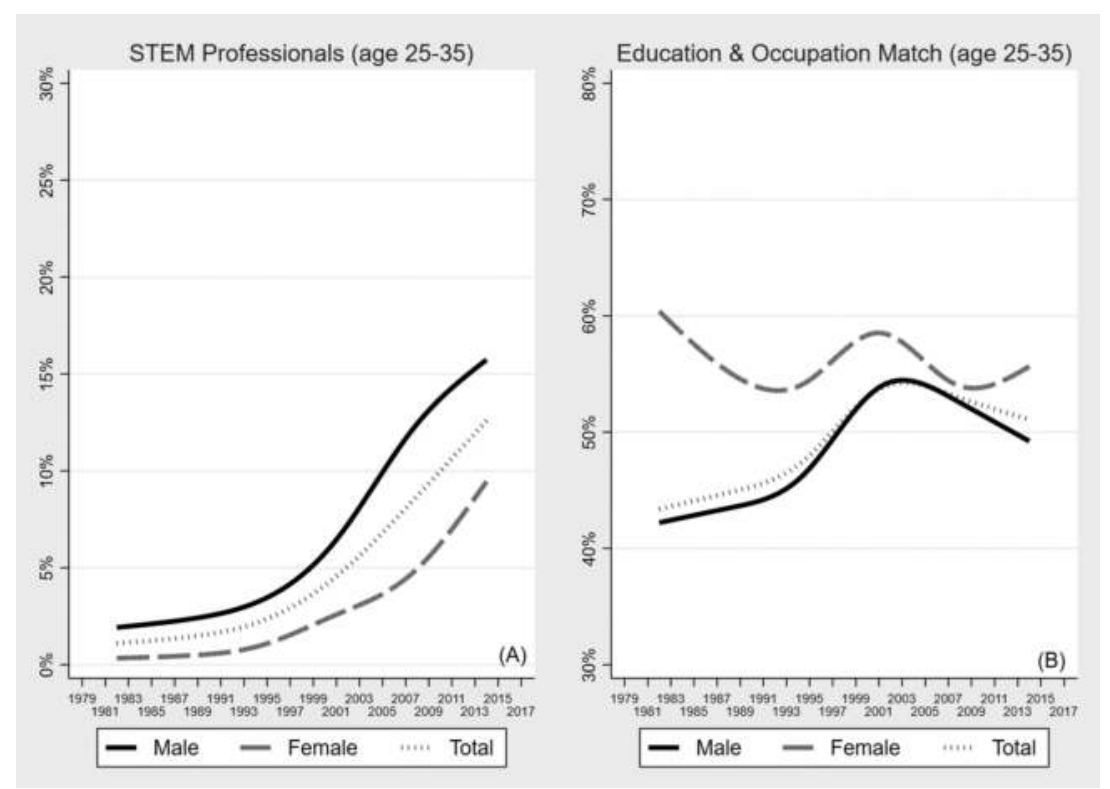

Figure 4.2 The impact of education expansion on occupational choice, 1979-2017. Note: Median smoothing applied. 
a bachelor's degree in STEM. This growth also reflected the rise in the labor market, although mildly. Overall, the segregation by gender in the STEM professional job market was improving. The ratio between the two gender groups shrunk from 5:1 to $3: 1$.

In the third stage, from 2001 to 2017, the convergence of participation in STEM professions between the two gender groups became obvious. As the impact of tertiary education expansion became stable (after 2001), the population trend accounting for the number of graduates by gender cohort in STEM fields also plateaued (see Figure 4.1). However, the demand for STEM professional positions in the labor market grew continually. The percentage of the youth generation who had STEM professional occupations increased from $4.01 \%$ to $12.87 \%$, almost 3.2 times more. This exponential growth reflected the urgent demands of high-tech professionals in the knowledge economy.

It is noteworthy that when men's participation rate is approaching its saturation point, shown as the S-shaped curve, women's participation rate keeps its growth momentum. In 2001, 6.11\% of males had a STEM professional position in the labor market. By 2017, this number increased to $15.74 \%$, almost 2.5 times more. Dramatically, women's growth is well above the national average. In 2001, 1.77\% of women had a STEM professional position. By 2017, this number increased to $10.01 \%$, about 5.6 times more. The growth of women in STEM professions was fueled by younger women. By the latest survey year (2017), the ratio between the two gender groups drops to 1.5:1 (down from 3:1 in 2001). The growth of women in STEM professional occupations fueled by higher education expansion, to a certain degree, offset the position vacancy which could not be filled only by men.

Figure $4.2 \mathrm{~B}$ visualizes the percentage of the population who got a college education in STEM and also had STEM professional positions. Over the past 38 years, women always had a higher percentage of matching between STEM education and occupation compared to men in their age cohort. This trend barely changed even though there was a significant increase in the number of women who were awarded bachelor's degrees in STEM, which suggests that women who completed STEM degrees were more determined to pursue STEM careers. Also, there is no sign to show any discrimination against women in the labor market of STEM professional occupations. Women are treated equally at their early career stage if they have educational opportunities to earn STEM professional qualifications.

\section{Discussion}

Educational expansion in Taiwan was a policy initiative aimed at generating greater educational equality and accessibility. Although educational expansion has been criticized as the cause for over-education and stagnant wage growth in recent years (Green \& Henseke, 2016), this study documents how such policy changed the participation patterns of women in STEM and the subsequent labor market in Taiwan. The expansion of tertiary education created 
opportunities for both men and women with Taiwanese women taking modest advantage of such opportunities to enroll in more STEM programs. Coupled with the decreased enrolment pattern into STEM programs by men in recent years, this Taiwanese case provides a historical perspective revealing how the transformation of education could help reduce gender inequality in STEM (Ramirez \& Wotipka, 2001).

Within the Taiwanese context, the delayed streamlining at the upper secondary school level prevented women from being filtered out of the STEM educational pathway. However, the leaky pipeline phenomenon women face between the upper secondary and tertiary levels was still severe. The possible self-selection or gender stereotyping during their teenage year still constrained girls' interests to explore STEM careers. When Taiwan expanded its tertiary education system, more and more youth had access to university education, but less and less youth showed interest in STEM careers. This tendency did not exclusively happen among women but with men as well. However, compared to older generations, younger women benefited from educational expansion because of greater opportunities to study at four-year universities and complete four-year professional degrees in STEM. They were more likely to obtain the educational qualifications required for the labor market in STEM fields.

These findings fill an important knowledge gap within the scarce literature concerning women in STEM and educational equality within the context of tertiary education expansion in Taiwan. Although much of the literature cited was from US sources, similar dynamics can be observed within the Taiwanese context. An expanded tertiary education system does provide opportunities for women, and for men, to increase their human capital within STEM fields. However, our findings also show that Taiwanese women are still prone to opt out of STEM fields during their upper secondary and tertiary education schooling levels.

These findings have two important policy implications. First, Taiwan's case shows that expanded capacity at the upper secondary level does not guarantee gender equality in STEM tertiary education. Women may still not choose STEM because of gender stereotypes. In this sense, the career exploration programs, which enhance youth's knowledge of each occupation, should be emphasized in the educational system, particularly in secondary schools. Second, tertiary education expansion did improve gender inequality in the labor market by providing women more opportunities to complete professional education in STEM fields. Young women seized the opportunity and completed STEM professional education, as did young men. This opportunity could not have happened if the capacity to access university STEM programs was still limited. However, there is still a clear ceiling effect constraining the growth of women in the STEM educational pipeline as documented in our study. This scenario sends a warning to policymakers that aggressive intervention to improve gender inequality is still needed in the educational system. 


\section{Conclusion}

Using national longitudinal data from 1979 to 2017 that surveyed the educational attainment and occupational choice of women in the labor market, our historical analysis shows that the process of educational expansion could bring many benefits to the underrepresented population group which traditionally used to be excluded from the education system. Using Taiwan as our case study, our findings remind researchers and policymakers that it might be necessary to reevaluate the pros and cons of educational expansion from a holistic perspective. It is not enough to only look at superficial data; rather, it is essential to consider how policy actions, like transforming two-year junior colleges to four-year universities and expanding a nation's education system, have impacted educational participation over the years.

As documented in this Taiwanese case study, diversified educational participation, like having more women receiving professional education in STEM as a result of education expansion, further facilitates the diversity of the labor market. Such dynamics can help develop human capital for science production and keep the momentum of national development in the era of the knowledge economy.

\section{Note}

1 The first author has been part of the Ministry of Education from 2007 to 2018 and engaged in the formation of higher education policy, which helped the authors identify and understand these materials.

\section{References}

Academia Sinica. (2018). Manpower utilization quasi-longitudinal data: 1979-2017 [data file]. Available from Survey Research Data Archive, Academia Sinica.

Astin, H. \& Sax, L. (1996). Developing scientific talent in undergraduate women. In C. Davis, A. Ginorio, C. Hollenhead, B. Lazarus, P. Rayman, \& Associates (Eds.), The equity equation: Fostering the advancement of women in the sciences, mathematics, and engineering (pp. 96-121). Jossey-Bass.

Baker, D. (2011). Forward and backward, horizontal and vertical: Transformation of occupational credentialing in the schooled society. Research in Social Stratification and Mobility, 29, 5-29.

Beede, D., Tiffany, J., \& Langdon, D. (2011). Women in STEM: A gender gap to innovation (Issue Brief No. 04-11). U.S. Department of Commerce. https://eric-ed-gov. libproxy.library.unt.edu/contentdelivery/servlet/ERICServlet?accno=ED523766

Bentley, J. T., \& Adamson, R. (2003). Gender differences in the careers of academic scientists and engineers: A literature review. (Report no. 00-327). www.nsf.gov/sbe/ srs/nsf03322/pdf/nsf03322.pdf

Blickenstaff, J. C. (2005). Women and science careers: Leaky pipeline or gender filter? Gender and Education, 17(4), 369-386.

Breen, R. (2010). Educational expansion and social mobility in the 20th century. Social Forces, 89, 365-388. 
Ceci, S. J., \& Williams, W. M. (2010). Sex differences in math-intensive fields. Current Directions in Psychological Science, 19, 275-279.

Chang, D. F. (2018). Effects of higher education expansion on gender parity: A 65-year trajectory in Taiwan. Higher Education, 76(3), 449-466.

Chang, D. F., \& ChangTzeng, H. C. (2018). Patterns of gender parity in the humanities and STEM programs: The trajectory under the expanded higher education system. Studies in Higher Education, 45(6), 1108-1120.

Cheryan, S., Siy, J. O., Vichayapai, M., Drury, B. J., \& Kim, S. (2011). Do female and male role models who embody STEM stereotypes hinder women's anticipated success in STEM? Social Psychological and Personality Science, 2(6), 656-664.

Corbett, C., \& Hill, C. (2015). Solving the equation: The variables for women's success in engineering and computing. American Association of University Women.

Diekman, A. B., Brown, E., Johnston, A., \& Clark, E. (2010). Seeking congruity between goals and roles: A new look at why women opt out of STEM careers. Psychological Science, 21, 1051-1057.

DiPrete, T. A., \& Buchmann, C. (2013). The rise of women: The growing gender gap in education and what it means for American schools. Russell Sage Foundation.

Eddy, S. L., \& Brownell, S. E. (2016). Beneath the numbers: A review of gender disparities in undergraduate education across science, technology, engineering, and math disciplines. Physical Review Physics Education Research, 12(2), 1-20.

Flashman, J. (2013). A cohort perspective on gender gaps in college attendance and completion. Research in Higher Education, 54(4), 545-570.

Fox, M. F. (2010). Women and men faculty in academic science and engineering: Social-organizational indicators and implications. American Behavioral Scientist, 53(7), 997-1012.

Frome, P. M., Alfeld, C. J., Eccles, J. S., \& Barber, B. L. (2006). Why don't they want a male-dominated job? An investigation of young women who changed their occupational aspirations. Educational Research and Evaluation, 12(4), 359-372.

Fu, Y. C. (2017). Science production in Taiwanese universities, 1980-2011. In J. J. W. Powell, D. P. Baker, \& F. Fernandez (Eds.), The century of science: The global triumph of the research university (pp. 173-203). Emerald.

Geiger, R., \& Feller, I. (1995). The dispersion of academic research in the 1980s. The Journal of Higher Education, 66(3), 336-360.

Green, F., \& Henseke, G. (2016). Should governments of OECD countries worry about graduate underemployment? Oxford Review of Economic Policy, 32(4), 514-537.

Hannum, E., \& Buchmann, C. (2005). Global educational expansion and socio-economic development: An assessment of findings from the social sciences. World Development, 33, 333-354.

Huang, P. M., \& Brainard, S. G. (2001). Identifying determinants of academic selfconfidence among science, math, engineering, and technology students. Fournal of Women and Minorities in Science and Engineering, 7(4), 315-337.

Jacobs, J. A. (1989). Revolving doors: Sex segregation and women's careers. Stanford University Press.

Kang, J., Hense, J., Scheersoi, A., \& Keinonen, T. (2018). Gender study on the relationships between science interest and future career perspectives. International fournal of Science Education, 41(2), 1-22.

Kelly, A. M. (2016). Social cognitive perspective of gender disparities in undergraduate physics. Physical Review Physics Education Research, 12(2), 1-13. 
Kinzie, J. (2007). Women's paths in science: A critical feminist analysis. New Directions for Institutional Research, 133, 81-93.

Konrad, A. M, Ritchie, J. E. Jr., Lieb, P., \& Corrigall, E. (2000). Sex differences and similarities in job attribute preferences: A meta-analysis. Psychological Bulletin, 126(4), 593-641.

Lee, J. A. (2008). Gender equity issues in technology education: A qualitative approach to uncovering barriers [Doctoral dissertation, North Carolina State University]. ProQuest Dissertations \& Theses Global]. https://libproxy.library.unt.edu/login?url=https://www-p roquest-com.libproxy.library.unt.edu/docview/304536802? accountid=7113

Lee, J. K., Alston, A. T., \& Kahn, K. B. (2015). Identity threat in the classroom: Review of women's motivational experiences in the sciences. Translational Issues in Psychological Science, 1(4), 321

Mann, A., \& DiPrete, T. A. (2013). Trends in gender segregation in the choice of science and engineering majors. Social Science Research, 42, 1519-1541.

Marginson, S. (2016). The worldwide trend to high participation higher education: Dynamics of social stratification in inclusive systems. Higher Education, 72(4), 413-434.

Ministry of Education. (2019a). Higher education statistics. Retrieved from: https:// eng.stat.gov.tw/public/data/dgbas03/bs2/yearbook_eng/y015.pdf

Ministry of Education. (2019b). Education statistical indicators [Data sets]. https:// english.moe.gov.tw/cp-86-18943-e698b-1.html

Okamoto, D., \& England, P. (1999). Is there a supply side to occupational sex segregation? Sociological Perspectives, 42, 557-582.

Penner, A. (2015). Gender inequality in science. Science, 347(6219), 234-235.

Ramirez, F. O., \& Wotipka, C. M. (2001). Slowly but surely? The global expansion of women's participation in science and engineering fields of study, 1972-92. Sociology of Education, 74(3), 231-251.

Riegle-Crumb, C., Moore, C., \& Ramos-Wada, A. (2011). Who wants to have a career in science or math? Exploring adolescents' future aspirations by gender and race/ ethnicity. Science Education, 95(3), 458-476.

Saucerman, J., \& Vasquez, K. (2014). Psychological barriers to STEM participation for women over the course of development. Adultspan fournal, 13(1), 46-64.

Seaton, G. A. (2011). Belonging uncertainty and psychological capital: An investigation of antecedents of the leaky pipeline in STEM [Master's thesis, Purdue University].

Severiens, S., \& ten Dam, G. (2012). Leaving college: A gender comparison in male and female-dominated programs. Research in Higher Education, 53, 453-470.

Seymour, E., \& Hewitt, N. M. (1997). Talking about leaving: Why undergraduates leave the sciences. Westview Press.

Shapiro, C. A., \& Sax, L. J. (2011). Major selection and persistence for women in STEM. New Directions for Institutional Research, 2011 (152), 5-18.

Shavit, Y., Arum, R., Gamoran, A., \& Menahem, G. (2007). Stratification in higher education: A comparative study. Stanford University Press.

Smith, E. (2011). Women into science and engineering? Gendered participation in higher education STEM subjects. British Educational Research Fournal, 37(6), 993-1014.

Sonnert, G., Fox, M. F., \& Adkins, M. (2007). Undergraduate women in science and engineering: Effects of faculty, fields and institutions over time. Social Science Quarterly, 88(5), 1333-1356.

Trow, M. (1973). Problems in the transition from elite to mass higher education. http://files.eric.ed.gov/fulltext/ED091983.pdf 
U.S. Department of Commerce \& National Economic Council. (2012). The competitiveness and innovative capacity of the United States. https://www.commerce.gov/ sites/default/files/migrated/reports/thecompetitivenessandinnovativecapacityoftheu nitedstates.pdf

van den Hurk, A., Meelissen, M., \& van Langen, A. (2019). Interventions in education to prevent STEM pipeline leakage. International Fournal of Science Education, 41(2), 150-164

van Staden, A., Ahmed, N., Getachew, Y., Gledhill, I. M. A., Kanjere, M., KhuluseMakhanya, S., \& Das, S. (2019). 'Gender shouldn't matter because we are all scientists here': A narration of the panel discussion at the 2nd International Women in Science Without Borders conference. South African Fournal of Science, 115(3/4), 33-36.

Wang, M. T., \& Degol, J. (2013). Motivational pathways to STEM career choices: Using expectancy-value perspective to understand individual and gender differences in STEM fields. Developmental Review, 33(4), 304-340.

Xie, Y., \& Shauman, K. A. (2003). Women in science: Career processes and outcome. Harvard University Press.

$\mathrm{Xu}, \mathrm{Y}$. (2015). Focusing on women in STEM: A longitudinal examination of genderbased earning gap of college graduates. The Journal of Higher Education, 86(4), 489-523. 


\title{
5 STEM Bachelor's Degree Attainment among Women of Color in the United States
}

\section{Using Geographic Analysis for Gender and Racial Equity Research}

\author{
Hyun Kyoung Ro, Yi Meng and Qiong Zhu
}

Science, Technology, Engineering and Mathematics (STEM) education has been the source of innovation for technology and economic development in the United States (Toulmin \& Groome, 2007; National Science Board, 2007; Spellings, 2006). A key policy of the U.S. education agenda has been to meet the social demand for STEM education. Producing more STEM graduates and ultimately increasing to a highly qualified and diversified scientific workforce has been the mission of STEM disciplines throughout early childhood to graduate education. According to the Bureau of Labor Statistics, career opportunities in STEM fields are expected to grow by $12.5 \%$ between 2012 and 2020, a faster rate than in non-STEM fields (U.S. Congress Joint Economic Committee, 2012). Without increasing women and underrepresented racial minorities $(\mathrm{URM})^{1}$ in STEM, the United States would not be able to meet the national demand.

In terms of four-year university enrollment, more than half of students are women in the United States (National Center for Science and Engineering Statistics, 2019). However, women have been underrepresented in STEM fields for decades (Chen \& Weko, 2009). The gender disparities in STEM undergraduate majors become wider when racial or ethnic minority demographics are taken into account (Ong et al., 2011). While URM students face more barriers and challenges than their White or Asian peers, women who hold these statuses have "double bind" barriers due to the intersection of gender and race/ ethnicity in traditionally White, male-dominated STEM disciplines (Malcom \& Malcom, 2011; Ong et al., 2011).

Researchers have found unique challenges among racially minoritized women $^{2}$ undergraduates in engineering (Ong et al., 2020; Ro \& Loya, 2015), physics (Ko et al., 2013; Ong, 2005), computer science (Ong, 2011), and mathematics (Borum \& Walker, 2012), or STEM in general (Ong et al., 2018). While these researchers explored sub-STEM disciplines, they nevertheless found several common themes. Women of color students experience a lack of mentoring, advising, and role models, microaggressions or stereotyping from their faculty and peers, and minimization of feelings, alienation, or

DOI: $10.4324 / 9781003053217-10$ 
exclusion from competitive environments (Borum \& Walker, 2012; Wilkins-Yel et al., 2019). On the other side, researchers have found that family support, strong pre-college programs, faculty mentoring, and curricular and co-curricular opportunities (e.g., undergraduate research) were critical factors in women of color's success (Carlone \& Johnson, 2007; Espinosa, 2011; Ong et al., 2011; Ong et al. 2018).

Although interest is emerging in women of color undergraduates in STEM fields (Ong et al., 2020), so far existing studies have focused on the impact of individual, disciplinary, or institutional characteristics on their success. Few studies address whether the local supply of colleges relates to student success among women of color as measured by STEM bachelor's degree attainment at a community level with respect to the "geography of educational opportunity" (Hillman, 2016). This is a critical question because the availability of colleges and universities substantially varies across local communities in the United States. (Hillman, 2016). The majority of U.S. students attend colleges close to home (Hillman, 2016; Miller, 2012; Tate, 2008); more than half of college students enroll within about 20 miles of their permanent home address (Hillman, 2017). Racially minoritized students are more likely to choose colleges close to home due to family and financial reasons (Klasik et al., 2018; Ovink \& Beazey, 2011). The inequity happens when communities with a more racially minoritized population have more two-year colleges but fewer four-year universities (Hillman, 2016). The lack of educational opportunities in local communities affects racially minoritized students' access to higher education and ultimately their completion of bachelor's degrees. In this chapter, we argue that the opportunity for higher education in communities is an even more important factor for women of color to complete STEM bachelor's degrees compared to their counterparts since women of color have close ties to their family and have familial obligations (Gonzalez et al., 2020; Ong et al., 2020).

The purpose of this study is to better understand how a structural barrier, such as the disparity in higher education opportunities by community, relates to STEM bachelor's degree attainment among women of color. In this chapter, we first introduce national-level efforts to promote gender and racial diversity in STEM fields through policies and professional associations. We then review scholarly literature addressing U.S. women, racially minoritized, and women of color undergraduates who study STEM majors. We also review literature on different types of minority serving institutions in the United States and how these institutions serve racially minoritized students, and, we address gaps in current literature. We apply the concepts of "intersectionality" (Crenshaw, 1989; Collins, 1990; Collins \& Bilge, 2016) and "geography of educational opportunity" (Hillman, 2016) as a theoretical framework. We present statistical results by analyzing two large-scale national data sets, the Integrated Postsecondary Education Data System (IPEDS) and the American Community Survey (ACS) to conduct a location-level analysis. Finally, we offer implications which target women of color who live in places with a lack of opportunities in higher education. 


\section{National Trends and Policies to Diversify STEM Undergraduates}

We start this section by demonstrating national statistics that show the gender and racial differences in STEM degree attainment in the United States. We then present the efforts of national policies and professional associations to promote gender and racial equity in STEM education and workforce.

\section{Gender and Racial Differences in STEM Degree Attainment}

In the 2015-16 academic year, women received over half of all bachelor's degrees, however, women's STEM ${ }^{3}$ degree attainment still falls behind their men counterparts $(36 \%$ vs. $64 \%)$ and varies greatly by field of study (National Center for Science and Engineering Statistics, 2019). According to the National Center for Science and Engineering Statistics (2019), women's highest degree share is in biosciences, while their lowest attainments are in computer science and engineering. While women earned about $61 \%$ of degrees at the bachelor's level in biosciences, only 19\% of computer science degrees, $21 \%$ of engineering degrees, and $19 \%$ of physics degrees were awarded to women. Similarly, about $20 \%$ of the doctorate degrees in computer science, engineering, and physics degrees were awarded to women.

Degree attainment among women in certain STEM disciplines has shown little progress in recent decades (National Center for Science and Engineering Statistics, 2019). From 1996 to 2016, women's participation in social sciences and engineering has gradually increased at all levels, while their education attainment in computer science, mathematics and statistics, and physical science has been stagnant. In computer science, for example, women's share of degrees has decreased from $27 \%$ to $19 \%$ at the bachelor level, and slightly increased from $28 \%$ to $31 \%$ and from $16 \%$ to $20 \%$ at the master's and doctorate level, respectively.

By the same token, the average share of STEM degrees received by URM students has gradually improved, but certain STEM disciplines still lack significant percentages of URM students (National Center for Science and Engineering Statistics, 2019). Overall, URMs earned about 22\% of all science and engineering $(\mathrm{S} \& \mathrm{E})^{4}$ degrees at the bachelor's level and 9\% at the doctorate level. In the 2015-16 academic year, Hispanics received about 15\% of STEM degrees at the bachelor's level, and Blacks earned about $12 \%$ of STEM degrees at the bachelor's level. While the share of Hispanic graduates has improved (14\% of science and $10 \%$ of engineering bachelor's degrees), Black representation has declined to less than $5 \%$ of the degrees in physical sciences, mathematics and statistics, and engineering.

The share of URM men's and women's degree attainment in STEM fields has increased at all levels, albeit with varying amounts of participation (National Center for Science and Engineering Statistics, 2019). At the associate's level, URM women earned more degrees in science and in science and 
engineering technologies (science, engineering, health, and other technologies), while their men counterparts tended to receive more associate degrees in engineering. At the bachelor's level, both Hispanic women and Black women received a higher share of degrees in psychology, social science, and biological sciences than in any other S\&E field. Black women's participation in computer science, engineering, mathematics and statistics, and physical science, however, has declined over the past 20 years.

\section{National Policies and Professional Organizations}

The United States has invested abundant financial resources to broaden participation among women and URM in STEM disciplines for decades (Wilkins-Yel et al., 2019). The Department of Education supports multiple grant programs which have been focused on promoting racial ethnic minority women and men in STEM fields at two-year and four-year colleges; for example, the Minority Science and Engineering Improvement Program (U.S. Department of Education, 2020) and the Hispanic Serving Institutions-STEM programs (U.S. Department of Education, 2019). The National Science Foundation (NSF) also supports research projects for a diverse and well-prepared engineering workforce through the Broadening Participation in Engineering grant (Smith, n.d.). Although it is not targeted at undergraduate students, but focused on faculty, the NSF created the ADVANCE-Institutional Transformation (IT) grant to build evidence-based research expanding the participation of women faculty in STEM (DeAro \& Camacho, n.d.). The ADVANCE grant has played a key role in developing an equitable environment for women faculty in STEM departments on campus, which also can affect women students in the long term.

In addition to national-level grant funds, there are multiple professional organizations to promote women and URM students' learning and success in STEM fields in the United States. For example, the Women in Engineering Proactive Network seeks to transform policies, practices, and culture in engineering education to attract, retain, and graduate women and support a network of women engineering students at 200 higher education institutions (Women in Engineering ProActive Network, n.d.). A number of nonprofit, professional organizations support STEM students of color, such as the National Society of Black Engineers (https://www.nsbe.org/home.aspx), American Indian Science and Engineering Society (https://www.aises.org/), the Society of Hispanic Professional Engineers (https://shpe.org/), and the Society of Asian Scientists and Engineers (https://www.saseconnect.org/about-sase). These organizations offer scholarships, networking, mentorship, and career development opportunities for racially minoritized college students and research shows that participating in these organizations has positive impacts on learning outcomes and persistence for students of color (Ro et al., 2016).

Despite the enormous investment and efforts of national policies and professional organizations, women and racially minoritized groups are still 
underrepresented in STEM fields and progress remains extremely slow. In the next section, we review empirical research addressing women, racially minoritized, and women of color students' experiences and performance in STEM undergraduate programs in the United States and discuss the gaps in the existing literature on gender and racial equity in STEM education literature.

\section{Women, Racially Minoritized, and Women of Color Students in STEM}

A substantial amount of research has been devoted to explaining the gender gaps in STEM enrollment and persistence. Scholars and policy makers have made a connection between mathematics proficiencies at an early age and STEM major choice and persistence (Seymour \& Hewitt, 1997). Students who have lower levels of mathematics and science scores, it is theorized, are less likely to choose and persist in STEM majors (Adelman, 1999, 2006). Yet, more recent national studies show that women students outperform men in mathematics in secondary and postsecondary education (Riegle-Crumb \& King, 2010; Wang et al., 2013). Mathematics achievement is not the reason women do not choose STEM fields; in fact, women who are good at mathematics tend to choose other majors which are more women-friendly, gender-balanced fields (Wang et al., 2013).

URM students have faced different challenges when they choose STEM majors. URM students tend to exhibit low levels of mathematics performance in secondary education because their schools do not offer advanced mathematic courses or resources to promote mathematic proficiencies; therefore, they are not able to choose a major in STEM due to admissions or degree requirements (Bozick \& Ingels, 2007; McGee \& Martin, 2011; Oakes, 2003). The lack of preparedness in mathematics performance and the lack of mathematic curricular exposure among URM students should not be understood as the individual students' deficiency. Scholars contend that secondary public school systems issues, such as lower quality mathematics curricula and lack of mathematic course sequences, a lack of direction and advice from mathematics teachers and school counselors, as well as other - parental, economic, social, and culturalfactors cause a lack of mathematics preparation among racially minoritized students (McGee \& Martin, 2011; Oakes, 2003).

While the majority of STEM education literature has focused on women and racially minoritized students, scholars have suggested that women of color students should receive more attention (Ong et al., 2020). Scholars claim that women of color experience a "double bind," which refers to the unique barriers faced by women scientists and engineers of color as they simultaneously navigate race- and gender-based discrimination and exclusion in White, male-dominated STEM fields (Malcom \& Malcom, 2011; Ong et al., 2011). Scholars have revealed double bind barriers and challenges that women of color students have faced in STEM disciplines (Ong et al., 201 1, 2020; Pawley, 2019; Wilkins-Yel et al., 2019). Black and Latina women students struggle to develop their identity as 
scientists or engineers when experiencing bias, stereotypes, and microaggressions from White faculty and peers (McGee, 2016). Asian women engineering students often express lower levels of self-assessed learning outcomes than their women peers even after accounting for college admission standardized test scores (Ro \& Kim, 2019). Women of color students express feeling unwelcomed, unsupported, and invisible (Espinosa, 2011).

Scholars do not just focus on the challenges and barriers that women of color students have faced in STEM. Rather, some researchers have revealed how and why women of color students stay and succeed in STEM fields (Gonzalez et al., 2020; Ong et al., 2018; Rodriguez et al., 2017). Founded on an asset-based approach, these studies emphasize how institutions should change the White, male-dominated culture of STEM fields through policies and practices rather than attempting to change individual women of color students. For example, studies show that women of color students want and need to create a "surrogate family support system" (Ong et al., 2020, p. 601). By conducting a systematic review of research with 65 empirical studies about women of color undergraduates in engineering, Ong et al. (2020) found that the "sense of family-like support" (e.g., a network that was "a home away from home" or "like family") is vital for women of color to feel a sense of belonging and persist in engineering (p. 601). These community gatherings can happen formally or informally with peers, faculty, or alumni (Ong et al., 2020).

\section{Minority Serving Institutions}

Students of color tend to have distinctive experiences across institutional settings, such as Historically Black Colleges and Universities versus Predominately White Institutions. In the following section, we review the literature on different types of minority serving institutions in the United States and how these institutions serve racially minoritized students, particularly in STEM fields.

Minority Serving Institutions (MSIs) have played a key role in expanding higher education opportunities for students of color and producing a diverse pool of graduates in STEM fields (John \& Stage, 2014). MSIs contain Historically Black Colleges and Universities (HBCUs), Hispanic Serving Institutions (HSIs), Tribal Colleges and Universities (TCUs), and Asian American and Native American Pacific Islander-Serving Institutions (AANAPISIs) (U.S. Department of Education, 2020b). While HBCUs have nurtured Black student success and ultimately have cultivated Black communities in general, these institutions also have contributed to diversifying STEM in the workforce and graduate education (Gasman \& Nguyen, 2014; Perna et al., 2009). The top 20 institutions that award STEM bachelor's degrees to Black students included ten HBCUs in 2006 and 2010 (Gasman \& Nguyen, 2014). In 2016, about 31\% of Black U.S. citizens and permanent residents who obtained S\&E undergraduate degrees did so from HBCUs (National Center for Science and Engineering Statistics, 2019). 
HSIs serve a large population of Hispanic or Latinx ${ }^{5}$ students. Many HSIs were historically Predominately White Institutions (PWIs), but became designated as HSIs after reaching 25\% Hispanic, full-time equivalent enrollment (John \& Stage, 2014). In 2017, there were 523 institutions that were designated HSIs, enrolling $66 \%$ of Latinx undergraduate students (Hispanic Associate of Colleges \& Universities, 2019). HSIs produced 40\% of the STEM bachelor's degrees earned by Latinx students in 2010 (Núñez et al., 2016).

TCUs provide college access primarily to American Indian students. Currently, there are 32 fully accredited TCUs which serve almost 30,000 college students (U.S. Department of Education, 2020a). Most TCUs have associate degree programs (U.S. Department of Education, 2020a); thus, Native American students who want to study STEM majors at the bachelor's level must enroll beyond TCUs. The federal government developed the AANAPISIs program in 2008 (National Commission on Asian American and Pacific Islander Research in Education [NCAAPIRE], 2012). Institutions with at least 10\% of Asian American and Pacific Islander (AAPI) students, a significant percentage of low-income students, or lower than average educational expenditure per student, receive federal grants through this program (NCAAPIRE, 2012).

Racially minoritized STEM students who attend MSIs have expressed positive perceptions of their college experiences (Palmer et al., 2013; Perna et al., 2009), compared to those attending PWIs. STEM students of color develop social support systems and network with their peers and alumni at MSIs (Carpi et al., 2017). For example, Black STEM students at HBCUs have positive relationships with their faculty and perceive HBCUs as nurturing environments (Gasman et al., 2017; Perna et al., 2009). Latinx STEM faculty members implement strategies, such as integrating Latinx students into the culture of STEM disciplines, offering professional networking, and supporting Latinx students beyond STEM majors, from within the university at HSIs (Bensimon et al., 2019). Studies also confirm that women of color STEM students have positive experiences and receive support from their peers and faculty at MSIs (Borum \& Walker, 2012).

Despite the contribution of MSIs in supporting racially minoritized students, these institutions have faced challenges in terms of funding and capacity in attempting to offer sufficient STEM educational opportunities. MSIs have relied heavily on public funding as a source of revenue and have received limited available financial support and space (Espinosa et al., 2018; National Academies of Sciences, Engineering, and Medicine, 2019; Nellum \& Valle, 2015; Nelson \& Frye, 2016). Lack of resources results in a lack of financial support for things like stipends or transportation for students to engage in internships, research, or other learning experiences. MSIs often do not have graduate students and post-doctoral students who can teach undergraduates; thus, laboratory training or undergraduate research opportunities could be more limited than at research universities (Carpi et al., 2017). Although MSIs have promoted gender and racial equity in STEM fields, their faculty and students have suffered from having relatively lower resources than those at predominately White institutions. 


\section{Conceptual Framework}

To better understand how the opportunities of higher education relate to STEM bachelor's degree attainment at a local community level, with a particular focus on racially minoritized women, we apply two conceptual frameworks: (1) intersectionality and (2) geography of education. We briefly explain the two frameworks and offer research questions in the following section.

\section{Intersectionality}

Anti-racism and feminist scholars posit that policy makers and researchers should apply an intersectionality lens to acknowledge "the complexities of oppression" and the "systemic structure of inequality" that women of color have faced (Harris \& Patton, 2019, p. 350; Crenshaw, 1989; Collins, 1990; Collins \& Bilge, 2016). As reviewed in this chapter, policy reports that analyze nation-wide statistics have shown that women, racially minoritized groups, and women of color are underrepresented in STEM education and in the workforce, relative to their share of the U.S. population. A significant body of literature also concludes that these groups have been excluded, stereotyped, and discriminated against in STEM fields (Ong et al., 2011; Ong et al., 2020). Although researchers found that more inclusive teaching and learning pedagogies, faculty mentoring and advising, and a variety of co-curricular opportunities can support women of color STEM undergraduates, these interventions are often limited to fixing individual or classroom environments. There is a dearth of studies to address how location- or community-level structures, such as the geography of educational opportunities, affect women of color STEM students' access, persistence, and degree completion. For example, researchers have not paid close enough attention to whether STEM degree attainment among women of color is evenly or unevenly distributed across the United States. Researchers have not addressed how the opportunities of higher education institutions by types (four-year or two-year, private or public, or MSIs) or the proximity of universities offering STEM degree programs relate to STEM bachelor's degrees among women of color.

In this chapter, we apply an intersectionality framework to secondary, quantitative data. Intersectionality studies have been used primarily in the form of qualitative studies, but scholars increasingly acknowledge the importance of an intersectionality framework in quantitative study design (Schudde, 2018). Intersectional scholars claim that collecting and analyzing quantitative evidence should demonstrate how social systems and power structures differently affect individuals who have intersected marginalized identities (Bauer, 2014; Schudde, 2018). While intersectionality scholars clarify that the contribution of the intersectionality framework is to reveal both "individual- and social-level causes" that reinforce the inequalities and perpetuate the oppression against marginalized groups, many intersectionality studies (both quantitative and qualitative) are limited by an individual-level analysis (Harris \& Patton, 2019). Intersectional 
quantitative researchers suggest that researchers should avoid simply summing up the parts of multiple social categories (Bauer, 2014). Rather, researchers should apply "an intersectional framework to processes or policies" (Bauer, 2014, p. 12). The focus of this chapter is the relationship between the number of STEM bachelor's degrees and the geography of educational opportunities at the community-level, rather than individual-level analysis.

\section{Geography of Education}

Studies on geography of education suggest a substantial geographical variation in the availability of colleges and universities (i.e., two-year vs. four-year, public vs. private) across local communities (Hillman, 2016, 2017; Klasik et al., 2018). The quantity and quality of higher education opportunities provided in local communities was highly associated with the racial/ethnic and socioeconomic compositions of the local population. Hillman (2016) found systematic patterns along lines of race and class, where communities with larger Hispanic populations and lower educational attainment levels tend to have more two-year colleges but fewer four-year colleges nearby. This disparity would affect those who aspire to pursue STEM majors more negatively, given that two-year institutions offer only a limited range of STEM majors (Wang, 2020).

Furthermore, existing studies on the benefits of MSIs to STEM access overlook whether MSIs are close enough to home for racially minoritized, low-income students who aspire to study STEM majors. Dache-Gerbino (2018) argues that many of the most racially segregated and low-income areas do not have MSIs nearby. Social network and familial commitments affect racial minority and lowincome students' college enrollment decisions (Byun et al., 2012; Cox, 2016). By interviewing 16 low-socioeconomic status (SES) Black and Latinx high school students, Cox (2016) found that her study participants experienced the stress of residential mobility throughout their life because of family backgrounds (e.g., immigrant, military) and much more complicated and less stable family configurations than their high-SES or White peers. While low-SES students and students of color aspire to attain four-year college degrees, their family income and employment, financial aid, and residential mobility often prevent them from enrolling in four-year colleges (Cox, 2016; Holland, 2020). These studies revealed low-SES students and students of color in metropolitan and rural areas, in particular, have more barriers to traveling from home to college due to familial obligations and culture.

While the proximity of school to home and residential mobility affects college choice among students of color, women of color students may consider these factors more seriously than their men of color or White peers. Family is one of the important factors in the college choice decision-making process for women of color (Perna et al., 2009). Women of color students who choose STEM majors show a higher level of self-efficacy and academic success from family members' support and encouragement (Zeldin \& Pajares, 2000; Perna 
et al., 2009). For example, literature indicates Latinx culture deeply relies on family support and encouragement; thus, Latinas perceive family as a resource to succeed in college (Contreras Aguirre et al., 2020; Gonzalez et al., 2020). Given that family culture and support is critical to women of color for their success in college, women of color undergraduates may want to choose colleges close to their home.

In this chapter, we do not measure how the distance of universities influence individual students' choice of STEM majors. To shed light on the communitylevel opportunities (or disparities) of higher education, we focus on the community-level opportunities and STEM bachelor's degree attainment for our analysis. We examine four research questions through a community-unit analysis.

Research Questions:

1 Do numbers of STEM bachelor's degree recipients by gender and race/ ethnicity differ by location (Northeast, Midwest, South, and West) in the United States?

2 Do numbers of STEM bachelor's degree recipients by gender and race/ ethnicity relate to the number of different types of higher education institutions (four-year vs. two-year, public vs. private) in a local community after controlling for community characteristics?

3 Do numbers of STEM bachelor's degree recipients by gender and race/ ethnicity relate to the number of Minority Serving Institutions in a local community after controlling for community characteristics?

4 Do numbers of STEM bachelor's degree recipients by gender and race relate to the number of STEM bachelor's degrees offered by higher education institutions after controlling for institutional and community characteristics?

\section{Methods}

\section{Data and Sample}

We analyze a community-level data set to examine how the number of STEM bachelor's degree recipients by gender and race/ethnicity varies across the United States (Research Question 1). To better understand the role of higher education opportunities in STEM bachelor's degree attainment in a community, we examine how the number of STEM bachelor's degree holders relates to the different types of higher education opportunities in a community (Research Questions 2 and 3). Finally, to study the importance of bachelor's level STEM learning opportunities, we examine how the number of STEM bachelor's degree recipients in a local community relates to the total number of STEM bachelor's degrees offered by four-year institutions in a local community (Research Question 4). We draw data from two large-scale national data sets, the U.S. Census Bureau's (2020) American Community Survey (ACS) and the Integrated Postsecondary Education Data System (IPEDS). 
The ACS is a national representative sample with an annual sample size of about 3.5 million addresses. It provides reliable and timely demographic, social, and economic data at both the individual and community level.

We generated a community-level data set based on ACS's Public Use Microdata Sample (PUMS) data to create measures of education attainment by combinations of academic majors at the bachelor's degree level and by gender and race. ${ }^{6}$ PUMS consists of individual records for about $1 \%$ of the total U.S. population, which allows us to generate reliable variables at the community-level. The smallest geographic areas that can be identified in the PUMS are the Public Use Microdata Areas (PUMAs), which are defined by the Census Bureau based on three criteria: (1) each PUMA must have a population of 100,000 or more; (2) PUMAs are based only on aggregations of counties and census tracts and do not cross state boundaries; and (3) boundaries are contiguous (U.S. Census Bureau, 2020). We use PUMAs as analytical units in this study as a proxy of local communities and aggregate individual-level characteristics to the PUMA level. ${ }^{7}$ Our sample includes 982 PUMAs identified $^{2}$ in 2018 ACS PUMS data. Unless otherwise noted, we refer to PUMAs as communities in the rest of the chapter for simplicity.

We use IPEDS to create community-level measures of higher education institutions at the PUMA level. We start with a full sample of U.S. degreegranting higher education institutions in the 2017-18 academic year and then aggregate institution-level characteristics to community-levels based on institutions' geographic locations by PUMA level. Since we are interested in the number of higher education institutions that can be physically and locally accessed, we exclude online-only institutions from the sample (Hillman, 2016). In the analyses of the second and third research questions, our analytical sample includes 490 PUMAs with at least one higher education institution offering STEM bachelor's degrees. ${ }^{8}$

\section{Variables}

The outcome variable is the number of people in the population who are over 25 years old and who have a bachelor's degree in a STEM major. The ACS has detailed information about the field of study for bachelor's degrees received by respondents and we coded these fields into 38 categories that can be largely matched to two-digit ${ }^{9}$ Classification of Instructional Programs (CIP) codes. We define STEM fields as Agriculture, Environment and Natural Resources, Architecture, Computer and Information Sciences, Engineering, Engineering Technologies, Biology and Life Sciences, Mathematics and Statistics, Physical Sciences, Nuclear, Industrial Radiology, and Biological Technologies, Electrical and Mechanic Repairs and Technologies, and Transportation Sciences and Technologies. We examine the outcome measure by six different racial-gender groups: White men, Asian men, URM men, White women, Asian women, and URM women. The URM group includes Black and African American, Hispanic of any race, Native American and 
Indian, and other or two or more races. All the analyses are conducted separately for each of these eight groups for comparison.

For the second research question, the independent variables of interest are variables of communities' higher education opportunities, including number of higher education institutions located in a community by institutional type (i.e., two-year private, two-year public, four-year private, and four-year public) in PUMAs. For the third research question, we measure the number of Minority Serving Institutions as independent variables. Specifically, we identify institutions as Black or African American serving institutions if either their Black or African American enrollment accounts for over 25\% of total enrollment (National Center for Science and Engineering Statistics, n.d.) or they are recognized as Historically Black Colleges or Universities (HBCUs). We define Hispanic Serving Institutions (other minority serving institutions) if their Hispanic enrollment is over $25 \%$ of their total enrollment, and we also define other minority serving institutions if their Asian, Native American or Indian, other or two or more races, and race unknown enrollment is over $25 \%$ of their total enrollment. The remaining institutions are labeled as non-minority serving institutions. For the fourth research question, to measure the STEM educational opportunities, we use the total number of STEM bachelor's degrees offered at four-year higher education institutions.

We also control for a variety of communities' demographic, social, and economic characteristics, including quartiles of the percentage of the nonWhite population, median income, population below the poverty level, number of employees working in STEM occupations, unemployment rate, and indicators of census regions (Northeast, Midwest, South, and West).

\section{Analytical Strategy}

For the first research question, we present the number of STEM bachelor's degree recipients by gender, race/ethnicity and geography. We provide descriptive statistics of STEM bachelor's degree recipients by gender (men, women) and the interaction between gender and race (White men, Asian men, URM men, White women, Asian women, URM women) across four different census regions (Northeast, Midwest, South, West). We also provide the gender and racial composition of each region to demonstrate the underrepresentation of women and URM women. For the second and third research questions, we employ Ordinary Least Squares (OLS) regression and run regressions separately by six racial-gender groups. We examine the relationship between the number of STEM bachelor's degree holders and the number of different types of higher education institutions in a local community after controlling for local community characteristics (Model 1). Keeping outcome and control variables the same, we replace the number of higher education institutions by type with the number of Minority Serving Institutions (Model 2). For the fourth research question, we include the number of STEM bachelor's degrees awarded by higher education institutions in Model 1 and Model 2 to examine the 
relationship between the number of STEM bachelor's degree recipients and the STEM higher education opportunities in a local community.

\section{Findings}

\section{STEM Bachelors' Degree Recipients by Gender, Race, and Geography}

In Table 5.1, we provide an overview of the percentage of STEM bachelor's degree recipients in the Northeast, Midwest, South, and West regions by race/ ethnicity and gender. We also offer the gender and racial population composition of these regions to show the over(under)representation of STEM bachelor's degree holders by gender and race/ethnicity in different regions. Compared to the population share of men and women (49\% vs. $51 \%)$, men have a higher percentage of STEM bachelor's degrees (67\%-70\%) than women $(30 \%-33 \%)$ in all four regions. Within each region, not surprisingly, White men account for the biggest share of STEM bachelor's degree holders. While White men STEM bachelor's degree holders are overrepresented (50\%-58\%) compared to their share of the population (30\% to $37 \%$ ) in each region, White women STEM bachelor's degree holders ( $20 \%$ to $23 \%$ ) are underrepresented compared to their share of the population $(31 \%$ to $38 \%)$ in all four regions. We observe both Asian men $(4 \%-11 \%)$ and Asian women $(2 \%-6 \%)$ STEM bachelor's degree recipients

Table 5.1 STEM Bachelor's Degree Recipients and Population by Gender, Race, and Geographic Region

\begin{tabular}{lcccccccc}
\hline Census region & Men & Women & $\begin{array}{l}\text { White } \\
\text { men }\end{array}$ & $\begin{array}{l}\text { Asian } \\
\text { men }\end{array}$ & $\begin{array}{l}\text { URM } \\
\text { men }\end{array}$ & $\begin{array}{l}\text { White } \\
\text { women }\end{array}$ & $\begin{array}{l}\text { Asian } \\
\text { women }\end{array}$ & $\begin{array}{l}\text { URM } \\
\text { women }\end{array}$ \\
\hline \multicolumn{7}{l}{ STEM Bachelor's Degree Recipients } \\
Northeast & $66.9 \%$ & $33.1 \%$ & $49.6 \%$ & $10.1 \%$ & $7.2 \%$ & $23.0 \%$ & $5.3 \%$ & $4.8 \%$ \\
Midwest & $69.0 \%$ & $31.0 \%$ & $55.0 \%$ & $6.6 \%$ & $7.4 \%$ & $23.1 \%$ & $3.5 \%$ & $4.5 \%$ \\
South & $69.9 \%$ & $30.1 \%$ & $58.0 \%$ & $4.2 \%$ & $7.7 \%$ & $23.2 \%$ & $2.4 \%$ & $4.6 \%$ \\
West & $69.6 \%$ & $30.4 \%$ & $49.9 \%$ & $11.4 \%$ & $8.3 \%$ & $19.8 \%$ & $6.0 \%$ & $4.6 \%$ \\
Populations & & & & & & & & \\
Northeast & $48.6 \%$ & $51.4 \%$ & $32.3 \%$ & $3.9 \%$ & $12.0 \%$ & $34.3 \%$ & $4.1 \%$ & $13.3 \%$ \\
Midwest & $48.6 \%$ & $51.4 \%$ & $34.0 \%$ & $1.8 \%$ & $12.5 \%$ & $35.7 \%$ & $2.0 \%$ & $14.0 \%$ \\
South & $49.2 \%$ & $50.8 \%$ & $37.1 \%$ & $1.0 \%$ & $10.9 \%$ & $38.3 \%$ & $1.2 \%$ & $11.5 \%$ \\
West & $49.4 \%$ & $50.6 \%$ & $30.1 \%$ & $3.7 \%$ & $15.4 \%$ & $30.8 \%$ & $4.1 \%$ & $16.0 \%$ \\
\hline
\end{tabular}

Northeast includes Connecticut, Maine, Massachusetts, New Hampshire, Rhode Island, Vermont, New Jersey, New York, Pennsylvania. Midwest includes Indiana, Illinois, Michigan, Ohio, Wisconsin, Iowa, Nebraska, Kansas, North Dakota, Minnesota, South Dakota, Missouri. South includes District of Columbia, Florida, Georgia, Maryland, North Carolina, South Carolina, Virginia, West Virginia, Alabama, Kentucky, Mississippi, Tennessee, Arkansas, Louisiana, Oklahoma, Texas. West includes Arizona, Colorado, Idaho, New Mexico, Montana, Utah, Nevada, Wyoming, Alaska, California, Hawaii, Oregon, Washington. 
to be overrepresented compared to their shares of the population $(1 \%-4 \%$ for both Asian men and Asian women) in all four regions. Both URM men (7\%-8\%) and URM women (4\%-5\%) STEM bachelor's degree holders have lower representation of URM men $(11 \%-15 \%)$ and URM women $(11 \%-16 \%)$ in the population across all regions. Despite the slight differences across regions, we observe White women, URM women, and URM men are underrepresented among STEM bachelor's degree recipients, compared to their population shares, in all four regions.

\section{STEM Bachelor's Degree Attainment and Geography of Opportunities}

By using OLS regression analyses, we examine how the number of STEM bachelor's degree recipients relates to higher education opportunities (measured by different types of higher education institutions in Model 1 and MSIs in Model 2) and STEM educational opportunities (measured by the total number of STEM bachelor's degrees awarded by four-year institutions) within a local community (measured by PUMAs). We run the OLS regression separately by gender and racial groups (See Table 5.2).

Table 5.2 STEM Bachelor's Degree Attainment and Geography of Opportunities

\begin{tabular}{|c|c|c|c|c|c|c|}
\hline & (2) & (3) & (4) & (6) & (7) & $(8)$ \\
\hline & $\begin{array}{l}\text { White } \\
\text { Men }\end{array}$ & $\begin{array}{l}\text { Asian } \\
\text { Men }\end{array}$ & $\begin{array}{l}\text { URM } \\
\text { Men }\end{array}$ & $\begin{array}{l}\text { White } \\
\text { Women }\end{array}$ & $\begin{array}{l}\text { Asian } \\
\text { Women }\end{array}$ & $\begin{array}{l}\text { URM } \\
\text { Women }\end{array}$ \\
\hline \multicolumn{7}{|l|}{ Model 1} \\
\hline \multirow{2}{*}{$\begin{array}{l}\text { Number of 4-year } \\
\text { public institutions }\end{array}$} & .007 & -.007 & .004 & .003 & .011 & .014 \\
\hline & $(.006)$ & $(.013)$ & $(.008)$ & $(.007)$ & $(.015)$ & $(.009)$ \\
\hline \multirow{2}{*}{$\begin{array}{l}\text { Number of 4-year } \\
\text { private institutions }\end{array}$} & .004 & .007 & $.009 *$ & .007 & $.019 * *$ & $.012^{*}$ \\
\hline & $(.003)$ & $(.007)$ & $(.006)$ & $(.004)$ & $(.008)$ & $(.006)$ \\
\hline \multirow{2}{*}{$\begin{array}{l}\text { Number of 2-year } \\
\text { public institutions }\end{array}$} & $-.008 *$ & -.011 & -.009 & -.007 & $-.023^{*}$ & $-.026 * * *$ \\
\hline & $(.004)$ & $(.011)$ & $(.006)$ & $(.005)$ & $(.013)$ & $(.007)$ \\
\hline \multirow{2}{*}{$\begin{array}{l}\text { Number of 2-year } \\
\text { private institutions }\end{array}$} & -.01 & -.007 & $.020^{*}$ & $-.015^{* *}$ & -.017 & .020 \\
\hline & $(.006)$ & $(.015)$ & $(.011)$ & $(.007)$ & $(.016)$ & $(.012)$ \\
\hline \multirow{2}{*}{$\begin{array}{l}\text { Log (number of } \\
\text { STEM BA degrees) }\end{array}$} & .002 & -.019 & .000 & .009 & .020 & .025 \\
\hline & $(.011)$ & $(.022)$ & $(.016)$ & $(.014)$ & $(.021)$ & $(.017)$ \\
\hline Observations & 487 & 447 & 482 & 483 & 430 & 468 \\
\hline R-squared & .912 & .701 & .761 & .897 & .666 & .72 \\
\hline
\end{tabular}



(2)
(3)
(4)
(6)
(7)
(8)

Model 2

\begin{tabular}{|c|c|c|c|c|c|c|}
\hline \multirow{2}{*}{$\begin{array}{l}\text { Number of Black or } \\
\text { African American } \\
\text { serving institutions } \\
\text { (including HBCU) }\end{array}$} & -.005 & -.000 & .008 & -.005 & -.006 & $.018 * *$ \\
\hline & $(.004)$ & $(.009)$ & $(.007)$ & $(.005)$ & $(.010)$ & $(.008)$ \\
\hline \multirow{2}{*}{$\begin{array}{l}\text { Number of His- } \\
\text { panic serving } \\
\text { institutions }\end{array}$} & .003 & -.007 & $.028 * * *$ & .001 & -.003 & $.019 *$ \\
\hline & $(.005)$ & $(.010)$ & $(.009)$ & $(.006)$ & $(.010)$ & $(.010)$ \\
\hline \multirow{2}{*}{$\begin{array}{l}\text { Number of other } \\
\text { minority serving } \\
\text { institutions }\end{array}$} & -.008 & $.091 * * *$ & -.000 & .005 & $.079 * * *$ & -.005 \\
\hline & $(.010)$ & $(.018)$ & $(.013)$ & $(.011)$ & $(.020)$ & $(.015)$ \\
\hline $\begin{array}{l}\text { Number of non- } \\
\text { minority serving } \\
\text { institutions }\end{array}$ & -.000 & & & $-.009 * * *$ & -.000 & $-.002 *$ \\
\hline \multirow[t]{2}{*}{$-.005^{* *}$} & -.001 & & & & & \\
\hline & $(.001)$ & $(.002)$ & $(.001)$ & $(.001)$ & $(.002)$ & $(.002)$ \\
\hline \multirow{2}{*}{$\begin{array}{l}\text { Log (number of } \\
\text { STEM BA degrees) }\end{array}$} & .005 & -.027 & .001 & .011 & .017 & $.030^{*}$ \\
\hline & $(.011)$ & $(.021)$ & $(.016)$ & $(.013)$ & $(.022)$ & $(.017)$ \\
\hline Observations & 487 & 447 & 482 & 483 & 430 & 468 \\
\hline R-squared & .912 & .712 & .764 & .896 & .672 & .719 \\
\hline
\end{tabular}

Note: Robust standard errors in parentheses. Outcome variables are logarithms of number of population who receive STEM bachelor's degree for each gender and racial group. All models include a full set of control variables: quartiles of the percentage of non-White population, logarithms of total population, median income, population below the federal poverty line, employees working in the STEM occupations, unemployment rate, and dummies of geographic regions. * $\mathrm{p}<0.1 * * \mathrm{p}<0.05 * * * \mathrm{p}<0.01$.

Model 1 from Table 5.2 indicates that there is no statistical relationship between the number of people who obtain STEM bachelor's degrees and the number of four-year public institutions in a community. We find that the number of Asian women and URM women who receive STEM bachelor's degrees increases about $2.0 \%$ and $1.2 \%$, respectively, for every additional four-year private institution in a community. However, the number of Asian women and URM women who receive STEM bachelor's degrees decreases about $2 \%$ and $3 \%$, respectively, for every one unit increase of two-year public institutions in a community. The number of White women who receive STEM bachelor's degrees also decreases about $1.5 \%$ for every one unit increase of two-year private institutions. The number of White men who receive STEM bachelor's degrees decreases about $0.8 \%$, for every additional 
two-year public institution in a community. The number of URM men who obtain STEM bachelor's degrees is positively related to the number of both four-year and two-year private schools in a local community.

Model 2 in Table 5.2 presents the relationship between the number of STEM bachelor's degrees attained by race/ethnicity and gender and the number of Minority Serving Institutions. We found that the number of people of color (Asian women, URM women, Asian men, and URM men) who obtain STEM bachelor's degrees is significantly positively associated with the number of Minority Serving Institutions in a local community. Specifically, for every additional number of Black or African American serving institutions (including HBCUs), the number of URM women who receive STEM bachelor's degrees in a local community increases $1.8 \%$. For every additional number of Hispanic Serving Institutions, the number of URM women who attain STEM bachelor's degree increases 1.9\% and the number of URM men who receive STEM bachelor's degrees increases 2.8\%. For every additional number of other minorities serving institutions, the number of Asian men and Asian women who attain STEM bachelor's degree increases $9.1 \%$ and $7.9 \%$, respectively. The number of non-minority serving institutions (i.e., Predominately White Institutions) is negatively associated with the number of White women, Asian women, and Asian men who obtain STEM bachelor's degrees in a local community. In terms of STEM educational opportunities, we find that the number of URM women who attain STEM bachelor's degrees is significantly positively associated with the number of STEM degrees that universities awarded in a community after controlling for number of minorities serving institutions and local community characteristics.

We acknowledge the limitations of our study. Although we recognize the difference in access and success among different URM groups, we combine the groups in the analysis due to sample size and missing cases. We also lump together different types of minority serving institutions into other minority serving institutions, which have served different racial and ethnic groups in the United States. We address the needs of future research to examine different educational opportunities for specific racial and ethnic gender groups in the following section.

\section{Discussion and Implications}

In this chapter, we examine how the number of residents who obtain STEM bachelor's degrees relates to the different types of higher education institutions (two-year vs. four-year, private vs. public), different types of Minority Serving Institutions, and number of STEM bachelor's degrees offered by four-year institutions in local communities. We discuss the findings with existing literature and offer implications for future research, policy, and practices.

First, we find that communities that have more Asian women and URM women residents with STEM bachelor's degrees have more four-year private institutions, but we did not find the same pattern with four-year public institutions. Second, when a community has more two-year public institutions, the 
community has fewer women of color residents with STEM bachelor's degrees. We want to emphasize that these findings do not imply any causal relationship. These findings relate to previous research in that the opportunities of higher education institutions have systematic patterns along lines of race and class (Dache-Gerbino, 2018; Hillman, 2016; Klasik et al., 2018). For example, Hillman (2016) found that communities with more two-year colleges but fewer four-year colleges nearby tend to have larger Hispanic populations and lower educational attainment. Our study offers a more nuanced relationship: communities having more four-year private colleges, but fewer two-year public colleges, have more STEM bachelor's attainment among women of color.

This finding may not be surprising in that communities with more higher education institutions have more residents with STEM bachelor's degrees. We only find that communities having more four-year higher education opportunities (and fewer two-year colleges) tend to have more Asian women, URM women, and URM men residents who earn STEM bachelor's degrees. Interestingly, we do not find this pattern with White women, White men, and Asian men. More research is needed to explore whether the different context of local communities may be attractive to women of color with STEM degrees. Although we control for a variety of communities' demographic, social, and economic characteristics in our analysis, communities that have more four-year private institutions may offer a more gender-balanced workforce, better K-12 educational opportunities for children, or more politically liberal living environment.

We also find communities with more MSIs have more racially minoritized residents who receive STEM bachelor's degrees, even after taking into account the structural diversity of local populations (i.e., the percentage of the non-White population). Again, this result does not suggest that the residents graduate from MSIs. Racially minoritized residents may receive their degrees from any type of institutions (and any locations), but seem to live in communities which offer more MSIs. As we acknowledge as the limitation of this study, we do not know specifically whether communities having more HBCUs have more Black residents with STEM bachelor's degrees or whether communities having more HSIs have more Hispanic residents with STEM bachelor's degrees. We also do not know the reason of the positive correlation. More studies focusing on individual-level analysis through both qualitative and quantitative studies are needed to examine whether the proximity of MSIs encourages racially minoritized students to access and to obtain STEM bachelor's degrees and how the relationship differs by gender. More studies need to address how the close ties to family among women of color affect how far they choose to travel to study for college education and STEM majors.

We also offer implications for policy and practice. We describe that the distribution of STEM bachelor's degree recipients by racial-gender groups does not vary across the four regions in the United States (Table 5.1). In all regions, URM men and women who obtain STEM bachelor's degrees are underrepresented, compared to their share of the population. For example, the West region, which has a higher percentage of the URM population, still contains similar 
percentages of URM STEM bachelor's degree recipients compared to other regions. Thus, efforts to increase the number of URM degree holders, particularly URM women, should continue to receive national attention regardless of region.

While the shortage of women of color in STEM fields happens everywhere, we also learn from this study that communities offering more four-year higher education institutions and MSIs have more women of color residents with STEM bachelor's degrees. When administrators and faculty offer STEM outreach programs to recruit more women of color students, we suggest that they should actively reach out to communities with fewer four-year institutions but more two-year institutions, or communities having a lack of higher education opportunities in general. The professional association for women and URM scientists and engineers also calls for offering more resources to communities with lack of higher education and STEM education opportunities.

\section{Conclusion}

The Department of Education in the United States advises that "... no matter where children live, they have access to quality learning environments. A child's zip code should not determine their STEM fluency" (U.S. Department of Education, 2020c). To achieve this goal, it is necessary to study how the geography of higher educational opportunities relates to STEM bachelor's degree attainment in local communities. In this chapter, we find that the number of residents who obtain STEM bachelor's degrees varies by the opportunities of higher education institutions in local communities. Particularly, the number of women of color residents who have STEM bachelor's degrees is positively associated with the number of four-year private institutions, but negatively related to the number of two-year public institutions. The availability of MSIs also positively relates to the number of STEM bachelor's holders among both men and women of color in a local community. The number of URM women STEM bachelor's degree holders is positively related to the number of STEM bachelor's degrees awarded by four-year institutions. Our study indicates that the opportunities of higher education, particularly four-year private institutions and MSIs, have a positive relationship with STEM success among women of color in a local community. Policy makers and scholars should pay attention to the disparities in the opportunities of higher education institutions to promote gender and racial equity in STEM education and workforce.

\section{Notes}

1 We use the term, "underrepresented racial minorities (URM)," when we include Blacks, Hispanics, American Indian/Alaska Natives, and Native Hawaiian or Other Pacific Islanders, and two or more races.

2 We use the terms "racially minoritized women" and "women of color" interchangeably when we include Asian American women and URM women. 
3 In the Status and Trends in the Education of Racial and Ethnic Groups 2018 report, STEM fields include biological and biomedical sciences, computer and information sciences, engineering and engineering technologies, mathematics and statistics, and physical sciences and science technologies.

4 As per the National Center for Science and Engineering Statistics 2019 report, degrees awarded data in science and engineering $(\mathrm{S} \& \mathrm{E})$ fields include astronomy, chemistry, physics, atmospheric sciences, earth sciences, ocean sciences, mathematics and statistics, computer sciences, agricultural sciences, biological sciences, psychology, social sciences, and engineering. The difference in the definition of S\&E and STEM is that S\&E includes social sciences; thus, there is a higher percentage of URM S\&E degree attainment.

5 We use the term "Latinx" to refer to students who self-identified as Hispanic or who trace their ancestry to Mexico, Central America, South America, Spain, and Caribbean islands, such as Cuba and Puerto Rico (Salinas \& Lozano, 2017).

6 The ACS PUMS data used in this study is download from the IPUMS USA database (Ruggles et al., 2020).

7 Person weights are used in aggregating individual-level variables to PUMA-level variables.

8 The sample size of each model varies ranging from 430 to 490 because outcome variables in some models (e.g., Asian women STEM bachelor's degree attainments in PUMAs) have missing values.

9 The Classification of Instructional Programs (CIP) codes, which was developed by the U.S. Department of Education's National Center for Education Statistics (NCES) is widely used in tracking and reporting fields of study and program completion in the Integrated Postsecondary Education Data System (IPEDS) (NCES, 2020).

\section{References}

Adelman, C. (1999). Answers in the tool box. Academic intensity, attendance patterns, and bachelor's degree attainment, (Report No. PLLI-1999-8021). National Institute on Postsecondary Education, Libraries, and Lifelong Learning.

Adelman, C. (2006). The toolbox revisited: Paths to degree completion from high school through college [Report]. U.S. Department of Education.

Bauer, G. R. (2014). Incorporating intersectionality theory into population health research methodology: Challenges and the potential to advance health equity. Social science \& medicine, 110, 10-17.

Bensimon, E. M., Dowd, A. C., Stanton-Salazar, R., \& Dávila, B. A. (2019). The role of institutional agents in providing institutional support to Latinx students in STEM. The Review of Higher Education, 42(4), 1689-1721. https://doi.org/10.1353/rhe.2019.0080

Borum, V., \& Walker, E. (2012). What makes the difference? Black women's undergraduate and graduate experiences in mathematics. The Journal of Negro Education, 81 (4), 366-378. https://www.jstor.org/stable/10.7709/jnegroeducation.81.4.0366

Bozick, R., \& Ingels, S. J. (2007). Mathematics coursetaking and achievement at the end of high school: Evidence from the Education Longitudinal Study of 2002, (Report No. 2008-2319). National Center for Education Statistics.

Byun, S. Y., Meece, J. L., \& Irvin, M. J. (2012). Rural-nonrural disparities in postsecondary educational attainment revisited. American Educational Research Fournal, 49(3), 412-437.

Carlone, H. B., \& Johnson, A. (2007). Understanding the science experiences of successful women of color: Science identity as an analytic lens. Fournal of Research in Science Teaching, 44(8), 1187-1218.

Carpi, A., Ronan, D. M., Falconer, H. M., \& Lents, N. H. (2017). Cultivating minority scientists: Undergraduate research increases self-efficacy and career ambitions for underrepresented students in STEM. Fournal of Research in Science Teaching, 54(2), 169-194. 
Chen, X., \& Weko, T. (2009). Students who study science, technology, engineering, and mathematics (STEM) in postsecondary education, (Report No. 2009-2161). National Center for Education Statistics.

Collins, P. H. (1990). Black feminist thought: Knowledge, consciousness, and the politics of empowerment. Routledge.

Collins, P. H., \& Bilge, S. (2016). Intersectionality (Key Concepts). Polity.

Contreras Aguirre, H. C., Gonzalez, E., \& Banda, R. M. (2020). Latina college students' experiences in STEM at Hispanic-serving institutions: Framed within Latino critical race theory. International Fournal of Qualitative Studies in Education, 1-14.

Cox, R. D. (2016). Complicating conditions: Obstacles and interruptions to lowincome students" college "choices." The Fournal of Higher Education, 87(1), 1-26.

Crenshaw, K. W. (1989). Demarginalizing the intersection of race and sex: A Black feminist critique of antidiscrimination doctrine, feminist theory and antiracist politics. The University of Chicago Legal Forum, 140(1), 139-167.

Dache-Gerbino, A. (2018). College desert and oasis: A critical geographic analysis of local college access. Fournal of Diversity in Education, 11(2), 97-116.

DeAro, J., \& Camacho, E. T. (n.d.) ADVANCE: Organizational change for gender equity in STEM academic professions (ADVANCE). National Science Foundation. http://nsf.gov/ADVANCE

Espinosa, L. L. (2011). Pipelines and pathways: Women of color in undergraduate stem majors and the college experiences that contribute to persistence. Harvard Educational Revierw, 81(2).

Espinosa, L. L., Kelchen, R., \& Taylor, M. (2018). Minority serving institutions as engines of upward mobility [Issue Brief]. American Council on Education. https:// vtechworks.lib.vt.edu/bitstream/handle/10919/86902/MSIEnginesUpwardMobility. pdf? sequence $=1$ \&isAllowed $=y$

Gasman, M., \& Nguyen, T. (2014). Historically Black colleges and universities (HBCUs): Leading our nation's effort to improve the science, technology, engineering, and mathematics (STEM) pipeline. Texas Education Review, 2(1), 75-89.

Gasman, M., Nguyen, T. H., Conrad, C. F., Lundberg, T., \& Commodore, F. (2017). Black male success in STEM: A case study of Morehouse College. Fournal of diversity in higher education, 10(2), 181.

Gonzalez, E. M., Fernandez, F., \& Wilson, M. (Eds.). (2020). An asset-based approach to advancing Latina students in STEM: Increasing resilience, participation, and success. Routledge.

Harris, J. C., \& Patton, L. D. (2019). Un/doing intersectionality through higher education research. The Fournal of Higher Education, 90(3), 347-372.

Hillman, N. W. (2016). Geography of college opportunity: The case of education deserts. American Educational Research Fournal, 53(4), 987-1021. https://doi.org/10. 3102/0002831216653204

Hillman, N. W. (2017). Geospatial analysis in higher education research. In M. Paulsen (Ed.), Higher education: Handbook of theory and research (pp. 529-575). Springer.

Hispanic Association of Colleges \& Universities. (2019). 2019 fact sheet: Hispanic higher education and HSIs. https://www.hacu.net/hacu/HSI_Fact_Sheet.asp

Holland, M. M. (2020). Framing the search: How first-generation students evaluate colleges. The Fournal of Higher Education, 91(3), 378-401

John, G., \& Stage, F. K. (2014). Minority-serving institutions and the education of U.S. underrepresented students. New Directions for Institutional Research, 158. https://doi.org/ 10.1002/ir.20046

Kim, A. Y., Sinatra, G. M., \& Seyranian, V. (2018). Developing a STEM identity among young women: A social identity perspective. Review of Educational Research, 88(4), 589-625. 
Klasik, D., Blagg, K., \& Pekor, Z. (2018). Out of the education desert: How limited local college options are associated with inequity in postsecondary opportunities. Social Sciences, 7(9). https://doi.org/10.3390/socsci7090165

Ko, L. T., Kachchaf, R. R., Ong, M., \& Hodari, A. K. (2013, January). Narratives of the double bind: Intersectionality in life stories of women of color in physics, astrophysics and astronomy. AIP Conference Proceedings, 1513(1), 222-225.

Malcom, L., \& Malcom, S. (2011). The double bind: The next generation. Harvard Educational Reviewe, 81(2), 162-172.

McGee, E. O. (2016). Devalued Black and Latino racial identities: A by-product of STEM college culture? American Educational Research Fournal, 53(6), 1626-1662.

McGee, E. O., \& Martin, D. B. (2011). "You would not believe what I have to go through to prove my intellectual value!" Stereotype management among academically successful Black mathematics and engineering students. American Educational Research Fournal, 48(6), 1347-1389.

Miller, P. M. (2012). Mapping educational opportunity zones: A geospatial analysis of neighborhood block groups. The Urban Review, 44(2), 189-218.

National Center for Education Statistics. (2020). IPEDS Classification of Instructional Programs (CIP). https://nces.ed.gov/ipeds/cipcode/default.aspx?y=56

National Academies of Sciences, Engineering, and Medicine. (2019). Minority serving institutions: America's underutilized resource for strengthening the STEM workforce (L. L. Espinosa, K. McGuire, \& L. M. Jackson, Eds.). National Academies Press.

National Center for Science and Engineering Statistics. (2019). Women, minorities, and persons with disabilities in science and engineering: 2019, (Report No. 19-304). National Science Foundation. https://www.nsf.gov/statistics/wmpd

National Center for Science and Engineering Statistics. (n.d.). Women, minorities, and persons with disabilities in science and engineering. National Science Foundation. https://ncses.nsf.gov/pubs/nsf19304/technical-notes\#minority-serving-institutions

National Commission on Asian American and Pacific Islander Research in Education. (2012). Asian American and Native American Pacific Islander-serving institutions: Areas of growth, innovation, and collaboration. https://files.eric.ed.gov/fulltext/ ED573710.pdf

National Science Board. (2007). A national action plan for addressing the critical needs of the U.S. science, technology, engineering, and mathematics education system. National Science Foundation.

Nellum, G. J., \& Valle, K. (2015). Government investment in public Hispanic-serving institutions [Issue Brief]. American Council on Education.

Nelson, C. A., \& Frye, J. R. (2016). Tribal College and University funding: Tribal sovereignty at the intersection of federal, state, and local funding [Issue Brief]. American Council on Education.

Núñez, A. M., Crisp, G., \& Elizondo, D. (2016). Mapping Hispanic-serving institutions: A typology of institutional diversity. The Fournal of Higher Education, 87(1), 55-83.

Oakes, J. (2003). Critical conditions for equity and diversity in college access: Informing policy and monitoring results [Research Paper]. University of California Berkeley All Campus Consortium on Research for Diversity. https://escholarship.org/uc/item/427737xt

Ong, M. (2005). Body projects of young women of color in physics: Intersections of gender, race, and science. Social problems, 52(4), 593-617.

Ong, M. (2011). The status of women of color in computer science. Communications of the $A C M, 54(7), 32-34$.

Ong, M., Jaumot-Pascual, N., \& Ko, L. T. (2020). Research literature on women of color in undergraduate engineering education: A systematic thematic synthesis. Fournal of Engineering Education, 109(3), 581-615. https://doi.org/10.1002/jee.20345 
Ong, M., Smith, J. M., \& Ko, L. T. (2018). Counterspaces for women of color in STEM higher education: Marginal and central spaces for persistence and success. Journal of Research in Science Teaching, 55(2), 206-245.

Ong, M., Wright, C., Espinosa, L., \& Orfield, G. (2011). Inside the double bind: A synthesis of empirical research on undergraduate and graduate women of color in science, technology, engineering, and mathematics. Harvard Educational Review, 81(2), 172-209.

Ovink, S. M., \& Veazey, B. D. (2011). More than "getting us through:" A case study in cultural capital enrichment of underrepresented minority undergraduates. Research in Higher Education, 52(4), 370-394.

Palmer, R. T., Maramba, D. C., \& Gasman, M. (Eds.). (2013). Fostering success of ethnic and racial minorities in STEM: The role of minority serving institutions. Routledge.

Pawley, A. L. (2019). Learning from small numbers: Studying ruling relations that gender and race the structure of US engineering education. Fournal of Engineering Education, 108(1), 13-31.

Perna, L., Lundy-Wagner, V., Drezner, N. D., Gasman, M., Yoon, S., Bose, E., \& Gary, S. (2009). The contribution of HBCUS to the preparation of African American women for Stem careers: A case study. Research in Higher Education, 50(1), 1-23.

Riegle-Crumb, C., \& King, B. (2010). Questioning a white male advantage in STEM: Examining disparities in college major by gender and race/ethnicity. Educational Researcher, 39(9), 656-664.

Ro, H. K., \& Kim, S. (2019). College experiences and learning outcomes of women of color engineering students in the United States. International Fournal of Gender, Science and Technology, 11(1), 55-82.

Ro, H. K., Knight, D. B., \& Loya, K. I. (2016). Exploring the moderating effects of race and ethnicity on the relationship between curricular and classroom experiences and learning outcomes in engineering. Fournal of Women and Minorities in Science and Engineering, 22(2).

Ro, H. K., \& Loya, K. I. (2015). The effect of gender and race intersectionality on student learning outcomes in engineering. The Review of Higher Education, 38(3), 359-396.

Rodriguez, S. L., Cunningham, K., \& Jordan, A. (2017). What a scientist looks like: How community colleges can utilize and enhance science identity development as a means to improve success for women of color. Community College Fournal of Research and Practice, 41(4-5),232-238.

Ruggles, S. Flood, S., Goeken, R., Grover, J., Meyer, E., Pacas, J., \& Sobek, M ... (2020). IPUMS USA: Version 10.0 [Data set]. IPUMS USA. https://doi.org/10. 18128/D010.V10.0

Salinas, C., Jr., \& Lozano, A. (2017). Mapping and recontextualizing the evolution of the term Latinx: An environmental scanning in higher education. Fournal of Latinos and Education. Advance online publication. http://dx.doi.org/10.1080/15348431. 2017.1390464

Sax, L. J., Kanny, M. A., Riggers-Piehl, T. A., Whang, H., \& Paulson, L. N. (2015). "But I'm not good at math": The changing salience of mathematical self-concept in shaping women's and men's STEM aspirations. Research in Higher Education, 56(8), 813-842.

Schudde, L. (2018). Heterogeneous effects in education: The promise and challenge of incorporating intersectionality into quantitative methodological approaches. Review of Research in Education, 42(1), 72-92.

Seymour, E., \& Hewitt, N. (1997). Talking about leaving. Westview Press.

Smith, P. E. (n.d.). Broadening participation in engineering (BPE). National Science Foundation. https://www.nsf.gov/funding/pgm_summ.jsp?pims_id=505632 


\section{Hyun Kyoung Ro, Yi Meng, and Qiong Zhu}

Spellings, M. (2006). A test of leadership: Charting the future of U.S. higher education. U.S. Department of Education.

Szelényi, K., Bresonis, K., \& Mars, M. M. (2016). Who am I versus who can I become?: Exploring women's science identities in STEM Ph.D. programs. The Review of Higher Education, 40(1), 1-31.

Tate, W. F.IV, (2008). "Geography of opportunity": Poverty, place, and educational outcomes. Educational Researcher, 37(7), 397-411.

Toulmin, C. N., \& Groome, M. (2007). Building a science, technology, engineering and math agenda. National Governors Association.

U.S. Census Bureau. (2020). Understanding and using the American Community Survey public use microdata sample files: What data users need to know. U.S. Government Printing Office. https:// www.census.gov/content/dam/Census/library/publications/2020/acs/acs_pums_hand book_2020.pdf

U.S. Congress Joint Economic Committee. (2012). STEM education: Preparing for the jobs of the future [Report]. https://www.jec.senate.gov/public/_cache/files/6aaa7elf-9586-47be-82 e7-326f47658320/stem-education - preparing-for-the-jobs-of-the-future-.pdf

U.S. Department of Education. (2019, February 28). Hispanic-serving institutions - science, technology, engineering, or mathematics and articulation program s. https:// www2.ed.gov/programs/hsistem/index.html

U.S. Department of Education. (2020a). 2010 review of federal agencies' support to tribal colleges and universities. https://sites.ed.gov/whiaiane/tribes-tcus/tribal-colle ges-and-universities/

U.S. Department of Education. (2020b). United States Department of Education lists of postsecondary institutions enrolling populations with significant percentages of undergraduate minority students. https://www2.ed.gov/about/offices/list/ocr/edli te-minorityinst.html

U.S. Department of Education. (2020c). Science, technology, engineering, and math, including computer science. https://www.ed.gov/stem

U.S. Department of Education. (2020, August 10). Minority science and engineering improvement program. https://www2.ed.gov/programs/iduesmsi/awards.html

Wang, X. (2020). On my own: The challenge and promise of building equitable STEM transfer pathways. Harvard Education Press.

Wang, M. T., Eccles, J. S., \& Kenny, S. (2013). Not lack of ability but more choice: Individual and gender differences in choice of careers in science, technology, engineering, and mathematics. Psychological science, 24(5), 770-775.

Wilkins-Yel, K. G., Hyman, J., \& Zounlome, N. O. (2019). Linking intersectional invisibility and hypervisibility to experiences of microaggressions among graduate women of color in STEM. Fournal of Vocational Behavior, 113, 51-61.

Women in Engineering ProActive Network. (n.d.) About WEPAN. https://www.wepa n.org/page/aboutwepan

Zeldin, A. L., \& Pajares, F. (2000). Against the odds: Self-efficacy beliefs of women in mathematical, scientific, and technological careers. American Educational Research Fournal, 37, 215-246 


\title{
6 A Comprehensive Approach to Addressing Gender Equity in STEM Subjects at Four-Year Universities in England
}

\author{
Hyun Kyoung Ro, Frank Fernandez and Benjamin Alcott
}

England has invested to develop a highly qualified and diversified workforce in science, technology, engineering, and mathematics (STEM) fields (Crawford et al., 2011; Smith, 2011). Multiple national initiatives, such as Girls into Science and Technology (GIST) and Women into Science Engineering (WISE), have been implemented to increase women's participation in STEM subjects in England (Smith, 2011; WISE Campaign, 2019, 2020). Despite these national efforts, women are still underrepresented in STEM. Becoming a matter of national concern, politicians have voiced their worries over the economy's overall health and security due to the inadequate number of women in STEM fields (Arnett, 2015). Similarly, the Royal Academy of Engineering argued that U.K. policymakers should improve the underrepresentation of women and minorities and should address its implications on the nation's global competitiveness (Harrison, 2012).

As access to higher education has been expanded in England (Callender, 2006; Greenaway \& Haynes, 2003), women's participation in higher education has increased. Women outperform men on key educational benchmarks. They are more likely to enroll and persist in college than men and they are more likely to obtain degrees and enroll in graduate schools than men in England (Archer et al., 2001; Chowdry et al., 2013; Teachman, 2002). Despite these educational achievements among women, they remain underrepresented in STEM fields (Chowdry et al., 2008; Smith 2011). Women accounted for 16\% of the technology workforce and 10\% of the engineering workforce in 2019 in the United Kingdom (WISE Campaign, 2019). Like other countries in this volume, the United Kingdom is unlikely to address gender inequalities in the labor market without first attending to educational inequalities.

Scholars have argued that women have been kept away from STEM subjects because of systemic and cultural components of STEM disciplines rather than individuals' interests or abilities in post-industrial countries including England (Butz et al., 2006; Gago et al., 2005). Historically, researchers found that women students were underrepresented in STEM fields because of their relatively weak mathematics achievement (e.g., Berryman, 1983). More recently, however, researchers have found that academic achievement in mathematics and science does not appear to account for gender differences in entry into

DOI: $10.4324 / 9781003053217-11$ 
STEM subjects in the United States (Riegle-Crumb et al., 2012; Xie \& Shauman, 2003). Also, scholars claim that there is no gender difference in interest in science subjects at an early age, but the masculine culture in science subjects dissuades women from studying STEM subjects in England (Archer et al., 2017; Kelly, 1985). While studies have documented gender disparities in STEM subjects in England (Smith, 2011), there is still a need for considering more comprehensive ways to promote gender equalities in STEM.

In this chapter we offer a comprehensive overview of women students' pathways to (or away from) studying STEM subjects in England. We include initial childhood intentions to enroll in STEM subjects, prior academic achievement in mathematics subjects (e.g., performance on A-level exams), and enrollment in STEM programs at universities, including prestigious Russell Group universities. We use data from the British Department of Education's Longitudinal Study of Young People in England (also known as Next Steps) to address STEM subject pathways from childhood to higher education. Based on our findings, we seek to provide implications for other post-industrial countries, which face similar challenges in terms of a lack of women in STEM fields. We offer implications on how nations can encourage students, parents, teachers, and faculty to promote women's participation in STEM subjects by considering both K-12 and higher education contexts.

\section{Context and Literature Review}

In this section, we first consider the secondary and postsecondary education context which can shape students' enrollment patterns and subject choices in England. We then focus on class and gender differences in enrollment patterns.

\section{Secondary and Postsecondary Education Context in England}

England has a national school curriculum and a central organization administering applications, making both school examinations and undergraduate admissions processes highly uniform for students across the country. One key feature of this education system is that students begin to specialize in subjects from an early age. During eighth grade, students select 10 subjects - from a range of approximately 30 options - on which they are tested at the end of the tenth grade in examinations known as General Certificates of Secondary Education (henceforth GCSEs). Schooling ceases to be compulsory after these exams; those who do not pass five or more GCSEs - around two-fifths in recent years (House of Commons Education Committee, 2013) - tend either to enter employment or leave the standard high school system, attending further education institutions in order to retake these exams or study vocational courses. Thus, students hoping to progress beyond the compulsory stages of education are required to choose appropriate GCSE subjects at the end of eighth grade and perform well in those subjects at the end of tenth grade. GCSEs provide a strong predictor of future university attendance (Chowdry et 
al., 2013), operating as a "symbolic and material currency in terms of future educational progression" (Davey \& Fuller, 2013, p. 3.1).

Students that pass at least five GCSEs are able to continue to the final two years of high school to take Advanced Levels exams (henceforth A-levels). Students choose three or four A-level subjects, can only study those for which they took GCSEs, and must select certain ones in order to study a particular discipline at the university. For example, students hoping to study medicine at the university need to take extended-science GCSEs as well as mathematics and biology at A-level. In their university applications, students must specify which discipline they plan to study. Students do not take introductory classes across a range of subjects during their degree programs; instead, they only study courses in either a single- or dual-subject program from the outset.

All undergraduate applications are managed by a single organization: the Universities and Colleges Admissions Service (henceforth UCAS). The application process is largely uniform across institutions: universities have access to candidates' personal statements, anticipated A-level results (as predicted by schoolteachers), and GCSE results. Only a minority of institutions use interviews to further screen applicants. UCAS has been in place for 20 years, GCSE exams for 28 years, and A-levels for over 60 years. For two decades, then, the undergraduate admissions process for English universities has followed a consistent pattern with a uniform process. The system is clear, but it requires students to envisage coherent academic trajectories and perform well in examinations from mid-adolescence.

\section{Prestigious Universities in England}

England has internationally recognized, prestigious universities in its higher education system (Shanghai Ranking Consultancy, 2014; Times Higher Education, 2015; U.S. News and World Reports, 2015). The Russell Group is one common means of classifying university prestige in England. While not an objective signifier of university quality, 22 of the 24 Russell Group universities are ranked among the top 30 U.K. universities in the Times' (2015) league tables. And, four are in the top 10 universities in the world, 15 are in the top 100, and all 24 members of the Russell Group are ranked among the top 250 universities in the world according to the 2018 QS World University Rankings (The Russell Group of Universities, n.d.).

Students' social class is one of the factors that allow (or prevent) access to Russell Group universities. Researchers found that low-socioeconomic status (low-SES) applicants are less likely both to apply and be admitted to Russell Group universities (Boliver, 2015; Reay et al., 2010). Ethnic minority students also were less likely to be admitted to Russell Group universities, even after accounting for the academic subject or program to which they applied (Boliver, 2013, 2016; Hemsley-Brown, 2015). Access to the Russell Group may in turn reinforce class and ethnic disparities, given that graduates of Russell Group universities are more likely to earn high salaries than students from 
other universities in England (Chevalier \& Conlon, 2002). Researchers have suggested that more studies examine how both family backgrounds and primary or secondary education influence students' readiness and access to study STEM subjects (Engberg \& Wolniak, 2013; Nunes et al., 2017; Ro et al., 2018) at prestigious universities or non-prestigious universities (Reay, 1998; Vincent et al., 2008; Walker \& Clark, 2010). However, few studies examine how the relationship between STEM subject choice and the selectivity of institution admission varies by gender.

\section{Class Disparities in University Enrollment}

Although student enrollment at higher education institutions in the United Kingdom has slowed down since 2000 (Bolton, 2020), the provision of university education has increased precipitously over the past half century. The number of universities tripled between 1960 and 2000; around 20 institutions were built in the 1960s, and 35 polytechnics were re-accredited as universities in 1992 (Greenaway \& Haynes, 2003). This growth in supply has been accompanied by a commensurate growth in demand. In 2000, student enrollment in the United Kingdom stood at 2 million, representing a fivefold increase since the 1960s (Greenaway \& Haynes, 2003). The proportion of citizens aged 18-22 who were enrolled at a university rose from 5\% in 1960 to $17 \%$ in 1990 and then to $33 \%$ in 2000 (Callender, 2006).

The long-term growth in application numbers should not mask that participation in higher education is highly stratified (Anders, 2012; Archer et al., 2003; Ball, 2008). To date, researchers in England have considered various dimensions of disparity. Enrollment rates have not been shown to differ substantially by region and distance from a university (Gibbons \& Vignoles, 2012), although they do differ greatly according to neighborhood deprivation and parental income (Singleton, 2010; Vignoles \& Powdthavee, 2009). Between the 1960s and 1980s, academic achievement became less predictive and social class more predictive of university applications (Machin \& Vignoles, 2004), a trend that continued into the 1990s (Blanden \& Machin, 2004; Galindo-Rueda et al., 2008; Glennerster, 2002). By 2009, students from the most advantaged quintile of households were six times more likely to attend university than those from the least advantaged quintile (Vignoles \& Powdthavee, 2009).

\section{Factors Shaping Gender Disparities in STEM Subjects at Prestigious Universities}

While men are consistently less likely to enroll in an undergraduate course than women (Archer et al., 2001; Chowdry et al., 2013), women are less likely to study STEM subjects than men (Smith, 2011). The first factor that affects gender disparities in STEM subject choice, particularly at prestigious universities, is students' social class. Class-based educational inequality of access to prestigious universities has been extensively documented (for example, Anders, 2012; Ball 
et al., 2002; Boliver et al., 2017; Gorard et al., 2006; Reay, 1998), yet there is a lack of research focusing on gender gaps in the intersection between subject choice and institutional prestige. Disparities in social class can be reinforced over time as richer students tend to gain more access to prestigious universities (Boliver, 2011; Hussein, McNally, \& Telhaj, 2009).

Subject choice also plays a role: students who earn degrees in STEM fields tend to have higher earnings than those in social science and humanities fields (Chevalier, 2011; Walker \& Zhu, 2011). In turn, the income benefits of STEM degrees can strengthen the selectivity of institutions. Using the National Longitudinal Survey of Youth in the United States, Davies and Guppy (1997) examine processes by which students enter lucrative fields of study, selective colleges, and lucrative fields within selective colleges. They classify, according to mean monthly income, 15 fields of study as "lucrative." They find that students' SES does not relate to access to lucrative fields after controlling for other background factors. However, SES predicts enrollment in selective colleges and lucrative fields within selective colleges. Few studies have addressed the intersection between enrollment at prestigious institutions and major choice by gender. One exception is Ro et al. (2018), who found that women students are less likely to study STEM subjects when they study at prestigious universities in England. Thus, it is critical to have more studies that examine the drivers of socioeconomic disparities between men and women in the intersection between STEM subject choice and prestigious institutional enrollment.

The second factor that researchers have examined in relation to access to postsecondary education is students' prior curricular exposure and academic achievement. Achievement differences tend to broaden throughout pre-elementary, elementary, and secondary education and it may be too late by secondary school to address university readiness gaps (Blanden \& Machin, 2004; Feinstein, 2003; Heckman \& Lochner, 2000; Jerrim \& Vignoles, 2013). However, previous studies of subject choice and university enrollment examined achievement gaps, especially in mathematics and science proficiency, at the secondary school level without addressing achievement at earlier educational stages. College admissions tests may overlook the cumulative effect of early-stage academic achievement and secondary educational curricula on university enrollment and subject selection (ACT, 2010; Zwick, 2006). More studies are needed to examine how students' earlier curricular experiences and achievement shapes their subject choice at a university, which may differ by gender.

The third factor is the culture or context of STEM disciplines rather than students' individual attributes. Researchers have raised the issue that secondary educational curricula and teachers' pedagogies and attitudes tend not to relate to the interests and values of women (Calabrese et al., 2008; Tan et al., 2013). Scholars argue that both men and women students express interest in science subjects, but women tend to receive less encouragement and resources from teachers and families to study science, particularly physical sciences, after their compulsory education (Archer, 2017; Mujtaba \& Reiss, 2013). 
Despite interest and aspiration to become scientists and engineers among women, the masculine culture of science, physics, and engineering fields dissuades women from continuing to pursue STEM subjects (Danielsson, 2012: Faulkner, 2007). Still, some women successfully navigate the masculine culture of STEM subjects, and this happens when women have a higher level of social class. Interviewing seven students from age 10 to 16 who aspired to continue with physics post-16 years of age, Archer et al. (2017) described their study findings of

structural and social class inequalities and the cultural arbitrary of physics not only potentially puts off girls (because they do not offer an attractive and/or achievable vision of who girls can be within these subject areas) but also may actively work against and prevent some girls ... from continuing, even when they want to. (p. 118)

Although we do not measure the culture of STEM disciplines in the analysis, we discuss our findings in the context of STEM disciplines, particularly at prestigious universities.

\section{Methods}

Informed by prior literature, we set out to examine individual and structural factors that may influence gender equity in U.K. STEM higher education. In particular, we described the gender difference in plans to study STEM subjects around age 17 to measure whether interests or plans vary by gender. We also present the gender difference in academic preparedness in terms of mathematics test scores at year 5 or 6 of primary school and later university preparatory curricular experiences which affect STEM subject choices and university enrollment. We then examined whether women had lower odds of enrolling in STEM higher education after accounting for family background and academic performance. Additionally, because prior literature suggests that Russell Group universities have exclusionary admissions practices, we tested whether access to STEM higher education by gender was stratified by university prestige.

To begin, given that we seek to offer implications from our study to other post-industrial countries, we checked how representative U.K. higher education is - in terms of enrollments by subject and gender - compared to the European Union (EU). We downloaded data from the European Institute for Gender Equality's Gender Statistics Database (GSD). The database includes information on the relative distribution of students enrolled in higher education by student gender and academic subject. GSD uses broad fields of study, so we classified "Agriculture, forestry, fisheries and veterinary," "Engineering, manufacturing and construction," "Information and Communication Technologies" and "Natural sciences, mathematics and statistics" as STEM subjects; all other fields were coded as non-STEM subjects. We found that the United Kingdom 
is relatively similar to the average for EU countries in both percentages of students studying STEM and non-STEM subjects and the gender split within STEM and non-STEM subjects. See Figure 6.1.

Although the structure of schooling varies throughout the EU, the U.K. case appears to represent a common challenge of gender inequality in STEM throughout Europe. We recognize that our findings are not generalizable to other countries in the EU. However, we hope that this chapter may provide some insights for other countries that may aspire to increase the percentage of students studying STEM subjects, as well as increase the percentage of women in STEM higher education.

\section{Data}

We analyze data from the British Department of Education's Longitudinal Study of Young People in England (LSYPE) data set (now extended as the Next Steps study) to examine gender equality in STEM higher education in the United Kingdom. LSYPE included seven waves of data collection from 2004 to 2010. The survey includes historical background (demographic) information, parental and family background data, measures of academic performance, and enrollment outcomes. For more information about sampling procedures and the structure of the LSYPE data set, as well as for examples of how LSYPE has been previously used to examine access to STEM higher education, see Alcott (2017) and Ro et al. (2018). Subjects were coded differently in LSYPE than in GSD (used for Figure 6.1). For our analysis of LSYPE data, we coded majors into mutually-exclusive STEM and non-STEM categories. We included biological sciences, physical sciences, mathematics, computer sciences, engineering, or technology-based academic programs as STEM subjects and all other subjects as non-STEM subjects (see Chen \& Weko, 2009).

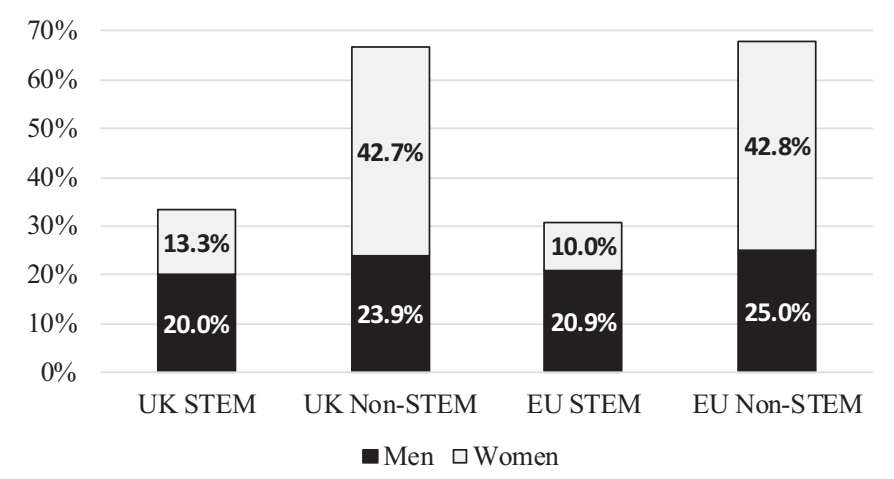

Figure 6.1 Percentages of men and women by STEM and non-STEM enrollment in the United Kingdom and EU. 


\section{Analytic Approach}

For this chapter, we started by examining gender differences in intention to study STEM at age 17 using a chi-square test. We also tested gender differences in academic preparedness (taking multiple A-levels in STEM fields) using a chi-square test, and we examined prior achievement using Wald tests to check whether mean differences in achievement between men and women were statistically significant.

To measure the gender differences by STEM subject choice and university enrollment by the level of institutional prestige, we examined data for LSYPE participants who enrolled at any type of university in any subject. As an analytical approach, we estimated logistic regression models for each outcome. We first examined whether women had lower odds than men of studying STEM at any university. Then, we considered whether women had lower odds compared to men of studying STEM at a Russell Group university. In our analyses, we controlled for students' social class background (i.e., whether their parents had a university degree and the relative income levels of their home neighborhoods using the British government's Income Deprivation Affecting Children Index scores) and their academic background, including early mathematics proficiency and secondary school preparation for university (including passing A-levels and taking science courses). We used the survey's sampling weights in our analyses. To account for missing data, we used a listwise deletion approach when there were missing values in the variables of interest. We did not use imputation procedures because analyses with listwise deletion have approximately unbiased estimates even when data are not missing at random (Little, 1992). We calculated inverse odds ratios by exponentiating odds ratios less than 1 for ease of interpretation (DesJardins, 2001).

\section{Findings}

We could not explain the gender disparity in STEM higher education through differences in STEM intentions. Results from Pearson's chi-squared test show that, compared to men, a statistically significant higher percentage of women intend to study STEM at age 17 ( $\mathrm{p}<0.05)$. Substantively, the difference in percentages was small $(8.3 \%$ of women compared to $7.9 \%$ of men), but it confirms that women's underrepresentation in STEM is likely not attributable to differences in interest or intention.

In terms of prior academic achievement, we first examined the bivariate relationship between gender and mathematics preparedness in primary school (year 5 or 6). A Wald test confirmed that girls scored lower, on average, than boys by approximately 18 points on Key Stage 2 mathematics tests $(\mathrm{p}<0.05)$. Prior to university enrollment, $16.9 \%$ of men took the more advanced science course offered during GCSEs (commonly known as "triple science," in contrast to the standard "double science") compared to $14.6 \%$ of women ( $p<0.001)$, however, women scored higher on A-level exams than men $(p<0.05)$. 
After our bivariate analyses of multiple indicators along the primary and secondary school pathway to studying STEM in higher education, we tested multivariate relationships among students' backgrounds and experiences and higher education enrollment. Compared to men, women had lower odds of studying STEM subjects at any university. Holding social class and academic background variables constant, men had approximately 60\% higher odds of studying STEM than women. Similarly, women had lower odds of studying STEM at the subgroup of Russell Group universities; men had 68\% higher odds of studying STEM at a Russell Group university than women. In our model that estimated odds of studying STEM at any university, we found that early mathematics performance was statistically related to enrollment in a STEM subject. However, for studying STEM at a Russell Group university, we found that social class mattered whereas early mathematics scores did not. Students whose parents had a university degree had 77\% higher odds of studying STEM within the Russell Group compared to students who were the first in their family to attend university.

We specified a third model to test whether women faced similarly long odds in attending Russell Group universities when we did not limit the sample to STEM students. Among students in all subjects, we found that women did not have statistically significantly different odds than men in attending Russell Group universities. In other words, the "penalty" for women in attending Russell Group universities appeared to be limited to enrollment in STEM fields. See Table 6.1.

Table 6.1 Women's Odds of Studying STEM or Attending Russell Group Universities: Data from Longitudinal Study of Young People in England (LSYPE)

\begin{tabular}{|c|c|c|c|c|c|c|c|}
\hline \multirow[b]{3}{*}{ Woman } & \multicolumn{3}{|c|}{$\begin{array}{l}\text { Studied STEM at any } \\
\text { university }(\mathcal{N}=3,940)\end{array}$} & \multicolumn{2}{|c|}{$\begin{array}{l}\text { Attended Russell Group to } \\
\text { study } \operatorname{STEM~}(\mathcal{N}=1,050)\end{array}$} & \multicolumn{2}{|c|}{$\begin{array}{l}\text { Attended Russell } \\
\text { Group to study any } \\
\text { subject }(2,890)\end{array}$} \\
\hline & \multicolumn{2}{|c|}{ Odds ratio } & \multirow{2}{*}{$\begin{array}{l}\text { Std. } \\
\text { err. } \\
0.04\end{array}$} & Odds ratio & \multirow{2}{*}{$\begin{array}{l}\text { Std. err. } \\
0.11\end{array}$} & \multirow{2}{*}{$\begin{array}{l}\text { Odds } \\
\text { ratio } \\
1.08\end{array}$} & \multirow{2}{*}{$\begin{array}{l}\text { Std. } \\
\text { err. } \\
0.14\end{array}$} \\
\hline & 0.47 & $* * *$ & & $0.52 * *$ & & & \\
\hline $\begin{array}{l}\text { Triple science } \\
\text { GCSEs }\end{array}$ & 1.17 & & 0.11 & 0.99 & 0.18 & 1.02 & 0.16 \\
\hline Passed A-levels & 1.04 & $* *$ & 0.02 & 1.38 *** & 0.05 & 1.38 *** & 0.03 \\
\hline $\begin{array}{l}\text { Math Score at } \\
\text { Year } 5\end{array}$ & 1.52 & $* * *$ & 0.13 & 1.30 & 0.27 & 1.07 & 0.14 \\
\hline $\begin{array}{l}\text { Parent without } \\
\text { university } \\
\text { degree }\end{array}$ & 1.17 & & 0.12 & $0.57 * *$ & 0.10 & $0.49 * * *$ & 0.08 \\
\hline $\begin{array}{l}\text { Neighborhood } \\
\text { Poverty } \\
\text { (IDACI score) }\end{array}$ & 0.93 & & 0.05 & 0.86 & 0.11 & 0.95 & 0.08 \\
\hline Constant & 0.05 & $* * *$ & 0.02 & $0.03 * * *$ & 0.03 & $0.06 * * *$ & 0.03 \\
\hline
\end{tabular}




\section{Hyun Kyoung Ro et al.}

Our findings come with several limitations. First, we were not able to examine application data to account for self-selection effects. In other words, we did not know whether women applied to study STEM subjects at Russell Group universities and were denied admission or whether they only applied to universities outside the Russell Group. Second, conditional on admission, we were not able to account for factors that may have influenced students' decisions about where to enroll in college (e.g., distance to home, differences in costs of attendance). Third, we did not include early aspirations or intentions to study STEM because that variable in LSYPE was missing so many values that the sample sizes would have been drastically reduced in our analyses.

\section{Discussion and Implications}

Just like other post-industrial countries, England has invested to increase more women in STEM education and ultimately the STEM workforce. Increasing the participation of women in STEM promotes advancements in science, research, and technology, which enhances a nation's economic prosperity and societal well-being (Blair, 2006; Brennan \& Naidoo, 2008). Increasing women in STEM fields can also disrupt gender disparities in income, given that STEM fields usually offer higher earnings (Chevalier, 2011; Walker \& Zhu, 2011). Policy makers and scholars have emphasized increasing women's participation in STEM as a national priority for gender equity and economic development in England. While men are consistently less likely to enroll in an undergraduate course than women (Archer et al., 2001; Chowdry et al., 2013), women students are still less likely to study STEM subjects than men students (Smith, 2011). By revising literature from both secondary and postsecondary education and using a nationally representative, longitudinal study in England, we discuss several main findings with existing literature along with future research inquires and policy and practice implications.

Early mathematics achievement at year 5 and 6 differs by gender: women had lower scores than men. However, women performed better on A-level examinations than men. When we measured students' intention to study STEM subjects at universities by age 17, a greater number of women students actually expressed an intention to study STEM subjects than men. This finding is important because the lower level of STEM enrollment among women may not be attributable to lack of interest in studying STEM subjects. Educational aspiration or intention in general is directly and positively related to their actual enrollment in higher education (Hu, 2003), which we found was positively related to STEM enrolment in the regression analyses after controlling for gender. Building on the work of Archer et al. (2017), further qualitative inquiry is needed to explore the reasons for the disconnect between intention to study STEM subjects and actual subject choice among women in this study. Faculty and staff may interact with secondary school students who have intentions to study STEM subjects but who ultimately do not enroll in STEM. Teachers and school counselors may consider how to encourage 
women students who intend to study STEM subjects, to enroll in more STEM GCSEs, and to prepare to attend university.

It may not be surprising that we found women have lower odds of studying STEM subjects at any university and at Russell Group universities. It is interesting that the odds of studying any subject (i.e., both STEM and nonSTEM subjects) at Russell Group universities do not differ by gender. From our study, it is uncertain whether women do not "choose" to attend Russell Group universities when they study STEM subjects, or whether the prestigious universities have more preference for men students when admitting students to study STEM subjects. U.S. scholars have claimed that selective institutions have more male-preference admission processes (Bielby et al., 2014). However, U.S. researchers did not examine how the intersection between STEM disciplines and selective institutions encourages or prevents universities from accepting more women. This is a key question for future inquiry, given that educational degrees in STEM subjects, and from more prestigious institutions, help students secure high paying careers, social mobility, and leadership positions. More studies need to look at the admission and persistence, learning and engagement, and sense of belonging among women in STEM subjects at prestigious institutions.

We also offer new research ideas to examine the diverse backgrounds of women students who choose STEM subjects at different types of institutions. Although there are benefits to examining data from a nationwide and longitudinal study, we could not analyze the interaction effects between women and other background measures (e.g., parental education, social class) due to the small sample size. We found that students who have parents with university degrees are more likely to study at Russell Group universities and the effect of parental education on students' STEM subject choice at prestigious universities may differ by gender.

Parents can play a key role in en(dis)couraging their children to study STEM subjects. In addition to parental education, parental occupations may relate to students' STEM subject choice. Archer et al. (2017) found that girls who persist in physics subjects possess high levels of not only family capital, but more specifically science-oriented family habitus and cultural and social capital. Parents who work in elite or middle-class STEM fields may recognize the strategic potential for their children's major choice. Bengtsson's (1983) study of Swedish women university students found that a larger proportion of women studying natural sciences had fathers who studied or worked in the same field. While parents in non-science fields may underestimate their daughters' attraction to science books, parents in STEM fields may encourage their daughters to experience more science literacy. Parents with a high-level of economic capital and science-based social and cultural capital tend to help their daughters continue in the track of STEM subjects, despite the unwelcoming culture of STEM disciplines (Archer et al., 2017).

Human capital theory may explain the lower level of women's participation in STEM subjects at prestigious universities. According to human capital 
theory, students decide where and what to study on the basis of anticipated future earnings. Becker (1965, 1976) claimed that students operate according to the "well-known equilibrium condition" (1976, p. 123) that they should pursue additional higher education until the point where present costs outweigh expected future returns. Becker (1980) argued that parents may not only extend funds to help students attend costly universities, they may also help students think through the equilibrium condition - thereby influencing students' willingness to take financial risks and incur higher short-term university costs with the expectations of greater future earnings. While women were less likely to take degrees in STEM subjects (Chowdry et al., 2008; Smith, 2011), future returns may influence women students' decision for where they study when they choose to study STEM subjects (Ro et al., 2018). Future research should examine whether women students may not choose STEM subjects, particularly at prestigious universities, because women experience relatively lower income premiums from their college degrees and endeavor not to lose as much in foregone earnings as men.

We also offer policy and practice implications, which can be applicable in other post-industrial countries. For example, although educational systems in the United Kingdom and other post-industrial countries including the United States are substantially different, there are common challenges for improving gender equity in both countries. We argue that in post-industrial countries policymakers and teachers should consider supporting gender equity through early achievement in mathematics, secondary school course taking, and the importance of standardized university admissions tests. For example, the chapter on Germany in this volume by Dusdal and Fernandez also illustrates that women had interest in studying engineering but were deterred because they did not complete pre-requisite courses. Despite interest or intentions to study STEM, testing and course taking create opportunities to reinforce gender stereotyping or to allow gender stereotypes to manifest themselves in the pathway to STEM higher education.

\section{Conclusion}

In this chapter we offer a comprehensive overview of women students' pathways to (or away from) studying STEM subjects, including initial intentions to enroll in STEM subjects, prior academic achievement in mathematics and science, and actual enrollment in STEM programs at universities, including prestigious Russell Group universities, in England. We use a nationally representative, longitudinal data set to address STEM subject pathways by gender. While we found that women students express their intention to study STEM subjects at universities just like men, women students' actual enrollment is lower than men's in STEM subjects. Furthermore, women students are less likely to enroll to study STEM subjects at Russell Group universities than men, even though there was no difference in Russell Group universities by gender when we do not consider subjects. Further studies need to explore whether women do not 
choose prestigious universities when they apply to study STEM subjects or prestigious universities have male-preferences in admissions when they select students in STEM subjects. We also encourage scholars and practitioners to consider cultural contexts for both STEM disciplines and institutions rather than focusing solely on individual students' attributes, such as their intention to study STEM subjects or their academic achievement.

\section{References}

ACT. (2010). College readiness. http://files.eric.ed.gov/fulltext/ED510475.pdf

Alcott, B. (2017). Does teacher encouragement influence students' educational progress? A propensity-score matching analysis. Research in Higher Education, 58(7), 773-804.

Anders, J. (2012). The link between household income, university applications and university attendance. Fiscal Studies, 33(2), 185-210.

Andre, T., Whigham, M., Hendrickson, A., \& Chambers, S. (1999). Competency beliefs, positive affect, and gender stereotypes of elementary students and their parents about science versus other school subjects. Fournal of Research in Science Teaching, 36, 719-747.

Archer, L., Hutchings, M., \& Ross, A. (2003). Higher education and social class: Issues of exclusion and inclusion. Routledge Falmer.

Archer, L., Moote, J., Francis, B., DeWitt, J., \& Yeomans, L. (2017). The "exceptional" physics girl: A sociological analysis of multimethod data from young women aged 10-16 to explore gendered patterns of post-16 participation. American Educational Research Fournal, 54(1), 88-126.

Archer, L., Pratt, S. D., \& Phillips, D. (2001). Working-class men's constructions of masculinity and negotiations of (non) participation in higher education. Gender and Education, 13(4), 431-449.

Arnett, D. K. (2015). Plugging the leaking pipeline: Why men have a stake in the recruitment and retention of women in cardiovascular medicine and research. Circulation: Cardiovascular Quality and Outcomes, 8(2_suppl_1), S63-S64.

Ball, S. J. (2008). The education debate: Policy and politics in the twenty-first century. The Policy Press.

Ball, S. J., Davies, J., David, M., \& Reay, D. (2002). 'Classification' and 'judgement': Social class and the 'cognitive structures' of choice of higher education. British Journal of Sociology of Education, 23(1), 51-72.

Becker, G. S. (1965). A theory of the allocation of time. The Economic Fournal, 75(299), 493-517.

Becker, G. S. (1976). The economic approach to human behavior. The University of Chicago Press.

Becker, G. S. (1980). Human capital: A theoretical and empirical analysis, with special reference to education (2nd ed.). The University of Chicago Press.

Bengtsson, M. 1983Foraldraidentifikation hos ksinnliga naturvetare och humanister- utsecklingspsyhologiska, differentiella och socialpsyhologiska aspekter [Parental identification on the part of women studying natural sciences or the arts - Develop- mental, differential and social psychological aspects] [Doctoral dissertation, Lund University].

Berryman, S. E. (1983). Who will do science? Trends, and their causes, in minority and female representation among holders of advanced degrees in science and mathematics. Rockefeller Foundation. 
Bielby, R., Posselt, J. R., Jaquette, O., \& Bastedo, M. N. (2014). Why are women underrepresented in elite colleges and universities? A non-linear decomposition analysis. Research in Higher Education, 55(8), 735-760.

Blair, T. (2006, November 3) Our nation's future: Science. [Speech transcript]. https:// webarchive.nationalarchives.gov.uk/+/http://www.number10.gov.uk/Page 10342

Blanden, J., \& Machin, S. (2004). Educational inequality and the expansion of UK higher education. Scottish Fournal of Political Economy, 51(2), 230-249.

Boliver, V. (2011). Expansion, differentiation, and the persistence of social class inequalities in British higher education. Higher Education, 61, 229-242.

Boliver, V. (2013). How fair is access to more prestigious UK universities? The British Fournal of Sociology, 64, 344-364.

Boliver, V. (2015). Lies, damned lies, and statistics on widening access to Russell Group universities. Radical Statistics, 113, 29-38.

Boliver, V. (2016). Exploring ethnic inequalities in admission to Russell Group universities. Sociology, 50, 247-266.

Boliver, V., Gorard, S., \& Siddiqui, N. (2017). How can we widen participation in higher education? The promise of contextualised admissions. In R. Deem \& H. Eggins (Eds.), The university as a critical institution? (pp. 95-109). Sense Publishers.

Bolton, P. (2020, October 21). Higher education student numbers. UK Parliament. https:// commonslibrary.parliament.uk/research-briefings/cbp-7857/

Brennan, J., \& Naidoo, R. (2008). Higher education and the achievement (and/or prevention) of equity and social justice, Higher Education, 56, 287-302.

Butz, W. P., Bloom, G. A., Gross, M. E., Kelly, T. K., Kofner, A., \& Rippen, H. E. (2006). Is there a shortage of scientists and engineers? How would we know? [Issue Paper]. RAND Corporation. https://rand.org/pubs/issue_papers/IP241.html

Calabrese Barton, A., Tan, E., \& Rivet, A. (2008). Creating hybrid spaces for engaging school science among urban middle school girls. American Educational Research fournal, 45(1), 68-103.

Callender, C. (2006). Access to higher education in Britain: The impact of tuition fees and financial assistance. In P. N. Teixeira, D. B. Johnstone, M. J. Rosa, and H. Vossensteyn (Eds.), Cost-sharing and accessibility in higher education: A fairer deal? (pp. 105-132). Springer.

Carneiro, P., \& Heckman, J. J. (2002). The evidence on credit constraints in post-secondary schooling. The Economic Fournal, 112(482), 705-734.

Carneiro, P. and Heckman, J. J. (2003). Human capital policy. In J. J. Heckman, A. Krueger, \& B. Friedman (Eds.), Inequality in America: What role for human capital policies? (77-239). The MIT Press.

Chen, X., \& Weko, T. (2009). Students who study science, technology, engineering, and mathematics (STEM) in postsecondary education, (Report No. 2009-2161). National Center for Educational Statistics.

Chevalier, A. (2011). Subject choice and earnings of UK graduates. Economics of Education Review, 30(6), 1187-1201.

Chevalier, A., \& Conlon, G. (2002). Variations in the returns to university degree in the UK, a Cohort Analysis [Mimeo]. University College Dublin.

Chowdry, H., Crawford, C., Dearden, L., Goodman, A., \& Vignoles, A. (2008). Understanding the determinants of participation in higher education and the quality of institute attended: Analysis using administrative data. https://www.ifs.org.uk/publications/4279

Chowdry, H., Crawford, C., Dearden, L., Goodman, A., \& Vignoles, A. (2013). Widening participation in higher education: Analysis using linked administrative data. Journal of the Royal Statistical Society: Series A (Statistics in Society), 176(2), 431-457. 
Crawford, C., Johnson, P., Machin, S., \& Vignoles, A. (2011). Social mobility: A literature review. Department for Business, Innovation and Skills. https://assets.publishing.ser vice.gov.uk/government/uploads/system/uploads/attachment_data/file/32111/ 11-750-social-mobility-literature-review.pdf

Danielsson, A. T. (2012). Exploring woman university physics students "doing gender" and "doing physics." Gender and Education, 24(1), 25-39.

Davey, G., \& Fuller, A. (2013). Hybrid qualifications, institutional expectations and youth transitions: A case of swimming with or against the tide. Sociological Research Online, 18(1), 200-209. https://doi.org/10.5153/sro.2876

Davies, S., \& Guppy, N. (1997). Fields of study, college selectivity, and student inequalities in higher education. Social Forces, 75, 1417-1438.

DesJardins, S. L. (2001). A comment on interpreting odds-ratios when logistic regression coefficients are negative. AIR Professional File, 81(1), 1-7.

Dryler, H. (1998). Parental role models, gender and educational choice. British Fournal of Sociology, 375-398.

Engberg, M., \& Wolniak, G. C. (2013). College student pathways to the STEM disciplines. Teachers College Record, 115(1), 1-27.

Faulkner, W. (2007). 'Nuts and bolts and people': Gender-troubled engineering identities. Social Studies of Science, 37(3), 331-356.

Feinstein, L. (2003). Inequality in the early cognitive development of British children in the 1970 cohort. Economica, 70, 73-97.

Gago, J. M., Ziman, J., Caro, P., Constantinou, C. P., Davies, G., Parchmann, I., Rannikmae, M., \& Sjoberg, S. (2005). Europe needs more scientists: Report by the high level group on increasing human resources for science and technology. Office for Official Publications of the European Communities.

Galindo-Rueda, F., Marcenaro-Gutiérrez, O., \& Vignoles, A. (2008). The widening socioeconomic gap in UK higher education. In S. Gorard (Ed.), Quantitative research in education (Vol. 1, pp. 75-88). Sage.

Gibbons, S., \& Vignoles, A. (2012). Geography, choice and participation in higher education in England. Regional Science and Urban Economics, 42(1), 98-113.

Glennerster, H. (2002). United Kingdom education 1997-2001. Oxford Review of Economic Policy, 18(2), 120-136.

Glover, J., \& Fielding, J. (1999). Women and the sciences in Britain: Getting in? Fournal of Education and Work, 12(1), 57-73.

Gorard, S., Smith, E., May, H., Thomas, L., Adnett, N., \& Slack, K. (2006, July). Review of widening participation research: Addressing the barriers to participation in higher education. Higher Academy and the Institute for Access Studies. Higher Education Funding Council for England.

Grauca, J. M., Ethington, C. A., \& Pascarella, E. T. (1988). Intergenerational effects of college graduation on career sex atypicality in women. Research in Higher Education, 29(2), 99-124.

Greenaway, D., \& Haynes, M. (2003). Funding higher education in the UK: The role of fees and loans. The Economic Fournal, 113(485), F150-F166.

Harrison, M. (2012, September). Fobs and growth: The importance of engineering skills to the UK economy: Royal Academy of Engineering Econometrics of Engineering Skills Project. Royal Academy of Engineering. https://www.raeng.org.uk/publications/reports/jobs-a nd-growth

Heckman, J. J., \& Lochner, L. (2000). Rethinking education and training policy: Understanding the sources of skill formation in a modern economy. In S. Danziger 
\& J. Waldfogel (Eds.), Securing the future: Investing in children from birth to college (pp. 4783). Russell Sage Foundation.

Hemsley-Brown, J. (2015). Getting into a Russell Group university: High scores and private schooling. British Educational Research Fournal, 41, 398-422.

Hetherington, E. M. (1965). A developmental study of the effects of sex of the dominant parent on sex-role preference, identification, and imitation in children. Fournal of Personality and Social Psychology, 2(2), 188.

House of Commons Education Committee. (2013). From GCSEs to EBCs: The government's proposals for reform. London: The Stationery Office. https://www.parliament.uk/docum ents/commons-committees/Education/EIGHTH-REPORT-GCSEs-to-ECBs-Reform -HC-808.pdf

$\mathrm{Hu}$, S. (2003). Educational aspirations and postsecondary access and choice. Education Policy Analysis Archives, 11, 14.

Hussein, I., McNally, S., \& Telhaj, S. (2009). University quality and graduate wages in the UK (Paper No. 4043). Institute for the Study of Labor. ttps://www.econstor.eu/bit stream/10419/35561/1/59516773X.pdf

Jerrim, J., \& Vignoles, A. (2013). Social mobility, regression to the mean and the cognitive development of high ability children from disadvantaged homes. Fournal of the Royal Statistical Society: Series A (Statistics in Society), 176, 887-906.

Kelly, A. (1985). The construction of masculine science. British Fournal of Sociology of Education, 6(2), 131-154.

Kohlberg, L. (1966). A cognitive-developmental analysis of children's sex-role concepts and attitudes. In E. C. Maccoby (ed.), The development of sex differences (pp. 82-173). Stanford University Press.

Little, R. J. (1992). Regression with missing X's: A review. Fournal of the American Statistical Association, 87, 1227-1237.

Machin, S., \& Vignoles, A. (2004). Educational inequality: The widening socio-economic gap. Fiscal Studies, 25(2), 107-128.

Mujtaba, T., \& Reiss, M. J. (2013). What sort of girl wants to study physics after the age of 16? Findings from a large-scale UK survey. International Fournal of Science Education, 35(17), 2979-2998.

Nunes, T., Bryant, P., Strand, S., Hillier, J., Barros, R., \& Miller-Friedmann, J. (2017). Review of SES and science learning in formal educational settings. Education Endowment Foundation. https://royalsociety.org/ /media/policy/topics/education-skills/educa tion-research/evidence-review-eef-royalsociety-22-09-2017.pdf?la=en-GB

Piesse, A., \& Kalton, G. (2009). A strategy for handling missing data in the Longitudinal Study of Young People in England (LSYPE) (Report No. DCSF-RW086). Department for Children, Schools and Families.

Reay, D. (1998). "Always knowing" and "never being sure": Familial and institutional habituses and higher education choice. Fournal of Education Policy, 13(4), 519-529.

Reay, D., Crozier, G., \& Clayton, J. (2010). 'Fitting in' or 'standing out': Working-class students in UK higher education. British Educational Research Fournal, 36(1), 107-124.

Riegle-Crumb, C., King, B., Grodsky, E., \& Muller, C. (2012). The more things change, the more they stay the same? Prior achievement fails to explain gender inequality in entry into STEM college majors over time. American Educational Research Fournal, 49(6), 1048-1073.

Ro, H. K., Fernandez, F., \& Alcott, B. (2018). Social class, human capital, and enrollment in STEM subjects at prestigious universities: The case of England. Educational Policy, 1-28. https://doi.org/10.1177/0895904818813305 
Shanghai Ranking Consultancy. (2014). Academic ranking of world universities 2014. Shanghai Jiao Tong University. http://www.shanghairanking.com/ARWU2014.html

Singleton, A. D. (2010). The geodemographics of educational progression and their implications for widening participation in higher education. Environment and planning. 42(11), 2560-2580.

Smith, E. (2011). Women into science and engineering? Gendered participation in higher education STEM subjects. British Educational Research Fournal, 37(6), 993-1014.

Tan, E., Calabrese Barton, A., Kang, H., \& O'Neill, T. (2013). Desiring a career in STEM-related fields: How middle school girls articulate and negotiate identities-inpractice in science, Fournal of Research in Science Teaching, 50(10), 1143-1179.

Teachman, J. D. (2002). Stability across cohorts in divorce risk factors. Demography, 39(2), 331-351.

The Russell Group of Universities. (n.d.). Undergraduates from outside the EU. http s://www.russellgroup.ac.uk/for-students/undergraduate-study/students-from-out side-the-eu/

Times Higher Education. (2015). University guide 2015. http://extras.thetimes.co.uk/good universityguide/institutions/

U.S. News and World Report. (2015). Best global universities rankings. http://www. usnews.com/education/best-global-universities/rankings

Vignoles, A., \& Powdthavee, N. (2009). The socioeconomic gap in university dropouts. The B.E. Fournal of Economic Analysis \& Policy, 9(1). http://www.degruyter.com/view/ j/bejeap.2009.9.1/bejeap.2009.9.1.2051/bejeap.2009.9.1. 2051.xml

Vincent, C., Braun, A., \& Ball, S. J. (2008). Childcare, choice and social class: Caring for young children in the UK. Critical Social Policy, 28(1), 5-26.

Walker, M., \& Clark, G. (2010). Parental choice and the rural primary school: Lifestyle, locality and loyalty. Fournal of Rural Studies, 26(3), 241-249.

Walker, I., \& Zhu, Y. (2011). Differences by degree: Evidence of the net financial rates of return to undergraduate study for England and Wales. Economics of Education Review, 30, 1177-1186.

WISE Campaign. (2019). 2019 workforce statistics - 1 million women in STEM in the UK. https://www.wisecampaign.org.uk/statistics/2019-workforce-statistics-one-million -women-in-stem-in-the-uk/

WISE Campaign. (2020). Analysis of 2020 A-Level core STEM entrants - Number of core STEM A-levels completed by girls rises again. https://www.wisecampaign.org.uk/ statistics/analysis-of-2020-a-level-core-stem-entrants-number-of-core-stem-a-levels-com pleted-by-girls-rises-again/

Xie, Y., \& Shauman, K. A. (2003). Women in science. Harvard University Press.

Zwick, R. (2006). Higher education admissions testing. In R. L. Brennan (Ed.), Educational measurement (pp. 647-679). American Council on Higher Education and Praeger. 
$\Longrightarrow$ Taylor \& Francis Taylor \& Francis Group http://taylorandfrancis.com 


\section{Part 2}

Women's Choice and University Contexts 
$\Longrightarrow$ Taylor \& Francis Taylor \& Francis Group http://taylorandfrancis.com 


\section{Women in STEM in Ghilean Higher Education}

\section{Social Movements and Institutional Transformations}

Jeongeun Kim and Sergio Celis

Overall, women have made significant progress in Chilean higher education. Among the 18- to 24-year-old population, or the traditional college-age population, the proportion of women attending higher education is $44.5 \%$, compared to that of men being only 38\% in 2019 (Servicio de Información de Educación Superior [SIES], 2020a). The gap in college attendance between the two groups has increased 4.3 percentage points between 2007 and 2019 (SIES, 2020a), and in 2019, women represented almost 53\% of the first-year enrollment (SIES, 2020a). Moreover, women surpass their men counterparts in academic achievement, first-year retention, time-to-degree, and bachelor's degree completion (SIES, 2020a). However, despite this progress and positive indicators in educational attainment, women still face rooted social discrimination and stereotypes across ages and in various aspects of Chilean society (Rebolledo González \& Valdés Subercaseaux, 2018). In higher education, women are underrepresented in the highest academic hierarchies such as toplevel administration, as well as in some of the prestigious and high-paying fields in Chile (Andrade Lara, 2013). One of the areas where women are significantly underrepresented is in Science, Technology, Engineering, and Mathematics (STEM) fields (Bordon et al., 2020).

In May 2018, multiple student protests across university campuses sparked a large-scale feminist movement across the country (Palma Manríquez, 2018), which had ripple effects on gender structures in Chile. The feminist movement stood against sexual harassment on campuses and demanded victim protection and proper and faster investigations from university administrators (Palma Manríquez, 2018). The movement quickly escalated to a national phenomenon targeting a wide range of issues, such as domestic violence, family roles, and income inequality (Rebolledo González \& Valdés Subercaseaux, 2018). The feminist movement also criticized multiple dimensions where women were either excluded or discriminated against. STEM fields are one of the domains where these issues occur. For instance, in 2019, the number of first-year undergraduate men enrolled in engineering and other technology programs was $65.5 \%$ higher than that of women (SIES, 2020a). This disparity contributes to women's status in other social spheres, as participation of women in STEM is often linked to personal benefits, such as better 
job opportunities and higher income (Kim et al., 2015), and public benefits, such as high quality innovation produced by greater diversity in the field (Allen-Ramidal \& Campbell, 2014).

While the feminist movement boosted discussion of women's participation in STEM fields across higher education, STEM students, faculty members, and staff in Chile already had been very active in organizing multiple forms of movements to increase women's participation in and influence on STEM fields in the last decade (Villaseñor et al., 2020). For example, the feminist movement originating from engineering disciplines has been focusing on making relevant changes in Chilean STEM education.

In this chapter, we explore how grassroots movements influence women's participation in Chilean higher education and describe overall patterns in the evolution of women's participation in STEM undergraduate programs. The chapter consists of two parts. First, we begin by discussing a brief history of women's participation in STEM disciplines and other related areas in Chile. We then introduce the main characteristics of the Chilean feminist movement, focusing on the case of Faculty of Physical and Mathematical Science (FCFM) at the Universidad de Chile, where a scientific and intellectual movement (Frickel \& Gross, 2005) took place. To describe the case of FCFM, we review archival sources from the college, such as websites, magazines, undergraduate and master's theses, and personal communications with faculty members who were part of the grassroots movement. ' Second, we analyze the country's higher education enrollment data to describe the evolution of women's participation in STEM fields between 2007 and 2019. We use enrollment trends for exploring to what extent the grassroots initiatives influenced women's representation in STEM across different types of institutions. We conclude the chapter with a discussion of current and future challenges and opportunities for increasing women's participation in STEM in Chile.

\section{An Individual and Collective Journey}

About a century ago, Justicia Acuña enrolled in the, until then, all-men FCFM and in 1919 became the first woman engineer to graduate in South América (Dávalos, 2019b). Justicia Acuña then accomplished a distinguished professional career in the National Railway. In Chile, Justicia Acuña represents an important milestone and is an iconic figure for women's participation in STEM (Dávalos, 2019b). Although Justicia Acuña opened the path for women in STEM, the path remained narrow until the beginning of the 21st century. Up until 1960, only ten women had graduated from FCFM. Even in 2014 , women represented less than $20 \%$ of the entering cohort for the science and engineering programs at FCFM.

Adelina Gutiérrez was another woman who made history in STEM when she became the first Chilean woman PhD in Astrophysics, a degree obtained at Indiana University in the U.S. in 1964. Back in Chile, Adelina Gutiérrez became a faculty member at FCFM and was a leading figure in creating the 
first bachelor's degree program in astronomy in the country, which became a key field for the nation. Adelina Gutiérrez's pioneering research and teaching served as a role model for women in the academic profession in STEM fields, as we will further describe in this chapter.

In Chile, in the late 20th century, women needed to open up spaces in STEM disciplines and society at large. During this time, women started to participate in social spheres that, traditionally, were exclusively for men, such as science, business, arts, and politics. For instance, just in 1949, Chilean women obtained the right to vote in the presidential election. In addition to the many individual women who became heroes, leaders, and examples for future generations, women's collective action across the socioeconomic spectrum shaped the nation's destiny at crucial moments (Baldez, 2002). A central episode was women's action on Salvador Allende's presidency and Augusto Pinochet's dictatorship. Regarding the former, groups of upper- and middle-class women organized protests against Allende in the early 1970s and called for military action (Baldez, 2002). One of their most significant actions was the March of the Empty Pots (Crummett, 1977). Regarding the latter, women organized in multiple underground organizations (e.g., student protest, human rights, economic survival, women's right) across the country to resist Pinochet's oppression in the 1980s and to fight back to restore democracy (Baldez, 2002). Among those women was Michelle Bachelet, who would become the first woman president in Chilean history in 2006, crystalizing women's social and political power in society. In the current century, women continue to organize to achieve greater justice in a society where men still hold privileges.

\section{A Bottom-up Feminist Movement at FCFM}

The most significant social movements in Latin American contemporary history (e.g., Bellei \& Cabalin, 2013; Levy, 1991), such as the feminist movement of 2018, emerged from universities. In particular, Universidad de Chile played a significant role in these movements as the oldest and most prestigious public university in the country. Universidad de Chile was established in 1842, FCFM being among the university's first faculties, and very early on became a catalyst for national progress (Jaksic \& Serrano, 1990). Even though the feminist and other historical movements were led by students at Universidad de Chile and other traditional universities, faculty members have substantially contributed to collective actions and political changes (Jaksic, 1989). Here, we explore one of the cases of faculty mobilization, describing how a group of women faculty members at FCFM began to challenge school and university authorities several years before 2018 .

According to Snow et al. (2004), social movements are conceptualized as "collectivities acting with some degree of organization and continuity outside of institutional channels to challenge or defend extant authority" (p. 11). Collective action around STEM disciplines started to take form towards the end of the 2000s. In particular, a group of women faculty members at FCFM 
started to organize informal channels of communication and share their rough experiences with maternity leaves, academic evaluations, and promotions.

There were two mechanisms that facilitated the gathering at the beginning. First, women faculty organized a small group to do physical activities in the FCFM's gym during lunchtime. They created a mailing list just for FCFM women engineers and scientists (N. Hitschfeld, personal communication, September 23, 2015). Communication among women faculty was crucial because the campus of FCFM was geographically located far away from the other four Universidad de Chile campuses. The physical isolation of FCFM from the rest of the university reinforced a men-dominated environment and women being a distinct minority (Bonilla, 2016). However, this isolation resulted in a positive outcome as women faculty created STEM disciplinary-based organizations on the FCFM campus.

Second, women faculty used the college's academic initiatives to raise attention about women's participation in STEM. Over the 2000s, FCFM went through significant curriculum reform of their undergraduate programs, seeking to add more hands-on experiences and move from teacher-oriented towards student-oriented engineering education. During this period of reform, FCFM received several guests from prestigious engineering schools in the U.S. Several women faculty members that were involved in the curriculum reform attended the guests' talks. In those visits, some of these guests brought up the topic of women's participation in STEM as one of the key issues in the U.S. What the guests shared presented a 'model' of engineering education to FCFM women's participation as a legitimate engineering education problem and what practices to emulate to address the issue, as mimetic isomorphism explains (DiMaggio \& Powell, 1983). This model reinforced the topic among the women faculty members (N. Hitschfeld, personal communication, September 23, 2015), which consisted of less than 15\% of FCFM faculty at the time.

In 2011, the women faculty members' group started to call themselves Adelinas in honor of Adelina Gutiérrez. The group started discussions with FCFM authorities about issues such as the impact of maternity leaves on academic evaluations and promotions as well as the lack of opportunities for women faculty members to participate in key committees (Dávalos, 2019a), strategizing ways of ensuring women's participation in each of these committees and decision-making instances (Dávalos, 2019a). Adelinas' form of collective action resembles the concept of intellectual movements (Frickel \& Gross, 2005). According to Frickel and Gross (2005), for scientific or intellectual programs, breaking with the past requires collective action that varies in scope, and it is inherently political and episodic phenomena. Moreover, intellectual movements are usually led by high-status senior scientists and tend to be smaller in size, less revolutionary, and less risky than social movements. Senior faculty members among Adelinas assumed leadership, supported and mentored new colleagues, and made their voices heard in critical instances, such as at FCFM's strategic retreats. In 2014, Adelinas achieved a national milestone, when FCFM implemented an affirmative action policy for 
admitting more women into their undergraduate programs. This initiative was called Programa de Ingreso Prioritario de Equidad de Género (PEG), or gender equality admission program in English (Bastarrica et al., 2018).

\section{PEG: The Affirmative Action Program at FGFM}

To better understand women undergraduates who are admitted to FCFM, it is necessary to learn more about admission policies of higher education in Chile. Selective public and private universities in Chile have a centralized system for admission. The system, under the authority of the Ministry of Education, operates admissions based on the national admissions tests, including tests in mathematics, language, sciences (i.e., Biology, Chemistry, and Physics), and history and social sciences. In addition to the tests, the system includes high school GPA and high school ranking in the admissions criteria. Each university's programs define the weights given to the tests and high school academic achievement indicators and may designate numbers of students for special admissions up to about $20 \%$ of their entering cohort. After the test results are delivered, each student applies to up to ten programs, indicating their preferences using the centralized system. Then, an algorithm assigns the students to the different programs and universities according to their scores (Ríos et al., 2014). Finally, each program receives a list of admitted students and a waiting list for the most sought-after programs.

Like other programs, the context and admission process for FCFM and its PEG program are unique (Villaseñor et al., 2020). Currently, FGFM offers 13 undergraduate programs: 9 engineering specialties, 3 sciences (Physics, Astronomy, and Geophysics), and Geology. All students at FCFM are admitted to a two-year common core program before choosing any of the 13 majors. FCFM admits about 800 students and is one of the most selective academic programs in the nation, recruiting students in the top $5 \%$ of the national test scores. PEG was implemented in 2014 in order to increase the number of women entering FCFM undergraduate programs. PEG is a quota program that consists of admitting a certain number of women immediately below the admissions requirement cutoff. In other words, PEG admits women according to their places in the waiting list for the FGFM common core program. The PEG quota has increased from 40 women in 2014 to 55 in 2020.

Part of the PEG rationale is that it helps mitigate the gap in test scores between women and men. In all the standardized tests that measure math academic achievement at the K-12 level, there is a significant gap where men outperform women (Bordon et al., 2020; Mizala, 2018). This gap is also present in the national math test for university admissions, which is the one that has the most weight for FCFM and other engineering and science programs in Chile. Mizala (2018) indicates that this gender gap is influenced by stereotyping of women in schools and families. In particular, Paredes (2014) focused on the role of teacher gender and gender segregated classrooms on women students' math scores. Having a woman math teacher increased the average scores of women 
students in a national test, reducing one-fourth of the gender gap in math. The author explained the finding more as a role model impact than teachers' biases in the testing and grading, because the effect of teachers' gender was larger for gender segregated classrooms. Moreover, the study suggested the importance of family role models, such as mothers: the effect of teachers' gender had no effect for girls with mothers with higher levels of education. Bordon et al. (2020)'s analysis of applications to university majors in Chile supported this finding by showing that women are more likely to apply to health majors and less likely to apply to civil engineering and technology. While mother's field of occupation has a higher effect on daughters in health, business, social sciences and humanities, and law, for sons, father's field of occupation has a strong effect on their choices in all areas. Gender segregated schools also reinforced the gendered pattern of major choices via higher interaction with students of a certain gender. Finally, the authors also argued that the choice of a selective program is influenced by social stereotypes, as women may feel more insecure about their own knowledge and less apt to apply for more selective options, being risk averse and shying away from competition. Despite this gap, and as presented at the beginning of the chapter, women in both STEM and non-STEM majors outperform men in almost all academic achievement indicators once they attend higher education institutions.

PEG represents an inflection point for the participation of women in FCFM undergraduate programs. The percentage of women in the first-year FCFM common core program went from $19 \%$ in 2013 to $28 \%$ in 2014. Moreover, an unexpected effect was that the number of women applying to FCFM also increased (Bastarrica et al., 2018). In 2018, women represented almost 33\% of FCFM's first-year cohort. Increasing the number of women at FCFM is an essential step in changing a men-dominated culture that is still perceived as hostile to women (Bonilla, 2016; Villaseñor et al., 2020). For instance, over the first two years at FCFM, women students reported feeling ignored by teachers and teaching assistants, implicitly being excluded from peer study groups, and being victims of other microaggressions such as machistas' jokes by teachers and sexual harassment by peers (Bonilla, 2016; Villaseñor et al., 2020).

Adelinas' bottom-up actions influenced other key changes by promoting gender equity for women administrators, faculty, and graduate students. In 2014, FGFM launched the Programa de Equidad de Género en la Académica (PEGA), a program aimed to increase the number of women among FCFM faculty members. PEGA consists of scholarships for women to pursue doctoral studies abroad with the commitment to return to a tenure track position at FCFM. Currently, about $17 \%$ of the FCFM faculty are women. In 2018, the movement became institutionalized when a new position of Associate Dean of Diversity and Gender Issues was created. In 2019, FCFM's tallest building, which hosts faculty administration, including the Dean's office, was renamed the Justicia Acuña building. These milestones join more than 100 initiatives regarding gender issues, ranging from the promotion of engineering and science to girls in K-12 schools, training for teaching teams, and more women researchers in engineering. 
Despite the contribution of the FCFM faculty, many challenges persist in the long-run. One of the challenges is the distribution of women within FCFM programs. Some programs attract a relatively large number of women, such as Geophysics (40\%), Astronomy (38\%), Biotechnology Engineering (36\%), and Industrial Engineering (35\%). Yet other programs struggle to attract women students, such as Physics (16\%), Mathematical Engineering (15\%), and Electrical Engineering (11\%). To increase women students in these majors, FCFM has promoted several initiatives, from supporting research to understand the dynamics that influence students' major choice, organizing public talks with distinguished women in these fields, to inviting women students to become teaching assistants (e.g., Villaseñor et al., 2020).

The case of FCFM at Universidad de Chile is an example of the national feminist movement and the social changes of the first two decades of the century. Similar bottom-up changes have been reported in other STEM fields at Universidad de Chile and other science and engineering schools across the country (Paredes-Walker, 2020). Following the example of PEG, two other universities (Universidad Austral de Chile and Universidad Técnica Federico Santa María) located out of Santiago, the capital city, implemented similar affirmative action programs. Other programs have implemented initiatives to attract women without implementing quota systems. For instance, the engineering school at Pontificia Universidad Católica de Chile, another highly selective school, launched the Mujeres Ingeniería program in 2013, which promotes women's participation through focal initiatives in high schools and intensive networking among the current students, faculty members, and women alumni. Women's participation in STEM at this institution in terms of the first-year enrollment went from $19 \%$ in 2012 to $24 \%$ in 2015 (Farías, 2016).

The case of FCFM at Universidad de Chile is a case of a STEM school at a top-tier university, so it may not represent the trends in all higher education institutions in Chile. On the one hand, Bordon et al. (2020) found that there is a more considerable gap between men and women choosing STEM fields in most Chilean selective institutions. Similar trends have been reported in other countries such as the U.S. and U.K. Despite women students being increasingly represented in selective and very selective institutions in more recent years, they were consistently underrepresented in highly or most selective institutions (Kim et al., 2020), net of background and academic factors (Hearn, 1991; Davies \& Guppy, 1997; Ro et al., 2018). This might be in part the result of the most selective institutions tending not to offer traditionally women-dominated programs (Bobbitt-Zeher, 2007) and offering more degrees in fields where women are underrepresented, such as STEM (Bielby et al., 2014). On the other hand, literature on the social movement suggests that movements might have more significant influences on selective higher education institutions as selective institutions are often where the movement starts (Soule, 1997), and, those institutions might have resources to enact required changes in related practices. Thus, in the next section, we examine nationallevel data on women's enrollment in STEM undergraduate majors in Chile. 


\section{Jeongeun Kim and Sergio Celis}

Analyzing the higher education enrollment data between 2007 and 2019, we describe how women's enrollment in different STEM majors has changed over time at different types of higher education institutions.

\section{Evolution of the Participation of Women in STEM Undergraduate Education: 2007-2019}

This section presents descriptive analyses based on the publicly available historical enrollment data provided by SIES (2020b), a governmental agency at the Chilean Ministry of Education. The database includes enrollment counts and characteristics of enrolled students for all higher education programs aggregated at the program level between 2007 and 2019. For this study, we focused on undergraduate programs only.

It is important to introduce the Chilean higher education context in order to present the results. The Chilean higher education system consists of 150 institutions divided into three major types. Centros de formación técnica (vocational-technical centers) $(\mathrm{N}=52)$ offer (1) two-year programs (equivalent to ISCED level 5 programs; UNESCO, 2012), and (2) professional institutes $(\mathrm{N}=39)$ offer four-year programs (equivalent to programs at ISCED levels 5 and 6); (3) Universities $(\mathrm{N}=59$ ) are the only type of institutions allowed to grant bachelor, master's, and doctoral degrees (equivalent to programs at ISCED levels 6 and higher) (SIES, 2020c). In 2020, 1,151,727 students are enrolled across the three types of higher education institutions, with $11 \%$ at vocational-technical centers, $31 \%$ at professional institutes, and 58\% enrolled at universities (SIES, 2020d). Vocationaltechnical centers and professional institutes (technical and professional institutes, TPI hereafter) are considered open access teaching institutions and the majority of their students come from low-income families (Espejo, 2016). Across the higher education system, women represent about $53 \%$ of the undergraduate enrollment (SIES, 2020d).

To study the evolution of women's participation in STEM, we addressed three groups of institutions in this section: TPIs, universities, and top-tier universities in science and engineering. We employed the U.S. World and News Report's Best Global Universities for Engineering in Chile (2020) to define the top-tier institutions. Four Chilean universities appear in this ranking: Pontificia Universidad Católica de Chile, Universidad de Chile, Universidad de Concepción, and Universidad Técnica Federico Santa María. We classified programs into STEM and non-STEM programs, according to the 24 Organization for Economic Cooperation and Development (OECD) sub-areas of specialization. We included fields related to agriculture, forestry and fishing, architecture and construction, life sciences, physical sciences, industry and production, computing, engineering, mathematics and statistics, and environmental protection in STEM programs. Non-STEM programs included were those related to arts, education, humanities, social and behavioral sciences, law, business, medicine, journalism, veterinary, and services. 


\section{Women in STEM by Institutional Type}

We measured participation of women in STEM based on the first-year of enrollment, because it better hints at what has happened as social movements developed and universities, particularly the top institutions, have adopted admissions policies and practices to increase women in their STEM undergraduate programs. First, Figure 7.1, Panel (A) mirrors what was described in the previous section about the expansion of women's access to higher education in Chile. In 2007, the proportion of women among all first-year students in higher education institutions was $51.59 \%$, which increased to $57.20 \%$ by 2017. Yet, women's representation in STEM was steadily low at 20\%, except for a slight increase observed in 2008 (23.54\%) and 2017 (23.11\%). The increased representation of women in undergraduate education is mostly driven by the high proportion of women in non-STEM majors, which has been consistently above $61 \%$ and reached 65-66\% starting in 2017.

Panels (B)-(D) show that women's first-year enrollment in STEM is stratified by institutional type. Specifically, women's representation in STEM programs was highest among the four top-ranked universities. As FCFM set an example that other institutions followed, implementing admissions policies and initiatives to attract women, this might be an expected outcome. Panel (D) shows that the proportion of women among the first-year STEM students was consistently higher by over $10 \%$ at these four top-ranked institutions, compared to the national average as well as other institutional types for the last two decades. Also, this group of institutions observed a significant increase in
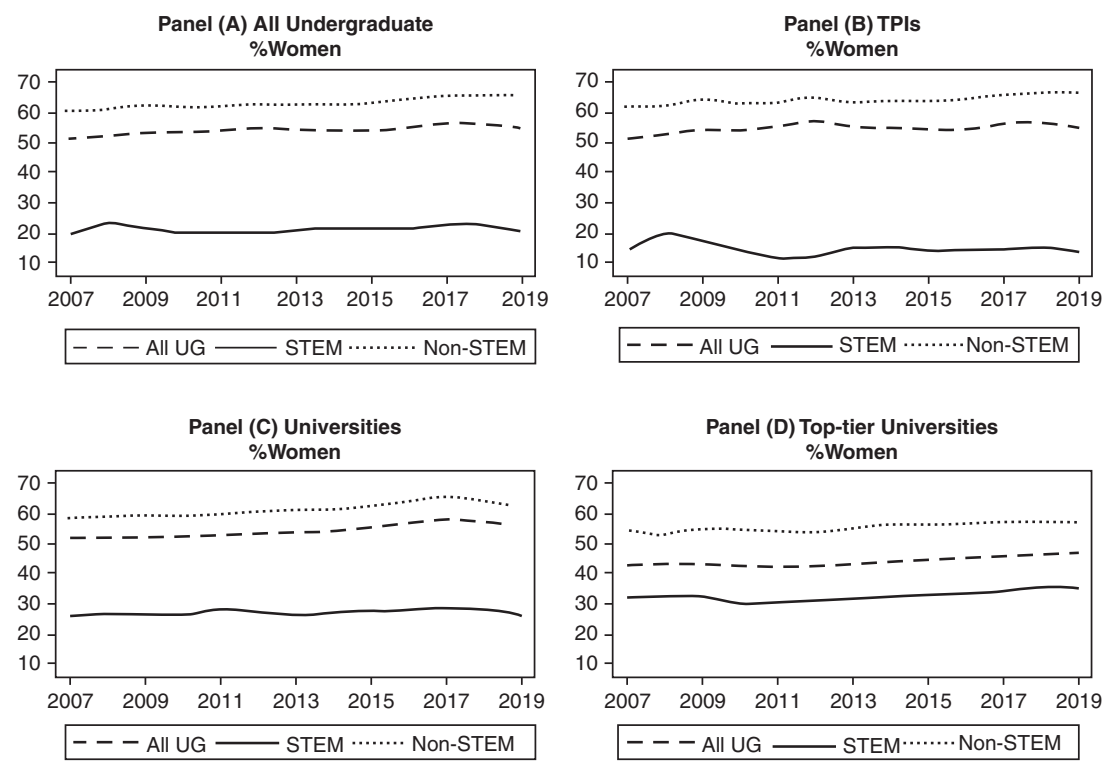

Figure 7.1 First-year Enrollment: Women in STEM vs non-STEM. 


\section{Jeongeun Kim and Sergio Celis}

women enrolled in STEM programs. On average, about 32\% of the STEM first-year students were women between 2007 and 2009, followed by a slight decline between 2010 and 2013 (30-31\%). Yet, in 2014, 2017, and 2018, women constituted $33 \%, 34 \%$, and $36 \%$, respectively, of the STEM first-year enrollment at top-ranked institutions. It is also important to note that only $42-$ $46 \%$ and $53-57 \%$ of the students were women across all majors and nonSTEM majors, respectively, which were lower than the national average for both measures.

These trends were the opposite for the other two institutional types. In particular, women remain strikingly underrepresented in the STEM programs at TPIs (See Panel (B)). On average, only 15\% of the first-year students were women (lowest in 2011 with $11.33 \%$ and highest in 2008 with 20.52\%). This is significant considering that $57 \%$ of all first-year students were women, which has increased by $5 \%$ since 2007 , and that the proportion of women students in non-STEM majors has been between $62 \%$ to $67 \%$ during the analytic period.

Panel $(\mathrm{C})$ reports the enrollment trends at universities other than the top four institutions. These institutions showed rather stable trends in the proportion of women first-years at around 26\% (2007-2010) to 27-29\% (20112017), which decreased by up to $3 \%$ point by 2019 . Meanwhile, the representation of women in non-STEM majors increased steadily from $59 \%$ in 2007 to $66 \%$ in 2017 , which remained at $64 \%$ in 2019. To sum, women's representation in STEM is higher at more selective institutions in Chile. This is different from trends reported in other countries such as the U.S. (Hearn, 1991; Davies \& Guppy, 1997; Kim et al., 2020) or U.K. (Ro et al., 2018) as well as previous observations made in Chile (Bordon et al., 2020). This finding might be attributable to changes in the admissions policies, such as affirmative action or other initiatives for attracting more women to STEM that were induced by social movements (Villaseñor et al., 2020). Also, prestigious universities tend to offer more degree programs in STEM fields, including those areas (e.g., life sciences, physical sciences) that have relatively higher levels of participation among women in the Chilean context. We provide related analysis in the following section.

\section{Women within STEM Fields}

Often, underrepresentation of women is discussed in STEM as a whole. Yet, gender gaps might appear differently in specific STEM majors (e.g., Sassler et al., 2017). Here, we focus on universities and examine trends in enrollment across different majors within STEM. Table 7.1 compares the percentage of women among first-year students in the university system across four fields: Life sciences (e.g., biology, biochemistry, environmental chemistry), Engineering (e.g., mining, civil, electrical), Physical sciences (e.g., geology, astronomy, chemistry, physics) and Computing (e.g., computer programming, information systems) between 2007 and 2019. 
Table 7.1 Percentage of Women by Major, First-year Students: All Universities

\begin{tabular}{|c|c|c|c|c|}
\hline & Life Sciences & Engineering & Physical Sciences & Computing \\
\hline 2007 & $\begin{array}{l}55.65 \% \\
\text { (16 institutions) }\end{array}$ & $\begin{array}{l}19.74 \% \\
\text { (35 institutions) }\end{array}$ & $\begin{array}{l}51.09 \% \\
\text { (18 institutions) }\end{array}$ & $\begin{array}{l}13.24 \% \\
\text { (40 institutions) }\end{array}$ \\
\hline 2009 & $\begin{array}{l}52.83 \% \\
\text { (16 institutions) }\end{array}$ & $\begin{array}{l}23.12 \% \\
\text { (33 institutions) }\end{array}$ & $\begin{array}{l}46.35 \% \\
\text { (19 institutions) }\end{array}$ & $\begin{array}{l}13.99 \% \\
\text { (39 institutions) }\end{array}$ \\
\hline 2011 & $\begin{array}{l}52.97 \% \\
\text { (17 institutions) }\end{array}$ & $\begin{array}{l}20.84 \% \\
\text { (35 institutions) }\end{array}$ & $\begin{array}{l}45.85 \% \\
\text { (23 institutions) }\end{array}$ & $\begin{array}{l}14.28 \% \\
\text { (39 institutions) }\end{array}$ \\
\hline 2013 & $\begin{array}{l}52.46 \% \\
\text { (15 institutions) }\end{array}$ & $\begin{array}{l}25.91 \% \\
\text { (38 institutions) }\end{array}$ & $\begin{array}{l}41.18 \% \\
\text { (25 institutions) }\end{array}$ & $\begin{array}{l}11.68 \% \\
\text { (40 institutions) }\end{array}$ \\
\hline 2015 & $\begin{array}{l}51.53 \% \\
\text { (15 institutions) }\end{array}$ & $\begin{array}{l}19.49 \% \\
\text { (37 institutions) }\end{array}$ & $\begin{array}{l}44.20 \% \\
\text { (26 institutions) }\end{array}$ & $\begin{array}{l}12.12 \% \\
\text { (38 institutions) }\end{array}$ \\
\hline 2017 & $\begin{array}{l}46.52 \% \\
\text { (16 institutions) }\end{array}$ & $\begin{array}{l}21.80 \% \\
\text { (38 institutions) }\end{array}$ & $\begin{array}{l}50.44 \% \\
\text { (25 institutions) }\end{array}$ & $\begin{array}{l}10.61 \% \\
\text { (35 institutions) }\end{array}$ \\
\hline 2019 & $\begin{array}{l}50.78 \% \\
\text { (17 institutions) }\end{array}$ & $\begin{array}{l}19.93 \% \\
\text { (39 institutions) }\end{array}$ & $\begin{array}{l}47.95 \% \\
\text { (25 institutions) }\end{array}$ & $\begin{array}{l}9.96 \% \\
\text { (35 institutions) }\end{array}$ \\
\hline
\end{tabular}

Notes: Analysis focuses on all universities, including the top-tier universities.

Not all majors in STEM have the same level of underrepresentation among women. Although the data do not allow us to analyze enrollment trends by specific disciplines, we observe the proportion of women among the first-year students enrolled across broader subject areas. In particular, life sciences programs filled over $50 \%$ of their first-year enrollment with women students, and even the lowest point for the proportion of women enrollment in the respective major was $47 \%$; similarly, women were $45-50 \%$ of first-year enrollment in physical sciences between 2007 and 2019. In contrast, engineering and computing majors have a significantly lower proportion of women among their first-year students, even though the number of institutions offering these programs is nearly twice the number of those offering life sciences and physical sciences. On average, women usually made up about $20 \%$ of the first-year enrollment in engineering programs, which peaked at $26 \%$ during the analytic period before decreasing again to $19.93 \%$, which is close to where the observation started in 2007. For computing majors, the proportion of women is even lower, showing mostly diminishing trends over time: in $2007,13.24 \%$ of first-year enrollment was women, which increased slightly through 2011 $(14.28 \%)$, then decreased to $9.96 \%$ as of 2019 . This underrepresentation among women in engineering and computing majors is critical considering that higher education is the gateway for women for science and technology professions and diverse social roles. Also, this suggests the importance of understanding women's access to STEM in a more nuanced way as well as understanding sub-field level participation when it comes to designing policies and practices to attract and support women. 


\section{Jeongeun Kim and Sergio Celis}

\section{Discussion}

While increasing women's representation and their voices in STEM is a keen interest in many countries, most approach it from a top-down perspective where public policy or related industry and organizations lead initiatives. In this chapter, we discussed how women's participation in undergraduate STEM programs might be improved via social movements using the Chilean case as an example. We first introduced the historical changes that happened at FCFM at Universidad de Chile to exemplify how women faculty members' grassroots movement produced relevant institutional changes to increase the participation of women in STEM, such as the PEG affirmative action for admission into engineering and physical science programs. The evidence suggests that women faculty members' collective action resembles a scientific and intellectual movement (Frickel \& Gross, 2005). The movement at FCFM was effective in increasing the percentage of women in undergraduate programs and institutionalized gender and diversity issues at the top administration level. The case of FCFM served as an example for other institutions that subsequently adopted institutional policies to attract more women students to STEM undergraduate programs, and FCFM is continuing to share its success stories and advise other engineering and science campuses in the country to follow suit.

It is important to note that it is too early to forecast how far the movement will go in its efforts. The grassroots movement is continuing work on its agenda to make FCFM a welcoming place for women, promoting science and engineering among K-12 students, and conducting research on gender related topics in STEM fields. It is also attending to issues with recruiting and retaining women faculty, such as hiring and promotion practices. Therefore, more future research is needed to examine the impact of the grassroots movement on gender equality in STEM fields. Future research is warranted for a deeper understanding of women students' experiences at FCFM and their trajectories beyond graduation such as access to graduate education or working in STEM professions that fit their majors. We encourage researchers to examine how the feminist social movement is perceived by students, faculty, and university administrators. Additionally, researchers may consider how the grassroots movement results in changes and adoption of policies and practices to attract, retain, and support women in STEM, as well as how these efforts are legitimized and encouraged by the central and local governments and related industries in Chile.

In this chapter, the analysis of the national trends in undergraduate enrollment data suggested that the social movement-induced, institutional changes that were made at FCFM, along with the nation's other prestigious institutions (e.g., the School of Engineering at Pontificia Universidad Católica), to attract more women might have achieved some success. The country's top four institutions already had a better representation of women in their STEM programs in 2007 compared to other institutions in the country. Yet, in the periods after the 
introduction of affirmative action (2014) or other engagement programs, the proportion of women among STEM first-year students increased by $2 \%$ in the first-year, and up to $5 \%$ approximately four-years after implementation. While this improvement shows the potential of making these academic units act as a spearhead that can influence the rest of the country's institutions in the long-run, the national-level statistics and data from institutions that provide more open access to higher education raise significant questions.

At the national level, women's participation in STEM is still and has been steadily low as women make up just above $20 \%$ of STEM enrollment, despite the drastic increase in women's access to higher education and academic achievements that surpass men. Yet, somehow, the mobilization of women on university campuses, and the greater public awareness about women's underrepresentation in STEM fields, is not yet reflected in the national data. This might be due to the stratification of higher education institutions and STEM programs where top schools with more resources have capacities to implement affirmative action policy, develop engagement programs and practices, and build faculty capacity (e.g., more women faculty in general and/or in STEM) thereby implementing a systematic approach. Also, the students who apply, receive admission, and matriculate to STEM programs at top institutions might have different attributes, such as higher socioeconomic status and better academic preparation than students enrolled in other types of institutions or non-STEM majors.

In fact, we found that women's enrollment in STEM is strikingly low for the last 12 years of analyzed data for TPI institutions. Since TPI enrolls students primarily coming from low-income families, their role in addressing the gender gap in STEM is important where the issues of gendered education and social class intersect. According to Sepúlveda (2019), Chile's vocational and technical education sector was firmly rooted in Chile's early industrialization process at the end of the 19th century. Women were from very early ages pushed towards service majors and clothing manufacturing. Since the 1980s, women have moved towards other TPI programs, such as education, health, and administration and accounting. Women remain underrepresented in vocational STEM programs, such as automotive mechanics or telecommunications, that provide the highest employability and income in the sector (Sepúlveda, 2019). These different major offerings at TPI institutions may place women in the lower paying jobs in the country. Usually, TPI is off student movements' radar and receives little attention from educational researchers in Chile. Public policy must pay greater attention to the participation of women in STEM programs at TPIs. Joining efforts with the successful programs in toptier universities in giving support to gender initiatives and programs TPIs is an action worthy to explore. The TPI sector represents about $40 \%$ of Chilean higher education and is an effective route for social mobility, and there is potential to significantly increase women in STEM.

In addition to the institutional type, we found that there is great variability of women enrollment within STEM programs. Underrepresentation of 


\section{Jeongeun Kim and Sergio Celis}

women is severe in engineering and computing fields across all universities, despite the number of institutions that offer engineering and computing is nearly twice more than the universities offering science majors. The FCFM case also shows that within engineering, there are significant differences between subfields, with low percentages of women in math and electrical engineering. While these are the key areas for Chile's economic sustainability and technological progress, not recognizing the nuanced placement of women across sub-STEM majors would have ramifications for women's career and life opportunities as well as for the diversity and innovation of Chilean society through science and technology. While different fields have unique norms and cultures, it is important to understand how women are attracted and retained across different types of institutions. It is also important to better understand how universities, departments, and faculty shape women students' experiences during college and influence their outcomes beyond undergraduate education.

\section{Conclusion}

The participation of women in STEM in Chilean higher education is unique and significant as their progress stems from social movements and scientific and intellectual movements internal to higher education. The achievement of these movements that resulted in institutional policies that increased women's representation in STEM suggests to other countries the pivotal role of letting faculty and students, particularly women groups' voices, be heard. While the systems' most prestigious institutions have led the changes and progress, we suggest that the Chilean and other educational systems consider how to encourage and support institutions that lack resources, capacities, or means to attract and support women undergraduates in STEM, considering the unique backgrounds of and challenges experienced by the students at these institutions.

\section{Note}

1 The corresponding author has been part of FCFM since 2015 and is currently part of the internal council of the Associate Dean's office for gender and diversity affairs, which helped the authors identify and understand these materials.

\section{References}

Allen-Ramidal, S. A., \& Campbell, A. G. (2014). Reimagining the pipeline: Advancing STEM diversity, persistence, and success. BioScience, 64(7), 612-618.

Andrade Lara, C. (2013). Del biombo à la cátedra: Igualdad de oportunidades de género en la Universidad de Chile. https://doi.org/10.34720/3vwj-m574

Baldez, L. (2002). Why women protest: Women's movements in Chile. Cambridge University Press.

Bastarrica, M. C., Hitschfeld, N., Samary, M. M., \& Simmonds, J. (2018). Affirmative action for attracting women to STEM in Chile. Proceedings of the 1st International Workshop on Gender Equality in Software Engineering, 45-48. 
Bellei, G., \& Cabalin, C. (2013). Chilean student movements: Sustained struggle to transform a market-oriented educational system. Current Issues in Comparative Education, 15(2), 108-123.

Bielby, R., Posselt, J. R., Jaquette, O., \& Bastedo, M. N. (2014). Why are women underrepresented in elite colleges and universities? A non-linear decomposition analysis. Research in Higher Education, 55(8), 735-760.

Bobbitt-Zeher, D. (2007). The gender income gap and the role of education. Sociology of Education, 80, 1-22.

Bonilla, N. (2016). Experiencia académica de estudiantes mujeres en primer año de ingeniería. propuestas de mejoramiento de los sistemas de apoyo a estudiantes con mirada de género [Unpublished master's thesis]. Universidad de Chile.

Bordon, P., Canals, C., \& Mizala, A. (2020). The gender gap in college major choice in Chile. Economics of Education Review, 77, 102011. https://doi.org/10.1016/j.econe durev.2020.102011

Crummett, M. A. (1977). El poder pfFeminino: The mobilization of women against socialism in Chile. Latin American Perspectives, 4(4), 103-113.

Dávalos, A. (2019a). Red Adelina Gutiérrez: Académicas por la equidad de género. Beauchef Magazine, 12, 16-18.

Dávalos, A. (2019b). La primera ingeniera de Sudamérica: Un logro con Justicia. Beauchef Magazine, 12, 26.

Davies, S., \& Guppy, N. (1997). Fields of study, college selectivity, and student inequalities in higher education. Social Forces, 75(4), 1417-1438.

DiMaggio, P., \& Powell, W. (1983). The iron cage revisited: Institutional isomorphism and collective rationality in organizational fields. American Sociological Reviewe, 48(2), $147-160$.

Espejo, A. (2016). La educación técnico-profesional en el futuro. Estudios Sociales, 124(1), $161-178$.

Farías, J. (2016). Mujeres ingeniería UC y más mujeres para la ingeniería y las ciencias de la U. de Chile: una mirada al impulso del acceso, experiencia y permanencia de las mujeres en las carreras ingenieriles y cientificas en Chile [Unpublished master's thesis]. Universidad de Chile.

Frickel, S., \& Gross, N. (2005). A general theory of scientific/intellectual movements. American Sociological Reviewe, 70(2), 204-232.

Hearn, J. C. (1991). Academic and nonacademic influences on college destinations of 1980 high school graduates. Sociology of Education, 64(3), 158-171.

Jaksic, I. (1989). Academic rebels in Chile: The role of philosophy in higher education and politics. State University of New York Press.

Jaksic, I., \& Serrano, S. (1990). In the service of the nation: The establishment and consolidation of the Universidad de Chile, 1842-79. The Hispanic American Historical Review, 70(1), 139-171.

Kim, C., Tamborini, C. R., \& Sakamoto, A. (2015). Field of study in college and lifetime earnings in the United States. Sociology of Education, 88(4), 320-339.

Kim, J., Jung, J., \& Mlambo, Y. A. (2020). Institutional selectivity and occupational outcomes for STEM graduates: A generational comparison. The Fournal of Higher Education. https://doi.org/10.1080/00221546.2020.1819945

Levy, D. (1991). The decline of Latin America activism. Higher Education, 22(1), 145-155.

Mizala, A. (2018). Género, cultura y desempeño en matemáticas. Anales de La Universidad de Chile, 14, 125-150. 
Palma Manríquez, I. (2018). Debates abiertos en la coyuntura sobre las instituciones universitarias por las estudiantes del movimiento mayo feminista. Anales de La Universidad de Chile, 14, 89-107.

Paredes, V. (2014). A teacher like me or a student like me? Role model versus teacher bias effect. Economics of Education Review, 39, 38-49. https://doi.org/10.1016/j.econe durev.2013.12.001

Paredes-Walker, V. (2020). Mujeres que marcan precedentes en Ingeniería. Su experiencia en la carrera académica en una universidad de investigación en Chile. Revista Iberoamericana de Educación Superior, 30(11), 137-159.

Rebolledo González, L., \& Valdés Subercaseaux, X. (2018). Género y orden social: Dificultades para implementar relaciones de género igualitarias en la vida cotidiana. Anales de La Universidad de Chile, 14, 17-30.

Ríos, I., Larroucau, T., Parra, G., \& Cominetti, R. (2014). College admissions problem with ties and flexible quotas. Article no. 2478998. http://dx.doi.org/10.2139/ssrn.2478998

Ro, H. K., Fernandez, F., \& Alcott, B. (2018). Social class, human capital, and enrollment in stem subjects at prestigious universities: The case of England. Educational Policy. https://doi.org/10.1177/0895904818813305

Sassler, S., Michelmore, K., \& Smith, K. (2017). A tale of two majors: Explaining the gender gap in STEM employment among computer science and engineering degree holders. Social Sciences, 6(3), 69-96.

Sepúlveda, L. (2019). Estudiantes mujeres en educación técnica profesional en Chile: Continuidad y ruptura en inclusión educativa. Sinéctica, 53(1),1-19.

Servicio de Información de Educación Superior (SIES). (2020a). Informe de brechas de género en educación superior: Datos 2019. Ministerio de Educación de Chile. https:// www.mifuturo.cl/wp-content/uploads/2020/03/Brechas-de-genero-en-educacionsuperior_SIES_2019.pdf

Servicio de Información de Educación Superior (SIES). (2020b). Base de datos de matriculados en educación superior: Histórica 2007-2020. Ministerio de Educación de Chile. https://www.mifuturo.cl/bases-de-datos-de-matriculados/

Servicio de Información de Educación Superior (SIES). (2020c). Instituciones de educación superior vigentes: 31 de diciembre de 2019. https://www.mifuturo.cl/institu ciones-de-educacion-superior-en-chile/

Servicio de Información de Educación Superior (SIES). (2020d). Informe 2020: Matrícula en educación superior. https://www.mifuturo.cl/wp-content/uploads/ 2020/07/Informe-matricula_2020_SIES.pdf

Snow, D. A., Soule, S. A., \& Kriesi, H. (2004). Mapping the terrain. In D. A. Snow, S. A. Soule, and H. Kriesi (Eds.), The Blackwell companion to social movements (pp. 3-16). Blackwell Publishing.

Soule, S. A. (1997). The student divestment movement in the United States and tactical diffusion: The shantytown protest. Social Forces: A Scientific Medium of Social Study and Interpretation, 75(3), 855-882.

UNESCO Institute for Statistics. (2012). International standard classification of education ISCED 2011. http://uis.unesco.org/sites/default/files/documents/interna tional-standard-classification-of-education-isced-2011-en.pdf

U.S. World and News Report. (2020). Best global universities for engineering in Chile. https://www.usnews.com/education/best-global-universities/chile/engineering

Villaseñor, T., Celis, S., Queupil, J. P., Pinto, L., \& Rojas, M. (2020). The influence of early experiences and university environment in female students choosing geoscience programs: A case study at Universidad de Chile. Advances in Geosciences. 53, 227-244. 


\title{
8 Examining Gender (In)Equality in German Engineering
}

\author{
Considering the Importance of Interest, \\ Perceptions, and Choice
}

\author{
Jennifer Dusdal and Frank Fernandez
}

After the United States and China, Germany is the world's main producer of research in science, technology, engineering, and mathematics (STEM) fields. This development has been fostered by the institutionalization of strong research universities and extra-university research institutes (Dusdal et al., 2020). In addition, laboratories and research institutes within companies have established strong university-industry relationships (e.g. Dusdal, 2018; Dusdal, Powell, \& Oberg, 2019). Germany spends more per capita on STEM research and development than either the United Kingdom or France, which are two other major European leaders in STEM. Still, the persistent underrepresentation of women in STEM (Nimmesgern, 2016) has a massive negative impact on the labor force and economic growth. The European Institute for Gender Equality (n.d.) projected that achieving gender parity in STEM education would increase employment in the European Union (EU) by up to 1.2 million jobs. Additionally, the Institute projected that improving gender equality would increase the EU's per capita GDP up to $0.9 \%$ by 2030 and up to $3 \%$ by 2050 (or by up to $€ 180$ billion by 2030 and up to $€ 820$ billion by 2050).

The United Nations Educational, Scientific and Cultural Organization (UNESCO) has called for leaders around the world to address the persistent, near universal underrepresentation of women in engineering (UNESCO, 2015). Within the EU, countries face a noticeable labor force shortage in STEM. The European Commission (EG) forecasts 7 million job openings for the STEM sector by 2025. Thus, the EC and EU have implemented several measures to increase women's participation in STEM (e.g. UNESCO's For Women in Science Programme, funded by L'Oréal ${ }^{1}$ to address gender segregation in research and science, career challenges for women, a lack of women in leadership positions in academia and industry, gender imbalance in access to research funding, and gender-biased research (Fatourou et al. 2019).

As a global leader in STEM research, the German government has focused on improving women's attainment in engineering fields through the implementation of various national initiatives to foster equal opportunity and to attract and retain women in STEM fields (Best et al., 2013). Although Germany is at the forefront of producing talented graduates in STEM, in 2015 fewer than one out of three students were STEM graduates (OECD, 2017 as cited in Isphording \& Qendrai, 
2019). In a 2019 report, the Federal Ministry for Family Affairs, Senior Citizens, Women and Youth (BMFSFJ) declared that "in the face of digital transformation, demographic change and the resulting lack of skilled workers, it is important to attract young women to STEM careers and increase the number of women students, especially in computer science and electrical engineering" (BMFSFJ, 2019, p. 30).

Gender remains one of the most crucial factors in study choice and decision for engineering and natural sciences in Germany (Heine et al., 2006). Since the 1990s, English-language studies that examined German women's access to higher education often focused on enrollment patterns following the reunification of East and West Germany (e.g., Ammermüller \& Weber, 2005; Blossfeld et al., 2015). Scholars found that women in what used to be East and West Germany experienced different opportunities and challenges. For example, women earned a larger percentage of engineering degrees in East Germany than in West Germany; that is, there was a larger participation gap in STEM education between women and men in West Germany. However, the gender gap in what was West Germany began to improve as women experienced more opportunity and better pay in the engineering labor market. Even though women in East Germany historically had greater access and attainment to engineering education, they were still underpaid relative to men (Ammermüller \& Weber, 2005).

Beyond focusing on the German experience with reunification, there are several studies that address women's access to higher education or labor market outcomes (e.g., Becker, 2014; Blossfeld et al., 2015; Grave \& Goerlitz, 2012; Kim \& Kim, 2003; Meyer \& Strauß, 2019; Reimer \& Steinmetz, 2009; Wahrenburg \& Weldi, 2007). However, relatively few papers examine women as undergraduates (e.g., Ammermüller \& Weber, 2005; Schlenker, 2009). While some studies consider the extent to which women are underrepresented, scholars often overlook why women choose not to study STEM and how those reasons compare to men. Research has shown (e.g., Seymour \& Hunter, 2019, Best et al., 2013 for an overview) that several different reasons, including a maledominated STEM culture (Solga \& Pfahl, 2009a, 2009b) and subject specific environments, for example particular learning cultures or a competition-oriented atmosphere, increase the drop-out rates among women (Brainard \& Carlin, 2001; Derboven \& Winker, 2010; Hetze, 2011; Ihsen et al., 2009; Seymour \& Hewitt, 1997; Wolffram et al., 2009) and disable their promotion to top academic positions (GWK, 2019). Teenage women have significantly less frequent contacts with STEM in their leisure time and through internships than teenage men, which might impact their study decisions (Best et al., 2013). Other factors that influence study choice include interest in the subject and previous attainment in related subjects (Elster, 2014).

To enhance women's participation in STEM fields in academia it is important to increase early interest in STEM subjects. Starting at an early age, parents should encourage young girls to take interest in STEM (Elster, 2014). Similarly, teachers and other women role models at school should 
support STEM aspirations (Bottia et al., 2015; Dasgupta \& Stout, 2014). Teachers should work to reduce gender stereotypes that are associated with STEM school subjects - such as the idea that boys are better at math than girls (Carlana, 2019; Makarova et al., 2019). To make high academic positions attractive for women, it is essential to create more attractive and flexible research-oriented careers (Wissenschaftsrat, 2013).

Therefore, the purpose of this chapter is to consider why German women may self-select out of STEM fields and to identify potential opportunities to encourage more women to study STEM. In the next section of the chapter, we briefly describe Germany's education system, because "[s]chools can inspire, reinforce, or discourage students' interest in pursuing a STEM field of study in higher education" (Jacob et al., 2020, p. 62). Then we discuss broad patterns in women's access to STEM education and employment opportunities in Germany. After our review of prior literature, we present data to show different ways that gender matters in German STEM higher education. In closing, we introduce policies and initiatives that are meant to support women in STEM in Germany and consider ways that they might hold transferrable lessons for other countries.

\section{From Primary Education to Higher Education in Germany}

The German educational system contrasts with those of many other countries around the world. It features early allocation and strong school segregation: from the age of ten in most German federal states (Bundesländer), pupils are placed within a highly stratified secondary school system. These tracks lead to different postsecondary opportunities, some more academic and others more vocational. The system of German schooling and skill formation leads to relatively low (but growing) proportions of each cohort to enter higher education as full-time university students. Vocational training opportunities in Germany's "dual system" of school-based training and in-firm apprenticeships remain attractive. A relatively small percentage of each cohort graduating secondary schooling begins hybrid postsecondary vocational education and training (VET) and higher education programs, often referred to as "dual studies," that combine in-firm training with postsecondary academic studies (Graf \& Powell, 2017; Graf, 2013). Taken together, these features cultivate the idea of "German exceptionalism" in schooling, VET, and higher education (Powell \& Solga, 2011, p. 49).

Studies show that an increase in distinct pathways (vocational vs. academic) led to a larger gender gap in STEM occupational aspirations (Sikora \& Pokropek, 2012; Han, 2016). Although science and math are compulsory subjects for all students in Germany, it does not reduce the gender gap in STEM fields in higher education enrollments (Jacob et al., 2020). In the subsections that follow, we describe some of the characteristics of the German education system and how it creates distinct pathways for women's postsecondary opportunities. 


\section{From Primary to Secondary School}

During the 20th century, cohorts of German children increasingly attended schooling for longer stretches of their youth (Becker, 2003). German expansion of primary and secondary schooling during the 20th century was part of a global pattern (Baker, 2014), but the ways that Germany broadened participation in primary and secondary schools - ultimately leading to higher education - occurred within the unique context of Germany's existing highly stratified and segregated education system. After completing primary school at approximately 10 years of age, German youth may attend lower secondary school (Hauptschule), intermediate secondary school (Realschule), or upper secondary school (Gymnasium) (Kim \& Kim, 2003). A recent development in German schooling is the regionally-variant implementation of comprehensive schools (Gesamtschule), which combine Hauptschule, Realschule, and Gymnasium tracks (for an overview of education as a lifelong process in Germany see Blossfeld \& Roßbach, 2019).

Students are selected into one of the three secondary schools, which offer different curriculums of varying lengths. Lower secondary schools are universally accessible to students who complete primary schooling; they are less academically oriented and satisfy compulsory education requirements. The intermediate secondary schools offer a more academically oriented six-year course of study, which culminates in a certificate of completion. Finally, the upper secondary school track enrolls students for nine years, teaches a curriculum that prepares students to complete the Abitur (a qualification granted by passing standardized exams that is required to attend a research university, regardless of subject choice), and provides a direct pathway to enroll at a university (Kim \& Kim, 2003). Usually, all students who attend Gymnasium follow a similar curriculum until grade 10 or 11, with no specialization. Only in the last two or three years of schooling do students have some opportunities for specialization; at that point, students may choose different domains (in addition to core subjects). For example, advanced level students in the Gymnasium may select courses with intensified instruction in fields such as social sciences, STEM subjects, or foreign languages (Jacob et al., 2020).

Over the latter half of the 20th century, decreasing percentages of students attended the lower secondary schools, while the intermediate and upper secondary schools became increasingly well-attended (Becker, 2003). Becker (2003) argues that the decades of expansion of German schooling and the re-balancing of the secondary schools benefited German girls, in particular. The Abitur provides evidence that young women have long been prepared to succeed in postsecondary education. Beginning with cohorts who were born around the late 1970s, women have had a higher likelihood than men of attaining the Abitur (Becker, 2014).

\section{Access to Postsecondary Opportunities in Germany}

In Germany, access to higher education is more stratified than in other countries, such as the United Kingdom (Kim \& Kim, 2003). As previously 
described, the most direct route to a traditional research university is to attend upper secondary school (Gymnasium) and pass the Abitur. Students could instead pass the Fachhochschulreife to gain admittance to the universities of applied sciences. Alternately, one non-traditional way to access universities is to receive accreditation for competencies that students have gained through VET, though these alternative pathways are followed by very few (Freitag, 2012).

As with secondary schools, the two postsecondary tracks offer different options to students. The German case is unique from other chapters in this volume (e.g., the U.S. case) because its higher education system consists of a binary structure with two main types of universities: universities of applied sciences (Fachhochschulen or Hochschulen) that are more technically oriented and mainly focus on teaching as well as applied research, and traditional research universities (Universitäten), which provide undergraduate, graduate, and doctoral training and combine basic research with advanced teaching. Compared to the thousands of colleges and universities in the United States, the German higher education system is relatively small, with 126 research universities, 232 universities of applied sciences, and 51 art and music colleges (Powell \& Dusdal, 2017). Whereas Germany's system of secondary schooling is gradually becoming less stratified, scholars argue that inequality is not declining - and may be increasing - when it comes to attaining access to research universities (Blossfeld et al., 2015).

Whichever pathway German postsecondary students take, their studies are closely linked to their occupational outcomes. For example, research universities have historically been perceived as enhancing a student's "probability of entering the privileged and lucrative service class" (Kim \& Kim, 2003, p. 20). For this reason, "children from higher educational origin opt against the less prestigious universities of applied science and prefer the more prestigious research universities to preserve their advantages at the labour market" (Blossfeld et al., 2015, p. 157). The research universities offer greater opportunities for prestigious employment, but their graduates are also subject to spells of unemployment, unlike alumni of universities of applied sciences (Reimer \& Steinmetz, 2009).

Women increasingly enroll in both types of universities as a result of evolving gender norms, expanding access to higher education, and women attained greater earning potential in the labor market (Becker, 2014; Blossfeld et al., 2015). In winter term 2019-2020, 1.8 million students were enrolled at research universities, whereas 1 million were enrolled at universities of applied sciences. The proportion of women who attended universities $(51.7 \%)$ was a bit higher than at universities of applied sciences (45\%) (DESTATIS, 2020a). Although women's opportunities are relatively better, compared to women of earlier generations, they are still not equal to those of men. In the winter term 2019-20, about 1 million students at German universities and universities of applied sciences were enrolled in science and engineering, from which only $31.4 \%$ were women. The percentage of women students $(24 \%)$ was especially low in engineering (DESTATIS, 2020b). 
Analyses of those data from the German Centre for Higher Education Research and Science Studies (DZHW) on university dropouts show that women who study subjects where they make up less than $35 \%$ of enrollments "face a drop-out risk which is 1.5 times higher than men's and almost twice the women's" in a subject where they are better represented (Meyer \& Strauß, 2019, p. 451). Even though women fare well during admissions because they tend to have performed better in secondary school and to have more conscientious personalities than men (Isphording \& Qendrai, 2019), they may not be equitably retained within STEM fields. Comparing subjects within STEM more broadly, gender differences are highest in traditional STEM subjects (e.g., physics, chemistry, biology, engineering, math, and technology). Yet, the gender gap decreases, when STEM is defined as including medicine or health related disciplines. When focusing on engineering and technology, the gender gap more than doubles compared to a traditional classification of STEM disciplines (Jacob et al., 2020).

Meyer and Strauß (2019) suggest that women tend to be at larger risk of dropping out of higher education when they study university subjects that are dominated by men because women give themselves lower self-assessments of their academic performance. ${ }^{2}$ Additionally, Meyer and Strauß (2019) attributed women's higher risk of dropping out to their perceptions that their academic subjects were difficult. Conversely, the researchers identify several experiences that are related to reduced drop-out risk among German university students; these include positively interacting with peers and developing relationships with professors (Meyer \& Strauß, 2019).

\section{Why Study STEM? (Under)Employment Opportunities in Germany}

One common assumption is that students should be motivated to study STEM subjects because they offer access to lucrative employment. Labor markets in different countries provide various opportunity structures that might support or inhibit young women and men to strive for a career in STEM (Charles \& Bradley, 2009). Hägglung and Leuze (2020) point out that a post-industrial structuring of the labor market "increases the male-favorable gender expectation gap in STEM fields" (p. 16), but they acknowledge that it is empirically very difficult to separate whether the labor market has an impact on the gender gap in STEM expectations through socialization or rational decisions.

As in most countries, STEM graduates tend to be paid more highly than nonSTEM graduates. In the mid 2000s, the baseline starting salary for German engineering graduates was approximately $40 \%$ higher than for graduates in the arts and humanities (Grave \& Goerlitz, 2012). Controlling for a variety of variables individual and employer-related variables, reduced but did not eliminate the pay gap across fields. Engineers who were men continued to be paid more than women engineers (Wahrenburg \& Weldi, 2007). Moreover, women are promoted less frequently, win fewer research grants when they stay in academia 
(Nimmesgern, 2016), establish fewer international collaborations (Zippel, 2017), and show less international collaboration patterns than men (Kwiek \& Roszka, 2020; Larivière et al., 2013), which is a crucial driver for academic career development and scientific productivity (Wagner, 2018).

There are two competing explanations for why women earn less than men in engineering - both are problematic. Several scholars argue that pay disparities are the result of the gender composition of particular professions (e.g., Ammermüller \& Weber, 2005; Reimer \& Steinmetz, 2009; Wahrenburg \& Weldi, 2007). In other words, the first interpretation is that women are paid less in occupations in which they do not make up a critical mass of the workforce and are paid more in occupations in which they make up a majority of workers. For instance, Ammermüller and Weber (2005) note that in the former East Germany, women had better access to engineering education than in former West Germany, yet women typically earn more as teachers than as engineers; the authors note that this pattern implies "that it is not worthwhile for either men or women to choose a field of study which is dominated by the opposite gender" (Ammermüller \& Weber, 2005, p. 12).

Another group of studies suggests that women engineers earn less than men because they tend to work part-time. Kim and Kim (2003) examine data from the German microcensus (Mikrozensus) and Labour Force Survey data from the United Kingdom. They find that the pay gap between German women and men is smaller than the pay gap between British women and men when analyses are limited to full-time employees in a broad range of occupations. Relative to British women, "German women seem to be more willing to choose part-time jobs, even if they are highly educated" (Kim \& Kim, 2003, p. 24).

A separate study of census data estimates that only $65 \%$ of engineers who were women worked full-time (compared to $93 \%$ of men), $23 \%$ worked part-time (compared to $3 \%$ of men), and $13 \%$ were not in the labor force (compared to $4 \%$ ). The percentage of engineers who work full-time drops from $65 \%$ to $42 \%$ among mothers. Although 23\% of women engineers work part-time, $40 \%$ of mothers who are engineers work part-time. Comparatively, 95\% of engineers who are fathers work full-time (Schlenker, 2009). Because the engineering labor market is so gendered, Germany has an untapped "reserve of female engineers ... [an] estimated 24,400 women who graduated in engineering are not in the labour force, [and an] additional 40,500 female engineers work part-time" (Schlenker, 2009, p. 260). Yet, Schlenker (2009) notes that too few women earn degrees in engineering, so even if more women worked full-time, Germany would still need to educate more women in engineering.

There is a large body of literature that discusses highly diverse reasons why women are leaving STEM (for an overview see Blickenstaff, 2005) and that acknowledges that women and men differ in their choice of field of study (for an overview see Jacob et al., 2020). First, studies indicate that women prefer to enroll in humanities or education, whereas men are more likely to enroll in engineering or science (e.g., Barone, 2011; Charles \& Bradley, 2002; Smyth \& Steinmetz, 2008; Xie et al., 2015). Additionally, subjects at secondary school 
seem to have an impact on study decisions in postsecondary education (Chachashvili-Bolotin et al., 2016; Mann \& DiPrete, 2013; Riegle-Crumb et al., 2012). For example, Jacob and colleagues (2020) find that studying more STEM subjects at secondary school is a predictor of studying STEM in higher education; yet they note that prior schooling in STEM is a necessary, but not sufficient, condition to enter related fields within higher education.

Third, labor market structures, economic decisions, and expected labor market returns explain varying study decisions (Moorhouse, 2017; Fervers et al., 2020 as cited in Jacob et al., 2020). Especially in STEM, a decrease of drop-out rates would be a very effective answer to fill the gap of academicallyqualified personnel and to increase the labor supply (Heublein, 2014). On the other hand, very recent research suggests that smaller representation of women in STEM fields is not necessarily a disadvantage if gender-neutral occupations also provide high wages (Hägglung \& Leuze, 2020; Magnusson, 2013). Fourth, career aspirations have an impact on STEM enrollments (e.g., Tai et al., 2006; Xie \& Shauman, 2003). Compared to other countries, Germany is characterized by a very "leaky pipeline" in STEM fields (Leemann et al., 2010 , p. 299) that results in a massive loss of women in STEM throughout their educational and occupational careers (Solga \& Pfahl, 2009a). This can generally be described as "layers in a sex-based filter" (Blickenstaff, 2005, p. 384) and a multi-complex problem with different issues.

Except for a few studies (e.g., Solga \& Pfahl, 2009a, 2009b; Isphording \& Qendrai, 2019; Jacob et al., 2020), there is limited English-language literature on women who study STEM fields in German higher education. The literature highlights characteristics of the German educational system that influence student pathways to higher education (i.e., secondary school track, Abitur, attending a traditional university or a university of applied sciences) or dropping out of higher education (e.g., Isphording \& Qendrai, 2019). Additionally, key studies focus on women's disparate outcomes in the labor market. However, there are too few studies that examine women's motivations and concerns about studying STEM subjects at universities. Finally, among the studies we discuss in this literature review, most rely on older data that provide important context but may no longer apply to more recent cohorts of students - such as focusing on differences between East and West Germany prior to unification. In the next section, we provide data to identify challenges and opportunities for women in STEM at German universities.

\section{Findings from the 2008 Panel of School Leavers}

The German Centre for Higher Education Research and Science Studies (DZHW), with funding from the German Federal Ministry of Education and Research, regularly conducts panel surveys of secondary school leavers (i.e., high school graduates). The survey collects three waves of data from participants who have the requisite qualifications to attend a German research university or a university of applied sciences. The 2008 cohort was the 17th 
cohort to receive the cohort-panel-design survey. The first wave of data was collected between 2007 and 2008, and the second wave of data was collected between 2008 and 2009. The final wave of data was collected between 2012 and 2013 (Heine et al., 2017).

We analyzed data from the second wave of the 2008 panel study of school leavers to determine the extent to which German women consider studying STEM, even if they do not choose to do so. We then seek to examine why women may choose or opt-out of studying STEM fields. Because many prior studies on German women in STEM focus specifically on engineering, we too examine engineering sciences as a subset of STEM subjects. We analyzed unweighted data and examined gender differences for two survey items. The first item asked: "Have you considered starting a course in the engineering sciences at a university or university of applied sciences?" Respondents who stated that they had definitely chosen to not study engineering were directed to a follow-up question: "Why did you decide not to start an engineering sciences degree?" The first question offered mutually exclusive responses; the second question allowed respondents to select multiple answers.

First, we seek to identify whether there are many women who consider studying engineering but then pursue a different subject. We also compare whether larger percentages of women consider and then forego studying engineering compared to men. We find that there was a larger percentage of women $(80 \%)$ than men $(20 \%)$ who simply did not consider studying engineering at all. Among respondents who considered engineering, but stated that it "played no part in their final decision," 60\% were women. There was a near even split among those who "seriously considered" studying engineering but declined to choose that subject. Among respondents who were still undecided and continued to show interest in engineering, the majority $(71 \%)$ were men. In the final category - those who definitively chose engineering - seven in ten were men and only three in ten were women. See Figure 8.1.

Other than lack of interest, women and men both gave four common reasons for choosing not to study engineering. Although the reasons were similar, the percentages differed between women and men. The most popular reason women gave for not studying engineering was that prior learning about technology discouraged them from studying engineering; approximately three in ten women selected that reason, where fewer than two in ten men chose the same response. The second most common response among women was that they were unable to complete prerequisite courses. Although more than one in four women identified prerequisites as a barrier (26\%), a slightly higher percentage of men selected the same response (28\%). Another 16\% of women stated that "an engineering degree would be too boring" (compared to $15 \%$ of men who said the same). The fourth most common answer was that engineering was "quite attractive, but I'd possibly not be able to handle the degree" (14\% of women, $22 \%$ of men). Only about $4 \%$ of women stated they were interested in studying engineering, "but as a woman, I don't think my chances are very high." See Table 8.1. 


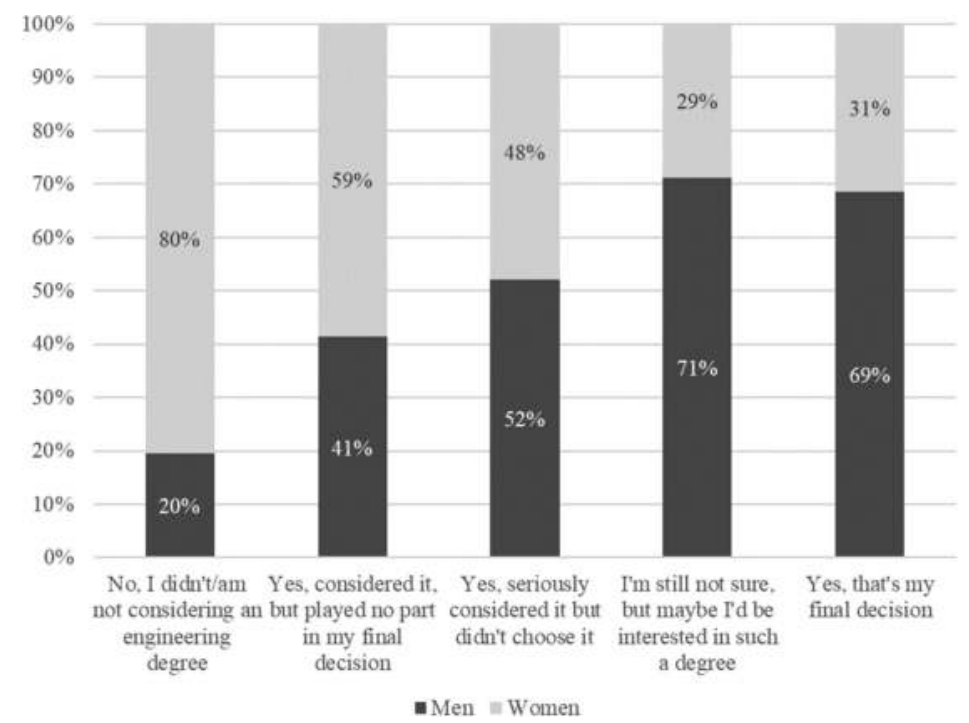

Figure 8.1 Percentages of secondary school leavers who considered studying engineering at a university or university of applied sciences.

Note: Authors' analysis of the 2nd wave of the DZHW Panel Study of School Leavers 2008. Translation of original survey items provided by DZHW.

Table 8.1 Reasons High School Leavers Decided Not to Start an Engineering Degree

\begin{tabular}{|c|c|c|c|c|}
\hline & Womer & & Men & \\
\hline & Yes & No & Yes & No \\
\hline My interests lie in other fields & $86 \%$ & $14 \%$ & $79 \%$ & $21 \%$ \\
\hline $\begin{array}{l}\text { The way technology was taught at school had a } \\
\text { negative effect on me }\end{array}$ & $30 \%$ & $70 \%$ & $17 \%$ & $83 \%$ \\
\hline $\begin{array}{l}\text { I cannot fulfill the prerequisites because of my } \\
\text { subject specializations in school }\end{array}$ & $26 \%$ & $74 \%$ & $28 \%$ & $72 \%$ \\
\hline I think an engineering degree would be too boring & $16 \%$ & $84 \%$ & $15 \%$ & $85 \%$ \\
\hline $\begin{array}{l}\text { Find the engineering profession quite attractive, but } \\
\text { I'd possibly not be able to handle the degree }\end{array}$ & $14 \%$ & $86 \%$ & $22 \%$ & $78 \%$ \\
\hline $\begin{array}{l}\text { The courses in the technical fields which interest me } \\
\text { are too far removed from real life }\end{array}$ & $4 \%$ & $96 \%$ & $5 \%$ & $95 \%$ \\
\hline $\begin{array}{l}\text { I'm interested in a degree/career in engineering but } \\
\text { as a woman I don't think my chances are very high }\end{array}$ & $4 \%$ & $96 \%$ & - & - \\
\hline $\begin{array}{l}\text { An engineering degree would be too work-intensive } \\
\text { for me }\end{array}$ & $3 \%$ & $97 \%$ & $5 \%$ & $95 \%$ \\
\hline $\begin{array}{l}\text { Because the career prospects are too insecure for me in } \\
\text { the subject area I'm interested in }\end{array}$ & $2 \%$ & $98 \%$ & $5 \%$ & $95 \%$ \\
\hline
\end{tabular}

Note: Authors' analysis of the 2nd wave of the DZHW Panel Study of School Leavers 2008. Translation of original survey items provided by DZHW. 
In addition to looking at the structure of educational systems and national enrollment data, we should consider how individual women make choices about whether to study STEM. Figure 8.1 shows that interest in STEM is not a binary construct. Although some women never considered majoring in engineering, other women gave varying degrees of consideration to studying engineering. In fact, some women who delayed choosing a final subject stated that they might still be interested in engineering. It seems that interest and time may both play factors in whether women ultimately pursue engineering.

Based on our findings, we argue that researchers should consider individual interests, perceptions, and choices when examining national gender disparities in STEM. For example, prior literature suggested that women may be less interested in studying engineering because women engineers often work parttime and earn less than men in engineering (e.g., Schlenker, 2009). Yet, less than $2 \%$ of women were concerned that "the career prospects are too insecure for me" in engineering. On the other hand, research shows that female students in engineering have an advantage compared to women in other disciplines to achieve an academic career (Barlösius \& Fisser, 2017). Women who decide to study engineering or even strive for an academic career seem to have a distinct aspiration for success, based on three attributes: a high level of self-confidence, a strong interest in STEM, and great determination to pursue their interests (Fisser, 2019). Women can and do succeed in STEM; thus, future research must continue to focus on choice and self-selection out of STEM. We now turn to considering ways that scholars, governments, and universities, can work toward improving gender equity in STEM.

\section{Implications for Research, Policy, and Practice}

The purpose of this chapter was to provide insights into the extent to which women consider studying engineering and select another field. Then, we wanted to understand their justifications for that choice. The 2008 Panel of School Leavers offered an opportunity to examine women in engineering as a subset of STEM. Although focusing on engineering is a limitation, it also allowed us to be consistent with prior literature on women in STEM in Germany. We found that examining data on subject choice offers several implications for supporting women's attainment in STEM fields.

First, we showed that German policymakers and educators may work to increase the percentage of women who consider studying STEM when they leave secondary school to attend a traditional research university or a university of applied sciences. Additionally, there was nearly a 20\% gap between women and men who considered engineering but then disregarded it when making a final decision. Recruitment, advising, or mentoring programs should target potentially persuadable women (i.e., those who show some interest in studying engineering) and encourage them to continue to see that as a viable and attractive option for university studies. Future research may expand on that choice process to reveal why some women first consider but then finally 
disregard engineering as a potential field of study. Additionally, approximately $30 \%$ of undecided respondents who could have still chosen to study engineering were women. Scholars and policymakers should work together to consider whether additional information, incentives, or sources of social and academic support could convince undecided women to ultimately choose engineering or some other STEM field.

When we examined the reasons women gave for not studying engineering, we found ways that organizations could incorporate changes to support women (interested) in STEM. For instance, prior negative exposure to technology or technology-related curriculum seemed to inhibit women's interest in engineering. Educators should try to incorporate different, culturally relevant pedagogical practices to engage students through learning with and without technology (e.g., Scott et al., 2009). Additionally, one-quarter of women stated that they were unable to complete the prerequisite courses they needed to be engineering majors. Schools should find ways to reduce prerequisite courses or move to co-requisite models: co-requisite courses take what instructors assume needs to be learned sequentially and instead allow students to simultaneously learn skills and concepts in the same academic term (see, e.g., Bullock et al., 2017). Finally, German schools and universities can adopt social cognitive perspectives to help women see themselves as able to complete STEM degrees, which are associated with increased interest in the subject (Kelly, 2016). Having outlined a short summary of our results, and implications for research, policy, and practice, we conclude with a presentation of initiatives that should encourage more women in Germany to study STEM, and to decrease persistent gender disparities.

\section{Promising Policies and Practices}

Though more can certainly be done, Germany has taken important steps toward improving gender equality in STEM. We briefly share some of those efforts, encouraging educators to consider integrating lessons detailed here into existing initiatives to attract women to STEM and to retain talented women in STEM higher education.

Since 2001, Germany's Federal Ministry for Family Affairs, Senior Citizens, Women and Youth (BMFSFJ) and the Federal Ministry of Education and Research (BMBF) have supported a national Girls' Day to encourage girls to consider STEM and technical fields where they are underrepresented (Best et al., 2013). ${ }^{3}$ In 2019, almost 100,000 young women and more than 10,000 organizations participated in the 19 th edition. ${ }^{4}$ The annual Girls' Day tradition is supported by funding from multiple federal agencies. The national campaign is recognized throughout the country with thousands of local events that engage nearly 2 million girls. Assessment data show that most girls are satisfied with Girls' Day programing. More importantly, seven in ten girls learn about professions that catch their interest, and many girls are able to see themselves pursuing technical or STEM professions (Girls' Day, n.d.). 
Similarly, in 2008 Germany's Federal Ministry of Education and Research launched the "Go MINT" - National Pact for Women in MINT careers" initiative (MINT is sometimes used interchangeably with the STEM acronym in German; directly translated MINT = mathematics, informatics, natural sciences, and technology). The purpose of Go MINT is "to open up the innovation potential of women for STEM in the long term, to attract more women to STEM careers and to present a modern image of STEM professions" (Komm Mach MINT, n.d.). Like Girls' Day, a national network of stakeholders organize local activities to encourage women to study STEM. The Go MINT initiative claims success for nearly doubling the number of women who choose STEM subjects as they enter higher education (Komm Mach MINT, n.d.).

Apart from such national efforts, individual universities have undertaken significant efforts to support women in academia and particularly in STEM. For example, the University of Augsburg created UniMento, a university mentoring program that pairs women faculty with women students (University of Augsburg, n.d.). Through UniMento, women students in STEM can receive career counseling and networking opportunities. The program seeks to establish year-long mentoring relationships and offers workshops to both mentors and mentees about how to have an effective mentoring relationship.

These three initiatives illustrate existing opportunities to address women's perceptions and choices about STEM fields - engineering in particular. For example, a sizable percentage of women said they did not choose to study engineering because they thought "an engineering degree would be too boring." If those women received mentoring through a program like UniMento, they might find satisfying career options. Additionally, initiatives like Girls' Day and Go MINT may help increase the percentage of women who consider and choose STEM fields. The variety of implemented initiatives gives the impression that gender equality in STEM has improved over the last decade, but evaluations indicate that attempts to attract enough women to STEM have failed to reach intended goals (GWK, 2019). Greater efforts must be made to expand women's success in STEM - and thus bolster Germany's achievement of its potential in these fields.

\section{Conclusion}

Prior studies examined inequality in STEM as a result of structural factors (e.g., differences in schooling between East and West Germany, educational tracking, qualifications like the Abitur, unequal employment, and earnings). However, it remains difficult to disentangle the actual reasons for sustained gender differences in STEM empirically (Isphording \& Qendrai, 2019). In future research, scholars will need to use multiple data sources and methods, including sequential analyses of progression or trajectories (Haas \& Hadjar, 2019) to investigate why women are underrepresented in STEM. Higher education research in Germany faces three problems that need to be tackled for a more in-depth explanation for 


\section{Jennifer Dusdal and Frank Fernandez}

student drop-out: definition and measurement of drop-out; clarification of the individual, institutional, and social causes; and dangers of above-average dropout of specific risk groups (here, women in STEM) (Heublein, 2014). For a better understanding of gender disparities in occupational preferences, it would be necessary to use longitudinal data to investigate changes in such preferences as well as to disentangle cultural and structural aspects that might have an impact on individual outcomes on the labor market (Hägglung \& Leuze, 2020, p. 17). By analyzing federal data on school leavers, we suggest that it is necessary to consider individual perceptions, motivations, and choices about academic subjects.

Germany leads Europe and is one of a few global leaders in STEM. Around the globe, nations use their higher education systems to promote economic growth and compete in STEM science production (Fernandez \& Baker, 2016, Fernandez \& Powell, in press). This chapter demonstrates that Germany has an opportunity to maintain and expand its considerable scientific STEM excellence by pursuing greater gender equality in STEM higher education.

\section{Notes}

1 https://en.unesco.org/science-sustainable-future/women-in-science

2 Meyer \& Strauß (2019, p. 448) found that self-assessed academic performance was statistically related to dropping out even after controlling for perceived difficulty of the subject and students' final grades.

3 In 2011, the equivalent "Boy's Day" has been implemented by the two ministries to attract more boys to underrepresented professions like education, social affairs, or health care. For more information, see https://www.boys-day.de

4 https://www.girls-day.de

\section{References}

Ammermüller, A., \& Weber, A. M. (2005). Educational attainment and returns to education in Germany: An analysis by subject of degree, gender, and region (ZEW Discussion Paper No. 05-017). Centre for European Economic Research. ftp://ftp.zew.de/pub/zewdocs/dp/dp0517.pdf.

Baker, D. P. (2014). The schooled society: The educational transformation of global culture. Stanford University Press.

Barlösius, E., \&. Fisser, G. (2017). Wie deuten Wissenschaftlerinnen im Maschinenbau ihren Erfolg [How do female academics in mechanical engineering interpret their success]? Forum: Qualitative Sozialforschung, 18(1).

Barone, C. (2011). Some things never change: Gender segregation in higher education across eight nations and three decades. Sociology of Education, 84(2), 157-176.

Becker, R. (2003). Educational expansion and persistent inequalities of education: Utilizing subjective expected utility theory to explain increasing participation rates in upper secondary school in the Federal Republic of Germany. European Sociological Review, 19(1), 1-24.

Becker, R. (2014). Reversal of gender differences in educational attainment: An historical analysis of the West German case. Educational Research, 56(2), 184-201. 
Best, K. L., Sanwald, U., Ihsen, S., \& Ittel, A. (2013). Gender and STEM in Germany: Policies enhancing women's participation in academia. International Fournal of Gender, Science and Technology, 5(3), 292-304.

Blickenstaff, J. C. (2005). Women and science careers: Leaky pipeline or gender filter? Gender and Education, 17(4), 369-386.

Blossfeld, P. N., Blossfeld, G. J., \& Blossfeld, H.-P. (2015). Educational expansion and inequalities in educational opportunity: Long-term changes for East and West Germany. European Sociological Review, 31(2), 144-160.

Blossfeld, H.-P., \& Roßbach, H. G. (Eds.). (2019). Education as a lifelong process: The German National Educational Panel Study (NEPS) (2nd ed.). Springer Verlag.

Bottia, M. C., Stearns, E., Mickelson, R. A., Moller, S., \& Valentino, L. (2015). Growing the roots of STEM majors: Female math and science high school faculty and the participation of students in STEM . Economics of Education Review, 45(C), 14-27.

Brainard, S. G., \& Carlin, L. (2001). A six-year longitudinal study of undergraduate women in engineering and science. In M. Lederman, \&. I. Bartsch (Eds.). The gender and science reader (pp. 24-37). Routledge.

Bullock, D., Callahan, J., \& Cullers, J. B. S. (2017). Calculus reform: Increasing STEM retention and post-requisite course success while closing the retention gap for women and underrepresented minority students (Paper No. 18474). Proceedings ASEE Annual Conference E Expo. https:// scholarworks.boisestate.edu/cgi/viewcontent.cgi?article $=1$ 196\&context $=$ math_facpubs

Carlana, M. (2019). Implicit stereotypes: Evidence from teachers' gender bias. The Quarterly Fournal of Economics, 134(3), 1163-1224.

Chachashvili-Bolotin, S., Milner-Bolotin, M., \& Lissitsa, S. (2016). Examination of factors predicting secondary students' interest in tertiary STEM education. International Journal of Science Education, 38(3), 366-390.

Charles, M., \& Bradley, K. (2002). Equal but separate? A cross-national study of sex segregation in higher education. American Sociological Review, 67(4), 573-599.

Charles, M., \& Bradley, K. (2009). Indulging our gendered selves? Sex segregation by field of study in 44 countries. American Fournal of Sociology, 114(4), 924-976.

Dasgupta, N., \& Stout, J. G. (2014). Girls and women in science, technology, engineering, and mathematics: STEMing the tide and broadening participation in STEM careers. Policy Insights from the Behavioral and Brain Sciences, 1(1), 21-29.

Derboven, W., \& Winker, G. (2010). Tausend Formeln und dahinter keine Welt. Eine geschlechtersensitive Studie zum Studienabbruch in den Ingenieurwissenschaften [A thousand formulas and yet no world behind. A gender sensitive study on drop-out in engineering]. Beiträge zur Hochschulforschung, 32(1), 56-78.

Dusdal, J. (2018). Welche Organisationsformen produzieren Wissenschaft. Zum Verhältnis von Hochschule und Wissenschaft in Deutschland [Which organizational forms produce science? The relationship of higher education and science in Germany]. Campus Verlag.

Dusdal, J., Oberg, A., \& Powell, J. J. W. (2019). Das Verhältnis zwischen Hochschule und Wissenschaft in Deutschland: Expansion - Produktion-Kooperation [The relationship between higher education and science in Germany: Expansion-Production - Collaboration]. In N. Burzan (Ed.), Komplexe Dynamiken globaler und lokaler Entwicklungen: Der Verhandlungsband des 39. Kongresses der Deutschen Gesellschaft für Soziologie vom 24.-28. September 2018 an der Georg-August-Universität Göttingen [Complex dynamics of global and local developments: Conference proceedings of the 39th Congress of the German Sociological Association from September 24-28 at the Georgia Augusta University of Göttingen]. 
Dusdal, J., Powell, J. J. W., Baker, D. P., Fu, Y. C., Shamekhi, Y., \& Stock, M. (2020). University vs. research institute? The dual pillars of German science production, 1950-2010. Minerva, 58, 319-342.

Elster, D. (2014). First-year students' priorities and choices in STEM studies-IRIS findings from Germany and Austria. Science Education International, 25(1), 52-59.

Fatourou, P., Papageorgiou, Y., \& Petousi, V. (2019). Women are needed in STEM: European policies and incentives. Communications of the ACM, 62(4), 52-57.

Federal Ministry for Family Affairs, Senior Citizens, Women and Youth (BMFSFJ). (2019). Report of the Federal Republic of Germany. https://www.unece.org/fileadmin/ DAM/Gender/Beijing_20/Germany.pdf

Fernandez, F., \& Baker, D. P. (2016). Educational transformations: Work and government policy in the schooled society. In J. Cote \& A. Furlong (Eds.), Handbook of the sociology of higher education (pp. 369-379). Routledge.

Fernandez, F., \& Powell, J. J. W. (in press). Neo-institutional approaches to understanding how higher education transforms society and the world of work. In J. Cote \& S. Pickard (Eds.), Routledge handbook of sociology of higher education (2nd ed.). Routledge.

Fervers, L., Jacob, M., \& Piepenburg, J. (2020). No risk, no gain. Experimental evidence on the role of risk-return preferences for gender differences in higher education - and what to do about it [Unpublished manuscript]. University of Cologne.

Fisser, G. (2019). Wahrnehmung biographischer (Un-)Sicherheit bei „Postdocs“ im Maschinenbau und in der Soziologie [Perception of biographical (in-)security of "Postdocs" in mechanical engineering and sociology]. Gottfried Wilhelm Leibniz University of Hannover. https://doi.org/10.15488/5330

Freitag, W. K. (2012). Zweiter und Dritter Bildungsweg in die Hochschule [Second- and thirdchance educational pathways into universities]. Working Paper No. 253 of the Hans Boeckler Foundation.

Gemeinsame Wissenschaftskonferenz (GWK). (2019). Chancengleichheit in Wissenschaft und Forschung: 23. Fortschreibung des Datenmaterials (2017/2018) zu Frauen in Hochschulen und außerschulischen Forschungseinrichtungen. [Equal opportunities in research and academia: The 23rd update to the data $(2017 / 2018)$ on women at universities and at nonuniversity research organizations]. Materialien der GWK, 65. Bonn, Germany.

Girls’ Day. (n.d.). Girls’Day: Future prospects for girls. https://www.girls-day.de/da ten-fakten/das-ist-der-girls-day/ein-zukunftstag-fuer-maedchen/english

Graf, L. (2013). The hybridization of vocational training and higher education in Austria, Germany, and Switzerland. Budrich UniPress.

Graf, L., \& Powell, J. J. W. (2017). How employer interests and investments shape advanced skill formation. PS: Political Science and Politics, 50(2), 418-422.

Grave, B. S., \& Goerlitz, K. (2012). Wage differentials by field of study - the case of German university graduates. Education Economics, 20(3), 284-302.

Haas, C., \& Hadjar, A. (2019). Students' trajectories through higher education: A review of quantitative research. Higher Education, 79, 1099-1118.

Hägglung, A. E., \& Leuze, K. (2020). Gender differences in STEM expectations across countries: How perceived labor market structures shape adolescents' preferences. Fournal of Youth Studies. https://doi.org/10.1080/13676261.2020.1755029

Han, S. W. (2016). National education systems and gender gaps in STEM occupational expectations. International Journal of Educational Development, 49, 175-187. https:// doi.org/10.1016/j.ijedudev.2016.03.004

Heine, C., Egeln, J., Kerst, C., Müller, E., \& Park, S.-M. (2006). Bestimmungsgründe für die Wahl von ingenieur- und naturwissenschaftlichen Studiengängen. [Determining reasons for 
the study choice of engineering and natural sciences]. HIS Hochschul-InformationsSystem/ZEW Zentrum für Europäische Wirtschaftsforschung (Studien zum deutschen Innovationssystem 4/2006).

Heine, C., Quast, H., Spangenberg, H., Lörz, M., Scheller, P., \& Willich, J. (2017). DZHW panel study of school leavers 2008 -Educational paths of school leavers with a higher education entrance qualification (Version 1.0.0). German Centre for Higher Education Research and Science Studies (DZHW). https://doi.org/10.21249/DZHW:gsl2008:1.0.0

Hetze, P. (2011). Nachhaltige Hochschulstrategien für mehr MINT-Absolventen [Sustainable higher education strategies to increase the number of STEM graduates] (2nd ed.). Stifterverband für die deutsche Wissenschaft.

Heublein, U. (2014). Student drop-out from German higher education institutions. European Fournal of Education, 49(4), 497-513.

Ihsen, S., Jeanrenaud, Y., Wienefoet, V., Hackl-Herrwerth, A., Hantschel, V., \& Hojer, C. (2009). Potenziale nutzen, Ingenieurinnen zurückgewinnen: Drop-Out von Frauen im Ingenieurwesen: Analyse der Ursachen und Strategien zu deren Vermeidung sowie Handlungsempfehlungen für eine erfolgreiche Rückgewinnung. [Using potentials, regaining female engineers: Women's drop out in engineering: Analysis of the causes, strategies as well as recommendations for a successful regain]. Wirtschaftsministerium BadenWürttemberg.

Isphording, I. E., \& Qendrai, P. (2019). Gender differences in student dropout in STEM (Report No. 87). IZA Institute of Labor Economics. http://ftp.iza.org/report_pdfs/ iza_report_87.pdf

Jacob, M., Iannelli, C., Duta, A., \& Smyth, E. (2020). Secondary school subjects and gendered STEM enrollment in higher education in Germany, Ireland, and Scotland. International Fournal of Comparative Sociology, 61(1), 59-78.

Kelly, A. M. (2016). Social cognitive perspective of gender disparities in undergraduate physics. Physical Review Physics Education Research, 12(2), 020116.

Kim, A., \& Kim, K. W. (2003). Returns to tertiary education in Germany and the UK: Effects of fields of study and gender (Paper No. 62). Mannheim Center for European Social Research (MZES). http://edoc.vifapol.de/opus/volltexte/2014/5156/pdf/wp_62.pdf

Komm Mach MINT. (n.d.). "Go MINT"-National Pact for Women in MINT careers. https://www.komm-mach-mint.de/english-information

Kwiek, M., \& Roszka, W. (2020). Gender disparities in international research collaboration: A study of 25,000 university professors. Foumal of Economic Surveys. https:// doi.org/10.1111/joes.12395

Larivière, V., Ni, C., Gingras, Y., Cronin, B., \& Sugimoto, C. R. (2013). Global gender disparities in science. Nature, 504, 211-213.

Leemann, R. J., Dubach, P., \& Boes, S. (2010). The leaky pipeline in the Swiss university system: Identifying gender barriers in postgraduate education and networks using longitudinal data. Swiss Fournal of Sociology, 36(2), 299-323.

Magnusson, C. (2013). More women lower pay? Occupational sex composition, wages and wage growth. Acta Sociologica, 56(3), 227-245.

Makarova, E., Aeschlimann, B., \& Herzog, W. (2019). The gender gap in STEM fields: The impact of the gender stereotype of math and science on secondary students' career aspirations. Frontiers in Education, 4(60), 1-11.

Mann, A., \& DiPrete, T. A. (2013). Trends in gender segregation in the choice of science and engineering majors. Social Science Research, 42(6), 1519-1541.

Meyer, J., \& Strauß, S. (2019). The influence of gender composition in a field of study on students' drop-out of higher education. European Fournal of Education, 54(3), 443-456. 
Moorhouse, E. A. (2017). Sex segregation by field of study and the influence of labor markets: Evidence from 39 countries. International Journal of Comparative Sociology, 58(1), $3-32$.

Nimmesgern, H. (2016). Why are women underrepresented in STEM fields? ChemistryA European Fournal, 22(11), 3529-3530.

Powell, J. J. W., \& Dusdal., J. (2017). The European center of science productivity: Research universities and institutes in France, Germany, and the United Kingdom. In J. J. W. Powell, D. P. Baker, \& F. Fernandez (Eds.), The century of science: The global triumph of the research university (pp. 55-83). Emerald.

Powell, J. J. W., \& Solga, H. (2011). Why are higher education participation rates in Germany so low? Institutional barriers to higher education expansion. Fournal of Education and Work, 24(1-2),49-68.

Reimer, D., \& Steinmetz, S. (2009). Highly educated but in the wrong field? Educational specialisation and labour market risks of men and women in Spain and Germany. European Societies, 11(5), 723-746.

Riegle-Crumb, G., King, B., Grodsky, E., \& Muller, C. (2012). The more things change, the more they stay the same? Prior achievement fails to explain gender inequality in entry into STEM college majors over time. American Educational Research Journal, 49(6), 1048-1073.

Schlenker, E. (2009). The labour supply of female engineers in Germany. Austrian Journal of Statistics, 38(4), 255-263.

Scott, K. A., Aist, G., \& Hood, D. W. (2009). CompuGirls: Designing a culturally relevant technology program. Educational Technology, 49(6), 34-39.

Seymour, E., \& Hewitt, N. M. (1997). Talking about leaving: Why undergraduates leave the sciences. Westview Press.

Seymour, E., \& Hunter, A.-B. (Eds.). (2019). Talking about leaving revisited: Persistence, relocation, and loss in undergraduate STEM education. Springer.

Sikora, J., \& Pokropek, A. (2012). Gender segregation of adolescent science career plans in 50 countries. Science Education, 96(2), 234-264.

Smyth, E., \& Steinmetz, S. (2008). Field of study and gender segregation in European labour markets. International Fournal of Comparative Sociology, 49(4-5),257-281.

Solga, H., \& Pfahl, L. (2009a). Wer mehr Ingenieurinnen will, muss bessere Karrierechancen für Frauen in Technikberufen schaffen [Who wants more female engineers must provide better career opportunities for women in technical occupations]. WZBrief Bildung No. 7.

Solga, H., \& Pfahl, L. (2009b). Doing Gender im technisch-naturwissenschaftlichen Bereich [Doing gender in the technical and natural sciences sector]. In J. Milberg (Ed.), Promotion of young talent in technology and science (pp. 155-218). Springer. https:// bibliothek.wzb.eu/pdf/2009/i09-502.pdf

Statistisches Bundesamt (DESTATIS). (2020a, September 12). Studierende nach Hochschularten, Ländern und Geschlecht [Students by type of higher education institution, country, and gender]. Fachserie 11, Reihe 4.1. https://www.datenportal. bmbf.de/portal/de/K254.html

Statistisches Bundesamt (DESTATIS). (2020b, September 17). Studierende in Mathematik, Informatik, Naturwissenschaft (MINT) und Technik-Fächern [Students in mathematics, informatics, natural sciences (MINT) and technical subjects]. https://www.desta tis.de/DE/Themen/Gesellschaft-Umwelt/Bildung-Forschung-Kultur/Hochschulen/ Tabellen/studierende-mint-faechern.html

Tai, R. H., Liu, C. Q., Maltese, A. V., Fan, X. (2006). Planning early for careers in science. Science, 312(5777), 1143-1144 
United Nations Educational, Scientific and Cultural Organization. (2015). UNESCO science report: Towards 2030. https://unesdoc.unesco.org/ark:/48223/pf0000235406

University of Augsburg. (n.d.). UniMento: Mentoring and career support. https:// www2.uni-augsburg.de/de/projekte/gendermainstreaming/UniMento/download/ information-about-the-project_englisch-version.pdf

Wagner, C. S. (2018). The collaborative era in science. Palgrave Macmillan.

Wahrenburg, M., \& Weldi, M. (2007). Return on investment in higher education: Evidence for different subjects, degrees and gender in Germany (Working Paper No. 709). Goethe University of Frankfurt. https://d-nb.info/1151473529/34

Wissenschaftsrat. (2013). Perspektiven des deutschen Wissenschaftssystems. [Perspectives of the German science system]. (Drs. 3228-3213). Braunschweig.

Wolffram, A., Derboven, W., \& Winker, G. (2009). Women withdrawers in engineering studies: Identity formation and learning culture as gendered barriers for persistence? Equal Opportunities International, 28(1), 36-49.

Xie, Y., \& Shauman, K. A. (2003). Women in science - Career opportunities and outcomes. Harvard University Press.

Xie, Y., Fang, M., \& Shauman, K. A. (2015). STEM education. Annual Review of Sociology, 41(1), 331-357.

Zippel, K. (2017). Women in global science. Advancing academic careers through international collaboration. Stanford University Press. 


\title{
9 Gender Equity in STEM Higher Education in Kazakhstan
}

\author{
Anna CohenMiller, Aray Saniyazova, Anara Sandygulova \\ and Zhanna Izekenova
}

In much of the world, the landscape of higher education is built upon a male-model that has not systematically included the presence of women. For fields traditionally associated with men, there is a greater gap between women's enrollment, progression, and success compared to men. Such disciplinary fields that heavily engage men include science, technology, engineering, and mathSTEM. Women in comparison have historically been underrepresented in such fields. The discrepancy between women and men's presence in STEM can be attributed to multiple factors, such as restricted educational access (e.g. Chachashvili-Bolotin et al., 2016; McClure et al., 2017), pervasive stereotypes and bias (e.g., Cvencek et al., 2015), as well as a lack of mentors (e.g. Cacace, 2009; Dawson et al., 2015) and role models (Almukhambetova \& Kuzhabekova, 2020; Cacace, 2009; Holmes et al., 2018). Broadly speaking, women's underrepresentation in STEM fields in higher education is evident in extensive reviews of research on the topic (Blickenstaff, 2005) and in current statistics. For example, the UNESCO world report from 2014 to 2016 notes the "huge disparities" (Bokova, 2017, p. 5) in women's access and progression in STEM fields globally.

Within higher education, men's presence in STEM fields outweighs the presence of women in similar positions (Funk \& Parker, 2018; Hughes et al., 2017; Van Miegroet et al., 2019). While women are increasingly enrolling in STEM fields for their courses of study, they are not consistently employed within such fields. In the United States, women enroll in college STEM fields at a similar rate as men (Hughes et al., 2017), however, their path within the discipline varies greatly. When women enter the academic workplace, the progression from junior to senior scholar is fraught. In other words, the academic pipeline from doctoral student to full professor (CohenMiller, 2014) does not function the same for women and men. Instead, the academic pipeline is said to "leak" for women academics (Goulden et al., 2011, p. 147; Van Anders, 2004; Ysseldyk et al., 2019). The result in the leaky academic pipeline can be seen in the major discrepancy between women and men in leadership positions.

Such issues of progression, promotion, and retention for women in academia are well known and evidenced in Western contexts. However, the topic has been under-examined in other regions of the world. Therefore, this chapter draws

DOI: 10.4324/9781003053217-15 
attention to one such context needing further exploration, Central Asia. Specifically, we explore gender equity in STEM in higher education within Post-Soviet Kazakhstan. The following sections speak to the unique landscape of education in Kazakhstan, focusing on women's engagement and access to STEM higher education and employment. As such, we discuss how success can be interpreted as related to gender equity in STEM, provide an overview of the historical-cultural context of Kazakhstan which informs current educational practice and policy, and examine data about the topic. Using this information, we discuss ways in which women studying STEM fields in Kazakhstan can be compared to those in other contexts. Additional next steps are provided for bridging gaps in the academic pipeline for women in STEM in Kazakhstan and the Central Asian region.

\section{Gender Equity (or Lack Thereof) in STEM: A Review of International and Kazakhstani Research}

When we think about gender equity in STEM fields, it is important to consider how the topic is being addressed. The concept of "success" within STEM can be viewed in various ways. For instance, some U.S. and Canadian researchers study gender differences in STEM through the lens of access to graduate programs (Fried \& MacCleave, 2009; Weber, 2011), through the rate of graduation (Primé et al., 2015; Litzler et al., 2005), through attrition in jobs (Buffington et al., 2016), or through promotion (Bystydzienski, 2020). These aspects can also be considered as a whole, or as a part of the academic pipeline at the points where women are recruited, hired, retained, and promoted within higher education. The academic pipeline can provide an indicator of success. In this chapter, we look specifically at the concept of employability. The concept of employability relates in particular to the idea of getting a job in accordance with your degree. The factors affecting employability and relationship to one's degree tends to relate to international and external factors, including the sociocultural context.

Society plays a role in the way women consider their ability and position in STEM fields. For instance, Wei-Cheng et al., (2020) conducted a cross-cultural comparison of Taiwanese and U.S. high school students' STEM career aspirations and examined how parental involvement, learning experience, and selfefficacy relate to STEM career aspirations (Wei-Cheng et al., 2020). Wei-Cheng et al. (2020) found gender disparities exist across both types of countries - one that is collectivist in nature and one that is individualistic. Consistent with previous research on the topic of STEM aspirations, they showed that high school students evidence clear gendered differences in this regard, demonstrating that "gender inequity is a function of social-cognitive factors and self-efficacy is one of the most important factors predicting STEM career aspiration of high school students regardless of nationality" (Wei-Cheng et al., 2020, p. 40).

As noted by the UNESCO world report (2017) on girls' and women's education in science, technology, engineering, and mathematics, the gender 
discrepancy is deep-seated and needs to be examined through multiple lenses, including within schools: "Education systems and schools play a central role in determining girls' interest in STEM subjects and in providing equal opportunities to access and benefit from quality STEM education" (p. 11). Girls continue to receive messages that STEM fields are not intended for them (Koch et al., 2014). In Kazakhstan, such an examination of the gendered nature of education is being addressed in research about and within secondary schools (CohenMiller et al., 2020; Durrani et al., forthcoming). For example, it has been found that textbooks in Russian, Kazakh, and English for 7th and 8th graders reinforce traditional stereotypes of what it means to be a "good" boy/ man and a good girl/woman (Durrani et al., 2019, forthcoming). Imagery and descriptions which emphasize and reproduce gendered standards of beauty for women and intelligence for men can contribute to girls' interest and access to science in higher education and beyond.

Moreover, gender discrepancies and bias are also found in higher education. Wang and Degol (2017) point to evidence of such unconscious bias (see Knobloch-Westerwick et al., 2013; Moss-Racusin et al., 2012). Notions of who is considered to be a better student and employee can be seen as gendered, prioritizing men and devaluing women. As noted by Moss-Racusin et al. (2012), in the U.S. "both male and female faculty judged a female student to be less competent and less worthy of being hired than an identical male student, and also offered her a smaller starting salary and less career mentoring" (p. 9). They continued on to point out that bias was consistent across women and men faculty members even when controlling for other variables, suggesting the bias is "likely unintentional, generated from widespread cultural stereotypes" (Moss-Racusin et al., 2012, p. 9). Therefore, for women university students, they are consistently undervalued by students and faculty.

In Kazakhstan, CohenMiller and Lewis (2019) examined gender-related practices in higher education, focusing on the formal curriculum. Conducting a gender audit of authorship of assigned readings, they found that faculty favored readings by men, with only about $15 \%$ of all readings authored by women (CohenMiller \& Lewis, 2019). Such disproportionate gendered representation of scholarship would suggest to students that knowledge is primarily associated with men (CohenMiller \& Lewis, 2019). Not only does the formal curriculum in higher education emphasize the presence and knowledge of men, but so too do major scientific events. For instance, the Astana Expo in 2017 highlighted scientific advantages with pavilions curated by European and Asian countries. In a study conducted by CohenMiller et al. (2020), they found that across all countries, not one pavilion had an equal representation of men and women in the imagery of science. In other words, both formal learning in institutions of higher education, as well as informal learning through media representations, propagate and reproduce gendered roles, largely ignoring women in STEM.

Other research in Kazakhstani higher education explored students' experiences in the transition to postsecondary education in Kazakhstan and 
determinants associated with their decisiveness to enroll in STEM majors (Almukhambetova \& Kuzhabekova, 2020). Almukhambetova and Kuzhabekovam (2020) identified the existence of contradictory societal expectations about gender roles and norms in schools and workplaces and the lack of women role models in STEM in Kazakhstan. Moreover, focusing on the academic pipeline, Kuzhabekova and Almukhambetova (2019) studied women's progression through leadership positions in two adjacent countries in Central AsiaKazakhstan and Kyrgyzstan. They found that informal networking can create barriers to the advancement of women and decrease promotion opportunities for those women who are outside of this "informal patronage network" (p. 14).

Across these studies, what continues to be evident is the need to further understand issues of equity and access for women in STEM fields in Kazakhstan, especially considering the gendered discrepancies which continue to persist despite country-wide efforts. Nationwide steps and programs have included those by international organizations and local initiatives (e.g. Ministry of Education and Science, Colorado STEM Summer Camp for girls from Kazakhstan, TechGirls, Girls in STEM) (for example, see U.S. Mission to International Organizations in Vienna, 2018). Some such efforts in Kazakhstan have included the State Program for the Development of Education and Science, which emphasized the importance of science education for both boys and girls. According to the State Program for the Development of Education and Science of the Republic of Kazakhstan, for 2016-2019, the new content education contains the elements of STEM education aimed to develop new technologies, scientific innovations, and mathematical modeling (On approval of the State Program for the Development of Education and Science of the Republic of Kazakhstan for 2016-2019, 2018). Moreover, other initiatives include programs organized by the U.S. Embassy and Consulate in Kazakhstan (2020), as well as, TechGirls four-week exchange program, the weeklong Destination Mars! Camp, and the Chevron sponsored Girls in STEM twoweek summer program based in Almaty, Kazakhstan (Seidakhmetova, 2019).

Other initiatives have included a recent program launched by UNICEF to encourage girls in STEM. The program focuses specifically on teaching and modeling the development of nanosatellites for girls and women between the ages of 14 and 35 (UNICEF, 2020). The UNDP in 2019 also highlighted women's and girls' contributions to technology by celebrating International Girls in ICT Day with the development and implementation of a program to distribute automated messages about gender equality - a gender bot (Kazin form International News Agency, 2019).

In summary, the continuing issues faced by women in STEM in Kazakhstan reflect the fact that men outnumber women in multiple STEM careers (UNESCO, 2016). As a result, men are more likely to be promoted to managerial positions. Moreover, in the Kazakhstani context there appears to be additional social-cultural factors that contribute to the underrepresentation of women in STEM. These factors, which will be discussed in further detail below, include the historical and cultural context of the country (Hofstede, 1991). 


\section{Historical and Cultural Context of Kazakhstan: A Unique Landscape}

Historically, the main role of women in Kazakh society was that of wife and mother. There is an old saying, "Daughter is a guest in the family," which implies that girls are expected to be treated with love and care in their families as once they get married they will accept the burden of household chores in their husband's house, including taking care of in-laws. In a nomadic society, such work implied not only working inside the home but also helping men with the herds and other outdoor activities. However, despite that, hardworking women were considered to be of a lower social status. When Kazakhstan was part of the Soviet Union, the issue of so-called "women's emancipation" was given great attention. Regulations and policies accepted at that time strove to provide women with equal access to education, healthcare, and labor force participation. Women were provided various social benefits to foster their education at all levels and encourage their active involvement in the socio-economic and political life of society (McLaughlin, 2018). Soviet-era efforts have created a foundation for gender equality and have been continued by independent Kazakhstan. After independence, Kazakhstan introduced national policies in accordance with international regulations aimed at advancing gender equality across various spheres such as the Beijing Platform of Action (endorsed in 1995), the Convention on the Elimination of All Forms of Discrimination against Women (CEDAW) (ratified in 1998), and the CEDAW Optional Protocol (ratified in 2001) (McLaughlin, 2018).

According to the Kazakhstan Country Gender Assessment (CGA) carried out by the Asian Development Bank in 2018, Kazakhstan is placed in Group 1 that comprises the countries where key gender and development indicators demonstrate high equality between men and women (McLaughlin, 2018). However, despite the overall reduction on the Gender Inequality Index, and relatively high equality in key indicators of the assessment, which are health, education and command over economic resources, Kazakhstan still ranks low in indicators for political representation of women (only 20.1\% parliamentary seats held by women), women's labor force participation $(66.1 \%$ compared to $77 \%$ for men), and gender wage differences (Agency of the Republic of Kazakhstan on Statistics, 2020). In terms of gender-based discrimination in social norms, practices, and laws, Kazakhstan shows low-level discrimination in the following dimensions: (i) discriminatory family code, (ii) restricted physical integrity, (iii) son bias, (iv) restricted resources and assets, and (v) restricted civil liberties, as measured by the Social Institutions and Gender Index (SIGI).

Though these facts demonstrate that women's social status has significantly changed and the concept of equality between men and women is widely accepted in modern Kazakh society, the traditional stereotype of women's role as wife, mother and daughter-in-law remains primary in public discourse (Akiner, 1997). For example, according to the Labor Code of Kazakhstan, both parents are entitled to three years of parental leave of which one year is 
paid with a monthly allowance up to $40 \%$ of their average salary. However, as men are culturally associated with the workplace, it is not surprising to see statistics indicating that predominantly women use parental leave (McLaughlin, 2018). Despite the fact that the Constitution, Labor Code, and other legal documents provide women and men with equal rights, the traditional cultural norms still have decisive power in many aspects of life in Kazakhstan. Women in Kazakhstan, by and large, are expected to both maintain a professional occupation and perform housework and childcare.

As Wei-Cheng et al. (2020) note, sociocultural context plays an important role in understanding gender disparities in STEM fields. In collectivist societies, such as Japan, the pressure for women to fulfill their social responsibilities can limit professional opportunities (Yoshikawa et al., 2018). Such findings are echoed in research about gendered roles and perceptions of students living in collectivist nations pursuing STEM careers (Wei-Cheng, et al., 2020). And in Kazakhstan, expectations and associations for women to take on the responsibilities of raising children, cleaning, cooking, as well as a career have repercussions on gender equity throughout the educational pipeline. To better understand gender equity in STEM fields in Kazakhstan, the following case study from a unique university within the country is presented. The study provides a deeper examination into admissions and progression for undergraduate and graduate students, as well as speaking to gender equity as shown in hiring and promotion for faculty.

\section{Case Study: An Examination into the School of Engineering and Digital Sciences-Undergraduate Students, Graduate Students, and Faculty}

The admission of university students in Kazakhstan is influenced by financial aspects of the higher education system. Universities in Kazakhstan have tuition fees and there are a limited amount of state grants awarded to those students with high performance in the nationwide, high-stakes exam - the Unified National Testing (UNT). The available grants for studying in higher education vary based upon the discipline. Grants to study in STEM fields far outweigh grants in social sciences and humanities fields, the latter being almost non-existent. A result of grants emphasizing STEM fields is that high school graduates often select those disciplines to avoid paying tuition fees. Therefore, students may prioritize finances over their interest in STEM. If a student reaches a certain number of points on the UNT, they can be offered a grant. For example, in Kazakhstan in 2020, the largest proportion of grants went to those interested in studying for an MS in Mechanical Engineering. If a student reaches 91 points on the UNT, they could receive that grant. However, for a student to be awarded a grant in Management or Law, they would need a 97 and 104, respectively (National Testing Center, 2020).

Nazarbayev University (NU) is unique within Kazakhstan because it does not require UNT scores; instead, it has a three-stage admission process. After submission of an application, the first stage is the British Council-developed 
Aptis exam, an assessment of English language skills. This assessment can be waived if an applicant has achieved a "competent" score (a 6.0 or higher) across all sections on the high-stakes International English Language Testing System (IELTS) exam. If an applicant scores a minimum passing score (165 out of 200), they proceed to the second stage. The student then takes an NU entrance test in English in two subjects-Mathematics and Critical Thinking and Problem Solving. Successful candidates move to the third stage. The third stage includes the IELTS examination where the minimum passing score is 6.0, indicating competence in English across all the sections. For graduate programs, the admission process is different. It consists of two stages: submission of the application with supporting documents including a language proficiency certificate, optional GRE certificate, and statement of purpose. Letters of recommendation are submitted directly to an admission committee, after which the candidate may proceed to an interview with the committee.

NU provides full funding to all accepted students regardless of major. This case study was conducted using data about both undergraduate and graduate students. It includes data from students enrolled in the BS, BEng, MS and $\mathrm{PhD}$ programs of the School of Engineering and Digital Sciences (SEDS). An autonomous research university in the capital of Kazakhstan, NU was founded in 2010 (Nazarbayev University, 2020). It is an English-medium institution with $75 \%$ of the faculty coming from international locations. Of the 441 faculty members, 34\% are women (NU). Apart from SEDS, NU has a School of Sciences and Humanities, Graduate School of Education, School of Mining and Geosciences, School of Medicine, and others. With a high aim of becoming the national brand of Kazakhstan higher education, NU is considered a highly prestigious and competitive university for Kazakhstani youth as it provides tuition-free education to its students similar to the fully funded King Abdullah University of Science and Technology (2020) in Saudi Arabia.

Because NU does not require UNT scores and provides full funding for those admitted, we believe there is a more realistic picture of students' selected major being driven by interest rather than financial need. Therefore, we see that this case study conducted on the data from NU students represents trends regarding women's interest in STEM fields and their potential accessibility.

Figure 9.1 demonstrates the percentage of women students accepted to the BS and the BEng degrees in six programs within the SEDS school for the last six years (2015-2020). The six programs include: BEng in Chemical Engineering, BEng in Civil Engineering, BS in Computer Science, BEng in Electrical and Electronic Engineering, BEng in Mechanical Engineering, BS in Robotics and Mechatronics. The most popular program for women is the BEng in Chemical Engineering as seen from the percentages of enrolled women students, which is the highest among the SEDS programs (average is $51 \%$ ). Since its inception, the numbers have increased at a steady rate for this program starting from $43 \%$ in 2015 to $64 \%$ in 2020. BEng in Electrical and Electronic Engineering and BEng in Mechanical Engineering also had a steady increase in numbers ranging from $6 \%$ in 2016 to $26 \%$ in 2020 and 


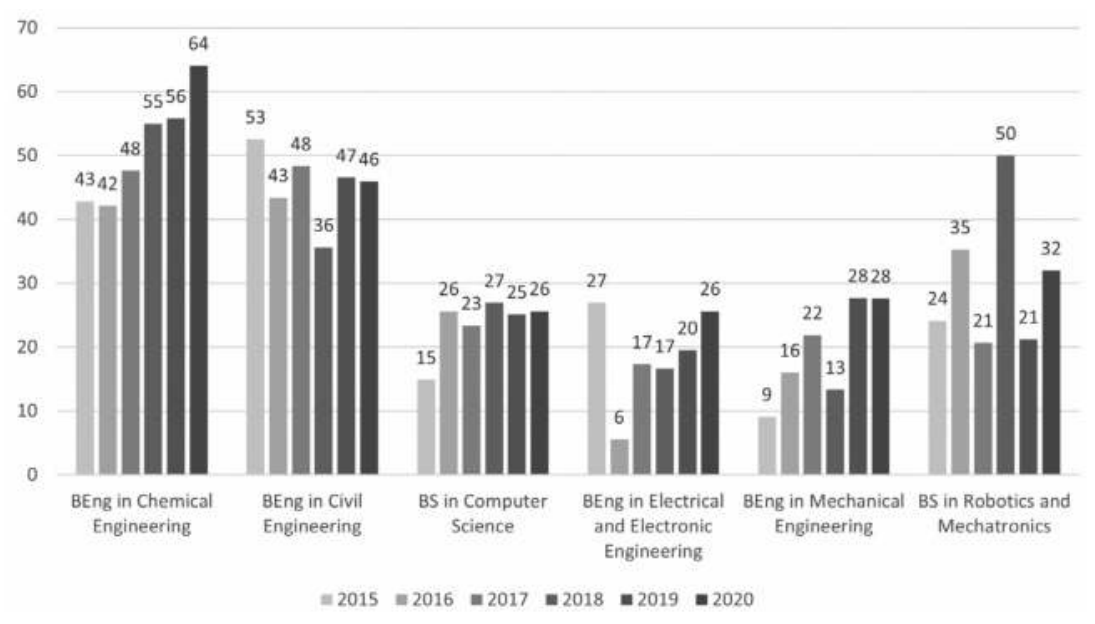

Figure 9.1 Percentage of women in BS and BEng degrees across six programs of SEDS for 2015-2020.

from $9 \%$ in 2016 to $28 \%$ in 2020, respectively. The growth seen in these programs for women students showed a slight decrease for the BS in Civil Engineering (from 53\% in 2015 to $46 \%$ in 2020). The BS in Computer Science and the BS in Robotics and Mechatronics continue to demonstrate stable numbers over the six year period with an average of $24 \%$ and $31 \%$ of women students in each program, respectively. Interestingly, the proportion of women in BS in Robotics and Mechatronics was unusually high at 50\% in 2018 with a sharp increase from $21 \%$ in 2017 followed by a sharp decrease back to $21 \%$ in 2019 .

In Figure 9.2 the graph plots the percentage of women students accepted to MS degrees in six programs within the SEDS school for the last six years (2015-2020). The six programs include: MS in Engineering Management, MS in Electrical and Computer Engineering, MS in Mechanical and Aerospace Engineering, MS in Robotics, MS in Civil and Environmental Engineering, and MS in Chemical and Materials Engineering. Overall, the percentage of women students increased at a steady rate for the MS in Mechanical and Aerospace Engineering from $13 \%$ in 2015 to $36 \%$ in 2020, while the percentage of women for the MS in Electrical and Computer Engineering and the MS in Civil and Environmental Engineering slightly decreased in the last two years from $46 \%$ in 2018 to $30 \%$ in 2020 and from $67 \%$ in 2018 to $30 \%$ in 2020, respectively. The MS in Engineering Management and the MS in Chemical and Materials Engineering programs continue to demonstrate steady numbers over the six year period with an average of $48 \%$ and $53 \%$, respectively, whereas the number of women in the MS in Robotics fell to zero for two years in 2018-2019 and increased sharply to $38 \%$ in 2020 . 


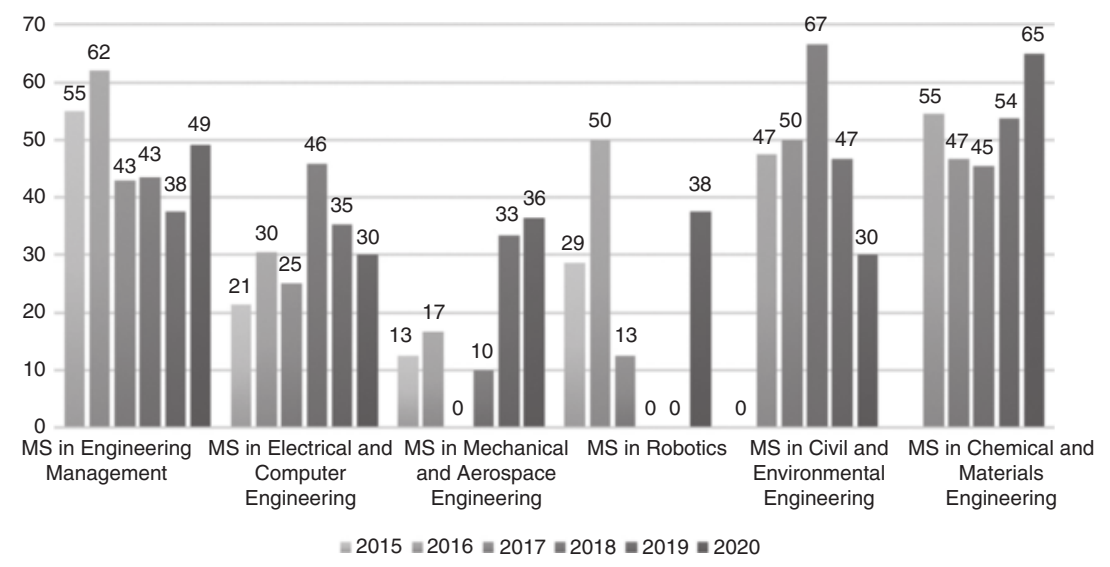

Figure 9.2 Percentage of women in MS degrees across six programs of SEDS for 2015-2020.

The enrollment trends for the MS in Engineering Management and the MS in Chemical Materials and Engineering programs indicate they are the two most popular programs among women with averages of $48 \%$ and $53 \%$ of enrollments over the last six years in each program, respectively. This trend was also demonstrated for the undergraduate program of the BEng in Chemical Engineering with an average of $51 \%$ women. While both the BEng in Civil Engineering and the MS in Civil and Environmental Engineering programs have a slight decline in numbers, they have almost the same average of women and men with an average of $45.5 \%$ and $40 \%$ for women, respectively. The department of Robotics and Mechatronics was the next least popular choice for women, where the numbers from the undergraduate program in the BS in Robotics and Mechatronics are slightly higher than for the MS in Robotics, which have $31 \%$ and $21 \%$, respectively. The next pair has even lower numbers with women in the BEng in Electrical and Electronic Engineering and the MS in Electrical and Computer Engineering averaging only 19\% and 31\%, respectively. In general, the next pair of the BEng in Mechanical Engineering and the MS in Mechanical and Aerospace Engineering demonstrates a similar trend and has the lowest numbers of women with an average of $19 \%$ and $18 \%$, respectively.

Since the overall numbers are limited in all programs across SEDS, broad conclusions may not be representative. From this data, it is possible to see a level of parity between genders for some programs, or the lack thereof for others. In the BS/BEng and MS SEDS programs at NU, two-thirds of the programs show near gender parity.

Regarding the SEDS PhD programs, the percentage of women across the whole school is $46 \%$ and showed a decreasing trend (from 54\% in 2015 to $40 \%$ in 2018) followed by a slight increase to $43 \%$ in 2020 . Interestingly, three $\mathrm{PhD}$ programs in Computer Science, Chemical Engineering, and Civil Engineering 
have exactly $50 \%$ women enrollment in 2020 . Similar to its MS counterpart, the $\mathrm{PhD}$ in Electrical Engineering includes $40 \%$ women, while two $\mathrm{PhD}$ programs, the $\mathrm{PhD}$ in Robotics and the $\mathrm{PhD}$ in Mechanical Engineering, demonstrated the lowest ratio of $20 \%$.

In 2020, among the graduates of MS programs, four programs showed a greater representation of women to men with $71 \%$ in the MS in Chemical and Material Engineering, $67 \%$ in the MS in Civil and Environmental Engineering, 57\% in the MS in Chemical Engineering, and 53\% in the MS in Electrical and Computer Engineering. There were seven programs where men outnumbered women, although with near gender parity in the MS in Engineering Management with women representing $42 \%$ of the total graduates. In Civil Engineering and Computer Science, MS graduate women included $39 \%$ and $36 \%$, respectively. Then the numbers of women graduates decrease dramatically to only $15 \%$ for the MS in Electrical and Electronic Engineering, 14\% for the MS in Robotics, 9\% for the MS in Mechanical Engineering, and no women in Mechanical and Aerospace Engineering.

Across the $\mathrm{PhD}$ programs, there is greater gender parity as compared to the undergraduate BS/BEng and MS programs. This finding might be explained by the fact that top men who graduate from the BS/BEng and MS programs often continue in a $\mathrm{PhD}$ program abroad while women are more likely to stay in a local $\mathrm{PhD}$ program. For women in Kazakhstan, choosing to continue in academia is more acceptable than employment in engineering, which is often located in geographically remote areas, with a need for long-term shifts away from the family.

These data from the undergraduate and graduate programs in the School of Engineering and Digital Sciences from 2015 to 2020 indicate that the majority of programs enroll and support men more than women. Yet, there are a few programs demonstrating gender parity or even greater enrollment of women in select STEM fields. The growing number of women in STEM fields at the university can be considered a sign in the right direction for gender inclusion in higher education. However, to ensure the move from gender parity (counting the number of individuals) to gender equity (fair and just treatment of women and men), it is important to consider the academic pipeline and women's progression through it. For example, when identifying the number of faculty members, there is a significant imbalance between women and men, with the vast majority of women in positions on the lowest rung of the academic ladder and men in all positions of leadership (Nazarbayev University School of Engineering and Digital Sciences, 2020).

Overall, the admission process at NU is both unique in its process and also its state funding. As shown internationally, students from cities with higher quality education have increased access to top universities. The same is true in Kazakhstan, as those in urban areas have greater access to high quality high school/secondary education, including private tutoring for high-stakes tests. 
For women students, especially those from cities other than the two major ones (Nur-Sultan and Almaty), and those from rural areas, the recruitment process is particularly important. Following Posselt's (2016) work on graduate admission and the issue of "who falls through the cracks," future research should examine issues of geographic equity for women and include rural women in recruitment, admissions, and progression initiatives in Kazakhstan.

\section{Lack of Women Mentors in STEM}

Considering the importance of mentorship in moving to future employment, an imbalance in women and men could strongly disadvantage either group of students. At NU, in the School of Engineering and Digital Sciences, there are 105 faculty members with 15 women representing approximately $14 \%$. Of the 15 women faculty, seven are in more temporary positions, working as postdoctoral scholars and instructors. These positions are often considered to be non-tenure track and require leaving the institution to find employment elsewhere after a limited amount of time. Of the remaining seven women in SEDS, which represents $6 \%$ of the faculty in the School, five are employed at the entry level as Assistant Professors and two have been promoted or recruited to Associate Professor. Apart from one position filled by a woman, Acting Vice-Dean of Academic Affairs, only men have been promoted or recruited as full professors or to positions of leadership such as Department Chair.

Overall, these descriptive data of SEDS undergraduate and graduate students as well as faculty at NU indicates common evidence that women's enrolment in university degrees in STEM may be on the rise in some departments but as a whole remain stunted compared to men. For STEM faculty recruited, hired, and promoted through the academic ranks there is evidence that problems exist in the academic pipeline. While there are increasing numbers of women enrolled in STEM fields, they are not systematically being inducted into academic positions. Instead, as shown internationally, women in academic positions are underrepresented, which can be attributed to sociocultural, historical, and institutional structures.

\section{Discussion and Takeaways}

Across countries, whether "developed" or "developing," or collectivist or individualistic nations, efforts continue to be implemented to address gender discrepancies of women in STEM. Yet, senior-level positions in higher education as well as in other workplaces continue to indicate a problem in the academic pipeline. Despite this troublesome trend, gender inequity in higher education is a topic of importance regularly researched internationally. Thus, while there continues to be evidence of structural and cultural obstacles, there is also hope for both gender parity and gender equity.

The potential challenges highlighted in this chapter speak to various sociocultural and historical contexts including the collectivist nature of Kazakhstan, 
the Post-Soviet context of women in the workforce, and traditional cultural practices. The combination of these cultural and political contexts infiltrate the educational system and are reproduced in educational and cultural media. These gendered representations teach consumers what it means to be a woman or a man and what professional fields are encouraged for each gender.

Interventions to address gender discrepancy and move towards gender equity need to start early and be incorporated throughout educational and cultural spheres. Such an approach is what Wang and Degol (2017) mention as "lifelong," including representation in the media to "strive to create more positive portrayals of female professionals in STEM fields, so that girls and women encounter wellrounded and realistic images of successful women scientists" (p. 131). Without recognizing the sociocultural influence, it can be easy to fall into the trap of telling women they need to "try harder," "negotiate more," or "lean in" (Sandberg \& Scovell, 2013). However, as Kim et al. (2018) note, the messages coming from the concept of leaning in (trying harder) can be problematic when major changes are needed structurally and socially; "self-improvement messages intended to empower women to take care of gender inequality may also yield potentially harmful societal beliefs" (p. 974). Thus, recognizing the multifaceted nature of pressures and culture is essential when addressing gender equity in STEM.

In addition to the sociocultural and historical context, role models and mentorship is recognized as essential for steady movement through the academic pipeline. In other words, having a lack of women across academic ranks in STEM fields can be an impediment to gender equity. As shown in the case study at NU, women represented less than $10 \%$ of all faculty in the School of Engineering and Digital Sciences, across six departments. Therefore, while there appears to be a growing trend of more women enrolling in STEM fields at this university in Kazakhstan, representation of STEM knowledge and leadership remains firmly held by men.

Mentorship can be considered from different perspectives, such as a means to show women the potential for support and connectedness (Wang \& Degol, 2017) and as a means to incorporate marginalized voices. Wang and Degol (2017) emphasize the importance of women mentors and peers throughout the academic pipeline because without women colleagues' support and connection, women may hesitate to pursue STEM careers. Ultimately, a central component to supporting women as undergraduate, master's and doctoral students in STEM is to increase gender equity among faculty.

Connected to mentorship and role models is the relevance of the work environment for women (Fouad et al., 2020), including addressing familial obligations for mothers and also for fathers (Wang \& Degol, 2017). As Fouad et al. (2020) explain, employers have an obligation to improve gender equity in the STEM workplace by implementing policies that provide opportunities for both men and women to advance, achieve goals, and balance their different roles. In Post-Soviet Kazakhstan, in combination with creating gender equitable departments of STEM faculty, the STEM work environment could be a particularly effective means to address the traditional and evolving roles expected of women. 


\section{Potential Challenges and Opportunities for Growth}

In Post-Soviet Kazakhstan, the challenges for gender equity in STEM in higher education is based upon three primary factors: traditional expectations of women's roles, continued emphasis on men as bearers of knowledge, and structural obstacles to and through the academic pipeline. Unfortunately, these challenges are not unique to Kazakhstan and can be seen throughout the world. Yet, internationally these challenges of gender equity are being discussed, and that is a first step. There is a growing awareness of issues of gender equity, the lack of role models, and problems in hiring and promotion.

While traditional roles and Soviet-history remain, there is also a burgeoning desire for change and an incredible speed at which changes are being made. Therefore, opportunities in Kazakhstan and other similar contexts may not need an excessive amount of time to create and implement changes. For instance, the government in Kazakhstan in 2009 introduced a law to guarantee equal rights and opportunities for men and women (2009), developed an action plan for gender policies through 2030 (Government of the Republic of Kazakhstan, 2017), and implemented the concept of family and gender policy (Ministry of Justice of the Republic of Kazakhstan, 2016).

Therefore, while Kazakhstan faces challenges regarding gender disparity in STEM disciplines and careers, there are steps that can be taken which could effectively move the nation towards gender equity. According to international and regional research, relevant practices for Kazakhstan and similar nations could include the following:

- Create spaces for mentoring girls and women in STEM disciplines, such as culturally responsive STEM training and camps (Ashford et al. 2017; Chukwurah \& Klein-Gardner, 2014; Taube \& Polnick, 2014).

- Take active steps to attract more women in STEM. One such way to effectively highlight the position of women in STEM is to alter the way sciences are taught in schools. For example, schools can include more imagery of women scientists, focus counseling on encouraging girls in STEM (Wei-Cheng, Shr-Jya, Jiaqi \& Johnson, 2020), and engage in more storytelling within science teaching to tap into talents typically associated with girls and women (Wang \& Degol, 2017).

- Develop and implement training and work toward institutional transformation surrounding issues of unconscious bias in higher education (CohenMiller \& Lewis, 2019), including addressing differences in recommendation letters for women and men (Bilimoria \& Liang, 2012).

- Alter the workplace culture to increase transparency and fairness in expectations for research (Willey, 2020) and eliminate the "motherhood penalty" (Mason et al., 2005) and the "chilly climate" for women in STEM (Hughes, 2014). Such changes could create a "culture of care" (Isgro \& Castañeda, 2015) and an organization which recognizes the 
relevance and need for equity and inclusion for women in academia, throughout all levels and disciplines.

\section{Conclusion}

In this chapter, we examined the topic of gender parity and equity in STEM fields in Kazakhstan. We investigated gender equality in the academic environment at the international level and research on gender and education in Kazakhstan. The country's sociocultural expectations creates pressure for women to have professional careers and simultaneously take on the responsibility of raising children, taking care of the home, and looking after older relatives. These expectations and associations for women who take on these multiple roles are reflected in the lack of gender parity and equity throughout the educational pipeline.

In this chapter, we used the case study of STEM undergraduate and graduate students and an examination of gender parity among faculty at Nazarbayev University to analyze the admission and progress of students and the gender gap among faculty in STEM disciplines. Through this examination, we argued the gendered imbalance of STEM university students and faculty should be addressed in multiple ways to promote gender parity and equity, including through raising awareness of gender bias disadvantaging women, through creating STEM spaces for women including focused mentoring to facilitate success, and through targeted recruitment, retention, and promotion practices.

\section{References}

Agency of the Republic of Kazakhstan on Statistics. (2020). https://stat.gov.kz/

Akiner, S. (1997). Between tradition and modernity: The dilemma facing contemporary Central Asian women. In M. Bruno, (Ed.), Post-Soviet women: From the Baltic to Central Asia (pp. 261-304). Cambridge University Press.

Almukhambetova, A., \& Kuzhabekova, A. (2020). Factors affecting the decision of female students to enrol in undergraduate science, technology, engineering and mathematics majors in Kazakhstan. International Fournal of Science Education, 1-21.

Ashford, S. N., Wilson, J. A., King, N. S., \& Nyachae, T. M. (2017). STEM 'sista' spaces: Creating STEM counterspaces for Black girls and women. In T. S. Ransaw \& R. Majors (Eds.), Emerging issues and trends in education (pp. 3-38). Michigan State University Press.

Bilimoria, D., \& Liang, X. (2012). State of knowledge about the workforce participation, equity, and inclusion of women in academic science and engineering. In D. Bilimoria \& X. Liang (Eds.), Gender equity in science and engineering (pp. 16-45). Routledge.

Blickenstaff, J. C. (2005). Women and science careers: Leaky pipeline or gender filter? Gender and Education, 17(4), 369-386. https://doi.org/10.1080/09540250500145072

Bokova, I. (2017). Foreword. In C. Chavatzia (Ed.), Cracking the code: Girls' and women's education in science, technology, engineering and mathematics (STEM) (p. 5). UNESCO.

Buffington, C., Cerf, B., Jones, C., \& Weinberg, B. A. (2016). STEM training and early career outcomes of female and male graduate students: Evidence from UMETRICS data linked to the 2010 census. American Economic Review, 106(5), 333-338. 


\section{Anna CohenMiller et al.}

Bystydzienski, J. M. (2020). Gender and STEM in Higher Education in the United States. In Oxford research encyclopedia of education. Oxford University Press.

Cacace, M. (2009). Guidelines for gender equality programmes in science. Practising Gender Equality in Science. www.retepariopportunita.it/Rete_Pari_Opportunita/UserFiles/ Progetti/prages/pragesguideline s.pdf

Chachashvili-Bolotin, S., Milner-Bolotin, M., \& Lissitsa, S. (2016). Examination of factors predicting secondary students' interest in tertiary STEM education. International Fournal of Science Education, 38(3), 366-390.

Chukwurah, C., \& Klein-Gardner, S. S. (2014). STEM summer institute: A model program for stem integration for girls. In J. Koch, B. Polnick, \& B. Irby. (Eds). Girls and women in STEM: A never ending story (pp. 153-174). Information Age Publishing.

CohenMiller, A. S. (2014). The phenomenon of doctoral student motherhood/mothering in academia: Cultural construction, presentation of self, and situated learning. [Unpublished doctoral dissertation]. University of Texas at San Antonio.

CohenMiller, A. S., \& Lewis, J. (2019). Gender audit as research method for organizational learning and change in higher education. In V. Demos, M. T. Segal, \& K. Kelly (Eds.), Gender and practice: Insights from the field: Vol. 27. Advances in gender research (pp. 39-55). Emerald Publishing. https://www.emerald.com/insight/content/doi/10.1108/S1529-212620190 000027003/full/html

CohenMiller, A. S., Koo, S., Collins, N., \& Lewis, J. (2020). EXPOsing gender in science: A visual analysis with lessons for gender awareness and science diplomacy. Gender, Technology and Development. https://doi.org/10.1080/09718524.2019.1695519

Gvencek, D., Kapur, M., \& Meltzoff, A. N. (2015). Math achievement, stereotypes, and math self-concepts among elementary-school students in Singapore. Learning and Instruction, 39, 1-10.

Dawson, A. E., Bernstein, B. L., \& Bekki, J. M. (2015). Providing the psychosocial benefits of mentoring to women in STEM: CareerWISE as an online solution. New Directions for Higher Education, 2015(171), 53-62.

Durrani, N. Kataeva, Z., CohenMiller, A., \& Makhmetova, Z. (in press). Teacher agency for gender justice in Kazakhstan [Conference presentation]. Comparative \& International Education Society (CIES).

Durrani, N., Kataeva, Z., CohenMiller, A., Seitkhadyrova, A., \& Badanova, A. (2019). The fearful khan and the delightful beauties. Masculinities and femininities in school textbooks in Kazakhstan [Conference presentation]. Central Eurasian Studies Society (CESS) Conference, Washington, DC.

Durrani, N., Kataeva, Z., CohenMiller, A., Seitkhadyrova, A., \& Badanova, A. (2020, March 25). "Ann's much __ (beautiful) than Mary": Gendered discourses in secondary school textbooks in Kazakhstan [Conference presentation]. CIES 2020 Education beyond the Human, Miami, Florida.

European Bank for Reconstruction and Development (EBRD). (2016). Life in transition: Kazakhstan. https://www.ebrd.com/what-we-do/economic-research-and-da ta/data/lits.html

Fouad, N. A., Kozlowski, M. B., Singh, R., Linneman, N. G., Schams, S. S., \& Weber, K. N. (2020). Exploring the odds: Gender differences in departing the engineering profession. Journal of Career Assessment, 28(3), 446-461. https://doi.org/10.1177/ 1069072719876892

Fried, T., \& MacCleave, A. (2009). Influence of role models and mentors on female graduate students' choice of science as a career. Alberta Fournal of Educational Research, $55(4)$. 
Funk, C., \& Parker, K. (2018). Women and men in STEM often at odds over workplace equity. Pew Research Center. https://www.pewsocialtrends.org/2018/01/09/women-a nd-men-in-stem-often-at-odds-over-workplace-equity/

Goulden, M., Mason, M. A., \& Frasch, K. (2011). Keeping women in the science pipeline. The ANNALS of the American Academy of Political and Social Science, 638(1), 141-162

Government of the Republic of Kazakhstan. (2017). Implementation action plan on the concept of family and gender policy in the Republic of Kazakhstan until 2030 (the first stage 2017-2019). https://online.zakon.kz/m/document/?doc_id=37659563

Hofstede, G. (1991). Empirical models of cultural differences. In N. Bleichrodt \& P. J. D. Drenth (Eds.), Contemporary issues in cross-cultural psychology (pp. 4-20). Swets \& Zeitlinger Publishers.

Holmes, K., Gore, J., Smith, M., \& Lloyd, A. (2018). An integrated analysis of school students' aspirations for STEM careers: Which student and school factors are most predictive? International Fournal of Science and Mathematics Education, 16(4), 655-675.

Hughes, C. C., Schilt, K., Gorman, B. K., \& Bratter, J. L. (2017). Framing the faculty gender gap: A view from STEM doctoral students. Gender, Work \& Organization, 24 (4), 398-416.

Hughes, R. (2014). The evolution of the chilly climate for women in science. In J. Koch, B. Polnick \& B. Irby (Eds), Girls and women in STEM: A never ending story (pp. 71-94). Information Age Publishing.

Isgro, K., \& Castañeda, M. (2015). Mothers in US academia: Insights from lived experiences. Women's Studies International Forum. 53, 174-181.

Kazinform International News Agency. (2019, May 1). UNDP Kazakhstan launches a Telegram GenderBot. https://www.lenta.inform.kz/ru/undp-kazakhstan-launches-a -telegram-genderbot_a3522426

Kim, J. Y., Fitzsimons, G. M., \& Kay, A. C. (2018). Lean in messages increase attributions of women's responsibility for gender inequity. Foumal of Personality and Social Psychology, 115(6), 974-1001. https://doi.org/10.1037/pspa0000129

King Abdullah University of Science and Technology. (2020). KAUST fellowship. https://a dmissions.kaust.edu.sa/phd-fellowship.html

Knobloch-Westerwick, S., Glynn, C. J., \& Huge, M. (2013). The Matilda effect in science communication: An experiment on gender bias in publication quality perceptions and collaboration interest. Science Communication, 35, 603-625. https://doi.org/10.1177/ 1075547012472684

Koch, J., Polnick, B., \& Irby, B. (Eds). (2014). Girls and women in STEM: A never ending story. Information Age Publishing.

Kuzhabekova, A., \& Almukhambetova, A. (2019). Women's progression through the leadership pipeline in the universities of Kazakhstan and Kyrgyzstan. Compare: $A$ Journal of Comparative and International Education, 1-19.

Law of the Republic of Kazakhstan on state guarantees of equal rights and equal opportunities for men and women $\S 223-I V$ ZRK. (2009). https://online.zakon.kz/Document/?doc_id= 30526983\#pos=2;-113

Litzler, E., Lange, S. E., \& Brainard, S. G. (2005). Climate for graduate students in science and engineering departments [Conference presentation]. Proceedings of the 2005 American Society for Engineering Education Annual Conference \& Exposition, Portland, OR.

Mason, M. A., Stacy, A., Goulden, M., Hoffman, C., \& Frasch, K. (2005, February). University of California faculty family friendly edge: An initiative for tenure-track faculty at the University of Califormia [Report]. University of California Berkeley. https://ucfam ilyedge.berkeley.edu/sites/default/files/ucfamilyedge.pdf 
McClure, E. R., Guernsey, L., Clements, D. H., Bales, S. N., Nichols, J., Kendall-Taylor, N., \& Levine, M. H. (2017). STEM starts early: Grounding science, technology, engineering, and math education in early childhood [Report]. The Joan Ganz Cooney Center at Sesame Workshop. https://joanganzcooneycenter.org/wp-content/uploads/2017/01/jgcc_ stemstartsearly_final.pdf

McLaughlin, K. (2018). Kazakhstan country gender assessment. Asian Development Bank.

Ministry of Justice of the Republic of Kazakhstan. (2016). Concept of family and gender policy in the Republic of Kazakhstan until 2030. https://www.akorda.kz/ru/npa-naciona lnoi-komissii

Moss-Racusin, C. A., Dovidio, J. F., Brescoll, V. L., Graham, M. J., \& Handelsman, J. (2012). Science faculty's subtle gender biases favor male students. Proceedings of the National Academy of Sciences of the United States of America, 109(41), 1-6.

National Testing Center. (2020). Unified national testing. www.testcenter.kz

Nazarbayev University. (2020). Nazarbayev University at a glance. https://nu.edu.kz/a bout-nazarbayev-university/nu-at-a-glance

Nazarbayev University School of Engineering and Digital Sciences. (2020). Faculty and research. https://seds.nu.edu.kz/faculty-and-research/faculty-list-2/

On approval of the State Program for the Development of Education and Science of the Republic of Kazakhstan for 2016-2019 § 460 (2018). https://zakon.uchet.kz/ rus/docs/P1800000460

Posselt, J. R. (2016). Inside graduate admissions: Merit, diversity, and faculty gatekeeping. Harvard University Press.

Primé, D. R., Bernstein, B. L., Wilkins, K. G., \& Bekki, J. M. (2015). Measuring the advising alliance for female graduate students in science and engineering: An emerging structure. Fournal of Career Assessment, 23(1), 64-78.

Sandberg, S., \& Scovell, N. (2013). Lean in - women, work and the will to lead. Knopf.

Seidakhmetova, B. (2019, August 8). STEM - идеи для Казахстана [STEM-ideas for Kazakhstan]. Komsomolskaya Pravda. https://www.kp.kz/daily/27010.1/4075826/

Taube, S., \& Polnick, B. (2014). Looking through a mirror with a third eye: Improving mathematics teaching in culturally diverse classrooms. In J. Koch, B. Polnick, \& B. Irby (Eds). Girls and women in STEM: A never ending story (pp. 193-216). Information Age Publishing.

UNESCO. (2016). Closing the gender gap in STEM: Drawing more girls and women into science, technology, engineering and mathematics. [UNESCO Asia-Pacific Education Thematic Brief]. UNESCO.

UNESCO. (2017). Cracking the code: Girls' and women's education in science, technology, engineering and mathematics (STEM). UNESCO.

UNICEF. (2020). UNICEF Launches Unisat nanosatellites program for girls [Press release]. https://www.unicef.org/kazakhstan/en/press-releases/unicef-launches-unisatnanosatellites-program-girls

U. S. Embassy and Consulate in Kazakhstan. (2020). 2020 TechGirls program. https:// kz.usembassy.gov/education-culture/opportunities/2019-techgirls/

U. S. Mission to International Organizations in Vienna. (2018, July 19). United States sends girls from Kazakhstan and Afghanistan to Colorado STEM summer camp. https:// vienna.usmission.gov/united-states-sends-girls-from-kazakhstan-and-afghanistan-to-color ado-stem-summer-camp/

Van Anders, S. M. (2004). Why the academic pipeline leaks: Fewer men than women perceive barriers to becoming professors. Sex Roles, 51(9-10), 511-521. 
Van Miegroet, H., Glass, C., Callister, R. R., \& Sullivan, K. (2019). Unclogging the pipeline: Advancement to full professor in academic STEM. Equality, Diversity and Inclusion: An International fournal, 39(2), 246-264.

Wang, M.-T., \& Degol, J. (2017). Gender gap in science, technology, engineering, and mathematics (STEM): Current knowledge, implications for practice, policy, and future directions. Educational Psychology Review, 29(1), 119-140. https:doi.org/ 10. 1007/s10648-10015-9355-

Weber, K. (2011). Role models and informal STEM-related activities positively impact female interest in STEM. Technology and Engineering Teacher, $71(3), 18$.

Wei-Cheng, M., Shr-Jya, C., Jiaqi, L, \& Johnson, E. (2020). Gender difference in STEM career aspiration and social-cognitive factors in collectivist and individualist cultures. Administrative Issues Foumal: Education, Practice E Research, 10(1), 30-46. https://doi.org/ 10.5929/2020.10.1.3

Willey, N. L. (2020). Parenting policies and culture in academia and beyond: Making it while mothering (and fathering) in the academy, and what COVID-19 has to do with it. Fournal of the Motherhood Initiative for Research and Community Involvement, 11(1), 201-217

$\mathrm{Xu}, \mathrm{Y} . \mathrm{J}$. (2008). Gender disparity in STEM disciplines: A study of faculty attrition and turnover intentions. Research in Higher Education, 49(7), 607-624.

Yoshikawa, K., Kokubo, A., \& Wu, C. H. (2018). A cultural perspective on gender inequity in STEM: The Japanese context. Industrial \& Organizational Psychology, 11, 301-309. https://doi.org/10.1017/iop.2018.19

Ysseldyk, R., Greenaway, K. H., Hassinger, E., Zutrauen, S., Lintz, J., Bhatia, M., Frye, M., Starkenburg, E., \& Tai, V. (2019). A leak in the academic pipeline: Identity and health among postdoctoral women. Frontiers in Psychology, 10, 1297. 


\title{
10 Black African Women in Engineering Higher Education in South Africa
}

\author{
Contending with History, Race, \\ and Gender
}

Yeukai Angela Mlambo

Globally, women and Black African ${ }^{1}$ women, in particular, are underrepresented in engineering professions. South Africa is not an exception. According to the Engineering Council of South Africa (2019), women represent less than 7\% of total registered professional engineers to date and about $24 \%$ of candidate engineers in training. In terms of race, Black Africans represent close to $20 \%$ of professional, registered engineers, while their white ${ }^{2}$ counterparts represent $74 \%$ (ECSA, 2019). Although women's presence is increasing in some engineering work spaces, including industry and government, they remain underrepresented in engineering academic careers in particular. Austin \& McDaniels (2006) state that a primary function of higher education is "to prepare the next generation of university faculty members" (p. 397). But what happens when university spaces are hostile towards Black women's bodies and identities? (Mabokela, 2001). Hurtado (1992) states that higher education environments are a product of history and context, institutional structures, group relations and ideologies. In essence, these historical backgrounds influence and impact how university campuses operate and how individuals engaging with and within those institutions experience the space(s).

In South Africa, higher education institutions continue to work their way out of their sullied apartheid pasts where Black women were excluded from full participation. Despite attempts at transforming institutional spaces and academic staff ${ }^{3}$ so that they reflect the diverse student population now attending these institutions, change remains slow. For example, across all institutions in 2018, Black academic staff as a combined aggregate of all non-white, permanent staff (i.e. African, Coloured, Indian or Asian) represented only 39.6\% of academic staff at public universities. In contrast, white people remained the largest population proportion of academic staff at $42.7 \%$ (Department of Higher Education \& Training, 2020). This in a country where white people make up less than $9 \%$ of the almost 59 million strong population.

Instead, in South African higher education Black Africans are over represented in support roles where they occupy about 97\% of administrative and service positions (Mabokela \& Mlambo, 2017). Where Black or Black Africans

DOI: $10.4324 / 9781003053217-1$ 
and women hold academic staff positions, they make up the majority of those below the $\mathrm{PhD}$ qualification, mostly employed as lectures or junior lectures (Mabokela \& Mlambo, 2017). In 2012, among Black Africans more narrowly, Black African women represented only 34 of the total 193 Black African professors at all public institutions (Price, 2014). By 2014, Black Africans represented only $4 \%$ of professors overall in South Africa, with Black African women in particular representing only $0.85 \%$ of the professoriate (Mlambo, 2017). In 2017, Black African representation among the South African public institution professoriate increased to $19.9 \%$, but Black African women in particular only represented $4.2 \%$ of South African professors overall (Higher Education Data Analyzer, 2020). In terms of engineering programs specifically, across all public institutions Black African women are glaringly absent. Where present, Black African women occupy junior roles and are often the only Black African individual among the academic staff in a department or college ${ }^{4}$ (Mlambo \& Mabokela, 2017).

When discussing the history of women's education in South Africa, Megan Healy-Clancy (2013) states that "consumed by the overarching racialized indignities of apartheid education, scholars have neglected how it was also a gendered project" (p. 121). I argue that for Black women in South Africa, race and gender play significant roles in not only their educational experiences, but ultimately in the career pathways Black women are able to pursue. Furthermore, race and gender are experienced as connected to a history that continues to devalue, exclude, and alienate Black Africans from academia even today. In an attempt to understand Black African women's absence in South African engineering academia, I focus my attention on understanding more broadly the factors that influence Black African South African women engineers' career choices, taking into consideration their higher education experiences.

In the next sections I provide background for understanding the racist and sexist history of higher education and engineering education in South Africa. Thereafter, using evidence from qualitative interviews conducted with 18 Black African women engineers who attended historically white institutions in South Africa, I highlight how race and gender continue to be significant factors impacting the higher education experiences of Black African women engineers I find that Black African women's experiences in higher education influence their career choices after graduation, directing them away from academia.

South Africa provides a unique socio-political context for understanding the ways in which the intersections of race and gender affect Black women's experiences in higher education more broadly, and in engineering higher education more specifically. To understand Black African women engineers' career decision-making and career outcomes as they relate to academia, one has to first understand the histories of higher education and engineering education in South Africa. Any effort to increase the percentage of Black African women who study engineering in South Africa must address the lack of Black African women who can act as teachers and mentors to future generations of undergraduate students. 


\section{Background to Higher Education and Engineering in South Africa}

The national elections in 1994 marked the end of the formal apartheid era, the transition to a new democratic South African government, and the introduction of new policies aimed at redressing the racial discrimination of apartheid higher education (Thomas, 1996). Prior to 1994, higher education access was segregated by race and ethnicity such that Black people were not permitted to attend or take on employment at designated white-only institutions (Reddy, 2004). Worth noting, engineering degrees were offered exclusively at these white-only institutions, which Black people could not easily access. Enrollment numbers at the time show how Black people had generally limited access to higher education overall. For example, in 1993, a year before the first democratic elections in South Africa, Black students represented only $6.3 \%$ of higher education enrollments. In the sciences, white students filled 67 enrollment positions for every one Black student, while in engineering the ratio was even wider as Black students represented one out of every 148 white students (Watson et al., 1997).

The discriminatory and segregated practices were rooted in the legislation of the Bantu Education Act, also known as the Black Education Act of 1953 as well as the Extension of University Education Act of 1959. Both legislative acts enforced racial segregation of educational facilities. The Bantu Education Act determined a specific and limited educational curriculum for Black Africans, rooted in the belief that "black people should be subjugated through education to enforce apartheid ideology" (Ndimande, 2013, p. 22). At its core, Bantu Education was intended to socialize Black people to accept the social norms of apartheid, by enacting educational frameworks that emphasized white superiority and Black inferiority. At the higher education level, the Extension of University Education Act expanded segregation to include higher education institutions, criminalizing any Black people that attended newly designated white institutions without written permission from the Minister of Internal Affairs. Alternate higher education institutions were created and designated for different racial and ethnic groups, with restrictions on who could attend based on their race or ethnic identity. Although the Extension of University Education Act was repealed in 1988, the irreparable damage such policies caused continue to plague the nation today (Akoojee \& Nkomo, 2007). Questions of belonging, though no longer explicitly stated, remain part of the unspoken foundation of South African higher education, albeit now couched in conversations about how to maintain quality as higher education institutions increase access (Akoojee \& Nkomo, 2007).

\section{Post-Apartheid Higher Education}

Post-apartheid policies, including the Education White Paper 3 (Department of Education, 1997) and the National Plan for Higher Education, called out 
racial inequalities in access and provided policy directives to "promote equity of access and redress past inequalities" (Ministry of Education, 2001, p. 12). In particular, Education White Paper 3 noted how problematic it was that despite institutions opening their admissions to students from all races, higher education staff at these institutions, primarily the historically white institutions (HWIs), remained overwhelmingly white (Mlambo, 2017). The White Paper stated, "unlike the changing student profile, especially in undergraduate programs, the composition of staff in higher education fails to reflect demographic realities ... Black people and women are severely underrepresented, especially in senior academic and management positions" (Department of Education, 1997, Section 2.94). While some progress has been made in terms of diversifying student representation, most higher education institutions "have retained as a majority the race group the university historically served" (Mlambo, 2017, p. 9).

Unfortunately, over 25 years after the end of apartheid, Black women continue to experience higher education as racialized and gendered spaces, which hinders Black women's meaningful participation as students, staff and faculty (Mabokela \& Mawila, 2004; Mabokela \& Mlambo, 2017; Mlambo, 2017). In addition to building names and plaques on campus being subtle reminders of the racist legacy, in some cases campus environments are blatantly harmful to Black bodies. Reports of incidents where Black bodies are dehumanized by white students create undue stress for Black students. For example, in 2008 four white students at the University of Free State made three Black women university cleaning staff drink urine and filmed the incident, which they had staged in protest of the university's decision to racially integrate the residence halls that until then had been divided by race (Norgaard, 2008). In a 2019 report, the Institutional Reconciliation and Transformation Commission (IRTG) of the University of Cape Town found that racism is rife at the University of Cape Town, a prestigious, world-ranked institution, which in 2015-2016 was the center of student protests against institutional racism with demands for decolonization of African higher education, including the removal of artifacts of colonization such as the Cecil John Rhodes statue. These are the higher education learning environments that Black students engage with on a daily basis in South Africa.

Today, the South African postsecondary school education and training system is made up of 26 public traditional and comprehensive universities and numerous other private institutions and technical colleges (DHET, 2020). In 2018, these public universities enrolled 1,085,568 students, a significant increase in access from the 495,356 enrolled in 1994. The highest enrollments were in science, engineering and technology (SET) programs, which accounted for $29.5 \%$ of enrolled students, followed by business $(26.1 \%)$, humanities and social sciences $(24.6 \%)$, and education (19.7\%). In the same year, SET programs registered 65,000 students who graduated from these programs, the highest number of graduates compared to other disciplines. 
In terms of enrollment, women's gross enrollment ratio surpasses men's enrollment by $40 \%$ overall and Black Africans occupy a $75.6 \%$ share of enrollment. While women represent the majority of students across all disciplines, they occupy a slight minority in SET (46.7\%). Despite Black African students representing a majority of the student population, academic staff remain predominantly white, and Black students in engineering are especially likely to complete their undergraduate and graduate education without being taught by a Black professor and definitely not by a Black female professor (Mlambo, 2017).

\section{Black Women's Post-Apartheid Higher Education Experiences}

Shortly after transitioning to democracy, a 1996 South African higher education report concluded that "the experiences by female and Black students and staff in particular suggest that conditions at institutions often do not facilitate the full participation of members of all social categories and groups" (National Commission on Higher Education, 1996, p. 39). The 1996 report pointed to the need for radical transformation of the policies and practices at institutions around the country for South Africa to move away from the racist and sexist norms of the apartheid era. However, by 2012, a quantitative study examining the relationship between student engagement and sense of belonging among South African higher education students highlighted how race remains a salient factor in the educational lives of Black African South African students (Wawrzynski, Heck \& Remley, 2012). Today, higher education institutions in South Africa are a constant reminder of an apartheid era that may have ended politically, but whose institutions, buildings, policies, and bodies continue to reflect and represent that dark legacy. This residual racism is also felt in the classroom, and is acted out by both lecturers and students (Wawrzynski et al., 2012; Cross et al., 2009).

African scholar Amina Mama (2003) argues that, “the 'African' universities established after independence did not mark a radical departure from the colonial modes of organizational and intellectual life" (p. 106), which she describes as "male preserves, dedicated to the production of good colonial subjects" (p. 105). In her analysis of the impact of gender on higher education in Africa, Mama (2003) goes on to explain how despite claims by African universities that they operate as neutral entities, "the institutional and intellectual cultures of African institutions are, in fact, permeated with sexual and gender dynamics" (Mama, 2003, p. 101). Furthermore, hostile higher education environments for women "operate in ways that are very likely to jeopardize women's academic career prospects" (p. 118).

In South Africa, Mama's insights can be observed in the composition of faculty and staff across the country. The experiences of Black women engineers are perhaps to be expected, given the history of the discipline as its purpose aligned with the higher education mandate during colonial times. The purpose of engineering in Africa was to advance the mission of the colonies. In doing so, engineering policies and the higher education spaces that trained engineers 
determined who could participate and in what ways (Muller, 2018). As noted previously, until 1994 with the transition to democratic rule, Black Africans were treated as second class citizens in South Africa. Various laws forbid full or any participation of Black South Africans from a majority of higher education and employment spaces. White men could enroll in engineering courses, but Black people had to apply for special permission to attend white institutions, which were the only places offering engineering credentials (Cruise, 2011). Some sectors such as mining were subject to legislation that prohibited hiring women engineers. In addition, non-whites were not allowed to become certified miners effectively securing the senior mining positions for white people only and deterring Black women from pursuing mining engineering in particular (Cruise, 2011).

After 1994, as engineering companies began to more actively recruit and accept Black South Africans, more young Black people were encouraged to pursue engineering. National affirmative action policies were put in place to incentivize organizations that hired Black people and women. Companies began to provide higher education bursaries and sponsorship to recruit Black women into engineering, creating their own pipeline of future employees who would be contractually obligated to work for the company upon graduation, in exchange for a full scholarship (Republic of South Africa, 1998). Participation in engineering then became a pathway for social mobility for the individual and her family (Mlambo, 2017).

As Black people mostly came from low socio-economic backgrounds due to historical disenfranchisement, the ability to attend higher education with sponsorship and to subsequently secure a well-paying job upon graduation was appealing (Firfirey \& Caolissen, 2010). Black women were drawn to engineering, because it "was the embodiment of an apartheid system of exclusion that they were interested in infiltrating and establishing a legacy as one of the first Black women in the field" (Mlambo, 2017, p. 194). In contrast, academia was viewed as low paying in comparison to industry and had negative associations with the teaching profession (Mlambo, 2017). Given the restrictions on employment options during apartheid where Black women's career options were limited to teaching and nursing, "teaching was less prestigious and not appealing for these women" (Mlambo, 2017, p. 195). As industry spaces deliberately targeted women and Black women in particular, Black women were increasingly drawn towards careers in industry and away from academia.

Despite Black people having legal access to attend higher education institutions of their choice and no longer being restricted by their race, institutional environments and policies continue to reinforce the idea that Black people are unwelcome in these spaces, especially HWIs. In a study to understand the career choices of Black African women engineers in South Africa, I conducted 18 interviews with Black women engineers, all with postgraduate ${ }^{5}$ engineering degrees who found employment in industry, government, or academia. The women had attended undergraduate engineering programs both before and after 1994, with most participants having been undergraduate students after 
1994. The women ranged in age from 24 to $50+$, with an average age of 32 years. Participants represented various engineering programs, with civil and metallurgical engineering most represented. The purpose of the study was to understand their career choices and to explain why for most of the women, academia was not a first career choice. For this chapter, I focus on the findings related to the racialized and gendered undergraduate higher education experiences the women described as factors influencing their career choices.

\section{Campus Climate, Black Experiences, Perceptions about Academia and Career Choice}

In reflecting on their higher education experiences, participants described their undergraduate experiences as taking place in white normative spaces, absent of mentorship for Black students, unwelcoming, and representative of an apartheid past where Black people were restricted from full and equal participation. I discuss some of their reflections and provide direct quotes as evidence to support their narratives.

\section{Whiteness as the Norm}

Participants described their higher education experience as a space where whiteness was the norm. The women shared how in their entire higher education experience in engineering, they had never been taught by a Black lecturer or professor. One participant recalls,

... we didn't have Black females or even Black lecturers to look up to at the time ... you know, the whole industry was white, it still is today. But back then it was more so, you know, so it's, it was difficult to even find, there were a few Black people and all male at the time ... (Lulama)

Another participant shared how white students often outnumbered Black students in their courses. Unfortunately, in order to survive their undergraduate sojourn, Black students had come to accept as status quo that whiteness was normative,

... Like we had accepted it. It's a matter of just saying we need to get our degrees and go, that's it. Yeah, we had accepted it ... it's just how it is, you can't change it, you are here so you just have to live with it. (Rose)

Once over the culture shock, participants quickly became accustomed to the racial imbalances in the classroom that favored white students. The prevalence of whiteness in engineering higher education reinforced the message that higher education was a white space, and, similar to apartheid times, Black bodies could be granted temporary access to gain their degrees with an understanding that they would move on to industry for their careers, and not remain in academia. 


\section{Limited Mentorship for Black Students}

A consequence of whiteness being the norm in engineering higher education was the lack of Black mentors available for Black students. For Black women, the absence of women role models can deter them from pursuing degrees and careers in SET. In terms of academic careers specifically, faculty are essential agents for socializing students into the culture of the discipline (Schuurman, Pangborn, \& McClintic, 2005). In reflecting on the absence of Black women mentors during their undergraduate studies, one participant shared,

I think I missed out. I think if there was someone like me, a Black woman, teaching me to become an engineer, I think that would've been that motherly touch to it as well. Someone you can go and speak to and ask questions. Someone who would inspire you. It would be more comfortable for you. I think I would have had a different perspective about engineering. (Mpho)

In addition to faculty not representing the diversity of the student population, participants reported how white professors would focus their recruitment, mentorship, and grooming efforts on white students and rarely, if ever, on Black students in their classrooms. One participant shared that no matter how good a Black student was, and even when peers would embrace them despite their racial differences, white lecturers were less open to engaging with Black students in the same way they did with white students. The limited engagement of white lecturers with Black students also meant that Black students were less likely to know about the career aspects of academia. "I think its just a lack of knowledge, information. Because I don't even know what qualifies one to be a professor, a lecturer. I don't know" (Teboho). Essentially, "Black people were not made aware of the rules of academia," thereby diminishing their potential to develop an informed interest in higher education as a career space (Mlambo, 2017, p. 209).

Additionally, Black women perceived that white lecturers pre-determined which white students they wanted to mentor into academic careers, therefore Black students, no matter how good, often did not stand a chance.

The lecturers decide who they want as lecturers by the time we graduate ... so if I come there and I'm like you know what I would love to teach this, but this guy has been groomed already for this position ... how are you gonna come in an destabilize that foundation? (Tumelo)

The absence of encouragement these women felt from their higher education lecturers was in sharp contrast to their pre-tertiary educational experiences, where teachers of all races were notably encouraging of these same Black women to pursue engineering. One participant shared that 
my teachers at school, you know when you're in high school ... they're the ones who shape your career choice, they tell you 'oh my gosh you're so good in maths you're so good in science you should consider engineering' (Melita). This encouragement and mentorship propelled them into engineering but was not sustained by their new instructors at the undergraduate level, who instead appeared to hold a deficit perspective of Black women's talents in engineering academia in particular. "The history of apartheid and the racial hierarchies and prejudices the apartheid system created which presented Black people as incapable scholars remained present among older academic staff in engineering higher education. (Mlambo, 2017, p. 126)

These feelings of racism and alienation dissuaded Black women from considering academic careers for themselves.

South African authors Cross, Shalem, Backhouse \& Adam (2009) reported similar findings where Black students from an HWI felt they were "undermined from an academic perspective and deliberately prevented from succeeding" in engineering and the humanities as "white students are offered academic support that is not offered to black students" (p. 32). As a result, the students experienced the institution as an unwelcoming space that favored white students and where Black students would never be viewed as capable students. Mangcu (2014) states that standards of academic potential in South African universities continue to be measured by whiteness. As young Black women do not see themselves in the faces of those occupying career positions in academia, there are effectively no opportunities to imagine oneself as performing that role.

In contrast, Black women undergraduate students increasingly found representations of themselves as well as willing mentors in industry spaces through the various internships Black women participated in during their school holiday breaks.

While now we were, I was in tertiary, coming for vacation work, I would see one Black engineer, young. You know, he just qualified. He's starting now as a manager. That will ignite the passion even more ... so those are the people that kept me going [they would say to me] - "Wow, we hear about you, we can see you're hard working. Keep going. You can do this. (Noku)

These experiential learning opportunities became the gateways to building understanding about what it means to be a Black African engineer in industry and reinforced the message that women, and Black African women specifically, were welcome in industry.

\section{Higher Education as Unwelcoming}

As industry welcomed Black African women with some enthusiasim, higher education continued to provide unwelcoming experiences for Black women. 
In my study, the absence of Black African women amongst engineering lecturers or professors added to feelings among Black African women students that academia was not meant for people who looked like them, and "that perhaps the academy itself did not want them" (Mlambo, 2017, p. 208). One woman shared,

And I suppose the environment as well. It's just not that attractive. It's still like an old boys club, if I can put it like that. So it's yeah, and it's like that wherever you go, whether it's (university 1, 2 or 3) it's still like that. It's still a club of closed circle of people who speak a particular language and you can go be the brave one and go in but then you risk being the token in the group. (Audrey)

Black African women also used white women as a benchmark to further determine whether or not Black women belonged in academic careers. One participant noted her reservations at trying to enter higher education career spaces where white women were also struggling to succeed. "Even the white women lecturers find it tough to compete in that male environment, and they are white!" (Tumelo). As a result, Black African women viewed their time in higher education as a temporary life event which would inevitably end upon conferral of their degrees, allowing them to move on to careers in industry. "... I think usually when we think of engineering, we tend to more think of not academia. Yeah, I think when you're thinking academics, you think I must go through it and go work somewhere else" (Vuyo). The Black African women in my study "had reconciled early in their higher education process that engineering academe was a white space Black people had to survive" (Mlambo, 2017, p. 197) and promptly leave for something else outside of the university space.

In addition to the negative experiences with faculty, their undergraduate experiences solidified for Black women that they would not want to pursue careers in academe.

The one decision that I made when I was a student, I said I'm not gonna be a lecturer. You need to know your stuff. Kids can be mean sometimes. They'll ask you certain things just to expose you. That's how students are. I said ok, you need to know your stuff when you become a lecturer so I am not gonna be lecturing anytime soon. (Teboho)

In the absence of mentors and already feeling alienated from the academy, Black women seldom sought out information that could challenge their (mis)perceptions. As a result, "An academic career, which would inevitably involve spending more time in a predominantly white space, was not even considered" (Mlambo, 2017, p. 125), or in the case of Teboho, was outright rejected based on the information she had at her immediate disposal. 


\section{Freeing Themselves and Their Families from Apartheid}

The less than positive higher education experiences Black women encountered are linked to the historical legacy of apartheid and the socio-economic positioning of Black African women over time in South Africa. In addition to navigating a hostile higher education environment, the Black African women were also actively working to free themselves and their families of the legacy of apartheid.

Black African women viewed higher education as an extension of their pretertiary schooling. Thus, they saw higher education lecturers as equivalent to their primary and high school teachers, integral in getting them to move on to their next educational phase, but not as career role models whom they themselves might wish to become one day. As higher education lecturers were equated with school level teachers, and given the legacy of apartheid that limited Black women to teaching roles, the Black women in my study who were eager to shake off the legacy of apartheid did not see teaching as a prestigious occupation in the current political dispensation. Instead, they believed it was their family and community duty to transcend the career designations imposed on Black women during apartheid by occupying spaces in the engineering industry where they were previously banned.

As first-generation engineers in their families, these Black African women were motivated to use their education to elevate their families and communities into previously unachievable socio-economic levels. Academia as a career was not perceived as providing the necessary social and economic resources to achieve that goal at the same rapid pace that industry careers could. A Dean of an engineering school in South Africa confirmed that academia does not have the same rewards that industry does in financial terms. For Black people who come from impoverished backgrounds, academia then becomes less appealing than industry. One Black African woman participant reiterated this notion of generational responsibility and why Black African women pursue engineering but do not consider academic careers in the process,

... as a Black woman, you want to go back home and do things for your home and that's why as soon as you get in a position to study, you want to go and do something that can bring finances to go and support your family. Because we feel a lot of responsibility. Especially in our generation, we felt that, okay, we were one of the first, you know, the first groups to get bursaries and get proper education ... as soon as you get that opportunity, you want to do it so that you can actually provide for your sisters, your mothers, your grandmothers because there is a lot of responsibility that you naturally just carry. (Mpho)

Black women's identities within their families and communities, coupled with their motivations to transcend pre-1994 policy restrictions, as well as the strong messaging of unbelonging they received from higher education spaces, influenced their career considerations away from academia. 


\section{Discussion}

This chapter explored how race and gender, within historical national contexts, influences the career considerations and choices of Black women engineers in South Africa away from academic careers and towards careers in industry. Despite representing the majority of the population, Black African women in South Africa remain noticeably underrepresented in engineering academia. As South African universities focus on redressing the inequities of apartheid by increasing access for Black students, faculty composition remains notably white and male, especially in engineering programs.

For Black African women engineers in South Africa, career pathways represent a journey of negotiating with social, cultural, economic, and historical barriers and incentives that guide Black women towards some careers and deter them from others. In this chapter, I argued that undergraduate higher education experiences influence postgraduation career outcomes for students. For Black African women in engineering, their higher education experience is often a process of surviving in predominantly white, male, and hostile spaces - both within their programs specifically and at the institution more broadly (Mlambo, 2017). These early higher education experiences remind them of who belongs and who does not belong in higher education spaces. These early messages not only impact their immediate educational experiences, but have a lasting impact on the perception of academia as places of work.

Almost 25 years after transitioning to democracy, Black African undergraduate engineering students continue to experience higher education as a racialized and gendered space. Given the glaring history of South African higher education, as well as the history of engineering in the country, it is not surprising that Black African women continue to feel like they do not belong in the academy.

Therefore, institutions should care about what environment they are creating as well as what educational experiences they are providing as these are linked to their institutional mandates to recruit, educate, and graduate students (Gayles \& Ampaw, 2011, p. 20). More often than not, teaching and learning spaces are racialized and gendered in ways that are unwelcoming to Black bodies in particular (Mlambo, 2017; Porter et al., 2018). As a result, the absence of Black women in engineering academia is a reflection of higher education spaces that still have not invited Black women as true participants in the modern African higher education project or in engineering education (Mlambo \& Mabokela, 2017). Hurtado (1992) states that "institutions that increase their commitment to diversity can significantly improve their social environments for minorities" (p. 21). Before even thinking about the transformation needed in the academic workplace for faculty and staff; to attract and retain Black African women and other minoritized identities, the learning environments in which they pass through while they are students need to embody inclusivity for Black women to even consider these spaces as possible places to pursue employment. 
In the absence of faculty who look like them, with no role models and no one providing additional information or trying to actively recruit these women for academe, Black African women come to experience higher education only as a transitory space, a necessary stepping stone on their way to other careers outside of academia (Mlambo, 2017). Failure to change higher education learning environments for Black women will hinder the ability to recruit and retain Black women in the academy and in engineering programs in particular.

\section{Implications}

The findings of this study have implications for policy and practice. At the policy level, the findings indicate that department and program faculty and staff are in a position to more directly influence the career considerations of students. Black African women lamented that they have little to no information about what an academic career entails. Access to information through student-facing faculty seminars, increasing undergraduate research programs, and providing similar vacation work opportunities to what industry offers will allow for more Black African women to understand what an academic career entails and to explore their potential place in the system.

Furthermore, institutions can allocate resources to support engineering departments to engage in more immediate and high-touch recruitment and grooming efforts to encourage more Black African women to consider academia as a career. Provision of more scholarship programs or tuition waivers for previously disadvantaged populations will allow for departments to build their own pool of future faculty, in the same way that industry streamlines the careers of recipients of their funding packages. As many Black African women are interested in pursuing postgraduate credentials, higher education institutions are at an advantage for recruitment if they can create pathways to academic careers by providing funding support and research opportunities for postgraduation education for Black students. In competition with industry, schools of engineering will fail to adequately recruit future faculty if they do not put forward significant resources to do so.

Race and gender remain salient factors influencing the higher education experiences of Black African women in engineering. The culture of whiteness as normative needs to be dismantled and replaced with a more inclusive culture that celebrates Black bodies and their intellectual contributions to science and engineering. In addition to physical representation, individuals want to see their ideas and their knowledge valued in the spaces where they are present. As faculty composition may be slow to diversify, the higher education environment needs to be welcoming to non-white students and Black African students should be able to recognize themselves in the curriculum, policies, and other symbols in the spaces where they engage, interact, and are educated. Culture change is not limited to representations among faculty, but encompasses other non-human messaging Black students receive as they survive higher education spaces. 


\section{Conclusion}

In my study, Black women engineering students reported an uneasy lack of confidence in their ability to teach others, even as they felt comfortable in their role practicing engineering in industry, government, or elsewhere. Ndimande (2013) reminds us that the purpose of education for Black people during the apartheid era was to subjugate, control, and stabilize the Black population to remain semi-skilled workers, subservient to their white counterparts. Furthermore, as Mama (2003) stated, higher education in Africa was meant to produce good workers to maintain the colonies. Black African women's discomfort with the academy is a result of decades of racialized and gendered messaging about belonging that has transcended generations. A failure to transform this damaging narrative about Black African women engineers' positioning in the knowledge enterprise will unlikely change the status quo, as Black African women will continue to opt out of academia.

\section{Notes}

1 In South Africa, Black is used to describe either all non-white individuals (including people of African, Coloured and Indian descent) or African people. For consistency with South African data reporting, in this chapter Black will be used to refer to all non-white peoples, while Black African will be used to describe individuals of African descent, distinct from Coloured, Indian and white South Africans. In South Africa, racial categories include Black African, Coloured, Indian/Asian, and white. Although the term Coloured is denigrating in some contexts, in South Africa this is an official racial category.

2 The use of the lowercase w for white or whiteness in this paper is the author's stylistic act of decentering whiteness in order to amplify Black women's experiences.

3 The word staff is used to refer to employees. South African higher education data refers to academic staff when identifying teaching and learning faculty employees.

4 College is used for ease of readership, but in South African colleges are referred to as faculties, (e.g. Faculty of Engineering) with departments used to delineate the different academic programs (e.g. Civil Engineering Department).

5 Postgraduate degrees in South Africa refer to any degree that is higher than a Bachelor's degree, e.g. honors, master's, or doctoral degrees.

\section{References}

Akoojee, S., \& Nkomo, M. (2007). Access and quality in South African higher education: The twin challenges of transformation. South African Fournal of Higher Education, 21(3), 385-399.

Austin, A. E., \& McDaniels, M. (2006). Preparing the professoriate of the future: Graduate student socialization for faculty roles. In J. C. Smart (Ed.), Higher education: Handbook of theory and research (Vol. 21, pp. 397-456). Springer. https://doi.org/10. 1007/1-4020-4512-3_8

Cross, M., Shalem, Y., Backhouse, J., \& Adam, F. (2009). How undergraduate students 'negotiate' academic performance within a diverse university environment. South African Fournal of Higher Education, 23(1), 21-42. 


\section{Teukai Angela Mlambo}

Cruise, J. A. (201 1). The gender and racial transformation of mining engineering in South Africa. The Journal of Southern African Institute of Mining and Metallurgy, 111, 217-224.

Department of Education. (1997). White paper for the transformation of higher education. http://www.che.ac.za/sites/default/files/publications/White_Paper3.pdf

Department of Higher Education and Training. (2020). Annual performance plan 2020/21. https://www.dhet.gov.za/SiteAssets/DHET\%20Annual\%20Performance $\% 20$ Plan $\%$ 202020.pdf

Engineering Council of South Africa. (2019). Annual report 2018/19. https://www.ecsa. co.za/news/Annual\%20Reports/2018-19\%20ECSA\%20Annual\%20Report.pdf

Firfirey, N., \& Carolissen, R. (2010). "I keep myself clean ... at least when you see me you don't know I am poor": Student experiences of poverty in South African higher education. South African Fournal of Higher Education, 24(6), 987-1002.

Gayles, J. G., \& Ampaw, F. (2011). Gender matters: An examination of differential effects of the college experience on degree attainment in STEM. New Directions for Institutional Research, 152, 19-25.

Healy-Clancy, M. (2013). A world of their own: A history of South African women's education. University of KwaZulu-Natal Press.

Higher Education Data Analyzer. (2020). Peer data reports. https://www.heda.co.za/ PowerHEDA/dashboard.aspx

Hurtado, S. (1992). The campus racial climate: Contexts of conflict. Institute for Higher Education Law and Governance Monograph, 90-97. https://www.law.uh.edu/ihelg/m onograph/90-7.pdf

Mabokela, R. O. (2001). Introduction: Soaring beyond boundaries. In R. O. Mabokela \& A. L. Green (Eds.), Sisters of the academy: Emergent Black women scholars in higher education (pp. xiii-2). Stylus Publishing LLC.

Mabokela, R. O., \& Mawila, K. F. N. (2004). The impact of race, gender, and culture in South African higher education. Comparative Education Review, 48(4), 396-416.

Mabokela, R. O., \& Mlambo, Y. A. (2017). Access and equity and South African higher education: A review of policies after 20 years of democracy. Comparative Education Review, 61(4), 780-803.

Mama, A. (2003). Restore, reform but do not transform: The gender politics of higher education in Africa. Fournal of Higher Education in Africa, 1(1), 101-125.

Mangcu, X. (2014, July). 10 steps to develop Black professors. City Press. https://www. uct.ac.za/usr/news/2014/10\%20steps\%20to\%20develop\%20black\%20profes sors.pdf

Ministry of Education. (2001). National plan for higher education. Pretoria, South Africa: Ministry of Education.

Mlambo, Y. A. (2011). Women in engineering academia: Reasons for commitment to the field [Master's thesis, University of Pretoria].

Mlambo, Y. A. (2017). Why not academia? The streamlined career choice process of Black African women engineers: A grounded theory study [Unpublished doctoral dissertation]. Michigan State University.

Mlambo, Y. A., \& Mabokela, R. O. (2017). 'It's more flexible': Persistence of women engineers in the academy. European Fournal of Engineering Education, 42(3), 271-285. https://doi.org/10.1080/03043797.2016.1158790

Muller, M. (2018). Decolonising engineering in South Africa-Experience to date and some emerging challenges. South African Fournal of Science, 114(5-6), 1-6. https://doi. org/10.17159/sajs.2018/a0270

National Commission on Higher Education (NCHE) (1996). A framework for transformation. Pretoria. 
Ndimande, B. S. (2013). From Bantu education to the fight for socially just education. Equity E Excellence in Education, 46(1), 20-35. https://doi.org/10.1080/10665684. 2013.750199

Norgaard, K. (2008, February 28). Whites tricked blacks into consuming urine, university says. CNNN. http://edition.cnn.com/2008/WORLD/africa/02/27/saf.racist.video/ index.html

Porter, C. J., Mlambo, Y., Hannibal, J., \& Karunaratne, N. (2018). (Re)defining student success: A qualitative study of Black undergraduate women pursuing veterinary medicine. Fournal of Women and Minorities in Science and Engineering, 24(1), 61-80.

Price, M. (2014). Staff transformation at UCT. University of Cape Town, Daily News. https:// www.news.uct.ac.za/article/-2014-07-14-staff-transformation-at-uct

Reddy, T. (2004). Higher education and social transformation South African case study. Council on Higher Education, Pretoria, South Africa. http://www.che.ac.za/sites/ default/files/publications/HEandSocialTransformationReport_25Feb2004.pdf

Republic of South Africa. (1998). Employment Equity Act No. 55, 1998. Cape Town, South Africa.

Schuurman, M. K., Pangborn, R. N., \& McClintic, R. D. (2005). The influence of workplace experience during college on early post graduation careers of undergraduate engineering students. Women in Engineering ProActive Network.

The Institutional Reconciliation and Transformation Commission. (2019, March). The final report. University of Cape Town. https://www.news.uct.ac.za/downloads/irtc/ IRTC_Final_Report_2019.pdf

Thomas, D. (1996). Education across generations in South Africa. The American Economic Review, 86(2), 330-334.

Wawrzynski, M. R., Heck, A. M., \& Remley, C. T. (2012). Student engagement in South African higher education. Journal of College Student Development, 53(1), 106-123. https://doi/org/10.1353/csd.2012.0007 


\title{
11 Approaches for Attracting, Retaining, and Progressing Women in Australian Undergraduate Engineering
}

\author{
Curricular Innovation Focused on \\ Humanitarian and Human-Centered \\ Design Concepts
}

\author{
Andrea M. Goncher and Shara Cameron
}

Education sectors across the world have invested in programs to widen participation in order to increase student diversity in the STEM degrees and careers (Education Services Australia, 2018; Berge, Silfver, \& Danielsson, 2018). Increasing the participation of women in STEM degrees and professions is a high priority for Australian universities, industry, and government. Despite national efforts, university engineering programs have faced challenges that include student retention and diversity within student and faculty populations (Cross et al., 2017). Reports conducted by the government, industry, and education sectors show recent trends of women's participation declining in the engineering industry and degree completion (Office of the Chief Scientist, 2016; Australian Academy of Sciences, 2019; Engineering for Australia Taskforce, 2020). The Australian Government, various Australian universities, and professional organizations have dedicated programs and initiatives for women in engineering (and STEM), contributing to a slow upward trend of women commencing engineering degrees (Corrigan \& Aikens, 2020).

The purpose of this chapter is to examine government-supported programs, university and industry partnerships, and inclusive engineering design programs to promote gender diversity in Australia. We describe example programs focused on attracting, supporting, and retaining women in engineering, e.g., engineering experiences for students in high school years nine and ten, curricular and co-curricular human-centered design experiences, inclusive engineering program design, and industry mentoring. We also include an example learning activity in human-centered design that educators can use to encourage women's participation in engineering and link the curriculum to engineering practice and potential future career applications. We chose these programs to show how faculty involvement (particularly by women professors) and diverse pedagogies can encourage women students to choose and complete their

DOI: $10.4324 / 9781003053217-2$ 
degrees in engineering. For example, women students are inspired to pursue STEM fields based on the relevance of STEM in their lives as well as exposure to female role models (Education Services Australia, 2018). In this chapter, we highlight important issues in attracting, retaining, and progressing women in engineering, as well as provide information that will help to support engineering educators in secondary, tertiary, and industry education.

\section{Contexts}

\section{Higher Education in Australia}

The Australian higher education system consists of 140 institutions in three major classifications: public $(\mathrm{N}=38)$, private $(\mathrm{N}=10)$, and other approved higher education institutions $(\mathrm{N}=92)$ (Department of Education, Skills, and Employment, 2020). The domestic student load for women and men in public universities was not extremely disparate during the period from 2015 to 2019. Female enrollment is slightly higher than male enrollment overall for university degrees (Higher Education Data Cube, 2020).

Participation in higher education has increased over the last two decades and international student enrollment has increased significantly since 2001 (Graham, 2018). Australia's unique higher education landscape includes its international education sector as one of Australia's top three exports (Department of Education and Training, 2018). While participation has increased, an imbalance in representation still challenges the STEM sector. A gender gap exists in Australian STEM education participation, with especially low participation from students from rural and regional areas and Aboriginal and Torres Strait Islander backgrounds. Australia has embraced the demand for a STEM-skilled workforce, realizing the importance of gender equity and the role of tertiary education in enabling women, including those from disadvantaged backgrounds, to be successful in these careers (Australian Academy of Science, 2019).

\section{STEM Enrollment in Australian Universities}

The Federal Government's Women in STEM Decadal Plan provides motivation for collaboration across the university sector, together with industry and schools, to broaden and deepen the impact on girls and women pursuing engineering studies (Australian Academy of Science, 2019). The creation of this plan recognizes the previous trends on women's participation in STEM and further advances women's participation in STEM fields. The number of women enrolled in university STEM courses increased between 2015 and 2018, however, men were enrolling in STEM programs at an almost proportional rate.

The situation is similar for data regarding STEM university qualification completions. More women and men are completing university STEM qualifications since 2015. The impact of women's underrepresentation in undergraduate 
STEM programs carries forward to women being under-represented in STEM careers and negatively couples with other factors such as workplace culture discrimination and bias and lack of work options and career progression opportunities (Australian Academy of Science, 2019).

Within STEM, women are particularly under-represented in engineering. Women in Australia make up $17 \%$ of university enrollments in engineering (Australian Academy of Science, 2019). Similarly, women only make up 12\% of the engineering workforce (Kaspura, 2019). Women typically earn less than their male counterparts, represented by an $16.7 \%$ pay gap in engineering (Australian Academy of Science, 2019, p. 7). Australia's national gender pay gap was $13.4 \%$ across all industries and has fluctuated between $13.4 \%$ and 18.5\% within the past 20 years (Workplace Gender Equality Agency, 2020).

\section{Professional Associations for Women in Engineering}

Engineers Australia (EA) is the national body for professional engineers with over 100,000 members across engineering disciplines. EA is also the accrediting body for engineering degree programs granting professional status to graduates within Australia and the international Washington Accord agreement (Howard \& Campbell, 2013). As of December 2020, EA listed 53 institutions with accredited engineering programs (EA, December 2020). Programs in various engineering disciplines are accredited at the Professional Engineer, Engineering Technologist, and Engineering Associate levels.

The relationship and interactions across the engineering professional body, accrediting agency, universities, and educators in Australia is rather uncommon in engineering education (Brodie \& Bullen, 2013; Howard \& Campbell, 2013). Engineers Australia, the Australian Council for Engineering Deans (ACED), and the Australasian Association for Engineering Education (AAEE) engage in partnerships and have connections to the university system. Through partnerships and analyses of the Australian engineering and education sectors, these organizations have produced comprehensive reports on these sectors and on the intersection of sectors (ACED, 2016). ACED has produced position statements specifically addressing the role of the mathematics requirements in secondary school for enrollment and participation in engineering education (ACED, 2019), developing engineering graduates engineers equipped to work in complex contexts through incorporating humanitarian engineering principles into the curriculum (2018), and increasing the participation of Indigenous people (ACED, 2017a) and women in engineering (ACED, 2017b). The Australian Council for Engineering Deans' identification of contemporary issues challenging the engineering sector, which includes increasing representation and participation of women in engineering, is important to increasing visibility within and outside of the profession and ultimately improving experiences for women in engineering.

To address the underrepresentation of women in Australian engineering, we review examples of programs and initiatives that support women in engineering based on EA reports as well as peer-reviewed research in the 
engineering education field. The examples presented in this chapter promote the attraction, retention, and progression of women in engineering at the undergraduate level. We structure the examples under three main recommendations: 1) Recruiting and supporting women students, 2) Recruiting and supporting women [academic] staff, and 3) Improving the curriculum (ACED, 2017b).

\section{Programs and Initiatives Focused on Women in Undergraduate Engineering Education}

The ACED position paper (2017b) on increasing women's participation in engineering presents three main recommendations: 1) Recruiting and supporting women students, 2) Recruiting and supporting women [academic] staff, and 3) Improving the Curriculum. In this section we provide examples of programs and initiatives that relate, align, and support the ACED's three recommendations for action. However, the programs and initiatives discussed in this report are not a comprehensive list of existing Women in engineering (WIE) structures, programs, initiatives, or other frameworks to support undergraduate women in engineering. The programs and initiatives presented in the following sections have national engagement either through universities and/or high schools, or have activities, outreach, or initiatives within the program that align approaches for attracting, retaining, and supporting women students and faculty.

\section{Recruiting and Supporting Women Students}

Increasing the participation of women in engineering through university-based and other outreach programs not only helps to provide support and networking systems for women students currently studying engineering, it also helps in the recruitment of prospective students. Australian universities typically have a WIE group that recruits and supports women students through different initiatives, programs, and foci. One example of a WIE university program is Fifty 50 at the Australian National University (ANU) (Fifty50, n.d.). Fifty50 is a student-led organization designed to narrow the gender gap in STEM fields through various programs, including mentoring (and increasing the visibility of such role models), engaging in the wider STEM community (the organization includes women students in science, technology, and mathematics), and advocating for policy change. The organization runs frequent events aimed at supporting equitable pathways through engineering into industry, which are open to students of all genders at ANU. These events offer notable additions to the standard curriculum through 1) short courses on programming languages and other technical content, 2) professional development help such as seminars on interview preparation, managing your online presence and LinkedIn, networking events aimed at creating mentoring-type connections between current students and alumni and professionals across fields, and 3) industry panels and networking events across STEM fields. 
In addition to live events for ANU undergraduate students, the Fifty50 website also hosts articles related to the initiatives that are offered live, as well as an ongoing blog, mentor facilitation, and a podcast to help reach out to the community beyond ANU. There is also a space to inquire about where to start and members are on hand to direct potential members to a constructive starting point for their STEM interests. Fifty50 has multiple coordinated programs, events, and initiatives that engage various stakeholders and align with the recommended program-level approach for shifting barriers for women students in STEM fields (Australian Academy of Science, 2019).

Another organization that brings together undergraduate engineering students, faculty, and industry volunteers is Power of Engineering Inc ( $\mathrm{PoE})$ (Power of Engineering Inc., 2019). The PoE organization is a collaborative effort between the Australian Government, schools, universities, and industry and was co-founded by two woman engineering graduates as a not-for-profit organization. One of their main programs to provide outreach to women students is a fully funded, one-day event for women students in Years 9 and 10 in secondary schools across Australia. This one of PoE's most successful events aims to have students consider careers in engineering, and features practical workshops delivered by women currently working in the engineering profession and engineering student volunteers. Year 9 and 10 students participate in hands-on, small group activities to learn about applications in biomedical, civil, and aerospace engineering fields. In the global pandemic context, PoE continued to engage students and show them the impact engineers have on society through their "engineering-in-a-box" reusable classroom resource. Since the beginning of $\mathrm{PoE}$ in 2012, the organization has reached 9,450 women students (Power of Engineering, 2020).

Engineering-based activities can provide opportunities for students to think systematically, solve important technical problems, and simultaneously provide tangible contributions to our society. Typically, women are interested in, and particularly good at, design thinking, i.e. thinking about problems holistically, handling uncertainty, and developing strategies and design decisions for solving problems (Coleman et al., 2020). Collaborative and supportive women in engineering organizations, programs, and initiatives, such as the examples discussed in this chapter, benefit engineering students as well as the future of the engineering profession.

\section{Recruiting and Supporting Women (Academic) Staff}

Gender inequality in STEM industries prevents organizations from recruiting and retaining women in the STEM sector. Lack of women in STEM positions, especially in senior or leadership roles, can be detrimental to the success of any organization (National Academies of Sciences, Engineering, and Medicine, 2020; Funk \& Parker, 2018). A diverse workforce leads to more diverse and creative perspectives and provides potential role models for women students in engineering schools (ACED, 2017b; NSF, 2005). Many Australian 
universities have prioritized these issues and are participating in national programs to improve the careers of women in science-based areas. Science in Australia Gender Equity (SAGE) program, which is based on the U.K.'s Athena SWAN (Scientific Women's Academic Network) model, is one nation-wide program and it is provided with millions of dollars in support from the Australian Government. Outcomes of the SAGE program in Australian universities include improved arrangements for caregiver or parental leave, expanded on-campus childcare, and women-only recruitment processes.

The engineering education (and STEM) community in Australia continues to provide other support networks for women academic staff and hosts WIE events at conferences, symposiums, workshops, and mentoring programs for junior faculty. The WIE panel at the IEEE Teaching, Assessment and Learning for Engineering (TALE) conference brought together panelists to discuss contemporary issues for women in engineering and provide a range of actionable advice on how they can implement strategies at their own institutions (Chakraborty et al., 2018). One example, the Women in STEM Symposium (2019), was designed to facilitate collaboration and minimize duplication of effort across universities, industries, and schools. The Women in STEM Workshop for Educators (WISTEMxQ workshop, 2020) targeted educators in STEM with students in years 5-8. The WISTEMxQ workshop was in conjunction with the Australian Government programs that highlight women's STEM careers and aim to increase girls' participation in engineering. The National Committee for Women in Engineering special interest group of the professional body, EA, works to attract and retain women in engineering careers and to support women across their engineering careers (Engineers Australia, 2021). The availability and use of these support networks throughout women's academic and professional careers is a consistent approach that should help women at various stages of their careers. Panels, workshops, events, or dedicated sessions that facilitate connections with other women academic staff (and faculty and staff that are involved in the recruitment and support of women academic staff) provide opportunities to help increase persistence of women in engineering.

\section{Improving the Curriculum}

Misconceptions around the engineering profession, including what an engineer actually does, can impact the number of women undertaking engineering studies. Women pursuing engineering degrees tend to persist in a curriculum that emphasizes the social contexts of engineering practice and is delivered by a gender-balanced academic staff team. Emphasizing human-centered design and sustainable development reflects contemporary needs for all engineering graduates and can attract more women (ACED, 2017b).

Programs can adopt innovative curricula to train Australian students about issues in the societal context of engineering. For example, engineering programs should address engineering's impact on the environment and emphasize the positive influence of humanitarian engineering (ACED, 2019). Humanitarian 
engineering-focused programs attract a significantly higher percentage of female engagement in this area compared to other engineering programs (Smith et al., 2017; Lynch \& Smith, 2020). Twenty-eight universities and over 10,000 students in Australia and New Zealand participate in a humanitarian engineeringfocused design challenge for first-year students (EWB, 2020). Humanitarian Engineering degrees, courses, and experiential opportunities are currently offered at 11 universities (Lynch \& Smith, 2020). The Australian Federal Government provides financial support for mobility programs that offer opportunities for overseas study experiences in humanitarian engineering (Department of Foreign Affairs and Trading (n.d.); Smith et al., 2017). Examples of humanitarian engineering education initiatives to improve curriculum, from a standpoint of increasing women's participation in engineering, are discussed in the following sections.

\section{Engineers without Borders Australia (EWB-A)}

In this section, we will introduce Engineering Without Borders Australia (EWBA) education programs which facilitate engagement between Australian (and New Zealand) undergraduate engineering students and domestic or international community partners. EWB-A offers school outreach programs, such as the EWB University Challenge Program, Humanitarian Design Summit, Bespoke Study Tour, the Influencer Fellowship, and other research projects. The Humanitarian Design Summit is an immersive (two-week, study abroad) learning experience for students from engineering and non-engineering majors to engage in community development and apply humanitarian engineering skills and insights in countries such as Cambodia, Nepal, and Timor-Leste. The Bespoke Study Tour is similar to the Summit and allows academics to work with EWB to incorporate programs that align with their curriculum. The Influencer Fellowship is designed for finalyear students who want to help reform practice and culture in the engineering sector and support sustainable development. Influencer Fellowship recipients receive professional mentoring and training from humanitarian and development practitioners. The EWB research program brings together community organizations, universities, and research centers to identify and conduct research that benefits communities through innovative engineering and development solutions. Students' research projects with EWB are part of their formal studies and can be their final-year thesis, research, or capstone project (EWB, 2020).

Universities' collaboration with EWB-Australia promotes students' understanding and ability to create positive change within developing communitieswithin and outside of Australia - through humanitarian engineering frameworks and socio-technical solutions. Women and men are motivated to participate in humanitarian engineering initiatives (Stoakley et al., 2017) when their values align with those initiatives. In the subsection that follows, we detail the EWB University Challenge and how it provides opportunities within the curriculum to support activities that align with women in engineering value sets and reflect the social contexts of engineering application. 


\section{The EWB University Challenge}

The EWB University Challenge incorporates learning humanitarian engineering with project-based activities as part of Australian and New Zealand first-year engineering curricula (EWB, 2020). The goal of the program is to involve students in learning the practices, behaviors, ethics, and cultures of professional humanitarian engineers and to develop a professional identity as humanitarian engineers. Curricular and co-curricular activities that draw upon the EWB annual challenge provide teams of student engineers the opportunity to solve real-world problems with human dimensions. The EWB University Challenge activities are designed to comprehensively support students' professional development, as engineers, based on integrating technical, teamwork, and communication skills.

The EWB University Challenge focuses on human-centered design (HCD) and requires students to understand wider cultural implications of their engineering solutions when designing for Indigenous communities in developing countries or in a domestic context. The HCD process is a practice-based approach that prepares students for life and work, either in engineering or in other areas, such as teaching them about sustainability and how to understand user needs. The PBE approach provides learning experiences and activities that prepare students for professional roles as engineers and fosters identity development. Documenting and reflecting on the HCD process is critical to developing the skills required to be a professional engineer and to applying the real-world practices of humanitarian engineering.

The types of curricular activities included as part of the EWB University Challenge are intended to prepare women (and men) engineering graduates to undertake sustainability challenges and other global issues (Brown et al., 2016). EWB-Australia develops the annual challenge with different community partners each year, such as the United Nations High Commissioner for Refugees (UNHCR) Zambia and Live and Learn Vanuatu, to provide a design brief for engineering students to employ HCD and a strengths-based approach to community improvement. Implementation of the EWB University Challenge varies across the 28 universities that undertake the challenge annually. Various learning activities centered around the challenge encompass key pedagogical purposes that include 1) Learning in communities of practice, 2) Developing critical and decision-making capabilities, and 3) Self-directed and transformative learning for practice (EWB, 2020).

Students undertaking the challenge typically utilize an engineering design approach and follow the HCD process. One method to facilitate students in developing an engineering design approach is to have them create an e-portfolio containing documentation as part of their self-directed and transformative learning for practice as humanitarian engineers. Design artifacts within the e-portfolio can include the project scope, ideation methods (brainstorming ideas, sketches, etc.), design notebook entries, team member evaluations, peer reviews, prototypes, failure reports, and final design documentation 
(Goncher \& Devitt, 2017). The EWB University challenge culminates with a design showcase where each university is represented by the universityselected team with their final design solution for the partnering community. The showcase is a forum for student teams to interact with teams from other universities, EWB-A professionals, engineers from industry, and selected community partner representatives.

\section{A Practical Leaming Activity for Engineering Educators Developing and Delivering Socio-Technical Course Content}

In this subsection, we describe an activity that can be implemented in most engineering design and/or community engagement projects to provide women in engineering programs with curriculum opportunities that show how engineering can be put into practice. Stoakley, Brown, and Matthee (2017) found that women and men whose value sets align with humanitarian engineering are motivated to participate in humanitarian projects. The proposed activity is based on the empathize phase of the HCD process. The design phase, "empathize," focuses on listening to the user to uncover wants, needs, pain points, and desired gains. In this activity, individual students or teams consult with a professional (who can be from other professions outside of engineering, e.g. a nurse, legal professional, or barber) to learn about their occupation, their life, strengths, and opportunities. This is an opportunity for teams to familiarize themselves with professions, practice communication skills, and gain a better understanding of the early phases of the HCD process.

- Learning Activity: Developing HCD Solutions through Engineering Community Engagement.

- Goal: Apply HCD skills and knowledge to solicit and interpret information from community members. The learning outcomes for this activity include 1) Application of skills in a practice-based context (students will apply their skills and knowledge to navigate a given context), 2) Use of human-centered design principles (students will be able to utilize HCD techniques to solicit and interpret information from community members and potential end-users of their engineering design solutions), and 3) Address important issues, approaches, or considerations in human-centered design (students will be able to identify and discuss the impact of applying human-centered design principles in a given context).

\section{- Activities and Desired Outcomes}

The first step is to consult with a community member in a specific occupation/job/career to learn more about their work, their life, and strengths to elicit opportunities for potential design solutions. Participants are encouraged to take photos and notes about what they observed, heard, and/or tried while spending time with the professional/community member. The second step is to create an empathy map of the community member's needs and assets. Students will use 
information collected through their consultation in Step 1 to identify and synthesize the community member's needs.

The final step is to provide and develop engineering design solutions for the identified need(s) and resulting design opportunity identified by engaging with the community member(s). The planned evaluation strategy (see Table 11.1) for this learning activity includes suggested reflective components that require students to think about the HCD process and the application of skills related to HCD in a real context. The instructor can use Table 11.1 to help guide students in creating artifacts that document their process and facilitate their reflection on the application of skills in a practice-based context, use of human-centered design principles, and addressing important issues, approaches, and considerations in human-centered design.

The "Developing HCD Solutions through Engineering Community Engagement" activity can be implemented as part of the EWB University Challenge or any design project where students interact with a community or specific user group. The combination of interaction with community members and the reflection on the activity/experiences will help students understand how the application of HCD-related skills can benefit their studies and their long-term professional experiences that require community engagement. The reflective component, and the learning activity itself, can contribute to an improved curriculum that relates to female engineering student values sets (Stoakley, Brown, Matthee, 2017).

Table 11.1 Engineering Community Engagement Evaluation Matrix

\begin{tabular}{|c|c|c|}
\hline Learning Outcomes & Artifacts & Reflections \\
\hline $\begin{array}{l}\text { Application of skills } \\
\text { in a practice-based } \\
\text { context }\end{array}$ & $\begin{array}{l}\text { - Proposed engineering solu- } \\
\text { tion and technical require- } \\
\text { ments for the professional to } \\
\text { use in practice } \\
\text { - Photos and videos of the } \\
\text { experience } \\
\text { - Drawings/visualizations of the } \\
\text { process }\end{array}$ & $\begin{array}{l}\text { What did you observe? } \\
\text { What did you ask? } \\
\text { What can the professional } \\
\text { (person(s) of focus in the } \\
\text { challenge) try to do } \\
\text { differently? }\end{array}$ \\
\hline $\begin{array}{l}\text { Use of human-cen- } \\
\text { tered design } \\
\text { principles }\end{array}$ & 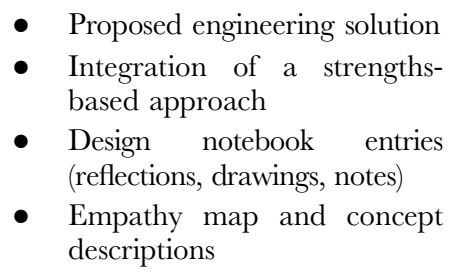 & $\begin{array}{l}\text { What different methods } \\
\text { did you use? } \\
\text { What worked well, why? } \\
\text { What didn't work well, } \\
\text { why? } \\
\text { What was challenging or } \\
\text { interesting? }\end{array}$ \\
\hline $\begin{array}{l}\text { Address important } \\
\text { issues, approaches, } \\
\text { and considerations } \\
\text { in human-centered } \\
\text { design }\end{array}$ & $\begin{array}{l}\text { - Journal-style reflections on the } \\
\text { activity and process of imple- } \\
\text { menting human-centered } \\
\text { design principles }\end{array}$ & $\begin{array}{l}\text { What would you do better } \\
\text { next time? } \\
\text { What improvements } \\
\text { would you make based on } \\
\text { what you learned? }\end{array}$ \\
\hline
\end{tabular}




\section{Conclusion}

In this chapter, we described and contextualized Australian undergraduate engineering education as it relates to increasing participation of women in engineering studies and future careers. We presented example programs and initiatives that address the needs and recommendations for action identified in contemporary reports by academia, industry/ professional organizations, and Australian Government departments. We illustrated successful university-level WIE programs that integrate undergraduate engineering students' activities with programs aimed at recruiting primary and secondary school students, provide or facilitate mentoring opportunities within the university, and connect undergraduate women engineers with industry networks and opportunities. We also highlighted examples of humanitarian engineering curricular and co-curricular experiences that promote gender diversity in engineering education.

We conclude that collaboration between stakeholders and across programs with a cohesive message will aid in getting women into engineering studies and keeping women in the profession. Barriers to participation in engineering occur at all points along women's academic and professional career pathways. No individual program or initiative, which exists to support the attraction, retention, and progression of women, can completely remove the barriers faced by women in engineering. Rather, programs and initiatives reinforced by academia, industry, and government have a significant opportunity to facilitate women along their engineering education and work pathways and have a positive impact on women's participation in engineering education and beyond.

\section{References}

Australian Academy of Science. (2019). Women in STEM decadal plan. Australian Academy of Science.

Australian Council of Engineering Deans. (2016). Position statement promoting engagement between industry and universities for improving engineering graduate capabilities and accelerating innovation. http://www.aced.edu.au/downloads/posi tion_statement_no_1.pdf

Australian Council of Engineering Deans. (2017a). Position statement embedding Aboriginal and Torres Strait Islander perspectives into the engineering curriculum. https://www.engineersaustralia.org.au/sites/default/files/resource-files/2017-09/POS ITION $\%$ 20STATEMENT $\% 20 \mathrm{No} \% 204 \% 20$ Indigenous $\% 20$ engineering $\% 20 \mathrm{DJH} \% 2$ 0v\%202\%20RWK\%20rev\%20logo\%20(002)\%20(00000002).pdf

Australian Council of Engineering Deans. (2017b). Position statement increasing the participation of women in engineering education. https://www.aced.edu.au/down loads/POSITION_STATEMENT_No_2_PromotingWomen.pdf

Australian Council of Engineering Deans. (2019). Position statement mathematics requirements for engineering education. http://www.aced.edu.au/downloads/ POSITION\%20STATEMENT\%20No\% 205\%20Mathematics\%20Requirements\% 20for\%20Engineering\%20Degrees.pdf 
Australian Council of Engineering Deans (ACED). (2018,April). Humanitarian engineering education providing an opportunity for a new generation of engineers [Position Statement]. Australian Council of Engineering Deans.

Berge, M., Silfver, E., \& Danielsson, A. (2018). In search of the new engineer: Gender, age, and social class in information about engineering education. European fournal of Engineering Education, 44, 1-16. https://doi.org/10.1080/03043797.2018.1523133

Brodie, L., \& Bullen, F. (2013, June), AAEE plenary - Engineering education: A national integrated approach. Paper presented at 2013 ASEE International Forum, Atlanta, Georgia. https:// doi.org/10.18260/1-2-17212

Brown, N. J., Price, J., Turner, J. P., \& Colley, A. (2016). 27th annual conference of the Australasian Association for Engineering Education, AAEE Lismore, NSW, Southern Cross University, 96-104.

Chakraborty, S., Ros, M., Cheng, E., Goncher, A., \& Vial, A. (2018). Panel sessionWomen in engineering networking panel. 2018 IEEE International Conference on Teaching, Assessment, and Learning for Engineering (TALE). https://doi.org/10. 1109/tale.2018.8615387.

Coleman, E., Shealy, T., Grohs, J., Godwin, A. (2020). Design thinking among firstyear and senior engineering students: A cross-sectional, national study measuring perceived ability. Fournal of Engineering Education, 109, 72-87.

Corrigan, D., \& Aikens, K. (2020). Barriers to participation in engineering and the value of interventions to improve diversity. https://cog-live.s3-ap-southeast-2.amazonaws.com/n/ 1271/2020/Jan/20/oZ3DuHs2Cklt1085UsDe.pdf

Cross, K., Miletic, M., Forin, T., Mina, M., Jain, A., Villa, E., Ingram, E. L. (2017). Panel: Influencing culture and curriculum via revolution. 2017 IEEE Frontiers in Education Conference (FIE). https://doi.org/10.1109/fie.2017.8190627.

van Driel, J. H., Vossen, T. E., Henze, I., \& and de Vries, M. J. (2018). Delivering stem education through school-industry partnerships: A focus on research and design. In STEM education: An emerging field of inquiry (pp. 31-44). https://doi.org/10. 1163/9789004391413_003.

Department of Education and Training. (2018). https://www.education.gov.au/.

Department of Education, Skills and Employment. (2020). uCube - Higher education data cube. http://highereducationstatistics.education.gov.au

Department of Foreign Affairs and Trade. (n.d.) The New Colombo plan mobility program. https://www.dfat.gov.au/people-to-people/new-colombo-plan/mobility-p rogram/Pages/mobility-Program.

Department of Industry, Science, Energy, and Resources. (n.d.) Advancing women in STEM strategy. Australian Government. https://www.industry.gov.au/data-and-p ublications/advancing-women-in-stem-strategy/snapshot-of-disparity-in-stem/womenin-stem-at-a-glance.

Education Services Australia. (2018). https://www.esa.edu.au/about/about-us.

Engineers Australia. (2020, December). Engineers Australia Accredited Programs.

Engineers Without Borders. (2020). https://www.ewb.org.au/

Fifty50. (n.d.) About. https://fifty50.org.au.

Funk, C. \& Parker, K. (2018, January 9). Women and men in STEM often at odds over workplace equity. Pew Research Center. https://www.pewresearch.org/social-trends/ 2018/01/09/women-and-men-in-stem-often-at-odds-over-workplace-equity/

Goncher, A.M., \& Devitt, J. (2017). Development of global competencies through humanitarian engineering experiences. https://researchoutput.csu.edu.au/en/p ublications/development-of-global-competencies-through-humanitarian-engineering 
Graham, R. H. 2018. The global state of the art in engineering education [Report]. https:// jwel.mit.edu/assets/document/global-state-art-engineering-education

Howard, P., \& Campbell, D. (2013). Invited Paper-Curriculum Development to meet Accreditation Requirements. 2013 ASEE International Forum Proceedings. https://doi. org/10.18260/1-2-17242.

Kaspura, A. (2019). The engineering profession: A statistical overview (13th ed.). Engineers Australia.

Lynch, E., \& Smith, J. I. (2020, June). Emergence and evolution of humanitarian engineering education in Australia. Paper presented at 2020 ASEE virtual annual conference. Virtual Online. https://doi.org/0.18260/1-2-34521

National Academies of Sciences, Engineering, and Medicine. (2020). Promising practices for addressing the underrepresentation of women in science, engineering, and medicine: Opening doors. The National Academies Press. https://doi.org/10.17226/25585.

National Committee for Women in Engineering (NCWIE). (n.d.) https://www.engineersa ustralia.org.au/Communities-And-Groups/Special-Interest-Groups/Women-In-Engin eering

National Science Foundation (NSF). (2005). The engineering workforce: Current state, issues, and recommendations.

Office of the Chief Scientist. (2016). Australia's STEM workforce: Science, technology, engineering and mathematics. http://www.chiefscientist.gov.au/wp-content/uploa ds/Australias-STEM-Workforce_April-2016_web.pdf.

Power of Engineering Inc. (2019). Inspiring the next generation about engineering. http://www.powerofengineering.org/

Power of Engineering Inc. (2020). 2020 Annual report. http://www.powerofengineering. org/.

Smith, J., Anderson, B., Brown, N., Colley, A. Stoakley, A. \& Turner, J. (2017). The rise of humanitarian engineering education in Australasia. in 28th Annual Conference of the Australasian Association for Engineering Education (AAEE), https://aaee.net.au/wp-con tent/uploads/2018/09/AAEE2017-Smith_Brown_Stoakley_et_al-Humanitarian_engi neering_education_in_australasia.pdf, p. 312.

Stoakley, A., Brown, N., \& Matthee, S. (2017). The role of a humanitarian focus in increasing gender diversity in engineering education ... In N. Huda, D. Inglis, N. Tse, \& G. Town (Eds.), 28th annual conference of the Australasian Association for Engineering Education (AAEE 2017) (pp. 438-446). Australasian Association for Engineering Education.

WISTEMxQ: Women in STEM Ambassador and Questacon Partnership. (2020). https:// womeninstem.org.au/wistemxq/

Women in Engineering and IT Symposium and Network (2019, October). https:// www.uts.edu.au/about/faculty-engineering-and-information-technology/women-en gineering-and-it/our-community-and-events/women-engineering-and-it-symposium -and-network-2019

Workplace Gender Equality Agency (WGEA, the Agency). (2021, February). https://www. wgea.gov.au/sites/default/files/documents/Gender_pay_gap_fact_sheet_Feb2020.pdf 


\title{
12 Aspiring and Becoming STEM Teachers in Hong Kong
}

\author{
A Gender Perspective
}

\author{
Hei-hang Hayes Tang, Derek Wai Sun Chun, Iris Chi \\ Yan Leung and Thomas Siu Ho Yau
}

Global low participation of women in Science, Technology, Engineering and Mathematics (STEM) education, as well as STEM-related jobs and professions, has drawn the attention of schools, educators, and policy makers. Reducing gender inequality in STEM may bring better equality and equity for world development (European Institute for Gender Equality, 2017). In Hong Kong, STEM education has become particularly timely since 2016 when the government launched policy initiatives which substantially impacted STEM education practices. Professional teachers have become crucial agents for inspiring students to build their aspirations for STEM-related occupations and professions (Margot \& Kettler, 2019). Therefore, in this chapter we consider how pre-service STEM teachers develop aspirations and capacity in women students to create a more gender equitable future in STEM disciplines and professions.

Sen's (1999) notion of the capability approach will be used as a conceptual framework for analyzing the collected data (Boni \& Walker, 2016). Although the capability approach has been utilized widely in elaborating on different gender and education issues, this study could be seen as a beneficial attempt to illustrate STEM gender-equity phenomenon. It also offers an insightful gender perspective on how STEM teachers-to-be perceived their teaching aspirations and constructed STEM teacher identities in Hong Kong. By using the methods of educational ethnography and qualitative interviewing, this chapter reports findings based on life stories (as cross-case studies) of eight pre-service women teachers majoring in STEM-related programs at the largest teacher training university in Hong Kong. We conduct iterative dialogues between the casestudy students and the researchers through autobiographical writings, feedback, and interviews. Educational autobiography involves critical reflection on one's learning experiences, actions, and aspirations (Franzosa, 1992; Powell, Zehm \& Garcia, 1996; Charissi, 2020). It is an ongoing reflective journey, which emphasizes critical inquiry and questioning about one's own behaviors, beliefs, and values. Empirical findings and analysis from this study will add contextual knowledge to the broader literature of science education, teacher identity, and teacher development, especially by understanding teacher identity as a process (Avraamidou, 2014). This chapter will also inform policy recommendations

DOI: $10.4324 / 9781003053217-3$ 
about teacher education, career and life planning education, and the role of STEM teachers in pursuing gender justice (Molyneux \& Razavi, 2002) in different education systems across the world.

\section{STEM, Education, and Gender in Hong Kong}

STEM has gained increasing attention from countries over the past decade (Sanders, 2009). In Hong Kong, in response to the ever changing economic, scientific, and technological development, STEM education was first proposed by the Hong Kong Special Administrative Region's former Chief Executive, Leung Chun-ying, in the 2015 Policy Address and furthered in the 2016 Policy Address. STEM education acts as a key emphasis in the ongoing renewal of the school curriculum that is essential for students' life-long learning and whole-person development. With the implementation of STEM education in schools, apart from cultivating students' interest and developing a solid knowledge base in science, technology, and mathematics, Hong Kong also aims

to strengthen students' ability to integrate and apply knowledge and skills across different STEM disciplines, and to nurture their creativity, collaboration and problem solving skills, as well as to foster their innovation and entrepreneurial spirit as required in the 21st century. (Education Bureau, 2016, p. 1)

Given the strategy proposed in the 2015 and 2016 policy addresses, the Hong Kong government adopted a holistic and integrated approach to implement STEM education, including 1) renewing the curricula of the science, technology, and mathematics education as key learning areas; 2) enriching learning activities for students; 3) providing learning and teaching resources; 4) enhancing the professional development of schools and teachers; 5) strengthening partnerships with community key stakeholders; and 6) conducting reviews and disseminating good practices (Education Bureau, 2016, p. 2). In view of this latest development in STEM education, professionalism of STEM education is the priority, as based on the proposed policy agenda, which creates training programs and in-service programs to expand beneficiaries to a larger group of stakeholders.

Generally, Hong Kong maintains an excellent performance record on different international assessments. TIMSS (Trends in International Mathematics and Science Study) and PISA (Programme for International Assessment) have indicated that the education systems for science and mathematics in East Asian countries, like Hong Kong, are among the top ten in the world (Mullis et al., 2016). Hong Kong is promoting STEM education as a crucial step towards fostering an innovative mindset among students (Education Bureau, 2016). With strong primary and secondary school preparation, as evidenced by TIMSS and PISA, there has been a steady increase in the number of 
students enrolling in STEM programs at the university level over the last decade. There were 26,525 students studying STEM-related subjects ${ }^{1}$ at local universities funded by the University Grant Committee in 2006/2007, 27,323 in $2011 / 2012,35,925$ in 2016/2017, and 36,971 in 2018/2019, respectively (Census and Statistics Department, 2019a). However, gender imbalance has been prominent. Among undergraduate programs in the sciences, there were approximately $36 \%$ women and $63 \%$ men in $2006 / 2007$. In $2018 / 2019$, the gender imbalance persisted with women making up approximately $39 \%$ of the student population of STEM-related majors. For engineering and technology disciplines, $31 \%$ were women in 2006/2007 and the figure dropped to $29 \%$ in 2018/2019 (Census and Statistics Department, 2019b). However, there were more women university students than their men counterparts in the majors of Dentistry (64.3\%) and Medicine (51.4\%) (Women's Commission, 2019).

In Hong Kong, the demand for talent with STEM-related skills has been rising in response to global changes. In 2008, 103,107 people $(2.94 \%$ of the total workforce) worked in information and communication technology. This figure had increased to 129,641 in 2017 , which equaled $3.39 \%$ of the total workforce (Census and Statistics Department, 2019a; 2019b). Gender difference remains a serious issue in the STEM workforce. In the information and communications industry, men outnumber women constantly. Estimates suggest that there were 74,000 men and 35,400 women working in the information and communications industry in 2008, and 92,700 men and 41,800 women in the industry in 2018 (Census and Statistics Department, 2019b).

Like other post-industrial countries, including the United States, Hong Kong has experienced gender imbalance in STEM-related work (Beede et al., 2011). The gender imbalance of STEM-related study and work in Hong Kong is driven by different factors. Yeung and Liao's study (2016) concluded that junior secondary students studying STEM-related subjects were affected by their childhood experience and exposure to STEM, their self-perceived ability, selfinterest, and aspirations. These experiences were shaped by social structural factors stemming mainly from school. Gender stereotypical beliefs on the part of students and teachers significantly affect girls' intention to study STEM subjects. According to another, larger mixed method study (Chan \& Cheung, 2018), which surveyed 2,807 International Standard Classification of Education (ISCED) level 3 students in Hong Kong, there are gender differences in taking STEM-related electives in The Hong Kong Diploma of Secondary Education (HKDSE). Compared with men, women students are 28\% less likely to take at least one STEM elective and $41 \%$ less likely to take extended/advanced mathematics modules in the HKDSE curriculum. The gender differences in taking physics and information and communication technology (ICT) electives are even larger. Women are approximately $52 \%$ and $72 \%$ less likely than men students to take these subjects, respectively. Even when women have taken STEM-related electives in HKDSE, they are less likely to consider STEM majors in higher education and when pursuing STEM-related careers. Despite some women students investing more resources and time in STEM electives 
than men, they still hold more negative perceptions of, and are less interested in, STEM learning domains (Chan \& Cheung, 2018).

Students' subject perception (self-efficacy, interests, and perceived value), preference on job characteristics, and stereotypical beliefs in STEM are important in explaining women's choice and dropout rate at different stages of learning. Low self-efficacy in STEM subjects undermines their persistence in STEM studies or careers (Simon, Aulls, Dedic, Hubbard \& Hall, 2015). Compared with men students, women in Hong Kong report a more positive perception of the language/humanities domain (Chan \& Cheung, 2018). In addition, women students typically hold stronger gender stereotypical beliefs about STEM, such as the perception that boys are better than girls in learning science or the idea that girls are more suitable to studying language and humanities.

Cultural norms and concern surrounding university entrance also exerts an influence on students' subject choices. In fact, most secondary schools in Hong Kong with good academic performance numbers prefer science to arts streams and place a higher regard on STEM subjects. Prestigious majors in Hong Kong's universities, such as medicine, dentistry, and global business administration, welcome talented graduates from the science stream. Those high achieving students, including women students, would consequently choose science subjects due to status concerns and for strategic reasons. Moreover, the newly established Hong Kong Academy of Sciences, which aims at boosting the science, technology, and innovation systems in the region and raising the profile of Hong Kong as a center of scientific excellence, recommends greater emphasis on advanced mathematics and extols the future career prospects of studying STEM (The Hong Kong Academy of Sciences, 2017).

As a result of prioritizing or favoring STEM education, there is clear stratification between elite students who tend to study the science stream and their non-elite peers in the arts stream. In 2019, more than half of the HKDSE Examination candidates did not take any STEM elective subjects ${ }^{2}$ whereas the enrolment in advanced mathematics declined remarkably from over $22 \%$ in 2011-2012 to approximately 14\% in 2018-2019 (Legislative Council Secretariat, 2020). Moreover, the narrow job prospects for STEM graduates because of the underdeveloped innovation system of Hong Kong (Sharif \& Tang, 2014; Lo \& Tang, 2020; Tang, 2020; Tang \& Chau, 2020) hinders the majority of non-elite students in their aspiration for higher education and careers in STEM-related fields.

In the next section, we will discuss the socio-cultural construction of STEM teacher identity. We will especially consider how teachers can challenge stereotypes and help students question assumptions that lead them away from aspirations for the STEM fields. Teachers are seen as important agents for shifting gender stereotyping in STEM and related future careers among students and for pursuing gender justice during the schooling processes. 


\section{Construction of STEM Teacher Identity}

The conceptual construct of teacher identity is useful for examining teacher learning and development of pre-service STEM teacher identity, particularly in understanding teacher identity as a process (Avraamidou, 2014). According to Trent (2010), teacher identity is an iterative process of construction encompassing the dynamics of creation and recreation. This echoes the view by Britzman (2003) that learning to teach is "the process of becoming: a time of formation and transformation, of scrutiny into what one is doing, and who one can become" (p. 31). She claims that becoming a teacher is a struggle for voice. The interplay and negotiation of three dimensions of voice, namely, biography, emotions, and institutional structure, which contribute to teacher identity formation. Biography is the experiences of a person's life and of their journey of schooling. Emotions are about the personal, intimate, and internal aspects of teacher identity and how inconsistencies, uncertainties, and something kept silent contribute to becoming a teacher. Institutional structures represent forces that legitimize and exert influence over subjectivities and practices within teaching (Britzman, 2003; Huang, et al., 2019).

Wenger (1998) considers identity as the process of engagement, imagination, and alignment. Teachers can learn through engaging in different communities of practice, referring to "groups of people who share a concern, a set of problems, or a passion about a topic, and who deepen their knowledge and expertise in this area by interacting on an ongoing basis" (Wenger et al., 2002, p. 4). Teacher identity is formed by different components including subject knowledge, shared values, self-efficacy, a sense of membership, beliefs, and so on (Collopy, 2003; Drake, et al., 2001; Wenger, 1998). Those shared attributes enable the differentiation of one teacher group from another (Sachs, 2001).

In the existing literature, most previous research focused on the identity of science teachers, while less is known about STEM teachers. Only in recent years has there been an emerging field of research investigating the topic of STEM teacher identity. For example, Horvath, et al. (2018) found that teacher identity and the satisfaction of student teaching experiences predict pre-service STEM teachers planned and actual entry into the teaching profession. Teacher identity also mediates the relationship between perceived satisfaction and outcomes of student teaching. Additionally, El Nagdi, et al. (2018) interviewed eight STEM teachers to better understand the unique nature of STEM teacher identity and found that almost all teachers interviewed saw their identity as a developing/ emerging identity. Social and personal factors continuously impact teachers' views of themselves and their roles. Nevertheless, collaboration, flexibility, awareness of students' needs, and advocating equity and inclusion were identified as pivotal characteristics of STEM teachers.

While embracing the broader perspective that STEM is more comprehensive than individual science subjects, the STEM teachers in the study still cling to their individual identities as teachers of stand-alone subjects. El Nagdi and Roehrig (2020)'s follow-up study demonstrated professional growth of STEM 
teachers that had a progressive mindset and student-centered classroom practices. Sampled teachers were able to consider themselves as moving towards to an established STEM teacher identity, which was initially seen as a dialogical, dynamic, and evolving process that results from the interaction of personal and professional traits within new educational experiences. Another study tried to design an initial framework for STEM teacher identity in terms of four attributes that teachers develop across places and time: behaviors, practices, beliefs, and pedagogical knowledge (Adams, 2020). The framework outcomes were: motivation and engagement with STEM; achievement in STEM and pursuit of STEM interests and careers (Adams, 2020).

To summarize, it is understood that STEM teacher identity is an important concept for making sense of the changes and continuities of issues related to teacher education, gender, and STEM. Compared with the well-researched area of science teacher identity, identity of STEM teachers is more complex and multifaceted and it is emerging as a research field alongside the development of STEM and changing gender relations.

\section{Capability Approach in Education}

This study adopts the capability approach (Sen, 1999; Boni \& Walker, 2016) as the conceptual framework. The capability approach is a normative and theoretical framework for addressing human inequalities and enhancing individuals' well-being, human development, and justice. It claims that it is a moral obligation of a society to guarantee people's freedom to achieve wellbeing. Also, human capabilities are essential for individuals to pursue and attain well-being. Alongside "capabilities," the concept of "functionings" is central to the capabilities approach (Boni \& Walker, 2016). A functioning refers to "the various things a person may value doing or being" (Sen, 1999, p. 75). Capabilities, on the other hand, refer to the freedoms (opportunities, potentials) a person has in order to make reasoned and reflective choices about using the resources they have (material, educational opportunities, public policy, etc.) in realizing their valued functionings. Evaluation of a person's well-being focuses on this interplay between capabilities and functionings. Factors affecting the process by which capabilities are converted into functionings are referred to as "conversion factors" (Robeyns, 2003). There are three categories of "conversion factors," namely, personal conversion factors, social conversion factors, and environmental conversion factors (Robeyns, 2017). Resources, such as the availability of various sorts of materials or any other personal, social, or environmental goods and influences, impact capability formation and conversion factors (Walker \& Loots, 2018). Regarding the focus of this chapter, the social conversion factor of education (such as a teacher preparation program for pre-service STEM teachers) is emphasized as the central point of analysis. This is because teacher education for STEM teaching and learning transforms the resources (e.g. new knowledge of STEM, state of the art technological development, and pedagogical knowledge and 
skills of teaching STEM subjects) and capabilities of women student teachers into their functionings. They then value the role of women STEM teachers and aspire to become a STEM teacher in the future and start to develop their teacher identity.

We use the capabilities approach as the conceptual framework in this chapter to inform the research questions, guide data collection and coding, interpret the qualitative data and develop implications for policy and practice. The approach is useful in evaluating policies and practices, especially those in education, and for developing agency, fostering aspirations, and achieving well-being of women teachers and students (DeJaeghere, 2018). Based on the conceptualization of capabilities, the framework is applied to examine the teacher identity formation process of Hong Kong's women pre-service teachers by addressing three research questions: (1) What are the factors that shaped the aspiration of women students in Hong Kong for studying an education degree in STEM-related education? (2) What are their lived experiences of studying the degree as a process of constructing their teacher identity and becoming a STEM teacher? (3) Does gender make a difference in the process of aspiring to become and becoming a STEM teacher? Why and how?

The capability approach has enormous potential for addressing feminist concerns and questions related to health, voting power, political power, domestic violence, education and women's social status (Kameshwara \& Shukla, 2017). Robeyns (2003) considered capabilities as real opportunities and selected a list of relevant capabilities. A gender inequality assessment was designed following a four-step process: unconstrained brainstorming, testing a drafted list of capabilities against available literature, engaging with other lists of capabilities, and debating the list with other people. Education and knowledge were among the list of capabilities Robeyns (2003) highlighted education and knowledge she thought imperative, suggesting that capability analysis of educational equality should investigate the hurdles faced by girls in educational achievements, such as sexist behavior, sexual harassment, gender differences in expectations, and encouragement against a men-dominated class atmosphere. These dimensions and concerns of the capabilities framework will guide the data coding and analysis which will be reported after the methodology section.

\section{Methodology}

This study uses educational autobiography (Franzosa, 1992; Powell, et al., 1996; Medina, 2016) and qualitative interviewing as research methods to guide the processes of data collection. Educational autobiography highlights an ongoing process which emphasizes critical inquiry and questioning about one's perceptions, beliefs, values, and behaviors. Through critical self-examination of an individual's beliefs, values, and practices, students undergo a transformation of their understanding about the particular issues of gender, STEM, capabilities, and teacher identity, and construct new knowledge through self-discovery and reflection of those issues (Ukpokodu, 2003). The reflective journey through 
an educational autobiography helps participants self-examine ways they respond to cognitive dissonance and change (Gunn et al., 2013).

According to the Transformative Learning Theory by Mezirow (1997), transformation through critical reflection and discourse occurs when an environment is safe and comfortable. People's interpretation of experiences with gender, education, capabilities, and identities are shaped by unconscious assumptions, worldviews, biases, or even prejudices. Those assumptions affect our beliefs, selfefficacy, decision-making, and interactions with others (Childs, 2005). Hence, the research methods of educational autobiography and qualitative interviewing offer valuable tools for pre-service teachers to critically question their deep-rooted assumptions and worldviews, experience transformation of their self-awareness, and construct better-informed knowledge. Also, critical reflection can enable students to gain knowledge of self and others, and more importantly, to recognize connections to and differences from others (Gunn et al., 2013).

In this study, eight student teachers of different STEM-related subjects (ranging from Biology, Chemistry, Information and Communications Technology, and Physics to Mathematics) were purposefully selected at the largest teacher training university of Hong Kong for the research sample (Table 12.1). Before formal interviews were conducted, each research participant was asked to write a reflective essay in response to guiding questions informed by the capabilities approach. The researchers read through the reflective essays and developed specific questions for the interview guide afterwards. The individual, semi-structured interviews, conducted from March to May of 2020, lasted for 1 to 1.5 hours with the aid of the contextualized interview guide. Based on the research questions, the interviews covered dialogues about the following open-ended themes:

- Can you share your story of why you become a pre-service teacher at this university? Why did you choose this major?

- What is your understanding about the new field of "STEM"? How is it different from other subjects, including the traditional science subjects?

- To what extent would you relate your major with the field of "STEM"? How and why?

Table 12.1 Research Respondents Information

\begin{tabular}{lll}
\hline & Major (Bachelor of Education, specialization) & Year of study \\
\hline Respondent 1 & Mathematics & 5 \\
Respondent 2 & Mathematics & 1 \\
Respondent 3 & Information and Communication Technology & 3 \\
Respondent 4 & Mathematics & 5 \\
Respondent 5 & Science & 3 \\
Respondent 6 & General Studies & 4 \\
Respondent 7 & Information and Communication Technology & 2 \\
Respondent 8 & Information and Communication Technology & 3 \\
\hline
\end{tabular}


- Can you tell us more about your learning experiences? What makes you identify yourself as a pre-service "STEM teacher," or not?

- Can you tell us more about your teaching experiences, including teaching practicums and part-time teaching jobs? How do they help you to construct your "teacher identity"?

- Does gender make a difference in the processes of aspiring and becoming a STEM teacher? Why and How?

- What are the needs for professional training of STEM teachers and implications for teacher education?

- Do you have any comments about the development of Science Education and teacher training/education in Hong Kong?

Verbatim transcription was produced for all interviews. The transcripts were read and re-read for thematic coding (Gibbs, 2007) guided by the conceptual framework of the capabilities approach.

\section{Positionality}

As qualitative researchers, we acknowledge our own role as interpreters for understanding the interview guide, engaging in dialogue during the interview processes, coding the data, generating themes, and analyzing the codes and themes from the qualitative data. Our training, experiences, and curiosities might have influenced the path of investigation, quotes selection, and themes identification (Luttrell, 2010). By way of ensuring the trustworthiness of this study, we make our positionality as researchers transparent (Luttrell, 2010; Walther, et al., 2013) and enhance the inter-rater reliability by coding and analyzing the data together. We identify ourselves as education researchers with similar ethnic backgrounds (Chinese, native-born in Hong Kong). Four of us had post-graduate training as educational researchers with different expertise and we all have research experience in education and gender. Three of us have experience teaching undergraduates and offering professional development programs in education.

\section{Findings}

The iterative processes of thematic coding discovered four themes from the qualitative data of educational autobiography and follow-up interviews. They are (1) motivations for aspiring to become STEM teachers, (2) gender stereotyping and STEM performance, (3) gender and aspirations for teaching STEM, and (4) gender and STEM teacher identity.

\section{Motivations for Aspiring to Become STEM Teachers}

Data from this study reveal that women students in teacher pre-service programs in Hong Kong do not face educational inequalities in accessing opportunities or resources for STEM-related education. They saw the importance of 
advanced technology and rising demand for STEM-related education in the new century. The educational processes, as the key social conversion factors in this study, facilitate the development of their aspiration, as well as capabilities and functionings. The women STEM pre-service teachers in Hong Kong generally possess the freedom, opportunity, and potential to make reasoned and reflective choices about using the resources they have through the teacher training program at the education university in realizing their valued functionings, i.e., becoming a professional STEM teacher in the future. In response to the question of why they chose an education major related to STEM, a respondent shared:

It is for better equipping myself for the new demands of the era. Nowadays, digital and technology-enabled teaching has become increasingly important. As young professionals to be, we should proactively learn and understand the knowledge of this aspect. As for me, I have a science background. I have a comparative edge of science, and my university major is primary mathematics education. I think I have the capability to further my studies about STEM-related teacher professional development. (Respondent 1, BEd Maths (Primary), Year 5)

Another respondent echoed the similar perspective and aspiration, especially in view of the prevalent trend of technology-enabled teaching across subject curriculum and the cross-curricular skill of design thinking:

In the current context of education, technology is increasingly integrated with other subjects, such as General Studies and Mathematics. Integrating technology with these two subjects enables us to teach students how to stimulate their design thinking or other new thinking approaches. Further, it may help their learning in Science. (Respondent 2, BEd Maths (Primary), Year 1)

\section{Gender Stereotyping and STEM Performance}

Despite the availability of opportunities and resources for STEM education and teacher training, students in Hong Kong still hold subjectivities about gender disparities in science performance which can in turn affect their capabilities and functionings building. Participants had personal conversion factors of self-efficacy and competencies to pursue STEM subject knowledge. These factors, combined with students' capabilities of reframing the traditional stereotyping of gender and STEM, help to make sense of the varied perceptions and subjectivities among the participants in this research. Respondent 1 perceived that there are gender differences in confidence and self-efficacy in learning and achievement in STEM-related subjects: 
Indeed, there are some gender differences in terms of self-confidence. Some girls think that boys are good at math, while boys somehow show their confidence in math. Although the teacher teaches us in the same way and s/he would not say which students are good or who are bad, some female students always like to say "the boys in that class are really good at math." Also, male students are in general more confident and active in class. Perhaps that's why they have better learning. (Respondent 1, BEd Maths (Primary), Year 5)

Such gender biased perceptions of Hong Kong women students affect their everyday interactions and personal observations about gender differences and inequality. The performance in Mathematics and Science subjects are also varied. One respondent stated:

For me, I hope there is no gender inequality. However, in my observation, as I had minored in science and attended to some science classes, most of them are men. The class performance of the men was better and more active than women, men were more willing to express their ideas and share with the professor, while women might not be the same. That's what I have observed in science lessons. But, it's different in mathematics lessons: most of the women perform well in math as you may need to be circumspect about mathematics. Everyone has her/his own strengths. As for me, I am not good at mathematics like Algebra. (Respondent 1, BEd Maths (Primary), Year 5)

\section{Gender and Aspirations for Teaching STEM}

The social conversion factors concerning social norms about STEM and gender affect the capabilities-functionings conversion through teacher education for pre-service STEM teachers, particularly in terms of empowerment of women student teachers for their disciplinary, interdisciplinary, and pedagogical knowledge and skills. With regard to developing aspirations for becoming a STEM-related teacher in Hong Kong, gender appears to be a more multifaceted issue than common assumptions hold. It is due to the gendered division of labor within Hong Kong's occupational structure that school teaching is relatively a feminine job, especially at the primary level. In response to the question about whether gender may affect the aspiration of becoming a STEM teacher in Hong Kong, a pre-service primary school mathematics teacher shared an alternative view:

It is hard to say whether gender stereotyping would affect the aspiration of becoming a teacher or not, as there is no relationship between gender and this aspiration ... Why can't girls study science? Why can't men study liberal arts? This is all about your attitude and your own choices. Don't be influenced by the society! (Respondent 2, BEd Maths (Primary), Year 1) 
Another respondent who was studying science education for high schools admitted that it takes time to nurture a woman role model in the field of STEM education across Hong Kong communities because women's self-esteem and self-efficacy seem relatively lower than men in terms of STEM competency. The finding affirms the effect of personal conversion factors, which can be reworked by the emerging environmental factors of capabilities-functionings conversion, especially in view of the role model of women STEM teachers:

As a woman, I am confident as I have relevant knowledge about STEM. Gender does not affect my teaching. However, I've read the news about Hong Kong's lack of women in STEM, I have the same feeling that men are relatively better than women. For example, men can complete tasks about programming and debugging more efficiently, while women might not be that fast or clear. In fact, I agree with the statement to a certain extent. (Respondent 5, BEd Science, Year 3)

\section{Gender and STEM Teacher Identity}

Concerning the professional identity of STEM teachers, the personal conversion factors relating to gender image and self-efficacy become even more important when gender stereotyping and bias are perceived and embodied individually. Some people in Hong Kong have an image of the professional, "archetypal" STEM teacher as a man more than as a woman. A respondent shared this opinion in reply to the question about whether gender factor affects her perception concerning the professional identity of STEM teachers:

I am worried others may think that I don't have as much computer knowledge as men do and that I cannot handle teaching well. Such personal perception makes me feel bad. (Respondent 5, BEd Science, Year 3)

Another respondent revealed her subjectivities about gender image and educational leadership in the STEM fields:

Perhaps it's because of the traditional mindset I used to hold. I think men's logical thinking is better than that of women. As for promoting teachers to be school leaders, most of the successful cases are men. Therefore, it seems more preferable promoting a male teacher to a female colleague. Let's take chemistry as an example, it's better to have a male teacher. By comparing some of my chemistry teachers, male teacher's lessons are more down-toearth and catchier. Female teacher's lessons are rather wishy-washy. They deliver knowledge related to the subject, yet whether the knowledge is important or not, no one knows. Therefore, I think it would be better to have a male chemistry teacher. However, for the subject of biology, it involves different topics like organisms, plants and the environment. Thus, I think female teachers are alright. (Respondent 5, BEd Science, Year 3) 
However, another pre-service teacher envisioned that successful women STEM teachers should be established as the role model over time. The following interview data shows the significance of environmental conversion factors of women role models in the STEM fields amidst the global trend of new human capital demands in the STEM fields and the opportunities for greater gender justice:

So far, I have never seen a female teacher of ICT. Instead, female teachers are well-positioned in handling gender's issues in STEM teaching and learning, they will consider it from a female's point of view. (Respondent 7, BEd ICT, Year 2)

\section{Summary of the Research Findings in Light of the Capabilities Framework}

Results of this research show that capabilities-functionings conversion factors do not stand-alone but interact with one another in the identity formation processes of women pre-service STEM teachers in Hong Kong. It is the interaction of these factors that converts capabilities into functionings and well-being (Chiappero-Martinetti \& Sabadash, 2014). Social and personal conversion factors play a role in the educational and professional development processes in STEM teacher education of student teachers. The findings also show that the personal and social conversion factors can be reworked by emerging environmental factors, especially in view of the role model of women STEM teachers amidst the global trend of talent shortages in the fields and the opportunities for greater gender justice.

Table 12.2 presents the summary of conversion factors from capabilities into functionings among women STEM pre-service teachers in Hong Kong. Based on the empirical findings, we found that the personal conversion factors can be categorized into (1) self-efficacy, referring to belief in one's own competencies and capabilities to pursue STEM as teachers; (2) STEM subject knowledge (referring to academic knowledge and interdisciplinary knowledge) and skills for pedagogical practices in STEM class teaching and activities; and (3) perception on gender stereotyping, i.e., the capabilities of individual women pre-service STEM teachers in reframing the traditional stereotyping of gender and STEM.

As mentioned earlier, teacher education for pre-service STEM teachers is the central social conversion factor for this study, as it directly contributes to the empowerment of women STEM student teachers for their disciplinary, interdisciplinary, and pedagogical knowledge and skills. STEM teacher education helps convert their capabilities into functionings, valuing their aspirations of becoming a STEM teacher, and realizing their valued functionings. The effect and outcome of STEM teacher education are contextualized against other social conversion factors, which include social norms concerning socialization of family, school, and peers regarding STEM and gender. 
Table 12.2 Summary of Conversion Factors From Capabilities into Functionings among Women STEM Pre-service Teachers in Hong Kong

Personal conversion factors

Self-efficacy

STEM subject knowledge

Perception of gender stereotyping

Social conversion factors

Teacher education for pre-service STEM teachers

Social norms

Environmental conversion factors

New human capital demand in the STEM fields and opportunities for greater gender justice

Global trend of STEM-led development and changing civic life in the digital age
Belief in own competencies and capabilities to pursue STEM as teachers

Academic knowledge and interdisciplinary knowledge and skills for pedagogical practices in STEM class teaching and activities

The capabilities of reframing the traditional stereotyping of gender and STEM

Empowerment of student teachers of STEM for their disciplinary, interdisciplinary, and pedagogical knowledge and skills

Socialization of family, school, and peers about STEM and gender

Importance of women role models in the STEM fields

Cultivation of digital literacy and career and life planning for STEM-related future career/ entrepreneurship and youth engagement

In a broader sense, environmental conversion factors interact with personal and social conversion factors in affecting the career aspiration and identity formation processes of student teachers of STEM teacher education. The new demand for human capital in the STEM fields gives rise to the possibilities of establishing women role models in the STEM fields, be they in the teaching profession or in other sectors and industries. These role models will play a positive part in the facilitation of capabilities-functionings conversion and in enhancing the opportunities for greater gender justice. Meanwhile, the global trend of STEM-led development and changing civic life in the digital age call for the cultivation of digital literacy in schoolchildren and of career and life planning for a STEM-related future and youth engagement.

\section{Discussion}

The key findings of this study show that women pre-service teachers in Hong Kong do not have less access than their men counterparts to the freedoms, educational opportunities, or human potential to make reasoned and reflective choices about the resources offered by educational policies and schooling practices to build capabilities for becoming STEM-related professional teachers in the future. They also have the functionings to value the professional engagement of STEM education, becoming role models of women STEM 
educators and deconstructing the existing gender stereotypes about STEM teaching and learning. To a certain extent, education in Hong Kong offers positive conversion factors for changing women students' capabilities into functionings, and realizing their valued functionings.

The main findings echo the literature of Hong Kong education and gender which reports that women students are not in relatively disadvantaged positions for the development of their capabilities and functioning. For example, previous research found that there are no gender differences in intrinsic motivation for education among university students in Hong Kong (Yau et al., 2012) and school girls reported higher levels of life satisfaction and spiritual health than their school boy peers (Yuen, 2015). In fact, the percentage of women university students are higher than men in the majors of Dentistry $(64.3 \%)$ and Medicine $(51.4 \%)$, despite the gender imbalance in Science (38.7\%), and Engineering and Technology (29.4\%) (Women's Commission, 2019). There was an increase in gender equity in terms of the visual and textual representation of women in the primary school English-language textbooks. However, some stereotyped images of the both sexes still persist such that women are portrayed in a more limited range of social roles which reinforce the 'male-first' phenomenon (Lee, 2014).

\section{Implications and Conclusion}

Based on the empirical analysis of this study, we demonstrate the potential of the capabilities approach to serve as a framework for addressing gender inequalities and enhancing students' well-being, human development, and justice within STEM fields and within the Hong Kong education context. Overall, our women pre-service teacher respondents provide a perception that gender stereotypes are concealed in STEM professions, coming from their first-person perspective. Although gender inequalities within STEM education and the local education system are not noticeable, gender stereotyping in STEM fields still exists in society, schools, and the mental outlook of individual women pre-service STEM teachers in Hong Kong. Empirical findings of this study show how stereotypes about women in STEM can sometimes be perpetuated by everyday interactions in the classroom, especially when STEM teachers are not conscious of the fact that stereotypes are internalized and are continuing to make their way into classrooms and schools. Therefore, Hong Kong schools are urged to initiate more diverse types of STEM programs because it can develop capabilities for women's aspirations and fascination for STEM and motivate their participation in the STEM taskforce (Cannady et al., 2017). One of the local popular programs Girls Go Tech (GGT) School Programme, which is a year-long, schoolbased program launched in 2015, aims to encourage women secondary school students from deprived backgrounds to pursue traditionally maledominated, STEM-related subjects to maximize their future career options (The Women's Foundation, 2015). Lam (2018) reported students successfully 
develop different employability skills to help achieve their future academic and career goals in STEM fields after participating in the program. When gendered stereotypes regarding STEM success threaten the career choices of women, they can also have damaging consequences on women's STEM selfefficacy and career motivation (Cundiff et al., 2013; Mascret \& Cury, 2015) and can negatively affect future career aspirations. To improve the effect of women's stereotyping on STEM aspirations, their expected feelings in STEM and exploration of STEM identity deserve more attention in our professional training programs and career and life planning education (Schuster \& Martiny, 2017). The explicit perception of a STEM identity can nurture a better formulation of STEM teacher identity and aspiration in STEM professionals (Seyranian et al., 2018).

As for the case of Hong Kong, it is even more timely to develop role models of women as active STEM educators and practitioners and democratize the worldview of STEM education and teacher identity. The education system is morally obligated to guarantee students of both genders the opportunity to achieve well-being. In the century of accelerating technological advancement, human capabilities for digital literacy as well as STEM literacy are of special importance to pursue and attain an improved wellbeing for our young women in STEM development. Achieving STEM aspirations through STEM teachers can be treated as equipping capabilities to accomplish functionings to overcome gender inequities in the STEM fields. Empirical analysis of this chapter recommends future research and policy directions for designing and implementing gender-equity intervention with a view to addressing the influences of stereotypes that threaten STEM teacher aspirations. Among various interventions, teacher education programs and professional development can help pre-service and practicing teachers to challenge their own assumptions and stereotypes so that they can, in turn, empower the younger generations to tackle the "gender-equality paradox" in Hong Kong throughout their careers as teachers of STEMrelated subjects (Breda, et al., 2020; Buck, et al., 2020). University faculties or schools of education can take on the intellectual leadership required by initiating open platforms and developing professional learning communities for discussing and co-developing gender-just institutional policies and practices for STEM education.

\section{Notes}

1 STEM-related programs include biological science, physical science, mathematical science, computer science and information technology, engineering and technology, architectural studies and town planning (Hong Kong Government of SAR, 2018. https://www.info.gov.hk/gia/general/201811/28/P2018112800583.htm

2 Mathematics is one of the four core subjects, whereas Biology, Chemistry, Physics, Combined Science, Integrated Science, Mathematics "module one" (M1) and Mathematics "module two" (M2) are STEM-related elective subjects. 


\section{References}

Adams, J. D. (2020). Designing frameworks for authentic equity in science teaching and learning: Informal learning environments and teacher education for STEM. Asia-Pacific Science Education, 1-24. https://doi.org/10.1163/23641177-BJA10016

Avraamidou, L. (2014). Studying science teacher identity: Current insights and future research directions. Studies in Science Education, 50(2), 145-179.

Beede, D., Julian, T., Langdon, D., McKittrick, G., Khan, B. and Doms, M. (2011). Women in STEM: A gender gap to innovation. Economics and Statistics Administration Issue Brief No. 04-11. https://papers.ssrn.com/sol3/papers.cfm?abstract_id=1964782

Boni, A., \& Walker, M. (2016). Global human development: Theoretical and empirical insights for social change. Routledge.

Bottia, M., Stearns, E., Mickelson, R., Moller, S., \& Valentino, L. (2015). Growing the roots of STEM majors: Female math and science high school faculty and the participation of students in STEM. Economics of Education Review, 45, 14-27. https://doi. org/10.1016/j.econedurev.2015.01.002

Breda, T., Jouini, E., Napp, G., \& Thebault, G. (2020). Gender stereotypes can explain the gender-equality paradox. Proceedings of the National Academy of Sciences, 117(49), 31063-31069.

Britzman, D. P. (2003). Practice makes practice: A critical study of learning to teach. State University of New York Press.

Buck, G. A., Cross-Francis, D, \& Wilkins-Yel, K. G. (2020). Research on gender equity in STEM education. In C. C. Johnson, M. J. Mohr-Schroeder, \& T. J. Moore (Eds.), Handbook of research on STEM education (pp. 289-299). Routledge.

Carrier, S. J., Whitehead, A. N., Walkowiak, T. A., Luginbuhl, S. C. and Thomson, M. M. (2017). The development of elementary teacher identities as teachers of science. International Fournal of Science Education, 39(13), 1733-1754.

Census and Statistics Department. (2019a). Hong Kong as an information society. Hong Kong Census and Statistics Department.

Census and Statistics Department. (2019b). Women and men in Hong Kong - Key statistics. Hong Kong Census and Statistics Department.

Chan, N., \& Rosenthal, H. (2014). Working memory moderates stereotype threat effects for adolescents in Hong Kong. Revue internationale de psychologie sociale, 27(3-4), 103-118.

Chan, A. K. W., \& Cheung, A. K. L. (2018). Gender differences in choosing STEM subjects at secondary school and university in Hong Kong. The Women's Foundation.

Cannady, M., Moore, D., Votruba-Drzal, E.et al. (2017). How personal, behavioral, and environmental factors predict working in STEMM vs non-STEMM middle-skill careers. International fournal of STEM Education, 4(22). https://stemeducationjournal. springeropen.com/articles/10.1186/s40594-017-0079-y

Chan, K. Y. C., Yeung, N. C. J., Kutnick, P. and Chan, R. Y. Y. (2019). Students' perceptions of engineers: Dimensionality and influences on career aspiration in engineering . International Journal of Technology and Design Education, 29, 421-439.

Charissi, A. (2020). The educational autobiography as a critical reflection tool towards personal and professional development of pre-service early years practitioners. European Fournal of Education Studies, 7(2).

Chiappero-Martinetti, E., \& Sabadash, A. (2014). Integrating human capital and human capabilities in understanding the value of education. In S. Ibrahim \& M. Tiwari (Eds.), The capability approach: From theory to practice (pp. 206-230). Palgrave Macmillan. 
Childs, E. C. (2005). Looking behind the stereotypes of the "angry black woman" an exploration of Black women's responses to interracial relationships. Gender E Society, 19(4), 544-561.

Cin, F. M., \& Walker, M. (2016). Reconsidering girls' education in Turkey from a capabilities and feminist perspective. International Fournal of Educational Development, 49, 134-143.

Collopy, R. (2003). Curriculum materials as a professional development tool: How a mathematics textbook affected two teachers' learning. The Elementary School fournal, 103(3), 287-311.

Cundiff, J. L., Vescio, T. K., Loken, E., \& Lo, L. (2013). Do gender-science stereotypes predict science identification and science career aspirations among undergraduate science majors? Social Psychology of Education, 16(4), 541-554.

Dasgupta, N., \& Stout, J. G. (2014). Girls and women in science, technology, engineering, and mathematics: STEMing the tide and broadening participation in STEM careers. Policy Insights from the Behavioral and Brain Sciences, 1(1), 21-29. https:// doi.org/10.1177/237273221454947 1

DeJaeghere, J. (2018). Girls' educational aspirations and agency: Imagining alternative futures through schooling in a low-resourced Tanzanian community. Critical Studies in Education, 59(2), 237-255.

Drake, C., Spillane, J. P., \& Hufferd-Ackles, K. (2001). Storied identities: Teacher learning and subject-matter context. Fournal of Curriculum Studies, 33(1), 1-23.

Education Bureau. (2014). Guide on life planning education and career guidance for secondary schools (1st ed.). https://careerguidance.edb.hkedcity.net/edb/export/sites/default/ lifeplanning/.pdf/about-careers-guidance/CLP-Guide_E_r3.pdf

Education Bureau. (2016). Report on promotion of STEM education: Unleashing potential in innovation. Hong Kong Education Bureau.

El Nagdi, M., \& Roehrig, G. (2020). Identity evolution of STEM teachers in Egyptian STEM schools in a time of transition: A case study. International Fournal of STEM Education, 7(41). https://doi.org/10.1186/s40594-020-00235-2

El Nagdi, M., Leammukda, F., \& Roehrig, G. (2018). Developing identities of STEM teachers at emerging STEM schools. International fournal of STEM Education, 5(36), 1-13. https://doi.org/10.1186/s40594-018-0136-1

European Institute for Gender Equality. (2017). Economic benefits of gender equality in the EU: How gender equality in STEM education leads to economic growth. https://eige.europa.eu/sites/ default/files/documents/2017.2082_mh0217177enn_pdfweb_20170803123353.pdf

Franzosa, S. D. (1992). Authoring the educated self: Educational autobiography and resistance. Educational Theory, 42(4).

Gibbs, G. R. (2007). Thematic coding and categorizing: Analyzing qualitative data. Sage.

Gokpinar, T, \& Reiss, M. (2016). The role of outside-school factors in science education: A two-stage theoretical model linking Bourdieu and Sen, with a case study. International Fournal of Science Education, 38(8), 1278-1303.

Grace, K., \& Eng, S. (2020). A capabilities approach to female graduates' post-secondary academic and career-related goal pursuit in Siem Reap Cambodia. Educational Research for Policy and Practice, 19, 281-299.

Gunn, A., Bennett, S., Evans, L. S., Peterson, B. J., \& Welsh, J. L. (2013). Autobiographies in preservice teacher education: A snapshot tool for building a culturally responsive pedagogy. International Journal of Multicultural Education, 15(1), 1-20. 
Horvath, M., Goodell, J. E., \& Kosteas, V. D. (2018). Decisions to enter and continue in the teaching profession: Evidence from a sample of US secondary STEM teacher candidates. Teaching and Teacher Education, 71, 57-65.

Huang, J., Wang, Y., and Teng, F. (2019). Understanding changes in teacher beliefs and identity formation: A case study of three novice teachers in Hong Kong. Teaching Education. https://doi.org/10.1080/10476210.2019.1693535

Kaleva, S., Pursiainen, J., Hakola, M.et al. (2019). Students' reasons for STEM choices and the relationship of mathematics choice to university admission. International Fournal of STEM Education, 6(43). https://stemeducationjournal.springeropen.com/a rticles/10.1186/s40594-019-0196-x

Kameshwara, K. K., and Shukla, T. (2017). Towards social justice in institutions of higher learning: Addressing gender inequality in Science \& Technology through capability approach. Administrative Science, 7(3), 22-35.

Kutnick, P., Chan, R. Y. Y., \& Chan, C. K. Y.et al. (2018). Aspiring to become an engineer in Hong Kong: Effects of engineering education and demographic background on secondary students' expectation to become an engineer, European Fournal of Engineering Education, 43(6), $824-841$.

Kutnick, P., Lee, B. P. K., Chan, R. Y. Y., \& Chan, C. (2020). Students' engineering experience and aspirations within STEM education in Hong Kong secondary schools. International Fournal of Educational Research, 103, 101610.

Lam, J. (2018, October 19). STEM education for all: Girls Go Tech Programme empowers HK female secondary students to pursue tech subjects. SCMP. https://www. scmp.com/yp/discover/lifestyle/features/article/3057512/stem-education-all-girls-gotech-programme-empowers

Lee, J. F. (2014). Gender representation in Hong Kong primary school ELT textbooks - a comparative study. Gender and Education, 26(4), 356-376.

Legislative Council Secretariat. (2020). Nurturing of local talent. Research Brief Issue 3. https:// www.legco.gov.hk/research-publications/english/1920rb03-nurturing-of-local-talent-20 200601-e.pdf

Lo, W. Y. W., \& Tang, H. H. H. (2020). Chasing phantoms? Innovation policy, higher education and the pursuit of a knowledge economy in Hong Kong. Fournal of Higher Education Policy and Management, 42(2), 178-193.

Luttrell, W. (2010). Introduction: The promise of qualitative research in education. In W. Luttrell (Ed.), Qualitative educational research: Readings in reflexive methodology and transformative practice (pp. 1-17). Routledge.

Makarova, E, Aeschlimann, B., \& Herzog, W. (2019). The gender gap in STEM fields: The impact of the gender stereotype of math and science on secondary students' career aspirations. Front. Education, 4(60). https://doi.org/10.3389/ feduc. 2019.00060

Margot, K. C., \& Kettler, T. (2019). Teachers' perception of STEM integration and education: A systematic literature review. International foumal of STEM Education, 6(2). https://stemeducationjournal.springeropen.com/articles/10.1186/s40594-018-0151-2 \#citeas

Mascret, N., \& Cury, F. (2015). "I'm not scientifically gifted, I'ma girl”: Implicit measures of gender-science stereotypes-preliminary evidence. Educational Studies, 41(4), 462-465.

Medina, Y. (2016). In the name of teaching: The embodied journey of a different kind of educator. Educational Studies, 52(2), 177-187. 
Mezirow, J. (1997). Transformative learning: Theory to practice. New Directions for Adult and Continuing Education, 74, 5-12.

Molyneux, M., \& Razavi, S. (Eds.). (2002). Gender justice, development, and rights. Oxford University Press.

Mullis, I. V. S., Martin, M. O., and Loveless, T. (2016). 20 years of TIMSS: International trends in mathematics and science achievement, curriculum, and instruction. TIMSS and PIRL International Study Center.

OECD. (2016). PISA 2015 results (Vol. 1): Excellence and equity in education. OECD Publishing.

OECD. (2019). PISA 2018 results (Vol. 1): What students know and can do. OECD Publishing. https://www.oecd.org/education/pisa-2018-results-volume-i-5f07c754-en.htm

Powell, R. R., Zehm, S. J., \& Garcia, J. (1996). Field experience: Strategies for exploring diversity in schools. Prentice Hall.

Robeyns, I. (2003). Sen's Capability Approach and gender inequality: Selecting relevant capabilities. Feminist Economics, 9(2-3), 61-92.

Robeyns, I. (2017). Wellbeing, freedom and social justice: The capability approach re-examined. Open Book Publishers.

Sachs, J. (2001). Teacher professional identity: Competing discourses, competing outcomes. Fournal of Education Policy, 16(2), 149-161. https://doi.org/10.1080/ 02680930116819

Sanders, M. (2009). STEM, STEM education STEM mania. The Technology Teacher, 68(4), 20-26.

Schuster C, \& Martiny S. E. (2017). Not feeling good in STEM: Effects of stereotype activation and anticipated affect on women's career aspirations. Sex Roles, 76(1), 40-55. https://doi.org/10.1007/s11199-016-0665-3

Sen, A. (1999). Development as freedom. Oxford University Press.

Seyranian, V., Madva, A., Duong, N.et al. (2018). The longitudinal effects of STEM identity and gender on flourishing and achievement in college physics. International Fournal of STEM Education, 5(40). https://stemeducationjournal.springeropen.com/a rticles/10.1186/s40594-018-0137-0

Shapiro, J. R. (2011). Different groups, different threats: A multi-threat approach to the experience of stereotype threats. Personality and Social Psychology Bulletin, 37, 464480. https://doi.org/10.1177/0146167211398140

Shapiro, J. R., \& Neuberg, S. L. (2007). From stereotype threat to stereotype threats: Implications of a multi-threat framework for causes, moderators, mediators, consequences, and interventions. Personality and Social Psychology Review, 11, 107-130. https: doi.org/10.1177/1088868306294790

Shapiro, J. R., \& Williams, A. M. (2012). The role of stereotype threats in undermining girls' and women's performance and interest in STEM fields. Sex Roles: A Fournal of Research, 66(3-4), 175-183.

Sharif, N., \& Tang, H. H. H. (2014). New trends in innovation strategy at Chinese universities in Hong Kong and Shenzhen. International Journal of Technology Management, 65(1), 300-318.

Simon, R. A., Aulls, M. W., Dedic, H., Hubbard, K. A., \& Hall, N. G. (2015). Exploring student persistence in STEM programs: A motivational model. Canadian Fournal of Education, 38(1), 1-27.

Simpson, A., \& Bouhafa, Y. (2020). Youths' and adults' identity in STEM: A systematic literature review. Fournal for STEM Education Research, 3, 167-194. 
Slavit, D., Nelson, T., \& Lesseig, K. (2016). The teachers' role in developing, opening, and nurturing an inclusive STEM-focused school. International fournal of STEM Education, 3 (7), 1-17. https://doi.org/10.1186/s40594-016-0040-5

So, W. W. M., \& Chiu, S. W. K. (2020). Challenges and opportunities with Hong Kong students' science, technology, engineering and mathematics aspirations. Policy Innovation and Co-ordination Office of the Government of the Hong Kong Special Administrative Region.

Spencer, S. J., Logel, G., \& Davies, P. G. (2016). Stereotype threat. Annual Review of Psychology, 67(1), 415-437.

Steele, C. M. (1997). A threat in the air: How stereotypes shape intellectual identity and performance. American Psychologist, 52(6), 613-629.

Stoet, G., \& Geary, D. C. (2018). The gender-equality paradox in science, technology, engineering, and mathematics education. Psychological Science, 29(4), 581-593. https:// doi.org/10.1177/0956797617741719

Talafian, H., Moy, M. K., Woodard, M. A.et al. (2019). STEM identity exploration through an immersive learning environment. Fournal for STEM Education Research, 2, 105-127.

Tang, H. H. H. (2020). The strategic role of world class universities and academic profession in regional innovation system: The case of China's Greater Bay Area. Asian Education and Development Studies.https://www.emerald.com/insight/content/ doi/10.1108/AEDS-10-2019-0163/full/html

Tang, H. H. H., \& Chau, C. F. W. (2020). Knowledge exchange in a global city: A typology of universities and institutional analysis. European Fournal of Higher Education, $10(1), 93-112$.

The Academy of Sciences of Hong Kong. (2017). Science, technology and mathematics education in the development of the innovation and technology ecosystem of Hong Kong. The Academy of Sciences of Hong Kong.

The Women's Foundation. (2015). Girls Go Tech. https://www.ggthk.org/stem_ hub/about.jsp

Trent, J. (2010). Teacher education as identity construction: Insights from action research. Foumal of Education for Teaching: International Research and Pedagogy, 36(2), 153-168. https:// doi.org/10.1080/02607471003651672

Ukpokodu, O. N. (2003). Teaching multicultural education from a critical perspective: Challenges and dilemmas. Multicultural Perspectives: An Official Fournal of the National Association for Multicultural Education, 5(4), 17-23.

Unterhalter, E. (2007). Gender, schooling and global social justice. Routledge.

Walker, M. and Loots, S. (2018). Transformative change in higher education through participatory action research: A capabilities analysis. Educational Action Research, 26(1), 166-181.

Walther, J., Sochacka, N. W., \& Kellam, N. N. (2013). Quality in interpretive engineering education research: Reflections on an example study. Fournal of Engineering Education, 102(4), 626-659. http://dx.doi.org/10.1002/jee.20029

Wenger, E. (1998). Communities of practice: Learning, meaning and identity. Cambridge University Press.

Wenger, E., McDermott, R., \& Snyder, W. (2002). Cultivating communities of practice: A guide to managing knowledge. Harvard Business School Press.

Women's Commission. (2019). Hong Kong women in figures 2019. Hong Kong Women's Commission.

Yau, H. K., Kan, M. S., \& Cheng Alison, L. F. (2012). The impact of curiosity and external regulation on intrinsic motivation: An empirical study in Hong Kong education. Psychology Research, 2(5), 295-307. 


\section{Hei-hang Hayes Tang et al.}

Yeung, D. and Liong, M. (2016). To STEM or not to STEM? Factors influencing adolescent girls' choice of STEM subjects [Final Report]. Hong Kong Women's Foundation.

Yuen, G. Y. (2015). Gender differences in life satisfaction and spiritual health among the junior immigrant and local Hong Kong secondary students. International Fournal of Children's Spirituality, 20(2), 139-154. 


\title{
13 Conclusion
}

\section{Unique but Transferable Approaches for Pursuing Gender Equity in STEM in Higher Education across the World}

\author{
Hyun Kyoung Ro, Elizabeth 7. Ramon and Frank \\ Fernandez
}

We collaborated to compile a volume that offers nine country case studies and one comparative study devoted to improving gender equity in STEM through undergraduate education. At the end of this volume, we seek to synthesize findings from across chapters to think about improving gender equity in STEM at the individual, institutional, and national levels. We also hope to offer suggestions for how policymakers and STEM educators may apply unique but potentially transferrable strategies presented in this volume. Finally, we suggest directions for innovative research and policy for pursuing gender equity in STEM fields after the economic and educational turmoil caused by the COVID-19 pandemic. We suggest five recommendations for future research, as well as for national- and institutional-level policies.

While we synthesize lessons from each chapter, we cannot help but revisit the social and economic impacts of COVID-19 on our life and on the contributions of women in STEM areas. Science and innovation are even more important in our life as demonstrated by their indispensable roles in providing a better scientific understanding of the virus, as well as in the development of vaccines and diagnostics treatments. And, as mentioned in the introduction, women scientists have been at the forefront of innovation and solutions, as the example of Dr. Patel and her team illustrate.

The OECD (2021) indicates science and innovation policies will face ongoing challenges from multiple, competing demands for finances and resources greatly exacerbated by the pandemic. However, as governments address ongoing challenges, there will be opportunities to reform science, technology, and innovation policy to promote a more equitable STEM landscape. We seek to shed light on how undergraduate education can play a critical role in offering "sustainable, equitable, and resilient futures" by improving the underrepresentation of women in STEM (OECD, 2021).

As with any volume, we reached a practical limit to the number of country case studies we could include in a single work. Though we contributed to the conversation on the need to approach gender equity in STEM as a global challenge, we did not particularly focus on countries with lower levels of gender equality, in terms of inequities in living conditions (e.g., earnings, tertiary enrollment ratio, life expectancy, or seats in parliament by gender).

DOI: $10.4324 / 9781003053217-4$ 
Therefore, future research should focus on countries with higher economic and general life risks as we explain below. Subsequently, we suggest implications to revise the current national and institutional systems and structures that have reinforced a culture dominated by men in STEM higher education. After that, we claim that scholars and policy makers should consider women STEM undergraduates who hold other marginalized identities. We also offer ways research and policy should extend gender binary to include transgender and nonbinary women's identities and experiences. Fourth, we suggest that researchers and policy makers consider and address equity challenges across STEM sub-disciplines and different types of institutions, rather than aggregating disciplines or institutions. Finally, we discuss what we would anticipate and prepare in order to improve gender equity in STEM after the COVID19 pandemic era.

\section{Approaching Gender Equity in STEM as a Global Challenge}

In this volume, we seek to emphasize the need for studies on access to and success in STEM fields in higher education (i.e., tertiary or postsecondary education) via an international and comparative perspective. However, we could not include all countries which have invested to recruit and retain more women in these fields. Stoet and Geary (2018) identify what they call an "educational gender-equality paradox" (p. 581), drawing upon expectancy-value theory (Eccles, 1983; Wang \& Degol, 2013), which suggests that students choose academic paths on the basis of their relative academic strengths (or weakness) and academic attitudes as well as social factors (e.g., economic benefits and risks of a STEM career). Some scholars argue that countries with high levels of gender equality have the largest STEM disparities by gender in secondary and tertiary education. Scholars have claimed that when economic opportunities are higher and risks are less, as with most gender-equal countries, individuals may choose academic and career paths based on their interests and academic strengths (Richardson et al. 2020; Stoet \& Geary, 2018, 2019; Wang et al., 2013). In Chapter 2, Lee at al. found a similar pattern across countries and discussed that both men and women students may choose a field of study based on individual preferences in Western society and individualist cultures. This may account for why the Middle East and North Africa region may be more open to women in STEM.

These studies imply that improving gender equity in STEM may not be equivalent to promoting gender equity in the broader society. Future research should address how women who obtain STEM university degrees have affected or promoted women's rights and improved gender norms in countries with both low and high levels of gender equality. In particular, much remains unknown to global readers about how STEM women students and professionals in countries with low gender equality face challenges and fight for women's rights and gender issues in STEM fields and their country. For example, many Middle Eastern countries have endorsed the Convention on the Elimination of all Forms of Discrimination Against Women (CEDAW) and shown a strong 
commitment to broaden access to STEM education and workforce for women (Islam, 2019). From the UNSCO and World Bank statistics, Islam (2019) suggests that there is not much gender difference and women even outnumber men in most STEM enrollment and degree attainment in higher education (except engineering). There is still a substantial disparity of women in the STEM workforce considering the percentage of women enrolled and graduating in STEM from higher education institutions.

For future inquiry, more country case studies on gender equity in STEM would help readers better understand the international and comparative outcomes on gender equity in STEM. In particular, Perez-Felkner et al. (2020) acknowledge that few studies have analyzed variation in postsecondary STEM gender gaps within developing countries. By analyzing the case of STEM postsecondary education in Cambodia, Perez-Felkner et al. (2020) suggest that researchers should conduct more studies on gendered STEM postsecondary education pathways in non-Western and industrializing country contexts. Our edited volume would offer implications for countries that devote policy to improving the issue of socioeconomic equity and to building human capital by broadening women's participation in STEM education and workforce.

\section{Changing Systems, Not Individuals}

Our chapter authors offer glimpses at how national- and institutional-level policies and practices have affected women in STEM fields, particularly in STEM undergraduate education. In this volume, some authors conclude that national policies to broaden women's participation in higher education were successful in their countries; however, the extent to which this occurred was disproportionate across different disciplines. For example, In Chapter 3, Lingyu et al. suggest that government policies surrounding the structure of the population, such as the one-child policy, and the structure of education, such as enrollment quotas, has increased the level of participation in education among women in China. In Chapter 4, Fu et al. write about the expansion of Taiwan's tertiary education system, which improved the participation of women in STEM education and the STEM labor market. Despite expanded opportunities, however, these authors found that women were still likely to self-select out of STEM during upper secondary and tertiary education. In Chapter 8, Dusdal and Fernandez present data from Germany showing that many women may delay decisions about whether to pursue their interest in STEM programs until well into tertiary education and introduces an example of how one university provides faculty mentorship to encourage women to pursue STEM opportunities.

We do not imply that all national-level, government-initiated policies are ineffective; rather, we argue that it is important to recognize that the expansion of educational access for women is not equivalent to STEM educational opportunities for women. Similarly, expanding STEM educational opportunities for women is not equivalent to creating labor market opportunities for women. In 


\section{Hyun Kyoung Ro et al.}

Chapter 11, for example, Goncher and Cameron introduce government-led initiatives, such as the Federal Government's Women in STEM Decadal Plan which develop collaboration across K-12 schools, universities, and industry to increase the number of women engineers in Australia. Reading across chapters, we suggest that developing countries may simultaneously consider educational expansion and STEM pipeline-focused policies. When government-initiated STEM education policies are implemented, researchers and policy makers should conduct follow-up studies to explore not only the impact of those policies but also the motivation that students have to study STEM majors. In Chapter 9, CohenMiller et al. explain that students may choose STEM for financial reasons because grants for STEM majors far exceed grants for other majors. In this case, women who obtain STEM degrees may want to choose other fields for their career if they were not satisfied with their learning, or with the culture of STEM disciplines, or if their major choice was simply a function of the financial realities of higher education in Kazakhstan.

Other authors also shed light on the need to transform systems and structures which have reinforced privilege among men (and ethnic majority populations) and discouraged women from entering and staying in STEM fields. In Chapter 5, Ro et al. emphasize that the local supply of schools offering fouryear university degrees and institutions offering STEM degrees are not evenly distributed across the United States (Hillman, 2016). In addition to disciplinary-level challenges, such as microaggressions, stereotyping, alienation, and exclusion, women, particularly women of color, face geographic disparities. More research is needed to examine the geographic disparities in STEM educational opportunities that function as structural barriers. In Chapter 10, Mlambo underscores how Black African women are discouraged from pursuing engineering degrees and academic careers in South Africa. For example, in South Africa, Black African women engineers see academic careers as part of the sexist and racist system they want to transcend and therefore they often decide to work in industry instead. Mlambo describes in her chapter how race-gendered experiences among Black African women engineering students and engineers occur within the context of historical apartheid, the legacy of which is still impacting higher education in South Africa and influencing the decision-making of Black South African women in STEM. She offers numerous suggestions for making higher education and engineering both more welcoming for Black women and for dismantling the culture of whiteness within South African higher education that precipitates a damaging narrative.

Almost all chapters in this volume suggest the importance of women role models and their mentoring and support, as well as networking between women students and professionals. Professional associations, such as the Women in Science and Engineering (WISE) in the United Kingdom, and Women in Engineering ProActive Network in the United States, are good examples. While we value the contribution of women mentors, these programs should not rely on individual women or overburden their service roles. Kwak 
and Ramirez (2019) state that these types of programs have been rightly criticized for their focus on changing women, which locates the responsibility on them, instead of a focus on changing structural barriers, which would correctly locate the responsibility on the system. In Chapter 11, Tang et al. found that gender stereotypes have been internalized (e.g., STEM subjects are a better fit for boys than girls) by pre-service STEM teacher education in Hong Kong; thus, stereotypes about women in STEM can be perpetuated by STEM teachers - even women STEM teachers in K-12 education. Developing systems to help individuals identify their own implicit biases against women is necessary to help support women to develop educational and career aspirations in STEM (Bearman et al., 2009).

\section{Better Understanding "Who We Are Addressing as Women?"}

We propose scholars and policy makers consider incorporating an intersectionality framework lens in order to better support women students who have other marginalized social identities (e.g., racially minoritized women, low socioeconomic-status women). Anti-racism and feminist scholars argue that incorporating an intersectionality framework in any gender equity work is necessary to dismantle structural barriers against these women who have intersected marginalized identities (Crenshaw, 1989; Collins \& Bilge, 2016). Given that intersectionality scholars traditionally address racially minoritized women, some readers may think that this recommendation is more directly relevant in the context of some countries than in others. For example, an intersectionality framework is necessary to understand racially minoritized women in the United States because of double bind barriers (see more in Chapter 5 this volume). Race and ethnicity may not be a salient factor in other countries; however, the framework still offers insights as women students' social identities and demographic backgrounds are not homogeneous, in terms of their social class, disability, age, sexual orientation, or immigrant backgrounds, in addition to their race/ethnicity. More importantly, the current system of STEM education and workforce may include not only privileged men but also privileged women and exclude women students with minoritized backgrounds (Archer et al., 2017).

We also want to challenge scholars and policy makers to take steps to help create more inclusive environments for transgender and nonbinary individuals who want to study STEM majors in higher education. In this volume we posit sex and gender are different in that sex should be used for biological differences between males and female, whereas gender should be used for differences between women and men that are developed socioculturally (see Hyde et al., 2019). Even though we believe that gender is a socially-constructed concept, we could not include transgender and nonbinary women. Recently, scholars have investigated how the culture of STEM environments has excluded transgender, gender nonconforming, or nonbinary undergraduates (Haverkamp et al., 2019; Miller et al., 2020). We suggest that more qualitative inquiries are needed to explore these students' experiences and success in STEM higher education. 


\section{Studying the Unique Context of Sub-STEM Disciplines and Different Types of Universities}

Institutional types seem to matter for gender equity in STEM fields. Studies often address STEM bachelor's degrees, but do not dig into which types of institutions women tend to choose and complete their degrees at when they study STEM subjects. In Chapter 6, Ro et al. study the gender disparity in undergraduate STEM enrollment in England, including enrollment at prestigious Russell Group universities. After controlling for social class and academic background, women had lower odds of enrolling in STEM than men at Russell Group universities. Ro et al. did not find the same pattern when they did not consider subjects (if they included all students who study both STEM and non-STEM majors) at Russell Group universities. Considering institutional types is critical for low-SES women and racially minoritized women because they may attend institutions which lack resources for experiential learning opportunities, such as internships, undergraduate research, or study abroad programs (see Kim and Celis, Chapter 7 this volume, and Ro et al., Chapter 6 this volume). Policy makers should consider investing in two-year community colleges, technical and professional schools, and minority serving institutions (as in the case of the United States) to better support women to obtain STEM bachelor's degrees and to succeed in the STEM workforce.

Many studies, both international/comparative studies and single country case studies, combine STEM disciplines together. When researchers examine gender equity issues, sub-disciplinary analysis is necessary, since women are overrepresented in biological/natural sciences but underrepresented in physical science, engineering, and computer science, particularly in undergraduate programs, across the world (Kwak \& Ramirez, 2019). Combining these two disciplines may elude the nuanced differences by gender in STEM disciplines. Kwak and Ramirez (2019) suggest that more comparative longitudinal studies are needed to examine the experiences of women relative to those of men in different STEM-subfield fields of study across different national contexts.

\section{Post-GOVID-19, What Would We Expect for Gender Equity in STEM?}

Countries took a lot of different approaches to providing primary and secondary education during the pandemic. Not surprisingly, the ways countries provided opportunities to learn during the pandemic differed by region and country wealth (Vegas, 2020), including internet access. Countries in Sub-Saharan Africa were unable to provide teachers with any training for remote teaching, while more than half of countries in Europe and Central Asia provided training to teachers. In addition to these challenges, the pandemic is also expected to indirectly inhibit women's right to education. According to UNESCO's 2020 Global Education Monitoring Report, child marriages, teen pregnancies, and genderbased domestic violence were projected to have sharply increased during the 
pandemic. Girls who dropped out of school during the pandemic were less likely than boys to return.

Historically, scholars have used international datasets to consider how girls are achieving in mathematics. One of the most commonly used datasets is the Programme for International Student Assessment (PISA). For example, Stoet and Geary (2013) analyzed several waves of PISA data to examine differences in boys' and girls' attainment in STEM and to understand how differences vary both within and across countries. As of this writing, the latest wave of PISA data collection was postponed because of the pandemic. At best, future research that will examine girls' preparation for studying STEM will have been disrupted by the changes in PISA data collection. Worse, countries could decline to participate in PISA if budgets are being cut amid competing economic challenges. Although more data will be collected to try to measure the effects of the pandemic, early projections suggest that the disruption to primary and secondary school has led to a decline in mathematics learning (Soland et al., 2020).

At the higher education level, there have been significant declines in women's enrollment at universities. For example, Australia witnessed as women's enrollments in its higher education system declined by more than 85,000 students (Zhou, 2020). Most of the women who dropped out or had to forego enrollment in Australian higher education were older than 25, suggesting that they had competing family responsibilities. The Australian numbers are striking because Australia is ranked highly among other countries in terms of gender equity for women (World Economic Forum, 2020).

In the wake of the pandemic, researchers will need to collect and analyze data to try to measure the effects of the economic and health threats on the pathway for women to study STEM in higher education. Policymakers will need to consider various opportunities so that they do not lose two generations of women in STEM: the girls who are either missing out on primary and secondary school or who are learning less mathematics through distance education, as well as the women who missed out on higher education because of the pandemic. Women will be crucial to international efforts to recover from the pandemic. Even before countries began adopting strict quarantine and social distancing measures, the European Institute for Gender Equality (n.d.) projected that if countries in the European Union (EU) could achieve gender parity in STEM fields, they would create more than 1 million good jobs in the EU and increase per capita GDP across the EU by up to $3 \%$ (more than $€ 800$ billion).

\section{Conclusion}

This volume is the result of collaborative efforts on a research agenda for advancing gender equity in STEM higher education. As editors, we had the opportunity and privilege of reviewing each chapter multiple times. The process of compiling and editing this volume allowed us to develop recommendations for continuing the conversation on how to pursue gender equity in 


\section{Hyun Kyoung Ro et al.}

STEM. While we scrutinize undergraduate education, the STEM pathway begins from early childhood and continues through women's careers. We hope that this work could also offer insights for scholars and policy makers who devote their efforts to enhancing gender equity in STEM in K-12 education, graduate education, and the workforce. We intend that our suggestions will inspire ideas for future scholarship and inform ideas for developing polices among readers. Finally, when we have been reading literature on women in STEM, almost all researchers begin with the observation that women are underrepresented in many STEM fields, and that this is not a single country's problem. We hope that our daughters' generation (currently six years to nine years) would encounter different stories about women in STEM disciplines when they are our age. We genuinely hope that our volume contributes to improving the underrepresentation of women in STEM through higher education.

\section{References}

Archer, L., Moote, J., Francis, B., DeWitt, J., \& Yeomans, L. (2017). The "exceptional" physics girl: A sociological analysis of multimethod data from young women aged 10-16 to explore gendered patterns of post-16 participation. American Educational Research Fournal, 54(1), 88-126.

Bearman, S., Korobov, N., \& Thorne, A. (2009). The fabric of internalized sexism. Journal of Integrated Social Sciences, 1(1), 10-47.

Collins, P. H., \& Bilge, S. (2016). Intersectionality (Key Concepts). Polity.

Crenshaw, K. W. (1989). Demarginalizing the intersection of race and sex: A Black feminist critique of antidiscrimination doctrine, feminist theory and antiracist politics. In A. Phillips (Ed.), Feminism and Politics (pp. 314-343). Oxford University Press.

Eccles, J. (1983). Expectancies, values, and academic behaviors. In J. T. Spence (Ed.), Achievement and achievement motives: Psychological and sociological approaches (pp. 75-146). W. H. Freeman.

European Institute for Gender Equality. (n.d.) Economic benefits of gender equality in the EU. https://eige.europa.eu/sites/default/files/documents/2017.2082_mh0217177enn _pdfweb_20170803123353.pdf

European Institute for Gender Equality. (n.d.) How gender equality in STEM education leads to economic growth. https://eige.europa.eu/gender-mainstreaming/p olicy-areas/economic-and-financial-affairs/economic-benefits-gender-equality/stemfi elds. Developmental Review, 33, 304-340.

Global Education Monitoring Report Team. (2020). A new generation: 25 years of efforts for gender equality in education. UNESDOC Digital Library. https://unes doc.unesco.org/ark:/48223/pf0000374514

Haverkamp, A., Butler, A., Pelzl, N. S., Bothwell, M. K., Montfort, D., \& Driskill, Q. (2019). Exploring transgender and gender nonconforming engineering undergraduate experiences through autoethnography. 2019 CoNECD-The Collaborative Network for Engineering and Computing Diversity. https://par.nsf.gov/biblio/10145278-exploring-transgender-gen der-nonconforming-engineering-undergraduate-experiences-through-autoethnography

Hillman, N. W. (2016). Geography of college opportunity: The case of education deserts. American Educational Research Journal, 53(4), 987-1021. 
Hyde, J. S., Bigler, R. S., Joel, D., Tate, C. C., \& van Anders, S. M. (2019). The future of sex and gender in psychology: Five challenges to the gender binary. American Psychologist, 74(2), 171.

Islam, S. I. (2019). Science, technology, engineering and mathematics (STEM): Liberating women in the Middle East. World Fournal of Education, 9(3), 94-104.

Kwak, N., \& Ramirez, F. O. (2019). Is engineering harder to crack than science? A cross-national analysis of women's participation in male-dominated fields of study in higher education. In A. W. Wiseman (Ed.), Annual review of comparative and international education 2018 (pp. 159-183). Emerald Publishing.

Miller, R. A., Vaccaro, A., Kimball, E. W., \& Forester, R. (2020). "It's dude culture": Students with minoritized identities of sexuality and/or gender navigating STEM majors. Fournal of Diversity in Higher Education. Advance online publication. http://dx. doi.org/10.1037/dhe0000171

Organization for Economic Co-Operation and Development. (2021). OECD science, technology and innovation outlook 2021: Times of crisis and opportunity. www. oecd.org/sti/oecd-science-technology-and-innovation-outlook-25186167.htm

Perez-Felkner, L., Felkner, J. S., Nix, S., \& Magalhães, M. (2020). The puzzling relationship between international development and gender equity: The case of STEM postsecondary education in Cambodia. International Fournal of Educational Development, 72, 102102.

PISA. (n.d.) Programme for International Student Assessment. OECD. https://www. oecd.org/pisa/

Richardson, S. S., Reiches, M. W., Bruch, J., Boulicault, M., Noll, N. E., \& ShattuckHeidorn, H. (2020). Is there a gender-equality paradox in science, technology, engineering, and math (STEM)? Commentary on the study by Stoet and Geary (2018). Psychological Science, 31(3), 338-341.

Soland, J., Kuhfeld, M., Tarasawa, B., Johnson, A., Ruzek, E., \& Liu, J. (2020, May 27). The impact of COVID-19 on student achievement and what it may mean for educators. Brookings. https:// www.brookings.edu/blog/brown-center-chalkboard/2020/05/27/the-impact-of-covid19-on-student-achievement-and-what-it-may-mean-for-educators/

Stoet, G., \& Geary, D. C. (2013). Sex differences in mathematics and reading achievement are inversely related: Within- and across-nation assessment of 10 years of PISA data. PLoS ONE 8(3), e57988. https://doi.org/10.1371/journal.pone.0057988

Stoet, G., \& Geary, D. C. (2018). The gender-equality paradox in science, technology, engineering, and mathematics education. Psychological science, 29(4), 581-593.

Stoet, G., \& Geary, D. C. (2019). A simplified approach to measuring national gender inequality. PloS ONE, 14(1), e0205349.

Vegas, E. (2020, April 14). School closures, government responses, and learning inequality around the world during COVID-19. Brookings. https://www.brookings.edu/research/schoolclosures-government-responses-and-learning-inequality-a

round-the-world-during-covid-19/

Wang, M., \& Degol, J. (2013). Motivational pathways to STEM career choices: Using expectancy-value perspective to understand individual and gender differences in STEM. Developmental Review, 13(4), 304-340.

World Economic Forum. (2020). Global gender gap report 2020. www3.weforum.org/ docs/WEF_GGGR_2020.pdf

Zhou, N. (2020, November 11). Female enrolment at Australian universities dropped by 86,000 in 2020 as 'pink recession' hit. The Guardian. https://www.theguardian.com/a ustralia-news/2020/nov/12/female-enrolment-at-australian-universities-dropped-by-86 000-in-2020-as-pink-recession-hit 


\section{Index}

Page numbers in bold refer to tables.

AANAPISI see Asian American and

Native American Pacific

Islander-Serving Institution

(AANAPISI)

Abitur 124, 125, 128, 133

academic majors, gender differences in 34-36

academic-oriented programs 46

academic performance: "female advantage" 37; gender differences in 36; self-assessments of 126; during undergraduate period 42 ;

of women 33 , 40; between women and men 41

ACED see Australian Council for Engineering Deans (ACED)

ACS see American Community Survey (ACS)

Acuña, Justicia 106

Adam, F. 166

Adelinas 108, 110

ADVANCE-Institutional Transformation (IT) 65

affirmative action program at FCFM 109-112

Alcott, B. 91

All-China Women's Federation 31

Almukhambetova, A. 143

American Community Survey (ACS) 63, 71,72

Ammermüller, A. 127

anti-racism 69, 213

ANU see Australian National University (ANU)

Arab States' Strategy for Science, Technology and Innovation 16

Archer, L. 90, 94, 95

Asian American and Native American Pacific Islander-Serving Institutions (AANAPISIs) 68

Asian American and Pacific Islander

(AAPI) students 68

Asian Development Bank in 2018144

"Asian Tigers" effect 16

asset-based approach 67

Associate Dean of Diversity and Gender Issues 110

Astana Expo 142

Athena Scientific Women's Academic Network (SWAN) model 179

Austin, A. E. 158

Australia 215; engineering education and community in 179; gender diversity in 174; higher education in 175, 215; recruiting and supporting women students in 177-180; secondary schools across 178; universities and students in 180; women in 176, 212

Australian Council for Engineering Deans (ACED) 176, 177

Australian engineering and education sectors 176

Australian Federal Government 180

Australian Government programs 179

Australian higher education system 175, 215

Australian National University (ANU) 177,178

Australian STEM education participation 175

Australian undergraduate engineering, women in 174; Engineers without Borders Australia (EWB-A) 180-183; Higher Education in Australia 175; 
recruiting and supporting women students 177-180; STEM enrollment in Australian Universities 175-177

Bachelet, Michelle 107

Backhouse, J. 166

Bantu Education Act 160

Becker, G. S. 96

Becker, R. 124

Beede, D. 51

Beijing Higher Women's Normal School 28

Beijing Platform of Action 144

Bengtsson, M. 95

Bespoke Study Tour 180

Black academic staff 158

Black African women in South Africa 158-159; campus climate, black experiences, perceptions about academia and career choice 164; freeing themselves and their families from apartheid 168; higher education as unwelcoming 166-167; limited mentorship for Black students 165-166; post-apartheid higher education 160-164; whiteness as norm 164

Black bodies 161, 164, 169, 170

Black communities 1, 67

Black inferiority, as a norm of apartheid 160

Black Lives Matter movement 1

Black people 160, 161, 163-168, 171

"Black quota system" xxi

Black students xxi, 160, 169; in engineering 162; limited mentorship for 165-166; mentorship for 164, 165166; postgraduation education for 170; STEM bachelor's degrees to 67; stress for 161

Black women 65, 158, 212; engineering students 171; engineers 7, 169; higher education learning environments for 170; Hispanic women and 65; hostile towards 158; mentors 165; post-apartheid higher education experiences 162-164; seldom 167; in South Africa 159 ; to teaching roles 168 ; undergraduate students 166; university 161 ; young 166

Bordon, P. 110, 111

bottom-up feminist movement 107-109

bottom-up feminist movement at FCFM 107-109

"Boy's Day" 134n3
Bradley, K. 22

Britzman, D. P. 191

Broadening Participation in Engineering 65

Brown, N. 182

Brown vs. Board of Education xxi

Bureau of Labor Statistics 62

Cameron, Shara 7, 212

capabilities-functionings conversion 197-200

carbon emissions 1

CEDAW see Convention on the

Elimination of All Forms of Dis-

crimination against Women (CEDAW)

CEDAW Optional Protocol 144

Centros de formación técnica 112

CET see College English TEST (CET)

"changing cultural characteristics" 22

Charles, M. 22

Chilean feminist movement 106

Chilean higher education 105-106; affirmative action program at FGFM 109-112; individual and collective journey 106-109; women participation in STEM undergraduate education $112-115$

"chilly climate" 15 , 48; idea 13 ; for women 152

China, rise of women in 27, 40-42; academic majors, gender differences in 34-36; academic performance, gender differences in 36; enrollment, gender differences in 34; historical context 28-30; labor market outcome 37-39; learning experiences, gender differences in 37 ; policy considerations 30-33

Chinese Academy of Social Sciences 37

Chinese political elites 30

chi-square test 92

CIP codes see Classification of Instructional Programs (CIP) codes class-based educational inequality 88 class disparities in university enrollment 88

"Classical Greek" curriculum xxi

Classification of Instructional Programs (CIP) codes 72, 80n9

co-education in primary school level 28

CohenMiller, A. S. 6, 142, 212

collectivist societies 145

College English TEST (CET) 42n2

"Compulsory Education Law" 31 
Constitution of the Central Government 28

Convention on the Elimination of All Forms of Discrimination against Women (CEDAW) 144, 210 "conversion factors" 192, 200; capabilities-functionings 199; environmental 199; personal 198; positive 201; social 196, 197, 200

co-requisite models 132

Cox, R. D. 70

Cross, M. 166 cross-national research on women 23 culture change 170

"culture of care" 152

curricular and co-curricular activities 181

Dache-Gerbino, A. 70

Davies, S. 89

decision-making process 70

"Decision on Reforming the Education System" 30

de facto segregation xxi

Degol, J. 142, 151

degree attainment 64 ; gender and racial differences in STEM 64-65; STEM bachelor's 63, 69, 71, 75-77, 79; STEM enrollment and 211

"Developing HCD Solutions through Engineering Community Engagement" activity 183

Development of National Education 31 digital literacy 200, 202

disparities in social class 89

"double bind" barriers 62, 65, 66

"dual system" of school-based training 123

dual-track system 46

Dusdal, Jennifer 6, 96

DZHW see German Centre for Higher Education Research and Science Studies (DZHW)

EA see Engineers Australia (EA) educational achievements 85, 193 educational attainment 58, 70, 78, 105 educational autobiography 187, 193-195 educational ethnography methods 7,187

educational expansion 57; pros and cons of 58; and STEM pipeline-focused policies 212; in Taiwan 56

"educational gender-equality paradox" 210 educational initiatives policies 3

educational opportunities 56, 63; distribution of 33, 34; of gender groups 51; geographic disparity in 6; geography of $63,69,70$; K-12 78; STEM 68, 73, 75, 77, 211, 212; of women in STEM 46

educational pipeline: gender equity throughout 145, 153; shifting composition of 51-54; STEM 46,57

educational reform 46-47, 51

educational systems 57, 151; German 123, 128; and national enrollment data 131; in United Kingdom 96 education expansion 58; on occupational choice 55, 55; tertiary 46, 47, 49-50, $53,56,57$

"Education Law" 31

education legislation 31

education pipeline, inequality in 55

'2015 Education Statistical Indicators' 50

Education White Paper 3 160, 161

El Nagdi, M. 191

empirical foci 5

engineering-based activities 178

engineering community engagement evaluation matrix 183, 183

Engineering Council of South Africa 158

engineering design approach 181 engineering design solutions 182, 183 engineering education community 179 engineering programs 164, 169, 170, 179, 180; accredited 176; at FCFM 106; first-year enrollment in 115 ; undergraduate 163; university 174 ; women in 182

Engineers Australia (EA) 176, 179

Engineers without Borders Australia (EWB-A) 180-183

England, four-year universities in: class disparities in university enrollment 88; gender disparities in STEM subjects at prestigious universities 88-90; methods 90-92; prestigious universities in 87-88; secondary and postsecondary education context in 86-87

English language skills 146

English-medium institution 146 environmental conversion factors 192, 199-200

ethnic minority students 87 European Commission (EC) 121 
European Institute for Gender Equality 121, 215; Gender Statistics Database (GSD) 90

European Technology Assessment Network 13

European Union's Horizon 202016

EWB-A see Engineers without Borders Australia (EWB-A)

EWB University Challenge Program 180-183

experiential learning opportunities 166, 214

Extension of University Education Act 160

\section{Fachhochschulreife 125}

faculty mobilization 107

Faculty of Physical and Mathematical Science (FCFM) 106, 108, 111, 118, $118 n 1$

FCFM see Faculty of Physical and Mathematical Science (FCFM)

"female-dominated fields" 30

female graduate students in China 39, 40

feminist movement: bottom-up 107-109; Chilean 106; large-scale 105; national 111; Western 33

feminist scholars 21, 69, 213

feminist social movement 116

Fernandez, Frank 6, 96

Fifty50 177, 178

Flashman, J. 50

Fouad, N. A. 151

four-year universities in England: class disparities in university enrollment 88; gender disparities in STEM subjects at prestigious universities 88-90; methods 90-92; prestigious universities in 8788; secondary and postsecondary education context in $86-87$

Frank, D. J. 21

Frickel, S. 108

Fu, Y. C. 211

Gabler, J. 21

GCSEs see General Certificates of Secondary Education (GCSEs)

Geary, D. C. 210,215

gender and aspirations for teaching STEM 197-198

gender and racial differences in STEM degree attainment 64-65

gender-based discrimination 66, 144 gender-based socialization 27 gender biased perceptions of Hong Kong 197

gender differences 189; in academic majors 34-36; in academic performance 36 ; in higher education enrollment 34; in learning experiences 37 ; in STEM degree attainment 64-65 gender discrepancies 142, 143, 150, 151 gender disparities 141; in income 94; national 131; in occupational preferences 134; in science performance 196; in STEM disciplines and careers 152; in STEM fields 145; in STEM higher education 92; in STEM persist 2; in STEM subjects 86, 88-90; in STEM undergraduate 62 ; in undergraduate STEM enrollment 214 gender division of labor 38 gendered division of labor 27, 197 gendered stereotypes 202

gender equality $14,15,23,31,34,42$, $121,143,144,209$; in academic environment 153; in China 40; in education 5, 28; in higher education 32 ; high levels of 210; paradox 202; principles of 33; in STEM 116, 132, 133; in STEM higher education 91, 134; in STEM tertiary education 57 "gender-equality paradox" 202 gender groups 52; educational pipeline of 51; heterogeneous effects to 53; leaky pipeline among 54; racial and ethnic 77 ; ratio between 55,56 gender imbalance 27, 121, 189, 201 gender inequalities $6,39,48,151,201$; in academic fields 39; assessment 193; in German engineering (see German engineering); in higher education in China 37; in STEM 2, 57, 178, 187; within STEM education 201; in undergraduate engineering education 6

Gender Inequality Index 144

gender inequities 3, 141, 150, 202

gender role socialization 47

gender segregated schools 110

gender stereotypical beliefs 189, 190

gender stereotyping 7, 48, 57, 96, 190, 196-199, 201

General Certificates of Secondary

Education (GCSEs) 86-87, 92, 95

geographic disparities 6, 212

geography of education $70-71$ 
German Centre for Higher Education Research and Science Studies (DZHW) 126, 128

German educational system 123, 128

German engineering 121-123; access to postsecondary opportunities in 124 126; implications for research, policy, and practice 131-132; panel of school leavers 2008 128-131; from primary education to higher education in Germany 123 ; from primary to secondary school 124; promising policies and practices 132-133; underemployment opportunities in 126-128

"German exceptionalism" in schooling 123

German microcensus 127

German schooling 123, 124

German schools and universities 132

GGT School Programme see Girls Go Tech (GGT) School Programme

Girls' Day 132, 133

Girls Go Tech (GGT) School Programme 201

Global Education Monitoring Report 2020214

Go MINT 133

Goncher, Andrea M. 7, 212

good social environment 29

government-initiated policies 211

government-initiated STEM education policies 212

GPAs 36, 37, 41, 109

grassroots movement 106, 116

Gross, N. 108

Guppy, N. 89

Gutiérrez, Adelina 106-108

Gymnasium 124

Hägglung, A. E. 126

Hanushek, E. A. 16

Harbin Institute of Technology 35, 35

HBCUs see Historically Black Colleges and Universities (HBCUs)

HCD see human-centered design (HCD)

HCT see human capital theory (HCT)

Healy-Clancy, Megan 159

higher-level graduate education 39

Hillman, N. W. 70, 78

Hispanic Serving Institutions (HSIs) 65, $68,73,77,78$

Hispanic women 65

Historically Black Colleges and Universities (HBCUs) 67, 73 historically white institutions (HWIs) 159, 161,163

HKDSE see The Hong Kong Diploma of Secondary Education (HKDSE)

Hong Kong Academy of Sciences 190

The Hong Kong Diploma of Secondary Education (HKDSE) 189

Hong Kong, STEM teachers in 187; capability approach in education 192-193; education and gender in 188-190; gender and STEM teacher identity 198-199; identity, construction of 191-192; light of capabilities framework 199-200; methodology 193-195; motivations for aspiring to become 195-198; positionality 195

Horvath, M. 191

HSIs see Hispanic Serving Institutions (HSIs)

"huge disparities" 140

human capital 13, 211; demands 199; for science production 58; in the STEM fields 200; within STEM fields 57

human capital theory (HCT) 47-48, 95-96

human-centered design (HCD) 179, 181; principles 182, 183; process 183; skills and knowledge 182

Humanitarian Design Summit 180

humanitarian engineering 182; curricular and co-curricular experiences 184; education initiatives 180; -focused programs 179-180; frameworks 180 ; initiatives 180; principles 176; with project-based activities 181

human rights 1

Hurtado, S. 158, 169

HWIs see historically white institutions (HWIs)

IEEE Teaching, Assessment and Learning for Engineering (TALE) conference 179

IELTS exam see International English Language Testing System (IELTS) exam

income benefits of STEM degree 89

indigenous communities 181

"individual- and social-level causes" 69

individualist culture 22, 210

industrial modernization 29

inequalities against women 3

Influencer Fellowship 180

"informal patronage network" 143 
institutional culture 4, 5

institutional racism 161

Institutional Reconciliation and Transformation Commission (IRTG) 161

institutional type 73, 113-114, 117, 214

Integrated Postsecondary Education Data System (IPEDS) 63, 71, 72, 80n9

intellectual leadership 202

intellectual movements 6, 108, 116, 118

International and Kazakhstani Research 141-143

International Classification of Education (ISCED) system 17, 24nl

International English Language Testing System (IELTS) exam 146

International Girls in ICT Day 143

International Standard Classification of Education (ISCED) 189

international testing regimes 16

international test scores 16

intersectionality $63,69-70$; framework 213; scholars 69, 213; studies 69

IPEDS see Integrated Postsecondary Education Data System (IPEDS)

IRTC see Institutional Reconciliation and Transformation Commission (IRTC)

ISCED system see International Classification of Education (ISCED) system

Islam, S. I. 211

Jacob, M. 128

Kazakhstan 140, 212; historical and cultural context of 144-145; International and Kazakhstani Research 141-143; potential challenges and opportunities for growth 152-53; school of engineering and digital sciences 145-150

Kazakhstan Country Gender Assessment (CGA) 144

Kazakhstani higher education 142

K-12 educational opportunities 78

Kim, A. 127

Kim, J. Y. 151

Kimko, D. D. 16

Kim, K. W. 127

Kinzie, J. 48

Kuzhabekova, A. 143

Kwak, N. 17, 23, 212, 214

Labor Code of Kazakhstan 144

labor market 39, 42, 126; outcomes 23, 37-39; segregation 22; of STEM professional occupations 56; women in 58
Labour Force Survey data 127

Lam, J. 201

"Law of the People's Republic of China on Compulsory Education" 32

Law on the Protection of The Rights and Interests of Women 31

"layers in a sex-based filter" 128

"leaky pipeline" 15, 54, 57, 128

learning experiences, gender differences in 37

Leung Chun-ying 188

Leuze, K. 126

Lewis, J. 142

Lingyu, Liu 211

Liong, M. 189

listwise deletion approach 92

Longitudinal Study of Young People in England (LSYPE) data set 91

lower secondary schools 124

low self-efficacy in STEM 189

low-socioeconomic status (low-SES) applicants 87

LSYPE data set see Longitudinal Study of Young People in England (LSYPE) dataset

male-dominated culture of STEM fields 67

"male-dominated fields" 30

male-dominated STEM fields 65, 66

male-preference admission processes 95

Mama, Amina 162, 171

Mangcu, X. 166

'manpower utilization quasi-longitudinal data' 50, 51

March of the Empty Pots 107

marginalized social identities 213

masculine culture of STEM subjects 90

mathematics achievement 65, 66

mathematics learning 215

Matthee, S. 182

McDaniels, M. 158

men-dominated culture 110

Mentorship 150, 151, 164-166

Meyer, J. 126, 134n2

Mezirow, J. 194

Millennium Development Goals 2

mimetic isomorphism 108

Minority Serving Institutions (MSIs) 67-68, 70, 73, 77-79

Mizala, A. 109

Mlambo, Y. A. 7, 212

modernization-inspired studies 14

Moss-Racusin, C. A. 142 
"motherhood penalty" 152

MSIs see Minority Serving Institutions (MSIs)

Mujeres Ingeniería program 111

multiple national initiatives 85

National Academy of Engineering xxi national affirmative action policies 163 National Center for Science and Engineering Statistics 64, 80n4

National Committee for Women in Engineering 179

National Comprehensive Social Survey 200834

national economic development 13 , $15-17$

national feminist movement 111

national gender disparities 131

national-level grant funds 65

National Longitudinal Survey of Youth in the United States 89

National Plan for Higher Education 160 national policies and professional organizations $65-66$

National Science Foundation (NSF) xxi, 65

national scientific activity 17

ANation at Risk 16

Nazarbayev University (NU) 145, 146

NCES see U.S. Department of Education's National Center for Education Statistics (NCES)

Ndimande, B. S. 171

non-minority serving institutions 77

non-science fields 95

non-STEM enrollment 91, 91

non-STEM fields 62

non-STEM programs 112, 113

non-white individuals $17 \ln 1$

not-for-profit organization 178

noticeable labor force shortage 121

NSF see National Science Foundation (NSF)

NU see Nazarbayev University (NU)

OECD see Organization for Economic Co-operation and Development (OECD)

OLS regression see Ordinary Least

Squares (OLS) regression

one-child policy $31-32,40$

one-size-fits-all policies $\mathrm{xx}$

Ordinary Least Squares (OLS) regression 73,75
Organization for Economic Co-operation and Development (OECD) 2, 112, 209

pandemic-induced slowdown 1

Panel of School Leavers 2008131

Paredes, V. 109

parent-child relationship 32

Patel, Nita 8

PBE approach 181

Pearson's chi-squared test 92

PEG see Programa de Ingreso Prioritario de Equidad de Género (PEG)

PEGA see Programa de Equidad de Género en la Académica (PEGA)

People's Republic of China (PRG) 28

Perez-Felkner, L. 211

personal "conversion factors" 192, 196, 198, 199

Pinochet, A. 107

PISA see Program for International Student Assessment (PISA)

PoE see Power of Engineering Inc (PoE)

Posselt, J. R. 150

post-apartheid higher education 160-164

post-apartheid policies 160

post-industrial countries 85, 96, 189

postsecondary opportunities in German engineering 124-126

post-Soviet context of women 151

post-Soviet Kazakhstan 141, 151, 152

poverty projections 1

Power of Engineering Inc (PoE) 178

practice-based approach 181

PRC see People's Republic of China (PRC)

Predominately White Institutions (PWIs) 68

pre-service STEM teachers 198

primary education to higher education in Germany 123

Professional associations for women in engineering 176-177

professional humanitarian engineers 181

professional learning communities 202

professional training programs 202

Programa de Equidad de Género en la Académica (PEGA) 110

Programa de Ingreso Prioritario de Equidad de Género (PEG) 109-112

Program for International Student Assessment (PISA) 16, 188, 215

"Program for the Development of Chinese Women" 31 
"Project 211" 42n1

project-based activities 181

"Project Hope" 33

Public Use Microdata Areas (PUMAs) 72, 73

PWIs see Predominately White Institutions (PWIs)

qualitative interviewing 187, 193, 194

racial-gender groups 78

"racially minoritized women" $79 \mathrm{n} 2$

Ramirez, F. O. 14, 17, 23, 213, 214

"red engineers" 30

"Regulations for Women's Higher Normal Education" 28

Relevant Laws and Regulations 31

"Report on Growth of Chinese Universities 2015" 35-36

"Research on Chinese Women's Higher Education Facing the 21st Century" 32,33

research respondents information 194, 194

Rising above the Gathering Storm 16

Robeyns, I. 193

Roehrig, G. 191

Ro, Hyun Kyoung 6, 89, 91, 212, 214

Royal Academy of Engineering 85

rural compulsory education 33

Russell Group universities 86-87, 90, 92, 93, 93, 94-96, 214

SAGE see Science in Australia Gender Equity (SAGE) program

Samoff, J. 2, 3

Schlenker, E. 127

school-based program 201

school of engineering and digital sciences 145-150

School of Engineering and Digital Sciences (SEDS) 146, 147, 147,148, 149,150

schools of education 202

science and engineering (S\&E) degrees 64 science education 16, 17, 143, 187, 198

Science in Australia Gender Equity (SAGE) program 179

Science of the Republic of Kazakhstan 143

Sciences and the Academy of Engineering 42

secondary public school systems issues 65,66
Second International Mathematics Study (SIMS) 16

S\&E degrees see science and engineering (S\&E) degrees

SEDS see School of Engineering and Digital Sciences (SEDS)

self-assessed learning outcomes 67

Sen, A. 187

"sense of family-like support" 67

Sepúlveda, L. 117

Severiens, S. 50

Shalem, Y. 166

Shauman, K. A. 50

"Siberian impact" 23

SIGI see Social Institutions and Gender Index (SIGI)

SIMS see Second International Mathematics Study (SIMS)

Snow, D. A. 107

social "conversion factors" 192, 196, 197, 199, 200

Social Institutions and Gender Index (SIGI) 144

social movements $1,111,116$

socioeconomic disparities 89

socio-technical solutions 180

South Africa, Black African women in 158-159; campus climate, black experiences, perceptions about academia and career choice 164; freeing themselves and their families from apartheid 168; higher education as unwelcoming 166-167; limited mentorship for black students 165-166; post-apartheid higher education 160-162; post-apartheid higher education experiences 162164; whiteness as norm 164

South African higher education 7, 161; Black Africans 158; culture of whiteness within 7, 212; data $17 \ln 3$; decolonization of 161 ; project 169 ; students 162

"Spring Bud Program" 31, 33

standard high school system 86

standardized university admissions tests 96

State Program for the Development of Education and Science 143

STEM bachelor's degree 63, 70, 72, 214; attainment 63, 69, 71, 80n8; attainment and geography of opportunities 75-76, 75-77; to Black students 67; recipients $73,74-75,78,79$ 
STEM Decadal Plan 175, 212

"STEM pathway" 48

STEM pre-service teachers in Hong Kong 199, 200

STEM professional positions 54, 54-56

STEM-related programs 202n1

STEM-skilled workforce 175

STEM Symposium 179

STEM teachers in Hong Kong 187; capability approach in education 192-193; education and gender in 188-190; gender and STEM teacher identity 198-199; identity, construction of 191-192; light of capabilities framework 199-200; methodology 193-195; motivations for aspiring to become 195-198; positionality 195

STEM undergraduate education 211; national trends and policies to diversify 64-66; role of 2; women participation in $112-115$

Stoakley, A. 182

Stoet, G. 210, 215

Strauß, S. 126, 134n2

Sub-STEM disciplines 214

"surrogate family support system" 67

Taiwan 49, 50, 58; educational expansion in 56, 57; educational reform in 46-47; higher education in 5; STEM professionals in 46 ; tertiary education system in 45, 57, 211

Taiwanese women 45, 57; analytic strategy 51; convergence of participation in STEM professional positions 54, 54-56; data description 50-51; educational reform in 46-47; effects of tertiary education expansion on 49-50; human capital theory and educational and occupational choices 47-48; schools and the leaky pipeline 48-49; shifting composition of educational pipeline $51-54$

TALE conference see IEEE Teaching, Assessment and Learning for Engineering (TALE) conference

Tang, H. H. H. 7, 213

TCUs see Tribal Colleges and Universities (TCUs)

teacher identity 187, 191, 193; STEM 190-192, 198-199, 202

TechGirls four-week exchange program 143 technical and professional institutes (TPI) programs 112, 114, 117

ten Dam, G. 50

tertiary education system expansion in

Taiwan 45, 49-50, 53, 54, 56, 57

"Thirteenth Five-Year Plan" 31

TIMSS see Trends in International

Mathematics and Science Study

(TIMSS)

TPI see technical and professional institutes (TPI) programs

traditional cultural norms 145

traditional gender stereotype 50

traditional stereotyping 196

Transformative Learning Theory 194

Trends in International Mathematics and Science Study (TIMSS) 188

Trent, J. 191

Tribal Colleges and Universities (TCUs) 68

tuition-free education 146

UCAS see Universities and Colleges Admissions Service (UCAS)

UN 2030 Agenda for Sustainable Development 2

underemployment opportunities in German engineering 126-128

underrepresented racial minorities (URM) 62, 64, 65, 75, 77, 79n1; students 65; women 79

UNDP 143

UNESCO see United Nations Educational, Scientific and Cultural Organization (UNESCO)

UNICEF 143

Unified National Testing (UNT) 145

UniMento 133

United Nations Educational, Scientific and Cultural Organization (UNESCO) 17, 18, 24n1, 39, 121, 141

United Nation's (UN) Sustainable Development Goals 15

United States, "women of color" in: ACS PUMS data 72; "double bind" barriers 62; geography of education 70-71; institutional type 73; intersectionality 69-70; Minority Serving Institutions (MSIs) 67-68; STEM bachelor's degree attainment 63 , 75-77; STEM bachelor's degree recipients 74-75; STEM undergraduates, national trends and policies to diversify 64-66 
universal coeducational class system 29 universal education system 45

Universal nine-year compulsory education 32-33

universities: of applied sciences 125; Black women 161; different types of 214; engineering programs 174; in England, four-year (see four-year universities in England); faculties 202; German schools and 132; Russell Group 86-87, 90, 92, 93, 93, 94-96, 214; STEM enrollment in Australian 175-177; and students in Australia 180

Universities and Colleges Admissions Service (UCAS) 87

UNT see Unified National Testing (UNT)

URM see underrepresented racial minorities (URM)

U.S. Department of Education's National Center for Education Statistics (NCES) 80n9

U.S. Embassy and Consulate in Kazakh$\operatorname{stan}(2020) 143$

Verbatim transcription 195

Vest, C. M. 16

VET see vocational education and training (VET)

vocational education and training (VET) 123

vocational non-STEM program 49 vocational-oriented programs 46 vocational track non-STEM programs 52 vocational track program 51 vocational track STEM programs 52, 54 vocational training opportunities 123

Wald test 92

Wang, M.-T. 142, 151

Washington Accord agreement 176

Weber, A. M. 127

Wei-Cheng, M. 141, 145

"well-known equilibrium condition" 96

Wen, D. M. 36

Wenger, E. 191

WEPAN see Women in Engineering ProActive Network (WEPAN)

Western feminist movement 33

White House Office of Science and Technology Policy xxi

WIE see women in engineering (WIE)

WISTEMxQ workshop 179 women: academicians, proportion of 42 ; academic performance of 33, 40; in Australia 176, 212; in Australian undergraduate engineering (see Australian undergraduate engineering, women in); Black (see Black women); Black African women in South Africa (see Black African women in South Africa); in Chilean higher education (see Chilean higher education); in China, rise of (see China, rise of women in); colleges, supporting 33; crossnational research on 23; emancipation 144 ; in engineering programs 182; graduates $14,17,18,21,37,39,55,149$; inequalities against 3 ; in labor market 58; liberation slogans 29; mentors in STEM, lack of 150; participation in education 40; participation in STEM undergraduate education 112-115; post-Soviet context of 151; social movements 14; in STEM fields 14-15, 27, 33; Taiwanese women (see Taiwanese women)

women-dominated programs 111

women in engineering (WIE): panel 179; programs 184; structures 177

Women in Engineering ProActive Network (WEPAN) xxi, 65

Women in STEM Workshop for Educators 179

"women of color" in the United States $\mathrm{xx}$, xxii, 62-77, 79n2; ACS PUMS data 72; "double bind" barriers 62; geography of education 70-71; institutional type 73 ; intersectionality 69 70; Minority Serving Institutions (MSIs) 67-68; STEM bachelor's degree attainment 63, 75-77; STEM bachelor's degree recipients 74-75; STEM undergraduates, national trends and policies to diversify 64-66 women-related policies 33

"women returning home" 33

Working Committee on Women and Children 31

World Bank (2019) 20

Wotipka, C. M. 14, 17

Xie, Y. 50

Yeung, D. 189

Yuen, C. Y. 36

Zika virus 8 


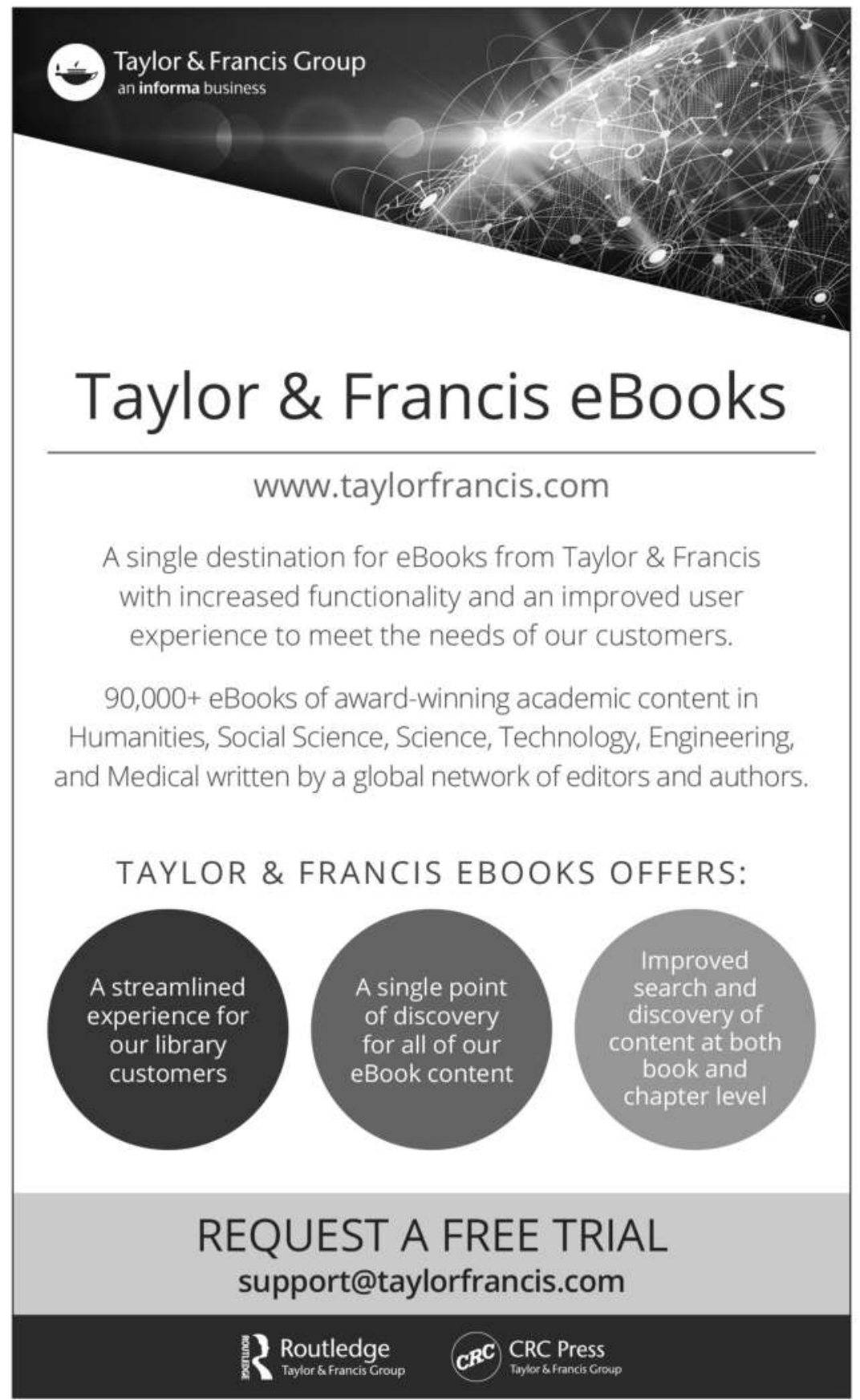

